LUDMILSON ABRITTA MENDES

\title{
O IMPACTO DOS USOS CONSUNTIVOS NA OPERAÇÃO DE SISTEMAS DE RESERVATÓRIOS PARA PRODUÇÃO DE ENERGIA ELÉTRICA
}

Tese apresentada à Escola Politécnica da Universidade de São Paulo para obtenção do título de Doutor em Engenharia

Área de concentração:

Engenharia Hidráulica

Orientador:

Prof. Dr. Mario Thadeu Leme de Barros

São Paulo

2012 
LUDMILSON ABRITTA MENDES

\section{O IMPACTO DOS USOS CONSUNTIVOS NA OPERAÇÃO DE SISTEMAS DE RESERVATÓRIOS PARA PRODUÇÃO DE ENERGIA ELÉTRICA}

Tese apresentada à Escola Politécnica da Universidade de São Paulo para obtenção do título de Doutor em Engenharia

Área de concentração:

Engenharia Hidráulica

Orientador:

Prof. Dr. Mario Thadeu Leme de Barros

São Paulo

2012 


\section{FICHA CATALOGRÁFICA}

\section{Mendes, Ludmilson Abritta}

O impacto dos usos consuntivos na operação de sistemas de reservatórios para produção de energia elétrica / L.A. Mendes. -- São Paulo, 2012. $167 \mathrm{p}$.

Tese (Doutorado) - Escola Politécnica da Universidade de São Paulo. Departamento de Engenharia Hidráulica e Ambiental.

1.Recursos hídricos (Gerenciamento) 2.Geração de energia elétrica 3.Reservatórios (Operação) I.Universidade de São Paulo. Escola Politécnica. Departamento de Engenharia Hidráulica e Ambiental II.t. 
À Roberta.

À Gracinha e ao Domingos. 


\section{AGRADECIMENTOS}

Ao amigo e orientador Prof. Dr. Mario Thadeu Leme de Barros, pela orientação das diretrizes deste trabalho, pela confiança e pelo apoio sempre demonstrados nos projetos desenvolvidos nos últimos seis anos.

À FDTE, pelo apoio financeiro durante a realização deste trabalho.

Ao Prof. Dr. João Damasio de Oliveira Filho, pela disponibilização das informações relativas às outorgas na bacia do São Francisco, pelas reflexões e debates que motivaram esta pesquisa em seu início.

Ao Prof. Dr. Renato Carlos Zambon, pelo auxílio fundamental ao tratamento do problema proposto. Ao Dr. João Eduardo Gonçalves Lopes, pela colaboração e troca de informações relevantes para o desenvolvimento da pesquisa.

Aos amigos e colegas de pesquisa MSc. Camila Brandão e MSc. Roberto Maximiano Pereira, pelas discussões relacionadas ao tema deste trabalho. Ao engenheiro Leonardo Teixeira Rocha, pelas informações que ajudaram a enriquecer esta pesquisa.

Ao amigo Dr. Daniel Jorge Caetano, pelo estímulo e pela contribuição técnica com os quais pude contar ao longo do desenvolvimento da tese.

À minha mulher, Roberta, por sua ajuda na concretização deste trabalho, sua compreensão e seu constante incentivo, principalmente quando deles mais careci.

A meus pais, Domingos e Maria das Graças, primeiros orientadores de minha formação, por seu apoio em todos os momentos. 
(...) amo os grandes rios, pois são profundos como a alma do homem. $\mathrm{Na}$ superfície são muito vivazes e claros, mas nas profundezas são tranquilos e escuros como os sofrimentos dos homens. Amo ainda mais uma coisa de nossos grandes rios: sua eternidade. Sim, rio é uma palavra mágica para conjugar eternidade.

(João Guimarães Rosa) 


\section{RESUMO}

Este trabalho trata da avaliação dos impactos que os múltiplos usos da água causam à operação dos reservatórios de uma bacia hidrográfica para a geração de energia elétrica. Apresenta-se o equacionamento do modelo HIDRO, desenvolvido em linguagem GAMS para tratamento de problemas de otimização em Programação Não Linear, cuja função objetivo inclui variáveis relacionadas não somente à geração de energia, como também ao fornecimento de água aos diversos usos do recurso hídrico tratados no problema. A aplicação do modelo é feita para a bacia do rio São Francisco, localizada entre as regiões Sudeste e Nordeste do Brasil, que conta com uma capacidade instalada de 10,7 GW em suas usinas hidrelétricas, as quais também realizam operações de controle de cheia. A região apresenta um expressivo uso consuntivo do recurso hídrico, principalmente voltado à irrigação de culturas, além de abastecimento humano e criação animal. Dentre os usos não consuntivos, têm-se a navegação e a conservação ambiental. Uma vez que grande parte da bacia é marcada por escassez hídrica, a operação de seu sistema de reservatórios vem sendo questionada no que se refere ao gerenciamento dos recursos hídricos. São avaliados os índices de atendimento da demanda de energia e da demanda hídrica para cenários de baixa afluência aos reservatórios. As relações de troca entre energia, uso consuntivo e conservação ambiental são avaliadas, levando-se em conta, também, os efeitos decorrentes da transposição das águas do São Francisco para o Nordeste Setentrional. As perdas na geração de energia decorrentes do aumento da demanda hídrica e do aumento da demanda ambiental são avaliadas. São estimados os custos relacionados às perdas na geração de energia se as demandas consuntivas atingirem o valor outorgado na bacia pelo Poder Público, valor este que não consegue ser plenamente atendido. $\mathrm{O}$ modelo proposto pode ser aplicado a quaisquer bacias hidrográficas com múltiplos usos do recurso hídrico.

Palavras-chave: Recursos hídricos (Gerenciamento). Geração de energia elétrica. Reservatórios (Operação). 


\begin{abstract}
This research presents a study conducted to evaluate the impacts of the hydroelectric power plants operation caused by the multipurpose uses of water resources. There are many conflicts involved in the operation of a reservoir system mainly due to competitive uses of water. That is the case of São Francisco River, located between the Southeast and Northeast regions of Brazil. The hydro system in this region has an installed capacity of $10.7 \mathrm{GW}$ and supports $13 \%$ of the Brazilian hydro electrical power. Due to the scarcity of water in this region, the operation of this system has been questioned in the last few years. The competitive uses of water in this region are water supply, irrigation and animal raising. The non-consumptive uses of water are navigation and environmental protection. The electrical sector is planning to review the reservoir operation rules in order to attend these demands. The study was conducted by applying the HIDRO model, which is an optimization PNL model developed with GAMS software that maximizes hydropower production. A new objective function was added to the HIDRO model in order to consider the treatment of energy and water demands the both. The trade-offs among energy, consumptive uses and environment protection are presented. The lack of energy due the increasing water demand implies costs which are evaluated according to some demand scenarios and different scarcity historical periods. Also the effect due the operation of the water transfer system from São Francisco to the neighboring basins is considered.
\end{abstract}

Keywords: Water resources management. Electric power generation. Reservoirs operation. 


\section{LISTA DE FIGURAS}

Figura 3.1 - Empreendimentos outorgados desde 1998 e que não tiveram construção iniciada 27

Figura 3.2 - Mapa do SIN, seus subsistemas e interligações 29

Figura 3.3 - Cronograma de expansão das usinas hidrelétricas do SIN 31

Figura 4.1 - Representação esquemática de uma usina hidrelétrica e grandezas envolvidas 39

Figura 5.1 - Mapa da bacia hidrográfica do rio São Francisco 50

Figura 5.2 - Distribuição da vazão captada por tipo de uso em cada região fisiográfica....... 53

Figura 5.3 - Distribuição da vazão consumida por tipo de uso em cada região fisiográfica .. 55 Figura 5.4 - Representatividade dos usos consuntivos na vazão outorgada na bacia do São

Francisco

Figura 5.5 - Distribuição do consumo outorgado nas áreas de contribuição dos reservatórios

Figura 5.6 - Evolução da área irrigada no Brasil e na bacia do São Francisco. 62

Figura 5.7 - Áreas irrigadas na sub-bacia do Alto Rio Grande, Oeste Baiano 64

Figura 5.8 - Vista aérea do canal de irrigação do Baixio de Irecê, Bahia. 65

Figura 5.9 - Áreas irrigadas em Jaíba, sub-bacia do Verde Grande, Norte de Minas 65

Figura 5.10 - Mapa de localização dos eixos da transposição do rio São Francisco 67

Figura 5.11 - Diagrama esquemático das usinas hidrelétricas da bacia do São Francisco .. 69

Figura 5.12 - Curva de permanência de ENA na bacia do S. Francisco ............................. 77

Figura 5.13 - Curva de permanência das médias-móveis de 7 anos de ENA ......................78

Figura 6.1 - Curvas de Pareto entre geração de energia e uso consuntivo no período abr/1998-mar/2005

Figura 6.2 - Curvas de Pareto entre conservação ambiental e uso consuntivo no período abr/1998-mar/2005 99

Figura 6.3 - Curvas de Pareto entre conservação ambiental e geração de energia no período abr/1998-mar/2005 100

Figura 6.4 - Curvas de Pareto entre geração de energia e uso consuntivo no período abr/1950-mar/1957 103

Figura 6.5 - Curvas de Pareto entre conservação ambiental e uso consuntivo no período abr/1950-mar/1957

Figura 6.6 - Curvas de Pareto entre conservação ambiental e geração de energia no período abr/1950-mar/1957 
Figura 6.7 - Curvas de Pareto entre geração de energia e uso consuntivo com variação dos

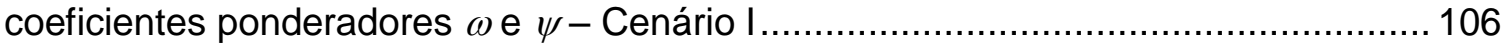

Figura 6.8 - Curvas de Pareto entre geração de energia e uso consuntivo com variação dos

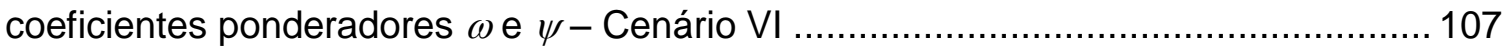

Figura 6.9 - Geração de energia para os diferentes períodos ........................................ 109

Figura 6.10 - Deficit de energia acumulado para os diferentes períodos de afluência ........ 110 


\section{LISTA DE TABELAS}

Tabela 1.1 - Evolução da Oferta Interna de Energia Elétrica ............................................. 19

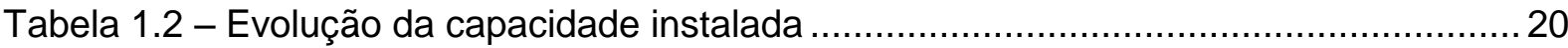

Tabela 3.1 - Empreendimentos outorgados desde 1998 e que não tiveram construção

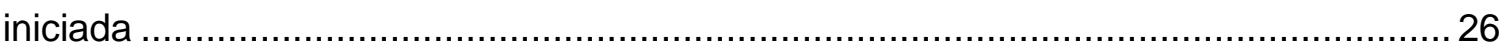

Tabela 3.2 - Capacidade de geração (kW) por tipo de aproveitamento em operação ........... 28

Tabela 3.3 - Usinas hidrelétricas do SIN em fase de construção ou planejadas ................... 30

Tabela 5.1 - Características hidroclimáticas das regiões da bacia do São Francisco ...........51

Tabela 5.2 - Distribuição da $Q_{M L T}$ e da $Q_{95}$ nas regiões fisiográficas ................................... 52

Tabela 5.3 - Balanço entre captação e disponibilidade hídrica na bacia do S. Francisco ..... 54

Tabela 5.4 - Vazão captada e disponibilidade hídrica na bacia do S. Francisco .................. 54

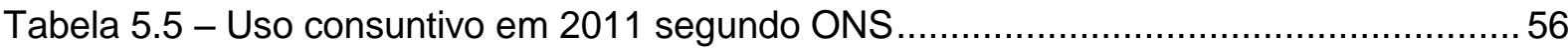

Tabela 5.6 - Distribuição das outorgas segundo o tipo de uso ..........................................56

Tabela 5.7 - Vazão de consumo outorgada até 2009 nas áreas de contribuição dos

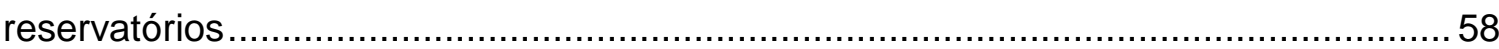

Tabela 5.8 - Diferença entre os valores de consumo segundo ONS e segundo CNARH .... 58

Tabela 5.9 - Características socioeconômicas da bacia do São Francisco ...........................60

Tabela 5.10 - Demanda média de abastecimento público segundo ONS...........................60

Tabela 5.11 - Demandas de abastecimento público da bacia do São Francisco atendidas por

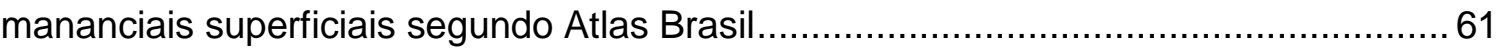

Tabela 5.12 - Vazão captada para usos industriais na bacia do São Francisco ....................61 61

Tabela 5.13 - Área irrigada e demanda de irrigação na bacia do São Francisco.................. 63

Tabela 5.14 - Estimativa da captação $\left(\mathrm{m}^{3} / \mathrm{s}\right)$ para irrigação na bacia ................................63

Tabela 5.15 - Distribuição do potencial hidrelétrico pelas bacias hidrográficas ....................69

Tabela 5.16 - Características dos aproveitamentos hidrelétricos da bacia do S. Francisco . 70

Tabela 5.17 - Evaporação líquida $(\mathrm{mm})$ dos reservatórios da bacia do S. Francisco ........... 70

Tabela 5.18 - Coeficientes dos polinômios dos reservatórios da bacia do S. Francisco ........ 70

Tabela 5.19 - Restrições operativas das usinas da bacia do São Francisco ........................ 73

Tabela 5.20 - Volumes de espera dos reservatórios para 2010-2011 …........................... 74

Tabela 5.21 - Vazão mínima para conservação ambiental a jusante dos reservatórios....... 75

Tabela 5.22 - Estatísticas da série histórica de ENA da bacia do S. Francisco ................... 76

Tabela 5.23 - Classificação dos períodos de seca na bacia do S. Francisco ....................... 77

Tabela 6.1 - Potência instalada e garantia física das usinas hidrelétricas ........................... 80

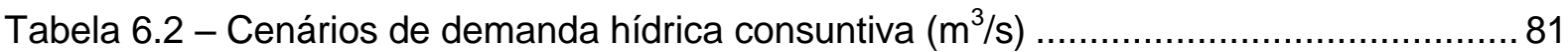


Tabela 6.3 - Volume final dos reservatórios

Tabela 6.4 - Restrições de defluência mínima dos reservatórios

Tabela 6.5 - Representatividade dos usos prioritários em relação à demanda hídrica ........ 84

Tabela 6.6 - Resultados do período abr/1998-mar/2005 sob restrição TMA300 .................. 86

Tabela 6.7 - Resultados do período abr/1998-mar/2005 sob restrição TMA400 .................. 86

Tabela 6.8 - Resultados do período abr/1998-mar/2005 sob restrição TMA500 .................. 86

Tabela 6.9 - Percentual de deficit e de falhas no atendimento de uso consuntivo no Cenário

VI.

Tabela 6.10 - Vazão média fornecida a uso consuntivo (UC), vazão turbinada média (R'), energia média gerada (E) e volume armazenado médio (S) no cenário $\mathrm{VI}$.................... 90

Tabela 6.11 - Resultados do período abr/1950-mar/1957 sob restrição TMA300 ................ 91

Tabela 6.12 - Resultados do período abr/1950-mar/1957 sob restrição TMA400 ................ 92

Tabela 6.13 - Resultados do período abr/1950-mar/1957 sob restrição TMA437 ................ 92

Tabela 6.14 - Relação de troca entre geração de energia e uso consuntivo na bacia do São Francisco para o período abr/1998-mar/2005

Tabela 6.15 - Variação da vazão fornecida a usos consuntivos pela transposição do São Francisco no período abr/1998-mar/2005

Tabela 6.16 - Variação da geração de energia pela transposição do São Francisco no período abr/1998-mar/2005

Tabela 6.17 - Relação de troca entre conservação ambiental e uso consuntivo no período abr/1998-mar/2005

Tabela 6.18 - Relação de troca entre conservação ambiental e geração de energia no período abr/1998-mar/2005

Tabela 6.19 - Relação de troca entre geração de energia e uso consuntivo na bacia do São Francisco para o período abr/1950-mar/1957

Tabela 6.20 - Variação da vazão fornecida a usos consuntivos pela transposição do São Francisco no período abr/1950-mar/1957

Tabela 6.21 - Variação da geração de energia pela transposição do São Francisco no período abr/1950-mar/1957 102

Tabela 6.22 - Relação de troca entre conservação ambiental e uso consuntivo no período abr/1950-mar/1957

Tabela 6.23 - Relação de troca entre conservação ambiental e geração de energia no período abr/1950-mar/1957

Tabela 6.24 - ENA média de 7 anos e permanência dos períodos selecionados 108

Tabela 6.25 - Atendimento energético para cada permanência de ENA 


\section{LISTA DE ABREVIATURAS E SIGLAS}

$\begin{array}{ll}\text { ABRH } & \text { Associação Brasileira de Recursos Hídricos } \\ \text { AL } & \text { Estado de Alagoas } \\ \text { ANA } & \text { Agência Nacional de Águas } \\ \text { ANEEL } & \text { Agência Nacional de Energia Elétrica } \\ \text { ASCE } & \text { American Society of Civil Engineers } \\ \text { BA } & \text { Estado da Bahia } \\ \text { CAR } & \text { Curvas Bianuais de Aversão ao Risco } \\ \text { CBH } & \text { Comitê de Bacia Hidrográfica } \\ \text { CBHSF } & \text { Comitê da Bacia Hidrográfica do Rio São Francisco } \\ \text { CCEE } & \text { Câmara de Comercialização de Energia Elétrica } \\ \text { CE } & \text { Estado do Ceará } \\ \text { Cemig } & \text { Companhia Energética de Minas Gerais S/A } \\ \text { Cepel } & \text { Centro de Pesquisa de Energia Elétrica } \\ \text { Cesp } & \text { Companhia Energética de São Paulo } \\ \text { CERH } & \text { Conselho Estadual de Recursos Hídricos } \\ \text { CF } & \text { Constituição Federal } \\ \text { CGH } & \text { Central Geradora Hidrelétrica } \\ \text { CGU } & \text { Central Geradora Undi-Elétrica } \\ \text { Chesf } & \text { Companhia Hidro Elétrica do São Francisco } \\ \text { CMO } & \text { Custo Marginal de Operação } \\ \text { CNARH } & \text { Cadastro Nacional de Usuários de Recursos Hídricos } \\ \text { CNRH } & \text { Conselho Nacional de Recursos Hídricos } \\ \text { Codevasf } & \text { Companhia de Desenvolvimento dos Vales do São Francisco e } \\ \text { Copel } & \text { do Parnaíba } \\ \text { COPPE } & \text { Companhia Paranaense de Energia } \\ \text { DAEE } & \text { Coordenação dos Programas de Pós-Graduação de Engenharia } \\ \text { Deso } & \text { Companhia de Saneamento de Sergipe } \\ \text { DF } & \text { Distrito Federal } \\ \text { Eletrobrás } & \text { Centrais Elétricas Brasileiras S/A } \\ & \end{array}$




\begin{tabular}{ll} 
ENA & Energia Natural Afluente \\
EOL & Central Geradora Eolielétrica \\
EPE & Empresa de Pesquisa Energética \\
EPUSP & Escola Politécnica da Universidade de São Paulo \\
FDTE & Fundação para o Desenvolvimento Tecnológico da Engenharia \\
GEF & Fundo Mundial para o Meio Ambiente \\
GERI & Grupo de Estudos de Relações Intersetoriais \\
GO & Estado de Goiás \\
ITP & Itaparica \\
Máx. & Máximo(a) \\
MG & Estado de Minas Gerais \\
Mín. & Mínimo(a) \\
MLT & Média de longo termo \\
MMA & Ministério do Meio Ambiente \\
MME & Ministério de Minas e Energia \\
NA & Nível d'água \\
OEA & Organização dos Estados Americanos \\
ONS & Operador Nacional do Sistema Elétrico \\
PAM & Complexo Paulo Afonso - Moxotó \\
PB & Estado da Paraíba \\
PCH & Pequena Central Hidrelétrica \\
PD & Programação dinâmica \\
PDDE & Programação dinâmica dual estocástica \\
PE & Estado de Pernambuco \\
PISF & Projeto de Integração do Rio São Francisco com Bacias \\
PL & Hidrográficas do Nordeste Setentrional \\
PLD & Programação linear \\
PLIM & Preço de Liquidação das Diferenças \\
PLS & Programação linear inteira mista \\
PMO & Programação linear sucessiva \\
PNL & Programa Mensal de Operação \\
PNLIM & Programação não linear \\
PNRH & Política Nacional de Recursos Hídricos \\
\hline & \\
\hline
\end{tabular}




\begin{tabular}{ll} 
PNUMA & Programa das Nações Unidas para o Meio Ambiente \\
QUE & Queimado \\
RBA & Retiro Baixo \\
RMBH & Região Metropolitana de Belo Horizonte \\
RMSP & Região Metropolitana de São Paulo \\
RN & Estado do Rio Grande do Norte \\
SE & Estado de Sergipe \\
SIN & Sistema Interligado Nacional \\
SIPOT & Sistema de Informações do Potencial Hidrelétrico Brasileiro \\
SNGRH & Sistema Nacional de Gerenciamento de Recursos Hídricos \\
SOB & Sobradinho \\
SSD & Sistema de Suporte a Decisão \\
TMA & Três Marias \\
TR & Período de retorno \\
UFBA & Universidade Federal da Bahia \\
UFRGS & Universidade Federal do Rio Grande do Sul \\
UFRJ & Universidade Federal do Rio de Janeiro \\
UFV & Usina Fotovoltaica \\
UHE & Usina Hidrelétrica de Energia \\
UTE & Usina Termelétrica de Energia \\
UTN & Usina Termonuclear \\
VE & Volume de espera para controle de cheias \\
VU & Volume útil \\
XIN & Xingó \\
\hline
\end{tabular}




\section{LISTA DE SÍMBOLOS}

$\varepsilon_{i}=$ produtividade específica da usina $i\left(\mathrm{MW} /\left(\mathrm{m}^{3} / \mathrm{s}\right) / \mathrm{m}\right)$

$\eta_{i}=$ rendimento médio da usina $i$, valor adimensional que considera a operação dos conjuntos turbina-gerador e a perda de carga dos circuitos hidráulicos desde a tomada d'água até o canal de fuga $\left(0<\eta_{i} \leq 1\right)$

$\omega=$ coeficiente ponderador do atendimento da demanda de energia

$\psi_{u}=$ coeficiente ponderador do atendimento do uso consuntivo $u$

$a_{0 i}, a_{1}, a_{2 i}, a_{3}, a_{4 i}=$ coeficientes do polinômio de quarto grau da equação do nível d'água do reservatório $i$ em função do seu volume armazenado

$A_{i, t}=$ área do reservatório $i$ no intervalo $t\left(\mathrm{~km}^{2}\right)$

$A f_{i}=$ área do reservatório a fio d'água $i\left(\mathrm{~km}^{2}\right)$

$b_{0 i}, b_{1}, b_{2 i}, b_{3 i}, b_{4 i}=$ coeficientes do polinômio de quarto grau da equação no nível d'água no canal de fuga de jusante da usina $i$ em função da sua vazão defluente

$C_{0 i}, C_{1 i}, C_{2 i}, C_{3}, C_{4 i}=$ coeficientes do polinômio de quarto grau da equação área do reservatório $i$ em função do nível d'água no reservatório

$d_{0 i}, d_{1}, d_{2 i}, d_{3 i}, d_{4 i}=$ coeficientes do polinômio de quarto grau da máxima vazão turbinada em função da queda para a usina $i$

$D_{i, t}=$ demanda objetivo de energia da usina $i$ no intervalo de tempo $t(\mathrm{MW})$

$D E_{i, t}=$ desvio de vazão (transposição) a montante do reservatório $i$ durante 0 intervalo $t$, valor considerado positivo se desviado para outras bacias e negativo se afluente à bacia $\left(\mathrm{m}^{3} / \mathrm{s}\right)$

$D H_{i, u, t}=$ demanda objetivo do uso consuntivo $u$ atendida a montante do reservatório i no intervalo de tempo $t\left(\mathrm{~m}^{3} / \mathrm{s}\right)$

$E_{i, t}=$ perda por evaporação no reservatório $i$ durante o intervalo $t\left(10^{6} \mathrm{~m}^{3}\right)$

$f_{0 i}, f_{1 i}, f_{2 i}=$ coeficientes do polinômio alternativo de segundo grau da área do reservatório $i$ em função do seu volume armazenado

$H_{i, t}=$ nível d'água montante da usina $i$ no intervalo $t(\mathrm{~m})$

$H b_{i, t}=$ queda bruta média da usina $i$ durante o intervalo $t(\mathrm{~m})$

$H f_{i}=$ nível d'água a montante da usina a fio d'água i no intervalo $t(\mathrm{~m})$

$H T_{i, t}=$ nível d'água no canal de fuga da usina $i$ no intervalo $t(\mathrm{~m})$ 
$i$ = índice de cada reservatório/usina hidrelétrica

$l_{i, t}=$ vazão incremental afluente ao reservatório $i$ durante o intervalo $t\left(\mathrm{~m}^{3} / \mathrm{s}\right)$

$I D_{i, t}=$ índice de disponibilidade das máquinas da usina $i$ no intervalo $t$, valor adimensional relativo à manutenção ou à expansão do sistema $\left(0 \leq I D_{i, t} \leq 1\right)$

$I E_{i, t}=$ taxa de evaporação do reservatório $i$ durante o intervalo de tempo $t(\mathrm{~m})$

$m_{i}=$ índice do reservatório/hidrelétrica imediatamente a montante de $i$

$n i=$ número total de reservatórios/usinas hidrelétricas

$n m_{i}=$ número total de reservatórios/hidrelétricas a montante de $i$

$n t=$ número total de intervalos de tempo;

$n u=$ número total de tipos de uso consuntivo

$P_{i, t}=$ energia produzida pela usina $i$ no intervalo de tempo $t(\mathrm{MW})$

$P^{\max }{ }_{i}=$ capacidade de geração da usina $i(\mathrm{MW})$

$Q_{95}=$ vazão com permanência de $95 \%$ no tempo

Qcap = vazão captada

Qdisp = disponibilidade hídrica superficial

$Q_{M L T}=$ vazão média de longo termo ou vazão média histórica

Qreg = vazão regularizada

$R_{i, t}=$ vazão defluente total da usina $i$ no intervalo $t\left(\mathrm{~m}^{3} / \mathrm{s}\right)$

$R_{i, t}^{\prime}=$ vazão turbinada pela usina $i$ no intervalo $t\left(\mathrm{~m}^{3} / \mathrm{s}\right)$

$R^{\prime \prime}{ }_{i, t}=$ vazão vertida pela usina $i$ no intervalo $t\left(\mathrm{~m}^{3} / \mathrm{s}\right)$

$R^{\max }{ }_{i, t}=$ vazão turbinada máxima da usina $i\left(\mathrm{~m}^{3} / \mathrm{s}\right)$

$R^{\min }{ }_{i}=$ vazão turbinada mínima na usina $i\left(\mathrm{~m}^{3} / \mathrm{s}\right)$

$S_{i, t}=$ volume armazenado no reservatório $i$ durante o intervalo $t\left(10^{6} \mathrm{~m}^{3}\right)$

$S^{\max }{ }_{i, t}=$ volume armazenado máximo no reservatório $i\left(10^{6} \mathrm{~m}^{3}\right)$

$S^{\min }{ }_{i, t}=$ volume armazenado mínimo no reservatório $i\left(10^{6} \mathrm{~m}^{3}\right)$

$t=$ índice do intervalo de tempo

$u=$ índice do uso consuntivo

$U C_{i, u, t}=$ vazão retirada do reservatório $i$ para atendimento do uso consuntivo $u$ no intervalo de tempo $t\left(\mathrm{~m}^{3} / \mathrm{s}\right)$

$U C^{\min }{ }_{i, t}=$ derivação mínima do reservatório $i$ no intervalo $t$ para atendimento de usos consuntivos considerados prioritários $\left(\mathrm{m}^{3} / \mathrm{s}\right)$

$Z$ = objetivo do modelo HIDRO 


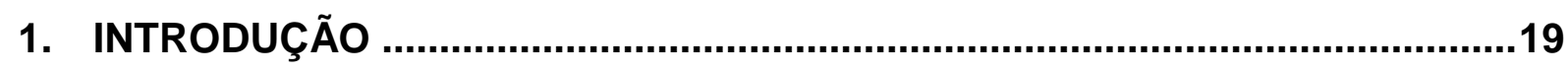

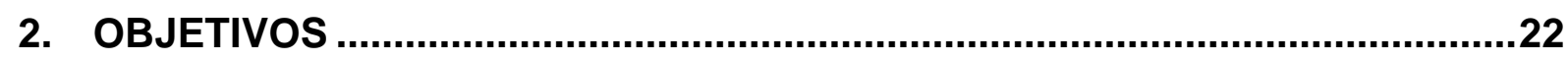

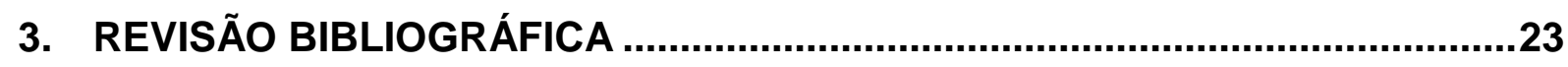

3.1. Sistema Nacional de Gerenciamento dos Recursos Hídricos ...............23

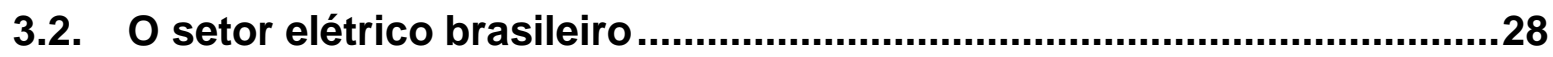

3.3. Estado da arte na modelagem de operação de reservatórios.................32

4. METODOLOGIA

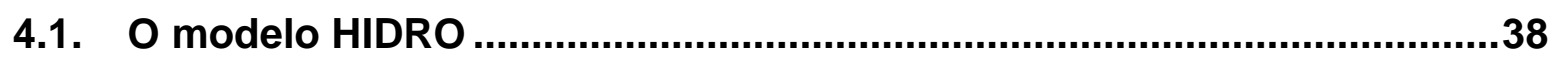

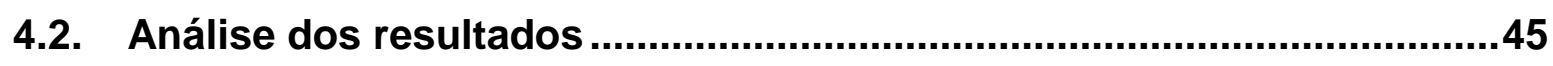

4.2.1. Avaliação dos índices de atendimento ............................................. 45

4.2.2. Estabelecimento das relações de troca - trade-offs - entre geração de

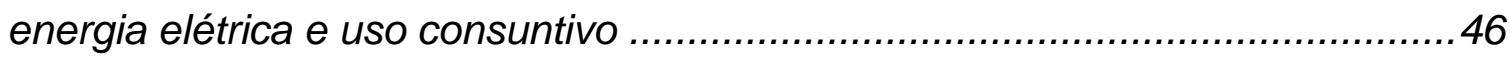

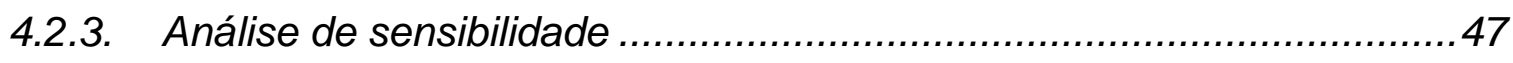

4.2.4. Avaliação do atendimento energético ao longo da curva de duração das

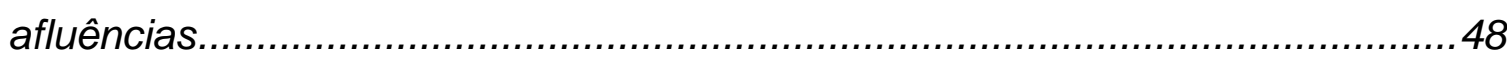

5. ESTUDO DE CASO: bacia hidrográfica do rio São Francisco .......................49

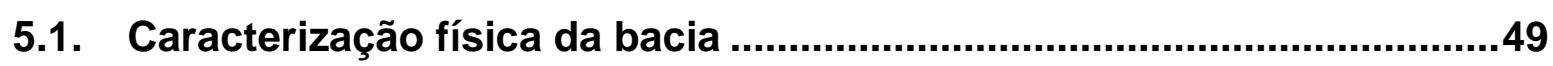

5.2. Descrição das principais demandas hídricas consuntivas ....................52

5.2.1. Abastecimento urbano e uso industrial............................................59

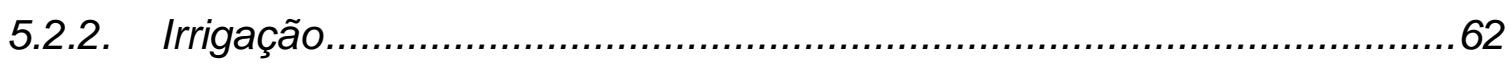

5.2.3. Transposição do rio São Francisco para o Nordeste Setentrional.........66

5.3. Descrição dos principais usos não consuntivos na bacia ....................68

5.3.1. Geração de energia pelas hidrelétricas ............................................68

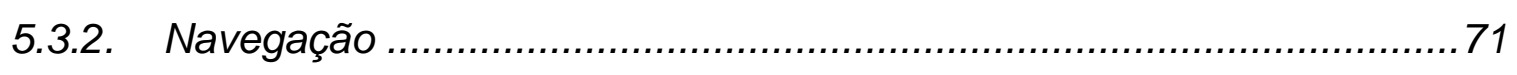

5.3.3. Restrições operativas das usinas ................................................... 72

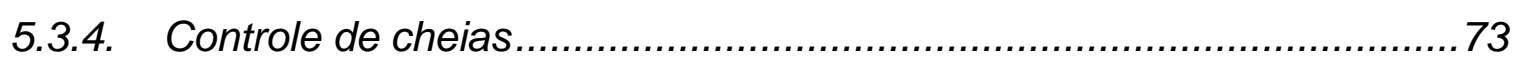

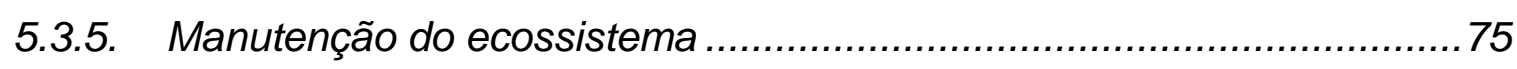

5.4. Histórico de afluências na bacia..........................................................75

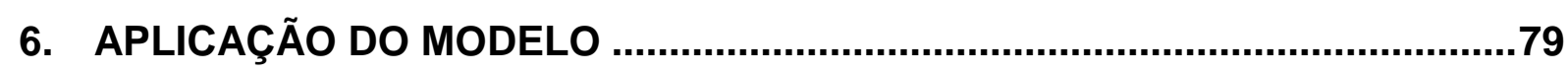

6.1. Variáveis de entrada e restrições operativas .........................................8 
6.1.1. Demanda objetivo. .80

6.1.2. Vazão afluente e perdas por evaporação ...................................... 82

6.1.3. Restrições operativas ......................................................... 83

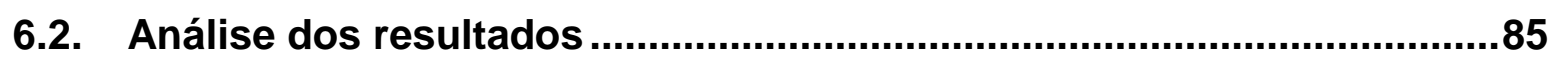

6.2.1. Análise dos índices de atendimento ............................................. 85

6.2.2. Análise das relações de troca entre geração de energia, uso consuntivo

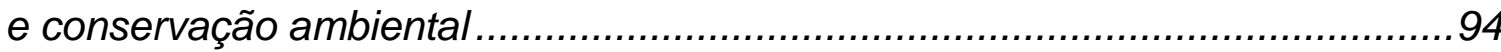

6.2.3. Análise de sensibilidade à variação de prioridade ............................... 105

6.2.4. Avaliação da geração de energia ao longo da curva de duração das afluências. 108

7. CONCLUSÕES 112

REFERÊNCIAS 117

APÊNDICE 125

Anexo A - Histórico do PLD (30/jun/2001 a 01/jun/2012) segundo CCEE. 146

Anexo B - Série histórica de ENA (MWmed) na bacia do rio S. Francisco 154

Anexo C - Resultados do Cenário I para o período abr/1998-mar/2005 156

Anexo D - Resultados do Cenário II para o período abr/1998-mar/2005. 157

Anexo E - Resultados do Cenário III para o período abr/1998-mar/2005 158

Anexo F - Resultados do Cenário IV para o período abr/1998-mar/2005 159

Anexo G - Resultados do Cenário V para o período abr/1998-mar/2005 160

Anexo H - Resultados do Cenário VI para o período abr/1998-mar/2005 161

Anexo I - Resultados do Cenário I para o período abr/1950-mar/1957 162

Anexo J - Resultados do Cenário II para o período abr/1950-mar/1957 163

Anexo K - Resultados do Cenário III para o período abr/1950-mar/1957 164

Anexo L - Resultados do Cenário IV para o período abr/1950-mar/1957 165

Anexo M - Resultados do Cenário V para o período abr/1950-mar/1957 166

Anexo N - Resultados do Cenário VI para o período abr/1950-mar/1957 167 


\section{INTRODUÇÃO}

Conforme a Lei Federal 9.433/97, que instituiu a Política Nacional de Recursos Hídricos, o Sistema Nacional de Gerenciamento dos Recursos Hídricos deve ser descentralizado, participativo e proporcionar o uso múltiplo das águas. Nesse sentido, toda a estrutura que se criou voltada à gestão das águas no Brasil procura atender a esses princípios. A descentralização se dá pela implantação do sistema de gestão por bacia hidrográfica. O incentivo ao uso múltiplo e o caráter participativo são assegurados pela representação de todos os usuários das águas de uma bacia hidrográfica em fóruns de negociação, os Comitês de Bacia, nos quais têm assento não apenas os usuários como também os governos e as instituições da sociedade diretamente interessadas no gerenciamento dos recursos hídricos.

Um dos principais usos da água no Brasil é a geração de energia elétrica. Segundo o Ministério de Minas e Energia (BRASIL, 2011), em 2010 os 405,1 TWh de energia gerados pelas hidrelétricas brasileiras representaram $74,3 \%$ da oferta interna de energia elétrica no País, avaliada em 544,9 TWh, conforme indicado na Tabela 1.1. Em termos de capacidade de geração instalada no Brasil, avaliada em 112,4 GW no ano de 2010, a parcela referente às hidrelétricas foi de $80,7 \mathrm{GW}$, ou $72 \%$ do total, conforme mostram os dados da Tabela 1.2.

Tabela 1.1 - Evolução da Oferta Interna de Energia Elétrica

\begin{tabular}{|c|c|c|c|c|c|c|c|c|c|c|}
\hline \multirow{2}{*}{ Fonte de geração } & \multicolumn{2}{|c|}{1970} & \multicolumn{2}{|c|}{1980} & \multicolumn{2}{|c|}{1990} & \multicolumn{2}{|c|}{2000} & \multicolumn{2}{|c|}{2010} \\
\hline & TWh & $\%$ & TWh & $\%$ & TWh & $\%$ & TWh & $\%$ & TWh & $\%$ \\
\hline Hidráulica & 39,8 & $87,3 \%$ & 128,9 & $92,4 \%$ & 206,7 & $82,9 \%$ & 304,4 & $77,4 \%$ & 405,1 & $74,3 \%$ \\
\hline Térmica & 5,8 & $12,7 \%$ & 10,4 & $7,5 \%$ & 15,6 & $6,3 \%$ & 43,9 & $11,2 \%$ & 103,2 & $18,9 \%$ \\
\hline Combustíveis fósseis & 5,0 & $11,0 \%$ & 7,9 & $5,7 \%$ & 8,2 & $3,3 \%$ & 27,0 & $6,9 \%$ & 60,7 & $11,1 \%$ \\
\hline Biomassa & 0,8 & $1,8 \%$ & 2,5 & $1,8 \%$ & 5,2 & $2,1 \%$ & 10,9 & $2,8 \%$ & 28,0 & $5,1 \%$ \\
\hline Nuclear & . & . & - & - & 2,2 & $0,9 \%$ & 6,0 & $1,5 \%$ & 14,5 & $2,7 \%$ \\
\hline Outras & - & - & 0,2 & $0,1 \%$ & 0,4 & $0,2 \%$ & 0,6 & $0,2 \%$ & 2,2 & $0,4 \%$ \\
\hline Importada & - & - & - & - & 26,5 & $10,6 \%$ & 44,3 & $11,0 \%$ & 34,4 & $6,3 \%$ \\
\hline TOTAL & 45,6 & $100 \%$ & 139,5 & $100 \%$ & 249,2 & $100 \%$ & 393,2 & $100 \%$ & 544,9 & $100 \%$ \\
\hline
\end{tabular}

Fontes: Resenha Energética Brasileira (BRASIL, 2011); Balanço Energético Nacional 2007 (EPE, 2007) 
Tabela 1.2 - Evolução da capacidade instalada

\begin{tabular}{|c|c|c|c|c|c|c|c|c|c|c|}
\hline \multirow{2}{*}{ Fonte de geração } & \multicolumn{2}{|c|}{1970} & \multicolumn{2}{|c|}{1980} & \multicolumn{2}{|c|}{1990} & \multicolumn{2}{|c|}{2000} & \multicolumn{2}{|c|}{2010} \\
\hline & GW & $\%$ & GW & $\%$ & GW & $\%$ & GW & $\%$ & GW & $\%$ \\
\hline Hidráulica & 8,8 & $80 \%$ & 27,7 & $83 \%$ & 45,6 & $86 \%$ & 61,1 & $83 \%$ & 80,7 & $72 \%$ \\
\hline Térmica e nuclear & 1,6 & $15 \%$ & 5,8 & $17 \%$ & 7,5 & $14 \%$ & 12,6 & $17 \%$ & 30,8 & $27 \%$ \\
\hline Eólica & - & - & - & - & - & - & - & - & 0,9 & $1 \%$ \\
\hline Total & 11,0 & $100 \%$ & 33,5 & $100 \%$ & 53,1 & $100 \%$ & 73,7 & $100 \%$ & 112,4 & $100 \%$ \\
\hline
\end{tabular}

Fontes: Resenha Energética Brasileira (BRASIL, 2011); Balanço Energético Nacional 2010 (EPE, 2010)

Conforme indicam os dados da Tabela 1.1 e da Tabela 1.2, a participação da energia gerada por fonte hidráulica em relação à geração total já foi mais expressiva. O Plano Decenal de Expansão de Energia 2019 (BRASIL, 2010) prevê que essa participação relativa diminua ainda mais e poderá chegar a $70 \%$ da capacidade instalada em 2019, devido à expansão das fontes não hidráulicas, notadamente eólica e biomassa. Em números absolutos, contudo, a capacidade instalada total das hidrelétricas deverá expandir até a marca de 116 GW em 2019.

A alta disponibilidade de potencial hidráulico próxima dos grandes centros de consumo foi um dos aspectos preponderantes para que o Brasil optasse pelo desenvolvimento da hidroeletricidade. Até o final da década de 1940, as atividades de geração, transmissão e distribuição de energia no País estiveram nas mãos de empresas privadas, sendo estrangeiras aquelas responsáveis por atender apenas as grandes cidades. A partir da década seguinte, o Governo Federal e os de alguns estados expandiram os investimentos no setor elétrico, em razão do salto da demanda provocado pelo aumento da industrialização e da urbanização. Iniciou-se, então, a construção e gradativa interligação de várias das usinas de grande porte que hoje formam o Sistema Integrado Nacional (SIN) (KELMAN et al., 2006).

O desenvolvimento industrial e econômico do País intensificou o uso dos recursos hídricos, seja quanto à crescente quantidade de água demandada, seja quanto à diversidade dessas utilizações. A redução da disponibilidade hídrica ocasionou, em algumas regiões brasileiras, situações em que os múltiplos usos da água se tornaram concorrentes e com potenciais conflitos entre os usuários.

Via de regra, enquanto a abundância de água garantia a ausência de conflitos relacionados à quantidade ou à qualidade dos recursos hídricos, a responsabilidade pela gestão das águas mantinha-se repartida, sem profundas interferências, entre as autoridades administrativas encarregadas de sua utilização e conservação. Na 
medida em que os conflitos pelo uso da água se agravaram, entraram em choque as funções dos vários setores interessados no gerenciamento dos recursos hídricos.

Em 2001, a crise de energia ocorrida no País demonstrou os conflitos e os impactos negativos desencadeados em um cenário de disputa pelo escasso recurso hídrico. As regras de operação dos reservatórios, impostas para suprir a demanda de energia, trouxeram consequências indesejáveis a outras atividades econômicas como a navegação, a agricultura irrigada, o turismo e o abastecimento público. Tornou-se evidente a necessidade de harmonização dos diversos usos e sistemas de recursos hídricos por meio de uma base de gerenciamento integrado. No caso da expansão e da operação dos sistemas de reservatórios, tornou-se imprescindível considerar todos os usos concorrentes que deles se beneficiam.

Esse cenário demonstra a grande importância da atuação dos agentes geradores de energia elétrica no processo de gestão de recursos hídricos. Essa participação, no entanto, ainda ocorre de forma relativamente pouco efetiva. De um lado, observa-se que os envolvidos na gestão das águas não se esmeram em trazer para o âmbito das discussões os agentes do setor elétrico, cujas contribuições em muito enriqueceriam as atividades de planejamento e os processos de negociação.

O setor elétrico, por sua vez, tende a considerar a água como um recurso que, embora essencial a suas atividades, possui custo zero de obtenção. Concomitantemente, a operação dos reservatórios das usinas que compõem o SIN é realizada pelo Operado Nacional do Sistema Elétrico (ONS) com a utilização de uma cadeia de modelos que tratam os demais usos do recurso hídrico como restrições a serem consideradas após atingidas as metas de geração de energia.

Além de acomodar tais conflitos, a otimização da operação do sistema elétrico brasileiro mostra-se um problema complexo em razão de outros aspectos: o tamanho do sistema brasileiro, considerado um dos maiores do mundo; a não linearidade e a interdependência das variáveis envolvidas; a estocasticidade dos fenômenos hidrológicos; a demanda crescente pela água, notadamente em bacias marcadas pela indisponibilidade hídrica.

Este trabalho procura, assim, contribuir para o gerenciamento dos recursos hídricos ao integrar, na operação de um sistema de reservatórios, tanto as demandas do setor elétrico como as de outros setores dependentes do uso consuntivo do recurso hídrico, buscando otimizar o desempenho do sistema, conforme as premissas expressas pela Política Nacional de Recursos Hídricos. 


\section{OBJETIVOS}

Este trabalho tem como objetivo geral avaliar o impacto causado na operação de um sistema de reservatórios para produção de energia elétrica pelo atendimento dos usos consuntivos do recurso hídrico.

Especificamente, busca-se analisar o impacto que 0 atendimento das demandas hídricas consuntivas como a irrigação, os usos industriais e os usos considerados prioritários pela legislação, como o consumo humano e a dessedentação animal, exerce sobre a produção de energia pelo sistema de usinas hidrelétricas de uma bacia hidrográfica marcada por problemas de disponibilidade hídrica e por conflitos entre os usuários.

Pretende-se determinar as relações de troca entre a geração de energia e as demandas hídricas consuntivas, bem como a variação do atendimento da demanda de energia e da demanda hídrica ao serem consideradas diferentes demandas hídricas não consuntivas como, por exemplo, a navegação e a conservação ambiental. Pretende-se também avaliar o custo associado a eventuais deficit de atendimento da demanda de energia pelas usinas hidrelétricas.

Uma vez que os modelos atualmente empregados pelo setor elétrico brasileiro tratam o atendimento dos usos consuntivos como restrições na operação dos reservatórios, este trabalho contribui para integrar o planejamento da operação do setor elétrico e o gerenciamento dos recursos hídricos. Para tanto, propõe-se tratar o problema da operação de um sistema de reservatórios para geração de energia elétrica com o emprego de um modelo que inclui, em sua função objetivo, tanto o atendimento das demandas de energia como das demandas hídricas consuntivas. 


\section{REVISÃO BIBLIOGRÁFICA}

A geração de energia por meio das hidrelétricas pertence à categoria dos usos não consuntivos dos recursos hídricos, ou seja, aqueles que retornam praticamente toda a quantidade da água utilizada à fonte de origem. Todavia, as regras de operação dos reservatórios, impostas para atender à demanda de energia, e a necessidade de disponibilizar às hidrelétricas as vazões que the foram outorgadas acabam por criar restrições aos demais usuários das águas localizados tanto a montante como a jusante dos aproveitamentos hidrelétricos.

Uma vez que o aproveitamento das águas para geração de energia elétrica é um uso significativo no País e, mais que isso, trata-se de um uso do recurso hídrico do qual decorre uma série de interferências com demais usuários da água, o setor elétrico constitui um ator relevante para o Sistema Nacional de Gerenciamento dos Recursos Hídricos (SNGRH).

Assim, este capítulo traz uma breve descrição sobre a configuração administrativa que o Estado brasileiro assume para gerir seus recursos hídricos. Em seguida, será descrito o setor elétrico brasileiro, com destaque para a geração de energia pelas hidrelétricas. Por último, é apresentado o estado da arte da modelagem de operação de sistemas de reservatórios.

\subsection{Sistema Nacional de Gerenciamento dos Recursos Hídricos}

A Constituição Federal (CF) de 1988 criou condições para que se introduzisse no País a gestão integrada e participativa dos recursos hídricos. A CF extinguiu o domínio privado das águas ao colocá-las sob domínio público - federal ou estadual - e atribuiu à União competência para instituir o SNGRH e para definir os critérios de outorga de direito de uso da água. Com relação aos potenciais de energia hidráulica, a Constituição determina que eles pertencem à União e que a ela cabe outorgar o seu aproveitamento mediante autorização ou concessão (BRASIL, 1988). 
O SNGRH foi instituído pela Lei Federal no. 9.433, de 8 de janeiro de 1997, a qual dá competência ao SNGRH para coordenar a gestão integrada dos recursos hídricos, arbitrar conflitos referentes ao uso da água, implementar a Política Nacional de Recursos Hídricos (PNRH), planejar e controlar o uso, a preservação e recuperação dos recursos hídricos e promover a cobrança pelo uso da água.

O SNGRH é integrado pelo Conselho Nacional de Recursos Hídricos (CNRH), pelos Conselhos Estaduais de Recursos Hídricos (CERH), pelos Comitês de Bacia Hidrográfica $(\mathrm{CBH})$, pelos órgãos gestores dos recursos hídricos em nível federal e em nível estadual e pelas Agências de Águas.

Os Estados e o Distrito Federal definem as regras de composição de seu

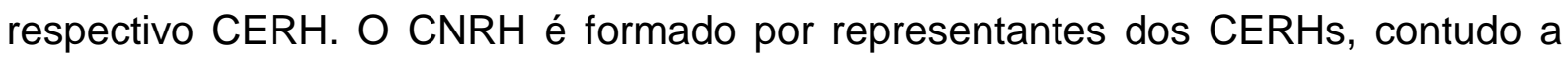
maioria dos votos pertence ao Poder Executivo Federal.

Os $\mathrm{CBH}$ são fóruns de discussão e de negociação compostos por representantes do Poder Executivo dos governos (federal, estadual, municipal), dos usuários da água e de organizações civis com atuação comprovada na bacia hidrográfica. Os representantes dos usuários podem ser escolhidos entre pessoas físicas ou jurídicas, de direito privado ou de direito público. A instituição de um $\mathrm{CBH}$ é objeto de aprovação do $\mathrm{CNRH}$, no caso das bacias de rios de domínio federal, ou dos CERHs, no caso das bacias de rios de domínio estadual.

Sobre o domínio das águas, conforme estabelecido pela Constituição Federal de 1988 em seu Art. 20, são considerados de domínio da União os rios, lagos e correntes de água que banham mais de uma unidade federada, que sirvam de fronteira entre o Brasil e um país vizinho ou que se estendam a território estrangeiro ou dele provenham (BRASIL, 1988). Com relação às águas de domínio dos estados, a CF de 1988 não considera de forma explícita os rios como bens estaduais. O inciso I do Art. 26 diz apenas que estão incluídas nos bens dos estados "as águas superficiais ou subterrâneas, fluentes, emergentes e em depósito, ressalvadas, neste caso, na forma da lei, as decorrentes de obras da União". Interpreta-se, portanto, que são de domínio estadual todos os rios que não pertencem à União e, dessa forma, permanece em prática o conceito expresso no Art. 5․ da antiga Constituição Federal de 1967, que considerava rio estadual aquele que possui nascente e foz dentro do território estadual (CABRAL; KELMAN, 2003).

Uma vez que as águas de um corpo hídrico são um bem de domínio público, o seu aproveitamento - seja para geração de energia elétrica, seja para atendimento 
de demandas como irrigação, criação animal, abastecimento público e usos industriais, entre outros - depende de autorização do Poder Público. Essa autorização é concedida por meio de um instrumento legal denominado outorga de direito de uso do recurso hídrico. A Agência Nacional de Águas (ANA), entidade vinculada ao Ministério do Meio Ambiente (MMA), é o órgão oficial responsável por emitir as outorgas para uso das águas de domínio da União. Para utilização das águas de domínio estadual, os pedidos de outorga devem ser encaminhados aos respectivos órgãos gestores de recursos hídricos dos estados. No caso do setor elétrico, além da outorga de direito de uso, aplica-se também outro instrumento de gestão caracterizado como autorização do Poder Público: a declaração de reserva de disponibilidade hídrica, também conhecida por outorga preventiva.

A outorga para uso da água foi criada pelo Código das Águas, o primeiro instrumento legal de gerenciamento de recursos hídricos do Brasil, estabelecido pelo presidente Getúlio Vargas no Decreto Federal n. 24.643 de 1934 e vigente ainda hoje (BRASIL, 1934). Embora fosse considerado avançado para a época, tendo servido de modelo para outros países, muitos de seus princípios não se efetivaram por falta de regulamentação, exceção feita aos pontos relativos ao aproveitamento hidrelétrico e justificada pelo contexto histórico-social do País à época. Em virtude da expansão do setor industrial brasileiro e da crescente urbanização a partir da década de 1950, o atendimento à demanda de energia tornou-se prioritário. Assim, ficou a cargo do Ministério de Minas e Energia (MME) conceder outorgas de captação de água para todas as finalidades exceto irrigação, cujas outorgas continuaram sob responsabilidade do Ministério da Agricultura (MENDES, 2007).

Hodiernamente, no caso específico do uso da água para geração de energia elétrica, antes de se licitar uma concessão ou de se autorizar o uso do potencial, é necessário que se declare previamente haver disponibilidade hídrica para a época em que o empreendimento estiver implantado. Esse procedimento permite, por exemplo, que os investidores realizem um adequado planejamento da central hidrelétrica. Essa reserva de vazão passível de ser outorgada é prevista no Art. 6․ da Lei Federal №. 9.984, de 17 de julho de 2000, e constitui o instrumento de reserva de disponibilidade hídrica. As outorgas preventivas têm prazo máximo de validade de 3 anos, variando conforme a complexidade do projeto, e não conferem direito de uso da água. 
Segundo a Lei Federal №. 9.984, de 17 de julho de 2000, a Agência Nacional de Energia Elétrica (ANEEL) deve promover junto aos órgãos gestores de recursos hídricos estaduais a prévia obtenção da declaração de reserva de disponibilidade hídrica no caso de aproveitamentos realizados em corpos hídricos de domínio dos estados. Quando o potencial hidráulico se localizar em corpo d'água de domínio federal, a declaração de reserva de disponibilidade hídrica deve ser obtida em articulação da ANEEL com a ANA. Neste caso, a ANA consultará os órgãos gestores de corpos hídricos estaduais que podem afetar o empreendimento ou que por ele serão afetados, a fim de se garantir os usos múltiplos na bacia hidrográfica. Essa articulação é prevista na Resolução ANA no. 131, de 11 de março de 2003.

A declaração de reserva de disponibilidade hídrica se transforma em outorga de direito de uso em favor da instituição que receber da ANEEL a concessão ou a autorização de uso do potencial de energia elétrica.

Conforme ANEEL (2012), no período de 1998 a 2012, ou seja, desde o advento da $\mathrm{PNRH}$, foram outorgados 558 empreendimentos de geração de energia elétrica que ainda não tiveram sua construção iniciada. Esse total inclui as usinas termelétricas (UTE), as centrais geradoras eolielétricas (EOL) e undi-elétricas (CGU) e os aproveitamentos hidrelétricos - centrais geradoras hidrelétricas (CGH), pequenas centrais hidrelétricas $(\mathrm{PCH})$ e usinas hidrelétricas (UHE). Os aproveitamentos hidrelétricos representam $19 \%$ da potência total dos empreendimentos outorgados, conforme mostrado na Tabela 3.1. A Figura 3.1 apresenta um gráfico com o número de outorgas e a potência de cada tipo de empreendimento.

Tabela 3.1 - Empreendimentos outorgados desde 1998 e que não tiveram construção iniciada

\begin{tabular}{lrrr}
\hline Tipo & Quantidade & Potência (kW) & \%Potência \\
\hline CGH & 61 & 40.698 & $0,2 \%$ \\
PCH & 134 & 1.849 .090 & $8,6 \%$ \\
UHE & 11 & 2.179 .042 & $10,1 \%$ \\
UTE & 150 & 11.768 .573 & $54,5 \%$ \\
EOL & 201 & 5.748 .590 & $26,6 \%$ \\
CGU & 1 & 50 & $0 \%$ \\
Total & $\mathbf{5 5 8}$ & $\mathbf{2 1 . 5 8 6 . 0 4 3}$ & $\mathbf{1 0 0 , 0 \%}$ \\
\hline
\end{tabular}

Fonte: ANEEL (2012) 


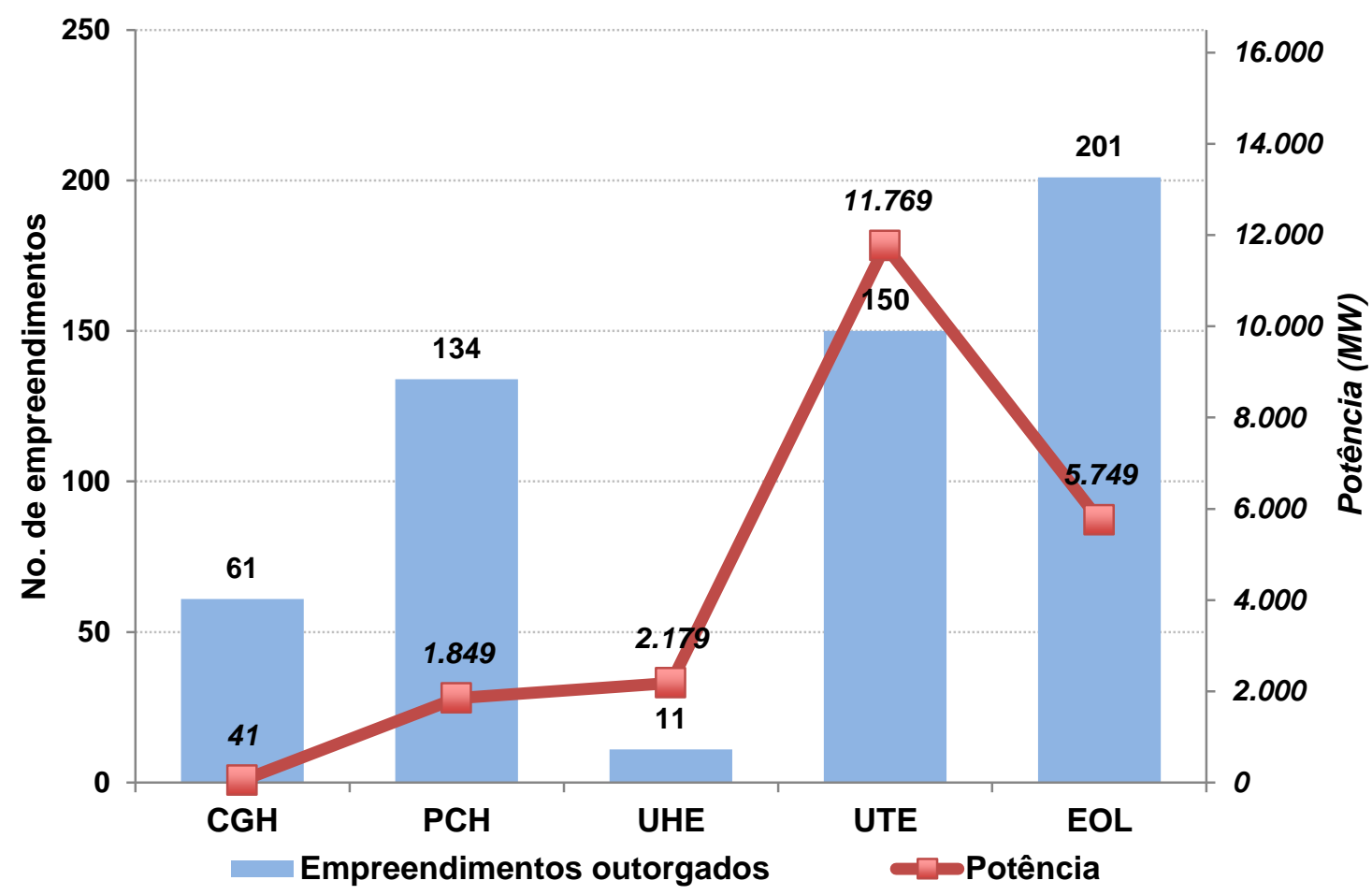

Figura 3.1 - Empreendimentos outorgados desde 1998 e que não tiveram construção iniciada

Os órgãos gestores de recursos hídricos, ao apreciarem uma solicitação de outorga, procedem ao cálculo da disponibilidade hídrica no corpo hídrico quando considerada a vazão de captação e ou de lançamento pleiteada juntamente com as vazões até então outorgadas. Caso a vazão remanescente fique abaixo do valor mínimo legalmente estabelecido em alguma seção ou trecho do corpo hídrico, o pedido é indeferido. A outorga, portanto, protege o usuário da água contra o uso predador de quem não a possui, uma vez que, em caso de escassez hídrica, os não outorgados devem limitar seu uso ou mesmo suprimi-lo, a fim de que seja garantida a utilização e, por consequência, os investimentos de quem é regularmente outorgado. Ressalta-se que, conforme expresso no Art. $1^{\circ}$. da Lei Federal $\mathrm{n}^{\circ}$. 9.433/97, "em situações de escassez, o uso prioritário dos recursos hídricos é o consumo humano e a dessedentação de animais" (BRASIL, 1997).

A outorga concedida às hidrelétricas registra apenas a vazão correspondente à geração máxima. Embora a geração de energia elétrica constitua um uso não consuntivo, as regras operativas dos reservatórios de regularização ocasionam variações na vazão defluente que impactam usuários situados a montante e a jusante do barramento. Nesse sentido, seria adequado que as regras operativas 
fossem consideradas pelos órgãos gestores por meio de um instrumento que complementasse a outorga de direito de uso, na forma, por exemplo, de uma outorga de operação. Essa prática, no entanto, exigiria uma interação do setor elétrico com os gestores de recursos hídricos mais efetiva que a atualmente observada.

\section{2. $O$ setor elétrico brasileiro}

O sistema de produção e transmissão de energia elétrica do Brasil, em razão de seu grande porte e da forte predominância de usinas hidrelétricas e com múltiplos proprietários, apresenta características que o distinguem no âmbito mundial.

Segundo informações da ANEEL (2012), há no Brasil 2.613 empreendimentos em operação, responsáveis pela geração de 117,5 GW de potência, 70,3\% dos quais de origem hidráulica - CGH, PCH e UHE. As usinas termonucleares (UTN) e as termelétricas (UTE) representam em conjunto 28,5\% da potência total. As usinas fotovoltaicas (UFV) e as centrais eolielétricas (EOL) em conjunto representam menos de $1,3 \%$ da potência total, conforme mostram os dados da Tabela 3.2.

Tabela 3.2 - Capacidade de geração (kW) por tipo de aproveitamento em operação

\begin{tabular}{lrrr}
\hline Tipo & Quantidade & Potência (kW) & \%Potência \\
\hline CGH & 376 & 221.854 & 0,19 \\
PCH & 427 & 3.939 .205 & 3,35 \\
UHE & 182 & 78.456 .459 & 66,76 \\
UTE & 1.545 & 31.422 .193 & 26,74 \\
UTN & 2 & 2.007 .000 & 1,71 \\
EOL & 73 & 1.479 .442 & 1,26 \\
UFV & 8 & 1.494 & 0 \\
Total & $\mathbf{2 . 4 1 7}$ & $\mathbf{1 1 7 . 5 2 7 . 6 4 7}$ & $\mathbf{1 0 0 , 0 0}$ \\
\hline Fonte: ANEEL (2012) & &
\end{tabular}

Os empreendimentos responsáveis por $97 \%$ da capacidade de produção de energia no País integram o chamado Sistema Interligado Nacional (SIN), formado pelas empresas das regiões Sul, Sudeste, Centro-Oeste, Nordeste e parte da região Norte. Apenas 3,4\% da capacidade de geração encontra-se desconectada do SIN, em pequenos sistemas isolados, localizados principalmente na bacia do Amazonas. 
Costuma-se dividir o SIN em quatro subsistemas geradores: Sudeste/CentroOeste, Sul, Nordeste e Norte. Historicamente, esses subsistemas desenvolveram-se de forma independente, desarticulados uns dos outros, a partir de investimentos do setor público realizados, principalmente, pelas empresas estaduais Cemig, Copel e Cesp e pelas federais Chesf e Furnas. Paulatinamente, pela construção de grandes troncos de transmissão, os subsistemas geradores foram interligados, a fim de se permitir o sinergismo das regiões, pois suas bacias hidrográficas apresentam comportamentos hidrológicos distintos como, por exemplo, a ocorrência dos períodos úmidos em meses diferentes do ano (KELMAN et al, 2006).

A Figura 3.2 apresenta o mapa do SIN, seus subsistemas geradores e principais interligações.

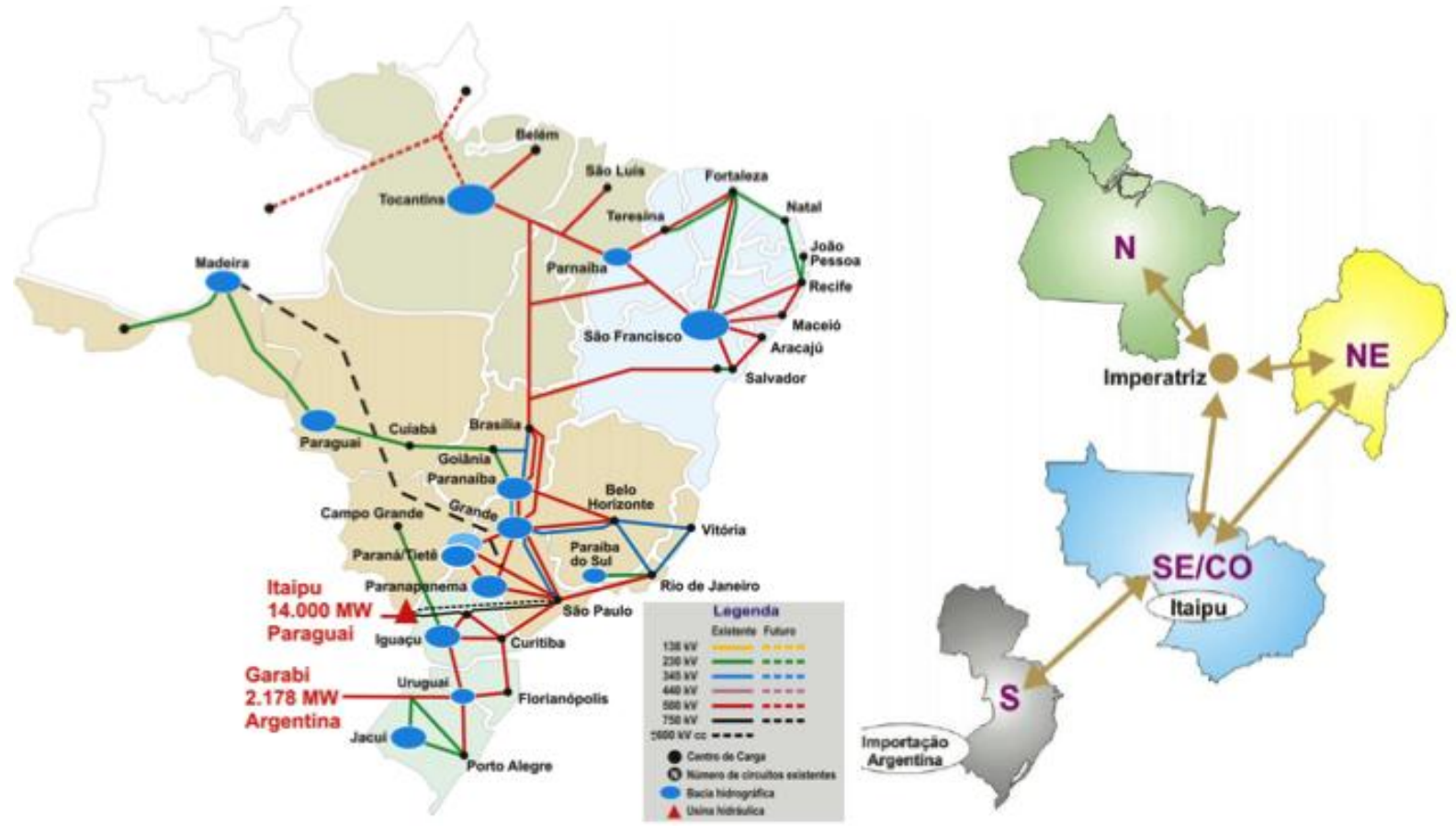

Figura 3.2 - Mapa do SIN, seus subsistemas e interligações

Para fins de planejamento da operação, representa-se o SIN por quatro subsistemas equivalentes e suas interligações. Cada subsistema é representado como um reservatório equivalente, que agrega o armazenamento e a produção de energia de todas as usinas hidrelétricas que a ele pertencem. Analogamente, agregam-se as usinas térmicas em quatro usinas equivalentes com custo crescente de produção, formado por uma composição dos custos de produção individuais. 
Conforme dados do Operador Nacional do Sistema Elétrico (ONS), o SIN é composto por 137 usinas hidrelétricas, o que não inclui as $\mathrm{PCHs}$. Com relação às 137 UHEs, 69 delas contam com reservatórios de regularização de vazões intra ou plurianual, e as outras 68 operam a fio d'água. Esses aproveitamentos somam $75,9 \mathrm{GW}$ de potência instalada, o equivalente a 74,6\% do total do SIN (ONS, 2011b).

Atualmente, encontram-se em construção 15 UHEs, cuja operação está prevista para iniciar até 2016. Há ainda 2 UHEs cuja construção ainda não foi iniciada e que também têm o início de operação previsto para 2016. A potência outorgada desses 17 aproveitamentos soma 20 GW (CCEE, 2012; ONS, 2011b).

A Tabela 3.3 apresenta as UHEs em construção e as UHEs planejadas com a respectiva potência outorgada. O cronograma de expansão da geração pelas UHEs do SIN é apresentado na Figura 3.3.

Tabela 3.3 - Usinas hidrelétricas do SIN em fase de construção ou planejadas

\begin{tabular}{|c|c|c|}
\hline UHE em construção & Potência outorgada (MW) & Entrada em operação \\
\hline Passo São João & 77 & $2011-2012$ \\
\hline Estreito Tocantins & 1.087 & 2011-2012 \\
\hline Mauá & 350 & 2012 \\
\hline Simplício & 306 & 2012 \\
\hline São Domingos & 48 & $2012-2013$ \\
\hline Santo Antônio & 3.151 & $2012-2016$ \\
\hline Batalha & 54 & 2013 \\
\hline Coaracy Nunes & 78 & 2013 \\
\hline Jirau & 3300 & $2013-2016$ \\
\hline Garibaldi & 175 & 2014-2015 \\
\hline Sto. Antônio do Jari & 300 & 2014 \\
\hline Ferreira Gomes & 252 & 2015 \\
\hline Colíder & 300 & 2015 \\
\hline Teles Pires & 1.820 & 2015 \\
\hline Belo Monte & 195 & $2015-2016$ \\
\hline Subtotal & 11.492 & \\
\hline UHE planejada & Potência outorgada (MW) & Início de operação previsto \\
\hline Baixo Iguaçu & 350 & 2016 \\
\hline São Roque & 135 & 2016 \\
\hline Subtotal & 485 & \\
\hline TOTAL & 11.977 & \\
\hline
\end{tabular}




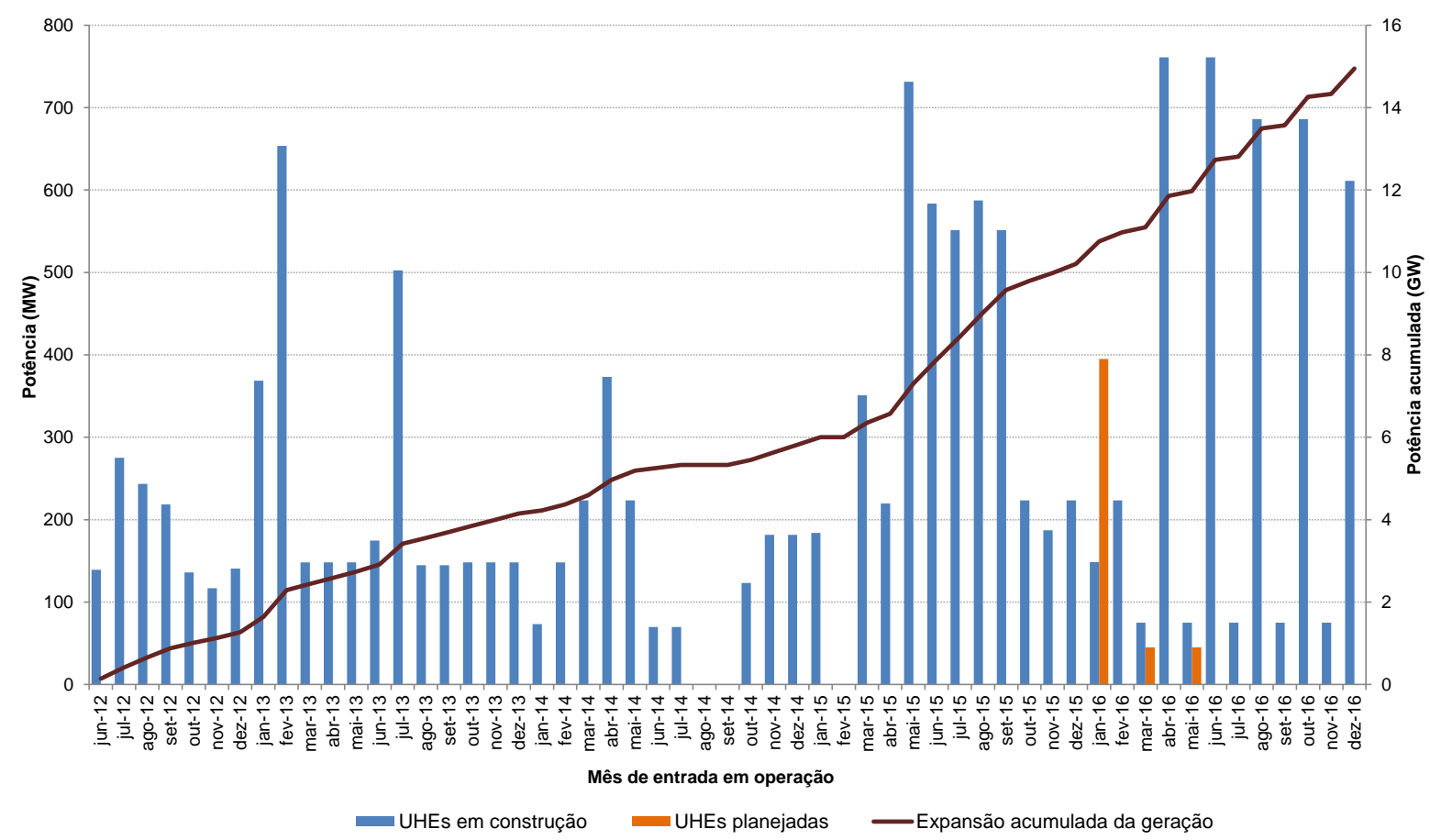

Figura 3.3 - Cronograma de expansão das usinas hidrelétricas do SIN

A característica principal da operação do SIN é aproveitar o potencial hídrico e minimizar o uso das usinas térmicas. Essa operação minimiza o custo de produção de energia elétrica, visto que o custo do combustível fóssil supera o custo de operação das hidrelétricas. O uso excessivo das hidrelétricas, contudo, aumenta o risco de não atendimento da demanda futura, pois a afluência aos reservatórios e o volume por eles armazenado dependem da precipitação, marcada pela estocasticidade. A água armazenada no sistema, portanto, é utilizada até um limite de segurança, a partir do qual se deve complementar a geração de energia com as térmicas (ZAMBON, 2008).

O ONS emprega modelos para gerenciamento dos reservatórios - dentre os quais o NEWAVE e o DECOMP - com o objetivo de minimizar os custos de geração térmica e atender a demanda de eletricidade com certa garantia. Trata-se, entretanto, de enfoque que não leva em conta a otimização conjunta dos outros usos da água. Atividades como abastecimento público, irrigação, lazer e turismo, navegação e preservação do meio ambiente são reduzidas à condição de restrições operativas. Mais do que isso, a maioria das pesquisas e trabalhos acadêmicos na área de operação de sistemas de reservatórios ainda não trata a idéia do uso múltiplo das águas de forma adequada (BRANDÃO, 2004).

Exemplos de como os usos múltiplos são tratados como restrições operativas: 
- O suprimento de água para abastecimento público e irrigação em geral é associado a um valor fixo a ser extraído do sistema;

- A navegação é tratada como valor mínimo a ser atribuído à vazão defluente e/ou como volumes que deixam os reservatórios durante operação das eclusas;

- O controle de cheias é considerado por meio da alocação de volumes sazonais de espera para acomodação das cheias de determinada magnitude, limitando descargas a jusante;

- Atividades de lazer e de turismo e preservação ambiental são consideradas pela manutenção de vazões mínimas a jusante, pela restrição de variações bruscas do nível d'água, impedindo níveis d'água muito baixos e também muito elevados.

A operação do SIN, portanto, envolve alguns dilemas. Se utilizadas excessivamente, as hidrelétricas podem não atender a demanda futura de energia em situações de escassez. Caso contrário, se as térmicas forem acionadas com muita frequência, o custo de geração aumenta e, concomitantemente, corre-se o risco de se promover o vertimento dos reservatórios, visto que, por terem sido mantidos mais cheios, eles não conseguirão armazenar o volume resultante de um cenário de chuvas intensas. Além disso, se a manutenção de grandes volumes armazenados por um lado maximiza a energia gerada em cada reservatório, por outro pode dificultar o pleno atendimento de demandas hídricas consuntivas, pois as defluências são menores. Ao mesmo tempo, retiradas constantes e intensas a montante afetam a vazão afluente aos reservatórios, o que diminui a energia gerada.

Percebe-se, assim, a complexidade que envolve a operação do sistema de reservatórios do SIN. Essa operação demanda a aplicação de técnicas de otimização que sejam capazes de tratar adequadamente os elementos envolvidos não apenas na geração de energia como também na gestão do recurso hídrico.

Apresenta-se, na sequência, a evolução da pesquisa acerca da operação de sistemas de reservatórios e alocação de águas.

\subsection{Estado da arte na modelagem de operação de reservatórios}

Labadie (2004) apresenta uma revisão dos trabalhos relativos à modelagem de operação de reservatórios e comenta as diferentes técnicas empregadas na 
otimização desses sistemas. Essas técnicas incluem programação linear ( $\mathrm{PL})$, programação não linear (PNL), programação dinâmica (PD), programação linear sucessiva (PLS), redes de fluxo (ou fluxo em rede). Labadie aponta algumas razões para a utilização limitada dos modelos de otimização, tais como as limitações de equipamentos para processamento dos modelos, a necessidade de se adotarem simplificações inadequadas, as dificuldades de entendimento e de implementação dos modelos e a pequena confiança depositada pelos tomadores de decisão e pelos operadores nos modelos de otimização.

Uma das formas apontadas por Labadie (2004) para aumentar o nível de confiança na utilização dos modelos de otimização é a aplicação desses modelos acoplados a Sistemas de Suporte a Decisão (SSD). Labadie destaca o MODSIM como exemplo de modelo de otimização associado a um SSD. O MODSIM, desenvolvido na Colorado State University a partir de 1979, é um modelo de fluxo em rede que permite ao usuário criar diferentes redes de reservatórios por meio de uma interface gráfica amigável em Windows. Integram o MODSIM um sistema de gerenciamento de dados e um modelo de otimização de redes de fluxo (AZEVEDO; PORTO; ZAHED FILHO, 2002).

No Brasil, modelos aplicados à otimização de sistemas complexos empregaram PL, PD e PNL. No caso da PL, destaca-se o SSD ACQUANET, desenvolvido por Porto et al. (2005), cujas primeiras versões foram baseadas no modelo MODSIM (ROBERTO; PORTO, 1999). O ACQUANET foi adotado em trabalhos voltados a análises de alocação de água em várias bacias hidrográficas do País para modelar casos interessantes como, por exemplo, a alocação de água na bacia do rio São Francisco, incluindo sua transposição para as bacias do Nordeste Setentrional (ANA/GEF/PNUMA/OEA, 2004d), a reversão do rio Piracicaba para o abastecimento da Região Metropolitana de São Paulo (RMSP), e a operação do Sistema Produtor de Água do Alto Tietê, também na RMSP (SCHARDONG et al., 2006). Atualmente, o ACQUANET integra módulos de alocação de água, qualidade da água, irrigação, produção de energia e curvas de aversão ao risco.

Barros et al. (2003), em uma parceria da Escola Politécnica da Universidade de São Paulo (EPUSP) com a Universidade da Califórnia (UCLA), criaram o modelo SISOPT para otimizar a operação de sistemas de geração de energia de grande porte pelo uso da técnica da PLS com o pacote MINOS. O modelo SISOPT foi aplicado ao complexo sistema hidrelétrico brasileiro com diferentes funções objetivo. 
O modelo SISAGUA, desenvolvido por Barros et al. (2005), aplica algoritmos de programação linear inteira mista (PLIM) e programação não linear inteira mista (PNLIM) na operação de sistemas complexos de adução de água formados por reservatórios, estações de tratamento e elevatórias. O SISAGUA foi aplicado em estudos do sistema de abastecimento da RMSP e também ao sistema de Taiwan, com a otimização processada pelo software General Algebric Modeling System (GAMS), da GAMS Development Corporation.

GAMS é um sistema de otimização com códigos específicos de programação aplicáveis a PL e a PNL, disponível para diferentes plataformas em computadores pessoais, estações de trabalho e computadores de grande porte. A linguagem GAMS é similar a outras linguagens de programação e o sistema inclui diversos algoritmos de otimização como, por exemplo, o MINOS (CIRILO, 2002).

Também com o uso da ferramenta GAMS, Brandão (2004) aplicou a técnica da PNL no desenvolvimento do modelo SFPLUS, voltado à otimização de sistemas de reservatórios de usos múltiplos na bacia do rio São Francisco. Foi empregado o pacote MINOS na otimização do sistema para condições hidrológicas definidas por três cenários distintos - seco, mediano e úmido. Procedeu-se à otimização seguindo dois métodos diferentes: o das restrições e o das ponderações. Os resultados permitiram a construção das curvas de Pareto, que explicitam as relações de troca ou trade-offs entre diferentes usos da água.

No método das restrições, a função objetivo buscou maximizar a energia média gerada no sistema, ou seja, incluiu-se apenas um uso da água - geração de energia - e os demais usos foram tratados como restrições. As curvas de Pareto para irrigação e geração de energia mostraram que, no São Francisco, em um cenário seco, cada $\mathrm{m}^{3} / \mathrm{s}$ de água destinado à irrigação levou à perda de $2 \mathrm{MWmed}$ na geração de energia elétrica, o equivalente a 17,5 GWh de energia ao longo de um ano. Uma limitação deste método é a impossibilidade de se trabalhar com mais do que três usos da água (BRANDÃO, 2004).

No método das ponderações, os usos competitivos da água foram incluídos na função objetivo, ponderados conforme sua prioridade de atendimento. A função objetivo buscou maximizar uma ponderação entre energia média gerada e vazão média extraída para irrigação. As relações de troca entre irrigação e geração de energia obtidas por este método mostraram que, em qualquer cenário hidrológico, o trade-off entre esses dois usos foi mais intenso na faixa em que a prioridade para 
irrigação variou de $40 \%$ a $75 \%$. A limitação deste método é a subjetividade associada à escolha dos coeficientes ponderadores do atendimento de cada uso (BRANDÃO, 2004).

A transposição das águas do São Francisco para as bacias do Nordeste Setentrional foi considerada por Brandão (2004), tendo por base a vazão de projeto cogitada à época, $54 \mathrm{~m}^{3} / \mathrm{s}$ nos dois eixos da transposição. Concluiu-se que, em um cenário de baixa disponibilidade hídrica, essa retirada implicaria em perdas da ordem de 3\% na geração de energia em todo o sistema São Francisco.

Brandão (2004) também considerou os aspectos estocásticos associados ao problema. Para o cenário seco, as curvas de Pareto obtidas a partir de afluências derivadas da série histórica mostraram-se coincidentes com as obtidas pela geração de séries sintéticas de vazões. Para os cenários mediano e úmido, as curvas obtidas a partir das séries sintéticas apresentaram gradientes mais acentuados e valores menores que as obtidas pela série histórica.

No planejamento da operação do SIN, o ONS emprega os modelos NEWAVE e DECOMP, desenvolvidos pelo Centro de Pesquisa de Energia Elétrica (CEPEL) da Eletrobrás e pela Coordenação dos Programas de Pós-Graduação de Engenharia (COPPE) da Universidade Federal do Rio de Janeiro (UFRJ) (ZAMBON, 2004).

O Modelo de Despacho de Geração Hidrotérmica (NEWAVE) emprega a programação dinâmica dual estocástica (PDDE) para minimizar o valor esperado do custo de operação do sistema. São considerados o custo presente do combustível das térmicas e o custo futuro da água. As variáveis de decisão são a geração hidrelétrica, a geração térmica e os intercâmbios entre os subsistemas do SIN. Toma-se a decisão sobre quanto será gerado por hidrelétricas e por térmicas para atender a demanda de energia, considerando um horizonte de um a cinco anos com passo de tempo mensal. O NEWAVE agrega todas as usinas pertencentes a determinado subsistema em um único reservatório equivalente de energia, com volume igual ao total da "energia armazenada" em cada reservatório do subsistema. Assim, o NEWAVE simplifica o SIN, ao tratar apenas quatro reservatórios equivalentes relativos aos quatro subsistemas (CEPEL, 2011).

A agregação das usinas em reservatórios equivalentes empregada no NEWAVE foi o artifício que permitiu o emprego da PDDE de forma a evitar a "praga da dimensionalidade" característica da PD. 
Os resultados do NEWAVE constituem os dados de entrada do Modelo de Determinação da Coordenação da Operação a Curto Prazo (DECOMP), que desagrega os quatro subsistemas equivalentes em usinas individualizadas para um horizonte de tempo de cinco semanas. O DECOMP, que emprega PL, define a geração hidráulica e térmica de cada usina do sistema, bem como o Custo Marginal de Operação (CMO), que pode ser entendido como um custo futuro mais elevado da água. Para cada subsistema é calculado seu $\mathrm{CMO}$, que é um dos parâmetros que definem o preço da energia elétrica no mercado de curto prazo (LOPES, 2007).

Procede-se à execução dos modelos NEWAVE e DECOMP uma vez por mês em uma reunião conhecida por Programa Mensal da Operação (PMO), da qual participam os agentes do processo de planejamento do setor elétrico. Em virtude da constante atualização das previsões hidrológicas, semanalmente é feita uma revisão do processamento do DECOMP pelo ONS. Previsões de seca tendem a elevar o valor do $\mathrm{CMO}$, previsões de grandes afluências tendem a reduzi-lo (LOPES, 2007).

Lopes (2007) desenvolveu o modelo SolverSIN no planejamento de operação de sistemas hidrotérmicos com uso da PNL. O SolverSIN mostrou-se mais simples que os modelos baseados na PDDE sem perder a propriedade de precisão. Mostrou-se também eficiente ao adotar equações de balanço hidroenergético para os reservatórios equivalentes de energia e ao aplicar funções de perdas por vertimento e por variação de queda aos reservatórios equivalentes.

Zambon (2008) desenvolveu um SSD para o planejamento de sistemas hidrotérmicos de grande porte chamado SSD HIDROTERM. O modelo HIDRO otimiza o sistema de usinas individualizadas, sendo esta uma diferença significativa em relação ao SolverSIN e ao NEWAVE, e busca o máximo aproveitamento da capacidade hidrelétrica instalada. O modelo TERM otimiza o despacho das usinas térmicas e os intercâmbios entre os subsistemas. Os modelos podem ser empregados isoladamente ou integrados no modelo HIDROTERM.

O modelo HIDRO corresponde a uma evolução do SISOPT sem o emprego da PL e da PLS. A função objetivo busca minimizar a complementação da energia gerada pelas hidrelétricas com energia gerada pelas térmicas para atendimento da demanda de energia. A função objetivo proposta por Zambon minimiza o quadrado da diferença entre a demanda energética e a produção de energia. Trata-se, portanto, de um modelo a ser resolvido por PNL, cujas variáveis de decisão são a vazão turbinada e a vazão vertida em cada usina (ZAMBON, 2008). 
Para gerar uma solução inicial completa e viável para a PNL, foi desenvolvido um simulador com três opções de operação para as usinas: fio d'água, turbinamento máximo e turbinamento e vertimento definidos pelo usuário. As demandas e a disponibilidade das usinas são variáveis no tempo. (ZAMBON, 2008).

O modelo TERM agrega as usinas térmicas e as demandas em subsistemas. Zambon propôs uma função objetivo que minimiza o custo total da geração térmica, dos intercâmbios e do deficit em cada passo de tempo. Os dados de entrada, para cada subsistema, são a previsão de demanda, a geração por PCH e UTN, a geração resultante do modelo HIDRO, energia importada e exportada, limites da geração térmica inflexível e máxima, limites de intercâmbio entre subsistemas e o custo das térmicas por subsistema. As variáveis de decisão são a geração térmica adicional e os intercâmbios em cada passo de tempo para cada subsistema (ZAMBON, 2008).

Zambon propôs ainda a execução do modelo HIDROTERM, ou por meio de um processo iterativo entre os modelos HIDRO e TERM, ou por uma formulação unificada. Neste caso, a função objetivo pode minimizar a complementação quadrática, como no modelo HIDRO, ou minimizar a soma do custo da geração térmica, dos intercâmbios e do deficit, como no modelo TERM (ZAMBON, 2008).

Os modelos do SSD HIDROTERM foram escritos em linguagem GAMS, o que torna muito flexível sua aplicação quando, por conta das características do problema, for desejável alterar a função objetivo e ou as restrições do problema.

Zambon (2008) aplicou o SSD HIDROTERM às oito usinas da cascata do rio Paranapanema e às 128 usinas do SIN em seus quatro subsistemas, com bom desempenho quanto ao tempo de processamento. $O$ equacionamento simplificado das usinas a fio d'água trouxe vantagens para a solução da PNL. A adoção da PNL e de usinas individualizadas mostrou-se mais precisa na operação do sistema, em razão dos ganhos de produtividade observados, com o deplecionamento inicial dos reservatórios com menor perda por unidade de volume e com a priorização do armazenamento nos reservatórios em série para maximizar a geração total.

O SSD HIDROTERM também foi aplicado, com interessantes resultados, na operação do reservatório de Itaipu (BARROS et al., 2009), na operação do SIN com diferentes funções objetivo (BARROS et al., 2008; ZAMBON et al., 2011) e na avaliação dos impactos econômicos da operação do SIN sob diferentes restrições de armazenamento (ZAMBON et al., 2010). 


\section{METODOLOGIA}

Os modelos adotados pelo ONS para a operação do SIN buscam maximizar a produção de energia elétrica pelas usinas. Os demais usos da água, notadamente as demandas hídricas consuntivas - abastecimento público, criação animal, irrigação e uso industrial - são tratados como restrições à maximização da geração de energia. Assim, este trabalho propõe uma nova forma de se proceder à operação dos reservatórios das usinas hidrelétricas de uma bacia hidrográfica marcada pelo uso intensivo do recurso hídrico.

Propõe-se otimizar a operação de um sistema de reservatórios de forma que, na função objetivo, seja contemplado não apenas o atendimento da demanda energética, como também o atendimento dos usos consuntivos do recurso hídrico. Dessa forma, a vazão retirada do sistema para atendimento das demandas consuntivas passa a integrar o conjunto de variáveis de decisão do modelo, conjunto do qual já fazem parte a vazão turbinada e a vazão vertida em cada usina.

Uma vez que a função objetivo inclui o atendimento de múltiplos usos, deve ser aplicado um coeficiente ponderador tanto para o atendimento da demanda objetivo de energia como para o atendimento de cada tipo de demanda hídrica objetivo considerada.

A região objeto deste estudo é a bacia hidrográfica do rio São Francisco, onde estão localizadas importantes usinas hidrelétricas, cuja potência total é de 10,4 GW. É também uma bacia com intenso uso consuntivo do recurso hídrico, principalmente para irrigação. Além disso, alguns dos principais reservatórios da bacia localizam-se em uma região com baixos índices pluviométricos e altas taxas de evaporação, o que contribui para um quadro de crescente conflito pelo uso da água.

\subsection{O modelo HIDRO}

A operação dos reservatórios da bacia do rio São Francisco, com vistas à geração de energia elétrica e ao atendimento dos usos consuntivos, será analisada 
com o emprego do modelo HIDRO, parte integrante do SSD HIDROTERM desenvolvido por Zambon (2008), com alterações na função objetivo original.

O modelo HIDRO otimiza o sistema composto por um conjunto de usinas com reservatórios, cuja representação esquemática e grandezas envolvidas são mostradas na Figura 4.1.

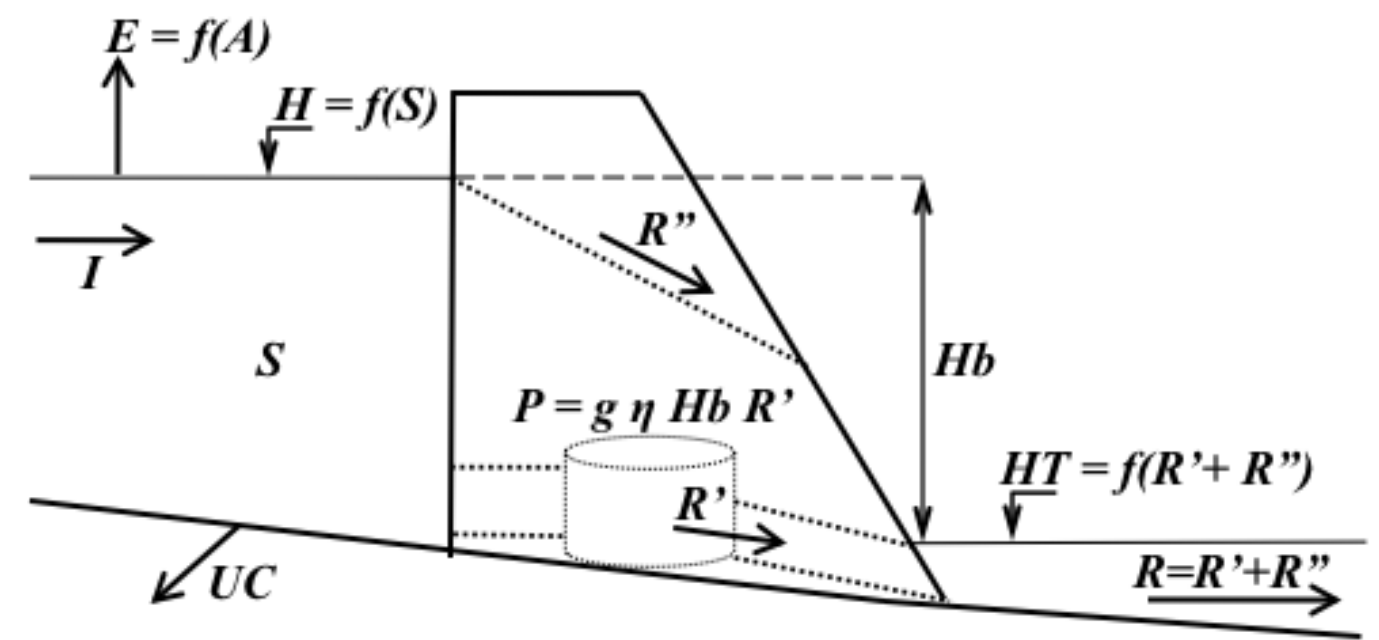

Figura 4.1 - Representação esquemática de uma usina hidrelétrica e grandezas envolvidas

Cada reservatório apresenta um volume de água armazenado ( $S$ ), que é alimentado pela vazão natural incremental afluente $(I)$ mais as vazões turbinadas e vertidas dos reservatórios a montante. Uma parcela do armazenamento se perde para o meio atmosférico por evaporação $(E)$, que é função da área do reservatório $(A)$, que é função do nível d'água montante $(H)$, que é função do volume armazenado $(E(A(H(S))))$. Outra parte do volume armazenado é retirada para atendimento das demandas hídricas consuntivas (UC). Há também a parte do volume armazenado que é utilizada para geração de energia elétrica pela vazão turbinada $(R)$. A vazão vertida $\left(R^{\prime \prime}\right)$ será liberada se houver excesso de água armazenada ou para atender demandas a jusante. O nível do canal de fuga a jusante $(H T)$ é função da vazão total defluente $\left(R=R^{\prime}+R^{\prime \prime}\right)$. A potência $(P)$ gerada em cada usina é função da vazão turbinada $(R)$ e da queda bruta $(H b)$, que é a diferença entre o nível d'água a montante $(H)$ e o canal de fuga a jusante do reservatório $(H T)$.

O modelo HIDRO considera cada usina hidrelétrica de forma individualizada, com o máximo aproveitamento possível da capacidade instalada, isto é, opera-se cada reservatório de forma a minimizar o deficit de energia. A produção segue a 
variação temporal da demanda de energia, de forma que a necessidade de complementação pelas usinas térmicas seja mínima. Quanto maior a necessidade de complementação de energia pelas térmicas, maior o gradiente médio dos custos dessa complementação. Uma função de complementação quadrática é utilizada para penalizar grandes desvios da geração pelas hidrelétricas em relação à demanda.

O modelo também busca maximizar as retiradas de água para o atendimento de diferentes demandas consuntivas da água - abastecimento público, irrigação, criação de animais, uso industrial. A retirada segue a variação temporal da demanda consuntiva considerada, de forma que o deficit de atendimento seja mínimo. Considera-se que a vazão retirada para atendimento dos usos consuntivos em cada usina/reservatório inclui não apenas as captações e derivações situadas no entorno do reservatório, como também todas as retiradas situadas na área incremental da bacia hidrográfica que contribui para o reservatório. Essa consideração é adequada, uma vez que, no modelo, a vazão afluente aos reservatórios é a vazão natural, ou seja, são desconsideradas as diversas interferências antrópicas.

O não atendimento das demandas hídricas gera aos usuários custos maiores quanto maior for o nível de deficit. Analogamente ao atendimento da demanda energética, uma função quadrática é utilizada para penalizar grandes diferenças entre a vazão retirada e a demanda hídrica. Trata-se, portanto, de um modelo de PNL, cuja função objetivo e cujas restrições são apresentadas na sequência.

Zambon (2008) propôs originalmente uma função objetivo que minimiza a complementação quadrática de energia, ou seja, o enfoque original do modelo HIDRO era o desempenho energético. Neste trabalho, propõe-se que a função objetivo minimize, também, o deficit de atendimento das demandas hídricas consuntivas. Assim, a função objetivo proposta pondera o percentual quadrático do deficit energético em relação à demanda de energia e o percentual quadrático do deficit hídrico em relação à demanda hídrica, sendo dada por:

$$
\min Z=\sum_{t=1}^{n t}\left[\omega\left(\sum_{i=1}^{n i} \frac{D_{i, t}-P_{i, t}}{D_{i, t}}\right)^{2}+\psi_{u}\left(\sum_{i=1}^{n i} \frac{D H_{i, u, t}-U C_{i, u, t}}{D H_{i, u, t}}\right)^{2}\right]
$$

onde:

$Z$ = objetivo do modelo HIDRO; 
$t=$ índice do intervalo de tempo;

$n t=$ número total de intervalos de tempo;

$i$ = índice de cada reservatório/usina hidrelétrica;

$n i=$ número total de reservatórios/usinas hidrelétricas;

$u$ = índice do uso consuntivo;

$\omega=$ coeficiente ponderador do atendimento da demanda de energia;

$\psi_{u}=$ coeficiente ponderador do atendimento do uso consuntivo $u$;

$D_{i, t}=$ demanda objetivo de energia da usina $i$ no intervalo de tempo $t(\mathrm{MW})$;

$P_{i, t}=$ energia produzida pela usina $i$ no intervalo de tempo $t(\mathrm{MW})$;

$D H_{i, u, t}=$ demanda objetivo do uso consuntivo $u$ atendida a montante do reservatório $i$ no intervalo de tempo $t\left(\mathrm{~m}^{3} / \mathrm{s}\right)$;

$U C_{i, u, t}=$ vazão retirada do reservatório $i$ para atendimento do uso consuntivo $u$ no intervalo de tempo $t\left(\mathrm{~m}^{3} / \mathrm{s}\right)$.

Ressalta-se que, em razão da demanda por energia ser sempre igual ou superior à capacidade de geração das usinas hidrelétricas, não é possível ocorrer a situação na qual a usina hidrelétrica passe zero de vazão por suas turbinas enquanto libera água por seu vertedor, o que caracterizaria uma operação do reservatório bastante questionável sob o ponto de vista econômico.

O modelo HIDRO fica sujeito às seguintes restrições:

- A vazão defluente total é a soma da vazão turbinada com a vazão vertida:

$$
R_{i, t}=R_{i, t}^{i}+R_{i, t}^{\eta}
$$

- Equação da continuidade para reservatórios de acumulação:

$$
S_{i, t}=S_{i, t-1}+d t_{t}\left\lfloor\sum_{m_{i}=1}^{n m_{i}} R_{m_{i}, t}+l_{i, t}-R_{i, t}-\sum_{u=1}^{n u} U C_{i, u, t}-D E_{i, t}\right\rfloor-E_{i, t}
$$

- Equação da continuidade para as usinas a fio d'água:

$$
0=d t_{t}\left\lfloor\sum_{m_{i}=1}^{n m_{i}} R_{m_{i}, t}+l_{i, t}-R_{i, t}-\sum_{u=1}^{n u} U C_{i, u, t}-D E_{i, t}\right\rfloor-E_{i, t}
$$

- Perdas por evaporação em um reservatório de acumulação:

$$
E_{i, t}=\frac{A_{i, t}+A_{i, t-1}}{2} I E_{i, t}
$$

- Perdas por evaporação em usinas a fio d'água:

$$
E_{i, t}=A f_{i} \cdot I E_{i, t}
$$


- Capacidade dos geradores:

$$
P_{i, t} \leq P_{i}^{\max } \cdot I D_{i, t}
$$

- Armazenamento mínimo e máximo, sem considerar o volume de espera para operações de controle cheia:

$$
S_{i}^{\min } \leq S_{i, t} \leq S_{i, t}^{\max }
$$

- Limites de vazão turbinada, vazão vertida e vazão para conservação ambiental:

$$
\begin{gathered}
R_{i}^{\min } \cdot I D_{i, t} \leq R_{i, t} \leq R_{i, t}^{\max } \cdot I D_{i, t} \\
R_{i, t}^{i} \geq 0 \\
R_{i, t} \geq R_{i}^{\min }
\end{gathered}
$$

- Queda bruta média para usinas com reservatórios de acumulação:

$$
H b_{i, t}=\frac{H_{i, t}+H_{i, t-1}}{2}-H T_{i, t}
$$

- Queda bruta média para reservatórios de usinas a fio d'água:

$$
H b_{i, t}=H f_{i}-H T_{i, t}
$$

- Energia produzida:

$$
P_{i, t}=9,81 \cdot 10^{-3} \cdot \eta_{i} \cdot H b_{i} \cdot R_{i, t}^{i}
$$

- Nível d'água a montante do reservatório, constante $\left(H f_{i}\right)$ para usinas a fio d'água:

$$
H_{i, t}=a_{0 i}+a_{i i} \cdot S_{i, t}+a_{2 i} \cdot S_{i, t}^{2}+a_{3 i} \cdot S_{i, t}^{3}+a_{4 i} \cdot S_{i, t}^{4}
$$

- Nível d'água no canal de fuga a jusante do reservatório:

$$
H T_{i, t}=b_{0 i}+b_{1 i} \cdot R_{i, t}+b_{2 i} \cdot R_{i, t}^{2}+b_{3 i} \cdot R_{i, t}^{3}+b_{4 i} \cdot R_{i, t}^{4}
$$

- A área do reservatório, que é constante $\left(A f_{i}\right)$ para usinas que operam a fio d'água, é dada pela equação (17) como função do nível d'água ou, de forma simplificada, pela equação (18) como função do armazenamento:

$$
\begin{gathered}
A_{i, t}=c_{0 i}+c_{1 i} \cdot H_{i, t}+c_{2 i} \cdot H_{i, t}^{2}+c_{3 i} \cdot H_{i, t}^{3}+c_{4 i} \cdot H_{i, t}^{4} \\
A_{i, t}=f_{0 i}+f_{1 i} \cdot S_{i, t}+f_{2 i} \cdot S_{i, t}^{2}
\end{gathered}
$$

- Limite de turbinamento em função da queda:

$$
R_{i, t}^{\max }=d_{0 i}+d_{1 i} \cdot H b_{i, t}+d_{2 i} \cdot H b_{i, t}^{2}+d_{3 i} \cdot H b_{i, t}^{3}+d_{4 i} \cdot H b_{i, t}^{4}
$$

- Desvio de vazão ou transposição do rio São Francisco para o Nordeste Setentrional a montante do reservatório de Itaparica:

$$
D E_{4, t}=26,4+R_{3, t}^{n}
$$


- Limites de operação da transposição do rio São Francisco:

$$
26,4 \leq D E_{4, t} \leq 114,3
$$

- Retirada mínima para demandas hídricas prioritárias em situações de escassez:

$$
\sum_{u=1}^{n u} U C_{i, u, t} \geq U C_{i, t}^{\min }
$$

onde:

$m_{i}=$ índice do reservatório/hidrelétrica imediatamente a montante de $i$;

$n m_{i}=$ número total de reservatórios/hidrelétricas a montante de $i$;

$n u=$ número total de tipos de uso consuntivo;

$A_{i, t}=$ área do reservatório $i$ no intervalo $t\left(\mathrm{~km}^{2}\right)$;

$A f_{i}=$ área do reservatório a fio d'água $i\left(\mathrm{~km}^{2}\right)$;

$D E_{i, t}=$ desvio de vazão (transposição) a montante do reservatório $i$ durante o intervalo $t$, valor considerado positivo se desviado para outras bacias e negativo se afluente à bacia $\left(\mathrm{m}^{3} / \mathrm{s}\right)$;

$E_{i, t}=$ perda por evaporação no reservatório $i$ durante o intervalo $t\left(10^{6} \mathrm{~m}^{3}\right)$;

$H b_{i, t}=$ queda bruta média da usina $i$ durante o intervalo $t(\mathrm{~m})$;

$\varepsilon_{i}=$ produtividade específica da usina $i\left(\mathrm{MW} /\left(\mathrm{m}^{3} / \mathrm{s}\right) / \mathrm{m}\right)$;

$\eta_{i}=$ rendimento médio da usina $i$, valor adimensional que considera a operação dos conjuntos turbina-gerador e a perda de carga dos circuitos hidráulicos desde a tomada d'água até o canal de fuga $\left(0<\eta_{i} \leq 1\right)$;

$H_{i, t}=$ nível d'água montante da usina $i$ no intervalo $t(\mathrm{~m})$;

$H f_{i}=$ nível d'água a montante da usina a fio d'água $i$ no intervalo $t(\mathrm{~m})$;

$H T_{i, t}=$ nível d'água no canal de fuga da usina $i$ no intervalo $t(\mathrm{~m})$;

$I D_{i, t}=$ índice de disponibilidade das máquinas da usina $i$ no intervalo $t$, valor adimensional relativo à manutenção ou à expansão do sistema $\left(0 \leq I D_{i, t} \leq 1\right)$;

$I E_{i, t}=$ taxa de evaporação do reservatório $i$ durante o intervalo de tempo $t(\mathrm{~m})$;

$l_{i, t}=$ vazão incremental afluente ao reservatório $i$ durante o intervalo $t\left(\mathrm{~m}^{3} / \mathrm{s}\right)$;

$P^{\max }{ }_{i}=$ capacidade de geração da usina $i(\mathrm{MW})$;

$R^{\prime \prime}, t=$ vazão vertida pela usina $i$ no intervalo $t\left(\mathrm{~m}^{3} / \mathrm{s}\right)$;

$R_{i, t}^{\prime}=$ vazão turbinada pela usina $i$ no intervalo $t\left(\mathrm{~m}^{3} / \mathrm{s}\right)$;

$R^{\max }{ }_{i, t}=$ vazão turbinada máxima da usina $i\left(\mathrm{~m}^{3} / \mathrm{s}\right)$;

$R_{i, t}=$ vazão defluente total da usina $i$ no intervalo $t\left(\mathrm{~m}^{3} / \mathrm{s}\right)$;

$R^{\min }{ }_{i}=$ vazão turbinada mínima na usina $i\left(\mathrm{~m}^{3} / \mathrm{s}\right)$; 
$S_{i, t}=$ volume armazenado no reservatório $i$ durante o intervalo $t\left(10^{6} \mathrm{~m}^{3}\right)$;

$S^{\max }{ }_{i, t}=$ volume armazenado máximo no reservatório $i\left(10^{6} \mathrm{~m}^{3}\right)$;

$S^{\min }{ }_{i, t}=$ volume armazenado mínimo no reservatório $i\left(10^{6} \mathrm{~m}^{3}\right)$;

$U C^{\min }{ }_{i, t}=$ derivação mínima do reservatório $i$ no intervalo $t$ para atendimento de usos consuntivos considerados prioritários $\left(\mathrm{m}^{3} / \mathrm{s}\right)$;

$a_{0 i}, a_{1}, a_{2 i}, a_{3 i}, a_{4 i}=$ coeficientes do polinômio de quarto grau da equação do nível d'água do reservatório $i$ em função do seu volume armazenado;

$b_{0 i}, b_{1}, b_{2}, b_{3 i}, b_{4 i}=$ coeficientes do polinômio de quarto grau da equação no nível d'água no canal de fuga de jusante da usina $i$ em função da sua vazão defluente;

$c_{0 i}, c_{1 i}, c_{2}, c_{3 i}, c_{4 i}=$ coeficientes do polinômio de quarto grau da equação área do reservatório $i$ em função do nível d'água no reservatório;

$d_{0 i}, d_{11}, d_{2 i}, d_{3 i}, d_{4 i}=$ coeficientes do polinômio de quarto grau da máxima vazão turbinada em função da queda para a usina $i$;

$f_{0 i}, f_{1}, f_{2 i}=$ coeficientes do polinômio alternativo de segundo grau da área do reservatório $i$ em função do seu volume armazenado.

As variáveis de decisão do modelo são, para cada reservatório e em cada intervalo de tempo, a vazão turbinada $\left(R_{i, t}^{\prime}\right)$, a vazão vertida $\left(R_{i, t}^{\prime \prime}\right)$ e a vazão retirada para usos consuntivos $\left(U C_{i, u, t}\right)$.

Os coeficientes ponderadores $\omega$ e $\psi_{u}$ expressos na equação (1) devem assumir valores complementares, ou seja, valores cuja soma é igual à unidade. Assim, esses adimensionais representam a preferência relativa entre $o$ atendimento da demanda de energia e 0 atendimento das diferentes demandas hídricas consuntivas consideradas. Seus valores, portanto, refletem os critérios adotados pelo operador do modelo ou pelo decisor.

O modelo de simulação gera uma solução inicial viável para PNL, na qual todos os reservatórios são operados a fio dá água, ou seja, com o volume armazenado constante e igual ao volume máximo. A operação a fio d'água mostrase, comumente, uma boa solução inicial para problemas de operação de reservatório tratados com PNL, sendo adotada em diversos estudos (LOPES, 2001; BRANDÃO, 2004; ZAMBON, 2008).

Devido à não linearidade, a perda por evaporação de cada reservatório é calculada por meio de iterações durante cada intervalo de tempo. A não linearidade ocorre pelo fato de a perda por evaporação ser função da média do armazenamento no início e no fim do intervalo de tempo, e o volume armazenado no fim de cada 
intervalo depende da solução da vazão defluente, que é uma das variáveis de decisão. Para resolver a não linearidade, é empregado o método das substituições sucessivas: para uma dada vazão turbinada $R_{i, t}^{\prime}$ e uma solução inicial para o volume armazenado $S_{i, t}$, calcula-se o novo armazenamento $S_{i, t}$ pelas equações (3), (5), (12), (15), (16) e (17). Por um processo análogo, calcula-se a máxima vazão turbinada: para um dado $H_{i, t-1}$ e uma solução inicial para $R^{\max }{ }_{i, t}$ calcula-se a nova $R_{i, t}^{\max }$ pelas equações (7), (12), (15), (16) e (19).

\subsection{Análise dos resultados}

O impacto dos usos consuntivos na operação do sistema de reservatórios da bacia do rio São Francisco será avaliado para condições de escassez hídrica. Serão selecionados, portanto, os períodos do histórico que representem as estiagens mais severas já registradas na bacia.

Serão considerados diferentes cenários de demanda hídrica consuntiva, relacionados ao consumo de água nas atividades desenvolvidas na bacia do rio São Francisco. As demandas hídricas não consuntivas serão representadas pelo limite mínimo imposto à defluência das usinas hidrelétricas, o qual pode variar em função dos usos a que se pretende atender.

Todas as informações acerca das demandas hídricas na bacia do São Francisco e dos requisitos de vazão mínima a jusante dos reservatórios, bem como do histórico de afluências na bacia, são apresentadas no Capítulo 5.

Em todas as avaliações e análises desenvolvidas sobre os resultados, as quais são descritas na sequência, serão mantidas as mesmas restrições de volume armazenado inicial e de volume armazenado final nos reservatórios.

\subsubsection{Avaliação dos índices de atendimento}

Para avaliar os índices de atendimento obtidos em períodos de escassez, o modelo HIDRO será aplicado de forma que, na função objetivo, seja atribuída a 
mesma prioridade tanto ao atendimento da demanda de energia como ao atendimento da demanda hídrica consuntiva.

Para quantificar a ocorrência de falhas no atendimento, deve ser definida uma faixa de valores em torno da qual a vazão fornecida e a energia gerada podem variar sem que se caracterize deficit.

Assim, em cada mês será considerado que houve falha no atendimento dos usos consuntivos se a variável UC, em qualquer reservatório da bacia, for menor do que $95 \%$ da demanda na área de contribuição incremental daquele reservatório naquele mês. Ou seja, haverá falha se o deficit hídrico em qualquer reservatório representar mais que 5\% da demanda consuntiva naquele reservatório.

Critério análogo valerá para a avaliação das falhas na geração de energia pelas hidrelétricas. Em cada mês será considerado que houve falha se a geração de energia em toda a bacia foi menor que $95 \%$ da demanda total de energia, ou seja, no mês em que o deficit de energia representou mais que 5\% da demanda.

Serão cotejados os valores das variáveis de decisão e dos índices de atendimento obtidos em cada reservatório para cada cenário de demanda hídrica, bem como para cada restrição de defluência mínima e entre as situações de transposição em operação e inativa.

\subsubsection{Estabelecimento das relações de troca - trade-offs - entre geração de energia elétrica e uso consuntivo}

O estabelecimento das relações de troca ou trade-offs entre geração de energia e uso consuntivo será feito sem que se associe uma preferência relativa maior a um dos tipos de atendimento em detrimento do outro.

Também será avaliado o impacto que o aumento da defluência mínima dos reservatórios para manutenção do ecossistema aquático provoca na geração de energia e no atendimento das demandas consuntivas.

Os resultados obtidos ao se considerar a operação da transposição do rio São Francisco serão cotejados com os resultados decorrentes da aplicação do modelo com a transposição inativa. Essa comparação permite verificar a influência da 
transposição na operação dos reservatórios e no atendimento dos usos da água dentro da própria bacia.

$\mathrm{A}$ atribuição de um preço médio $(\mathrm{R} \$ \mathrm{MWh})$ ao incremento médio ou à perda média observados na geração de energia permitirá associar valor monetário ao impacto causado pelo aumento da demanda hídrica consuntiva, pela operação da transposição e também pelo aumento da demanda de conservação ambiental.

Pode-se estimar o preço médio da energia a partir dos dados históricos do Preço da Liquidação das Diferenças (PLD), divulgados pela Câmara de Comercialização de Energia Elétrica (CCEE). O PLD é calculado com periodicidade semanal e com base no custo marginal de operação (CMO) pelo qual é valorada a energia comercializada no mercado de curto prazo.

Os dados históricos do PLD usados na estimativa do preço médio da energia e disponibilizados pela CCEE referem-se ao período de 30/junho/2001 a 25/maio/2012 e estão apresentados no Anexo A deste trabalho.

\subsubsection{Análise de sensibilidade}

Uma vez que a função objetivo expressa na equação (1) procura maximizar o atendimento de diferentes tipos de demanda em uma bacia marcada por múltiplos usos da água, ela permite que o decisor atribua diferentes prioridades de atendimento a cada tipo de demanda. Essa preferência relativa que decisor associa ao atendimento energético e ao atendimento dos usos consuntivos é expressa pelos coeficientes $\omega$ e $\psi$ e afeta diretamente os resultados das variáveis $P$ e UC.

Assim, será verificada a sensibilidade das variáveis $P$ e UC pela consideração de diferentes valores para os coeficientes $\omega$ e $\psi$. Nessa análise, o modelo HIDRO é aplicado para um período da série histórica marcado por escassez hídrica. Diferentemente da análise anterior, nesta não é considerado o aumento dos requisitos de vazão mínima a jusante dos reservatórios. São comparados os resultados obtidos para dois cenários de demanda hídrica consuntiva. Em ambos os cenários, será considerado o funcionamento da transposição do rio São Francisco. 


\subsubsection{Avaliação do atendimento energético ao longo da curva de duração das afluências}

Não sendo alcançada a demanda objetivo de energia nos períodos de maior escassez hídrica da bacia, será aplicado o modelo HIDRO para outros períodos de afluência escolhidos seguindo o ordenamento da curva de duração da energia natural afluente (ENA) média obtida no Capítulo 5. Serão avaliados os períodos referentes aos percentis notáveis de $100 \%$ até o percentil de $50 \%$.

Nesta avaliação, será considerado apenas um cenário de demanda hídrica consuntiva e apenas um conjunto de restrições de vazão mínima a jusante das usinas. Além disso, será considerada apenas a situação em que a transposição do São Francisco esteja em operação.

O percentual de deficit aceitável para o atendimento, de forma análoga às avaliações anteriores, será de $5 \%$ da demanda objetivo. 


\section{ESTUDO DE CASO: bacia hidrográfica do rio São Francisco}

\subsection{Caracterização física da bacia}

A bacia hidrográfica do rio São Francisco apresenta uma área de drenagem de $636.920 \mathrm{~km}^{2}$, o que representa $8 \%$ do Território Nacional. A bacia abrange 503 municípios de 7 unidades da federação: Minas Gerais, Goiás, Bahia, Pernambuco, Alagoas, Sergipe e parte do Distrito Federal.

Em decorrência da grande variação espacial das suas características físicas e climáticas, a bacia do São Francisco pode ser dividida segundo critérios geológicos, geomorfológicos, hidrográficos e climáticos em 4 regiões fisiográficas homogêneas:

- Alto São Francisco: Região compreendida entre as cabeceiras do rio principal, na serra da Canastra, e a foz do rio Jequitaí, em Minas Gerais. Apresenta clima predominantemente úmido. Nesta região localiza-se o reservatório da UHE Três Marias. O rio das Velhas, o rio Paraopeba e o rio Pará são os principais tributários neste trecho.

- Médio São Francisco: Região compreendida entre a foz do rio Jequitaí, em Minas Gerais, e a barragem da UHE Sobradinho, na divisa entre Bahia e Pernambuco. Possui regiões de clima tropical subúmido seco e semiárido. A vazão do rio principal neste trecho sofre a influência da regularização causada pelo reservatório de Três Marias. Os rios Grande, Corrente e Paracatu são os principais tributários neste trecho.

- Submédio São Francisco: Região compreendida entre a barragem de Sobradinho e a cidade de Belo Monte/AL. Região de clima árido a semiárido, beneficiada com a vazão regularizada pelos reservatórios de Sobradinho e de Itaparica. Nela localizam-se as UHEs Itaparica, Xingó e as do Complexo Paulo Afonso-Moxotó.

- Baixo São Francisco: Corresponde ao trecho entre Belo Monte/AL e a foz no oceano Atlântico, na divisa de Sergipe e Alagoas. Nesta região de clima tropical subúmido, o rio principal tem sua vazão regularizada pelos reservatórios de Sobradinho e de Itaparica. 
A Figura 5.1 apresenta um mapa da bacia hidrográfica do rio São Francisco e suas regiões fisiográficas.

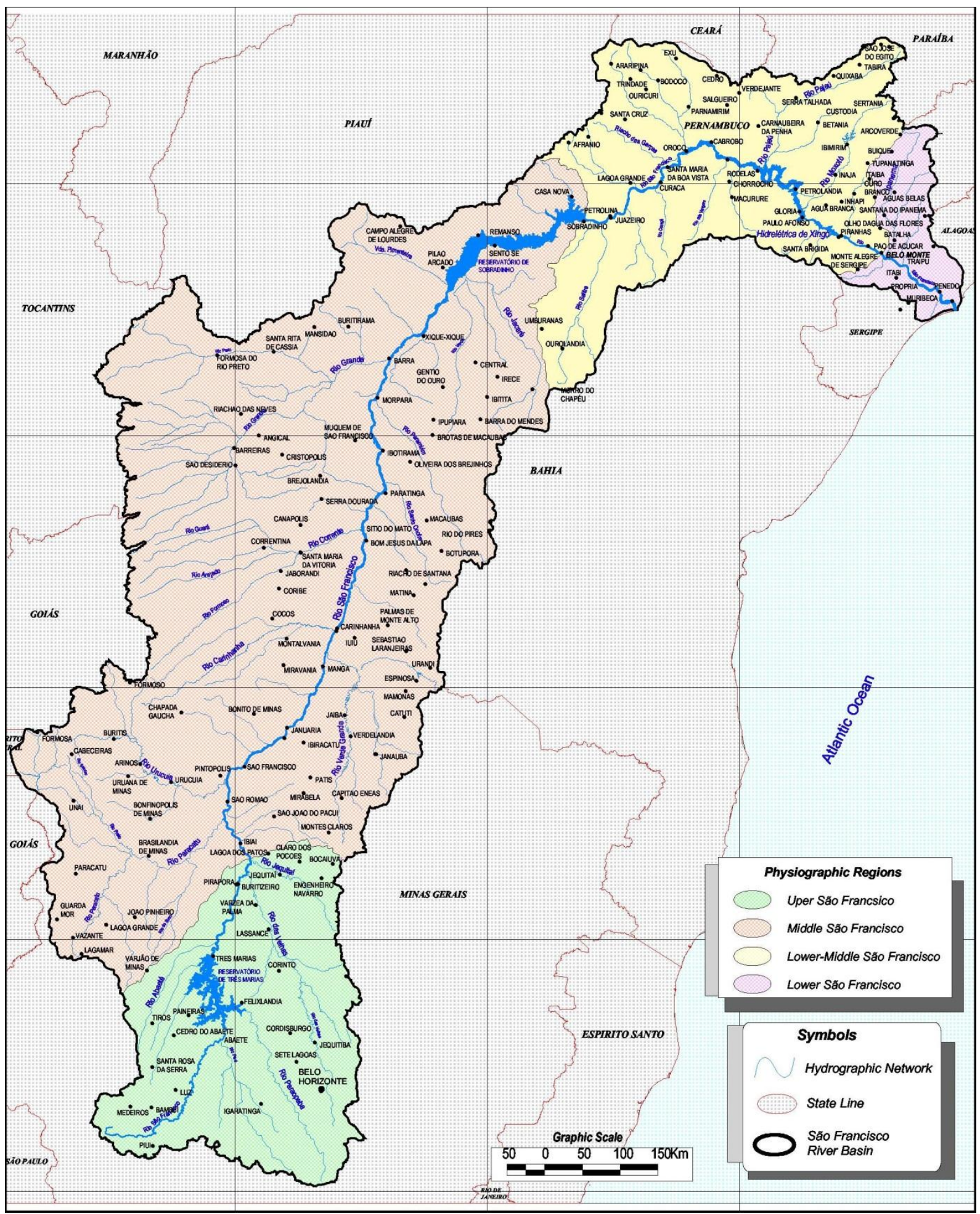

Fonte: ANA (2003a)

Figura 5.1 - Mapa da bacia hidrográfica do rio São Francisco 
As características hidroclimáticas das regiões fisiográficas da bacia constam na Tabela 5.1.

Tabela 5.1 - Características hidroclimáticas das regiões da bacia do São Francisco

\begin{tabular}{lcccc}
\hline \multirow{2}{*}{ Característica } & \multicolumn{4}{c}{ Regiões fisiográficas } \\
\cline { 2 - 5 } & Alto & Médio & Submédio & Baixo \\
\hline Área de drenagem $\left(\mathrm{km}^{2}\right)$ & 99.387 & 401.559 & 115.987 & 19.987 \\
Extensão do rio principal $(\mathrm{km})$ & 1.003 & 1.152 & 568 & 140 \\
& & & & \\
Vazão natural média $\left(\mathrm{m}^{3} / \mathrm{s}\right)$ & 1.189 & 2.708 & 2.812 & 2.850 \\
Vazão com permanência de $95 \%\left(\mathrm{~m}^{3} / \mathrm{s}\right)$ & 289 & 819 & 842 & 854 \\
Vazão incremental específica $\left(\mathrm{l} / \mathrm{s} / \mathrm{km}^{2}\right)$ & 11,9 & 3,8 & 0,9 & 1,9 \\
& & & & \\
Precipitação média anual $(\mathrm{mm})$ & 1.372 & 1.052 & 693 & 957 \\
Evapotranspiração média anual $(\mathrm{mm})$ & 1.000 & 1.300 & 1.550 & 1.500 \\
Temperatura média $\left({ }^{\circ} \mathrm{C}\right)$ & 23 & 24 & 27 & 25 \\
\hline Fon & & & &
\end{tabular}

Fonte: ANA (2005); CBHSF (2011).

As características hidroclimáticas da bacia apresentam grande variação entre as regiões fisiográficas. A precipitação média anual, por exemplo, que não passa de $500 \mathrm{~mm}$ em algumas áreas situadas no Submédio São Francisco, chega a $1.500 \mathrm{~mm}$ nas serras do Alto São Francisco e na foz. A distribuição sazonal das chuvas também varia ao longo da bacia. No Baixo São Francisco, o período chuvoso corresponde aos bimestres de maio-junho e de agosto-setembro. No Submédio São Francisco, as poucas chuvas concentram-se no trimestre de janeiro a março. Nas demais regiões, o trimestre mais úmido é o de novembro a janeiro e o trimestre mais seco é o de junho a agosto.

Ressalta-se que a bacia do São Francisco tem 53,8\% de sua área localizada no Polígono das Secas. São $343.784 \mathrm{~km}^{2}$ que se estendem do Médio ao Baixo São Francisco, caracterizados por frequentes e prolongadas estiagens. Em razão disso, observa-se que, nessas regiões, a evapotranspiração supera a precipitação, do que decorre a baixa vazão específica dessas áreas, sobretudo no Submédio São Francisco, conforme visto na Tabela 5.1.

Por apresentarem características tão díspares, as regiões fisiográficas contribuem em diferentes graus para os deflúvios do rio São Francisco. O Alto e o Médio São Francisco contribuem, respectivamente, com 42\% e 54\% da vazão média. As menores contribuições vêm do Submédio e do Baixo São Francisco, 4\% e $1 \%$ da vazão média respectivamente. Essa distribuição não muda significativamente quando se avalia a contribuição para a vazão com permanência de $95 \%\left(Q_{95}\right)$ - valor 
que é igualado ou superado em 95\% do tempo (ANA, 2005). A Tabela 5.2 apresenta a contribuição de cada região fisiográfica à $Q_{M L T}$ e à $Q_{95}$ do rio São Francisco.

Tabela 5.2 - Distribuição da $Q_{M L T}$ e da $Q_{95}$ nas regiões fisiográficas

\begin{tabular}{lrrrrr}
\hline \multirow{2}{*}{ Região fisiográfica } & \multicolumn{2}{c}{$\boldsymbol{Q}_{\text {MLT }}$} & & \multicolumn{2}{c}{$\mathbf{Q}_{95}$} \\
\cline { 2 - 3 } \cline { 5 - 6 } & \multicolumn{1}{c}{$\mathbf{m}^{3} / \mathbf{s}$} & $\%$ & & $\mathbf{m}^{3} / \mathbf{s}$ & $\%$ \\
\hline Alto & $1.189,2$ & $42 \%$ & & 288,7 & $34 \%$ \\
Médio & $1.519,8$ & $53 \%$ & & 530,6 & $62 \%$ \\
Submédio & 104,2 & $4 \%$ & & 22,9 & $3 \%$ \\
Baixo & 38,4 & $1 \%$ & & 11,5 & $1 \%$ \\
Bacia São Francisco & $\mathbf{2 . 8 5 0 , 6}$ & $\mathbf{1 0 0 \%}$ & & $\mathbf{8 5 3 , 7}$ & $\mathbf{1 0 0 \%}$ \\
\hline
\end{tabular}

Entre as unidades da federação, Minas Gerais e Bahia são as que mais contribuem para a vazão média, com $73,5 \%$ e 20,4\% respectivamente. Em seguida vêm Pernambuco com 3,2\%, Goiás com 1,2\%, Alagoas com 0,7\%, Distrito Federal com $0,6 \%$ e Sergipe com $0,4 \%$ (ANA, 2005).

\subsection{Descrição das principais demandas hídricas consuntivas}

O rio São Francisco é submetido à exploração econômica desde sua descoberta pelo navegador florentino Américo Vespucci, em 10 de outubro de 1501. Inicialmente, o rio atraiu o interesse dos colonizadores do litoral do Nordeste por uma característica hidrológica auspiciosa e incomum na região: sua vazão aumentava muito na estação de estiagem e diminuía durante a estação das chuvas (BURTON, 1977).

A ocupação da bacia ocorreu em duas frentes de povoamento. A primeira teve início no século XVI no Baixo São Francisco e evoluiu da foz em direção ao interior, aproveitando-se da navegabilidade do rio até a cachoeira de Paulo Afonso. A segunda ocorreu no Alto São Francisco, desencadeada pela exploração das riquezas minerais descobertas pelos bandeirantes paulistas no final do século XVII em Minas Gerais (ANA, 2005).

Atualmente, a presença de todos os tipos de uso do recurso hídrico é uma importante característica da bacia do rio São Francisco. Destacam-se a geração de energia por hidrelétricas, a irrigação de culturas e o abastecimento humano. Concomitantemente, registram-se outras demandas como os usos industriais, a 
diluição de efluentes, a pesca, a navegação, a aquicultura, as atividades turísticas e a manutenção da biota aquática. Tal quadro, aliado às condições socioeconômicas bastante diversas de suas regiões, algumas das quais marcadas por escassez hídrica e pobreza endêmica, tornam o estudo dessa bacia relevante sob o aspecto do gerenciamento dos recursos hídricos.

Conforme o Plano Decenal de Recursos Hídricos da Bacia Hidrográfica do Rio São Francisco (ANA, 2005), a vazão captada para usos consuntivos no ano 2000 foi, em média, de $166 \mathrm{~m}^{3} / \mathrm{s}$, dos quais 69\% destinavam-se à irrigação, 16\% ao abastecimento público, $9 \%$ ao uso industrial, 4\% à criação animal e $2 \%$ ao uso rural.

A Figura 5.2 apresenta a distribuição da vazão captada em relação aos usos em cada região fisiográfica.

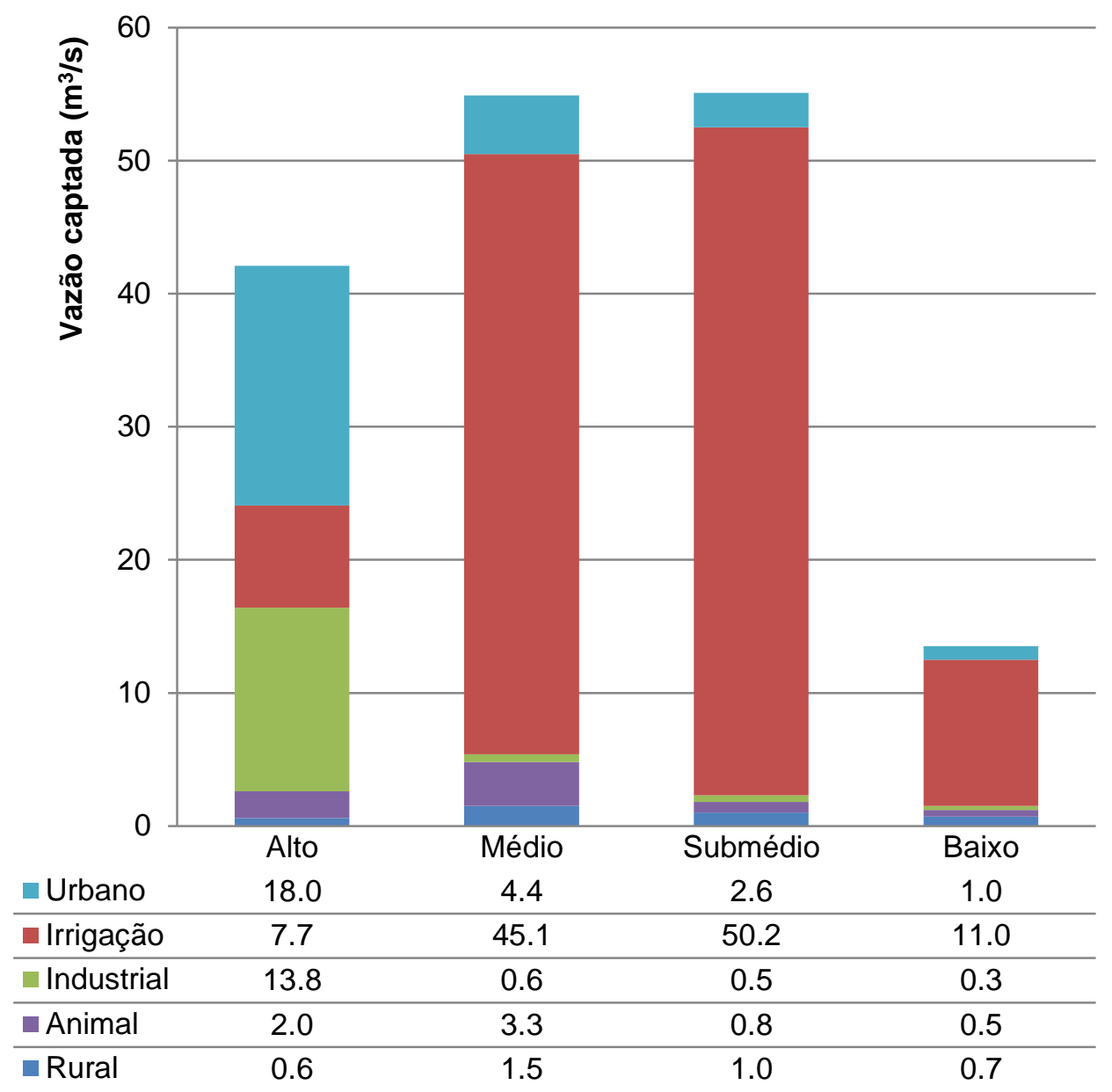

Figura 5.2 - Distribuição da vazão captada por tipo de uso em cada região fisiográfica 
A Tabela 5.3 apresenta, para toda a bacia do São Francisco, a representatividade da vazão captada para usos consuntivos (Qcap) em relação à vazão média de longo termo $\left(Q_{M L T}\right)$, à vazão com permanência de $95 \%\left(Q_{95}\right)$ e à vazão regularizada (Qreg).

Tabela 5.3 - Balanço entre captação e disponibilidade hídrica na bacia do S. Francisco

\begin{tabular}{|c|c|c|c|c|c|c|c|}
\hline \multirow{2}{*}{$\begin{array}{c}\text { Região } \\
\text { fisiográfica }\end{array}$} & \multicolumn{4}{|c|}{ Vazões acumuladas $\left(\mathrm{m}^{3} / \mathrm{s}\right)$} & \multirow{2}{*}{$\begin{array}{l}\text { Qcap } \\
Q_{M L T}\end{array}$} & \multirow{2}{*}{$\frac{Q \text { cap }}{Q_{95}}$} & \multirow{2}{*}{$\begin{array}{l}\text { Qcap } \\
\text { Qreg }\end{array}$} \\
\hline & Qcap & $Q_{M L T}$ & $Q_{95}$ & Qreg & & & \\
\hline Alto & 42 & 1.189 & 289 & 513 & $4 \%$ & $15 \%$ & $8 \%$ \\
\hline Médio & 97 & 2.708 & 819 & 513 & $4 \%$ & $12 \%$ & $19 \%$ \\
\hline Submédio & 152 & 2.812 & 842 & 1.815 & $5 \%$ & $18 \%$ & $8 \%$ \\
\hline Baixo & 166 & 2.850 & 854 & 1.815 & $6 \%$ & $19 \%$ & 9\% \\
\hline
\end{tabular}

A ANA considera, para a bacia do São Francisco, que a disponibilidade hídrica superficial (Qdisp) corresponde à vazão com permanência de 95\% nos rios sem regularização e, nos rios com regularização, à vazão regularizada somada à vazão natural incremental com 95\% de permanência. Assim, a representatividade da vazão captada para usos consuntivos Qcap em relação à disponibilidade hídrica Qdisp, em cada região fisiográfica, fica como apresentado na Tabela 5.4.

Tabela 5.4 - Vazão captada e disponibilidade hídrica na bacia do S. Francisco

\begin{tabular}{lccc}
\hline Região & Vazões acumuladas $\left(\mathbf{m}^{3} / \mathbf{s}\right)$ & Qcap \\
\cline { 4 - 4 } fisiográfica & Qcap & Qdisp & Qdisp \\
\hline Alto & 42 & 622 & $7 \%$ \\
Médio & 97 & 1.160 & $8 \%$ \\
Submédio & 152 & 1.838 & $8 \%$ \\
Baixo & 166 & 1.849 & $9 \%$ \\
\hline
\end{tabular}

Ainda segundo o Plano Decenal, as taxas de retorno na bacia eram, em média, de $80 \%$ para abastecimento urbano e industrial, $50 \%$ para uso rural e apenas $20 \%$ para irrigação e criação animal. A vazão de retorno na bacia era, em média, de $60 \mathrm{~m}^{3} / \mathrm{s}$, o que implica uma vazão consumida média em toda a bacia de $106 \mathrm{~m}^{3} / \mathrm{s}$, dos quais $87 \%$ referentes à agricultura irrigada (ANA, 2005).

As demandas hídricas consideradas prioritárias pela Lei Federal 9.433/97, isto é, o consumo humano - que inclui abastecimento urbano e rural - e a criação animal, representam $10,6 \%$ da vazão de consumo total na bacia do São Francisco segundo o Plano Decenal. Os usos prioritários são mais expressivos na parte alta da bacia. 
A Figura 5.3 apresenta a distribuição da vazão consumida por tipo de uso em cada região fisiográfica da bacia do São Francisco segundo o Plano Decenal.

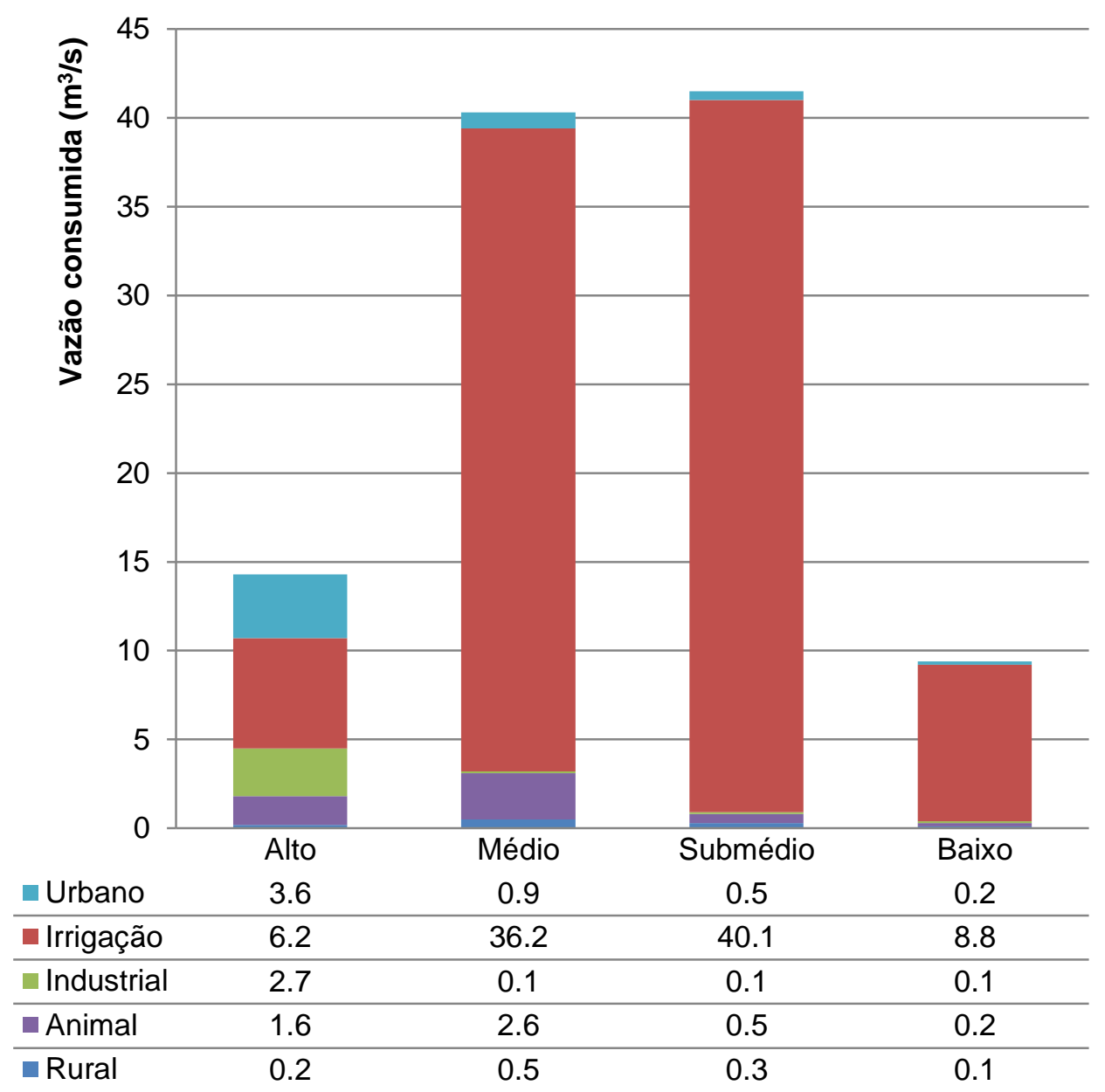

Figura 5.3 - Distribuição da vazão consumida por tipo de uso em cada região fisiográfica

Ressalta-se que os valores de vazão captada, de vazão consumida e de vazão de retorno adotados pelo Plano Decenal foram determinados no trabalho intitulado "Estimativas das vazões para atividades de uso consuntivo da água nas principais bacias do SIN", realizado pelo ONS em 2003. Esses valores servem de base para o ONS estabelecer as restrições de uso consuntivo na otimização da operação do SIN. O estudo também define taxas de crescimento do uso consuntivo que devem ser utilizadas na extrapolação dos valores para os anos posteriores.

A Tabela 5.5 apresenta os valores de uso consuntivo na área de contribuição incremental dos reservatórios da bacia do São Francisco para o ano de 2011, considerados na otimização do SIN. Esses valores constam nos arquivos de saída do NEWAVE disponibilizados pela CCEE (CCEE, 2011). 
Tabela 5.5 - Uso consuntivo em 2011 segundo ONS

\begin{tabular}{|c|c|c|c|c|c|c|c|c|c|c|c|c|c|}
\hline \multirow{2}{*}{ Reservatório } & \multicolumn{13}{|c|}{ Uso consuntivo $\left(\mathrm{m}^{3} / \mathrm{s}\right)$} \\
\hline & Jan & Fev & Mar & Abr & Mai & Jun & Jul & Ago & Set & Out & Nov & Dez & Média \\
\hline aixo & 1,2 & 2,4 & 1,5 & 2,7 & 1,8 & 2,3 & 2,3 & 2,0 & 2,3 & 1,4 & 1,0 & 1,0 & 1,8 \\
\hline Três & 4,2 & 8,4 & 5,4 & 9,6 & 6,4 & 8,3 & 8,0 & 7,1 & 8,0 & 4,9 & 3,6 & 3,5 & 6,4 \\
\hline Qu & 0,2 & 0,2 & 0,6 & 1,1 & 1,2 & 1,0 & 1,7 & 2,0 & 2,1 & 0,5 & 0,2 & 0,2 & 0,9 \\
\hline aho & 50,6 & 62,1 & 30,7 & 71,0 & 73,9 & 79,4 & 73,5 & 87,7 & 92,4 & 48,9 & 17,7 & 16,9 & 58,6 \\
\hline Ital & 57,1 & 45,7 & 17,9 & 47,9 & 49,1 & 40,1 & 46,5 & 57,6 & 68,5 & 69,3 & 70,4 & 40,9 & 50,9 \\
\hline P,Afonso-Moxotó & 2,6 & 2,2 & 1,0 & 2,2 & 2,1 & 1,4 & 1,3 & 1,9 & 2,7 & 2,6 & 2,9 & 1,8 & 2,1 \\
\hline Xingó & 0,3 & 0,3 & 0,2 & 0,3 & 0,3 & 0,2 & 0,2 & 0,2 & 0,3 & 0,3 & 0,4 & 0,3 & 0,3 \\
\hline Total & 116,2 & 121,3 & 57,3 & 134,8 & 134,8 & 132,7 & 133,5 & 158,5 & 176,3 & 127,9 & 96,2 & 64,6 & 121,0 \\
\hline
\end{tabular}

A despeito das informações acerca de vazão captada e de vazão consumida que constam no Plano Decenal, as outorgas emitidas para usos consuntivos na bacia do rio São Francisco permitem a consideração de valores diferentes dos até aqui apresentados. A partir de dados do Cadastro Nacional de Usuários de Recursos Hídricos (CNARH), referentes às outorgas para uso da água na bacia do rio São Francisco emitidas até outubro de 2009, chega a $767 \mathrm{~m}^{3} / \mathrm{s}$ a vazão total outorgada para captação na bacia e a $24 \mathrm{~m}^{3} / \mathrm{s}$ a vazão total outorgada para lançamentos, o que resulta um consumo total outorgado de $743 \mathrm{~m}^{3} / \mathrm{s}$ (UFBA, 2010).

A maior parte das outorgas concedidas na bacia destina-se à irrigação exclusivamente ou à irrigação aliada a outros usos. A irrigação é responsável por $79,6 \%$ de toda vazão captada e por $82,1 \%$ de todo o consumo (UFBA, 2010).

A Tabela 5.6 apresenta a distribuição das outorgas na bacia do rio São Francisco por tipo de uso.

Tabela 5.6 - Distribuição das outorgas segundo o tipo de uso

\begin{tabular}{lrrrrrr}
\hline & \multicolumn{2}{c}{ Captação } & & \multicolumn{2}{c}{ Consumo } \\
\cline { 2 - 3 } \cline { 5 - 6 } & $\mathbf{Q}\left(\mathbf{m}^{3} / \mathbf{s}\right)$ & \multicolumn{1}{c}{$\%$} & & $\mathbf{Q}\left(\mathbf{m}^{3} / \mathbf{s}\right)$ & \multicolumn{1}{c}{$\%$} \\
\hline Abastecimento público & 19,2 & $2,5 \%$ & & 6,6 & $0,9 \%$ \\
Criação animal & 73,3 & $9,6 \%$ & & 73,2 & $9,9 \%$ \\
Irrigação & 610,6 & $79,6 \%$ & & 610,3 & $82,1 \%$ \\
Indústria & 8,0 & $1,0 \%$ & & 2,4 & $0,3 \%$ \\
Transposição & 26,8 & $3,5 \%$ & & 26,8 & $3,6 \%$ \\
Outros & 28,8 & $3,8 \%$ & & 23,7 & $3,2 \%$ \\
Total & $\mathbf{7 6 6 , 7}$ & $\mathbf{1 0 0} \%$ & & $\mathbf{7 4 3 , 0}$ & $\mathbf{1 0 0} \%$ \\
\hline Fonte: UFBA (2010) & \multicolumn{3}{c}{}
\end{tabular}

Os usos considerados prioritários representam em conjunto $12,1 \%$ da vazão de captação outorgada na bacia e 10,8\% do consumo outorgado, conforme apresentado na Figura 5.4. Se o conjunto dos usos prioritários incluir a transposição do rio São Francisco, a qual se destina ao abastecimento urbano e de comunidades 
rurais, ele passa a representar $15 \%$ da vazão de captação outorgada e do consumo outorgado.

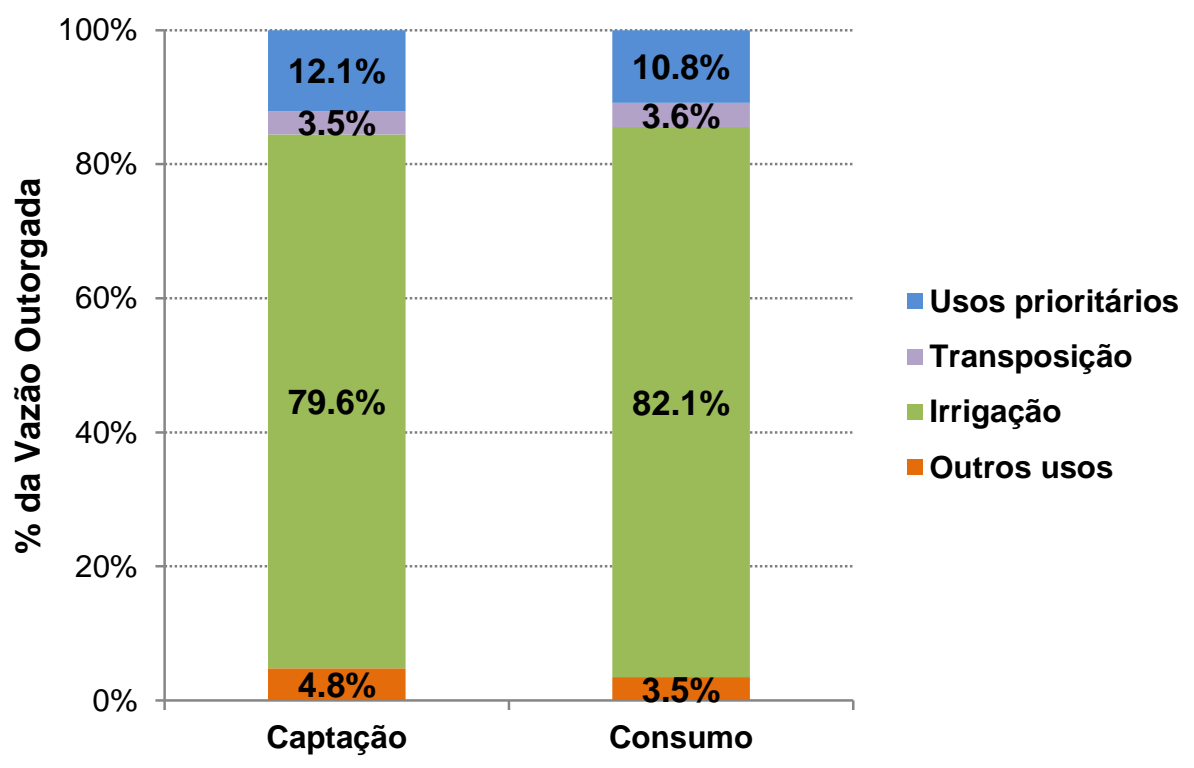

Figura 5.4 - Representatividade dos usos consuntivos na vazão outorgada na bacia do São Francisco

Descontadas as outorgas para uso de mananciais subterrâneos, tem-se que o total de captações superficiais outorgadas chega a $705 \mathrm{~m}^{3} / \mathrm{s}$ e que o total de lançamentos outorgados é de $14,5 \mathrm{~m}^{3} / \mathrm{s}$ em toda a bacia. Chega-se, portanto, a um consumo total de $690,5 \mathrm{~m}^{3} / \mathrm{s}$ outorgado para mananciais superficiais.

É possível agrupar as outorgas conforme a localização geográfica dos usuários relativa à área incremental de contribuição de cada um dos sete principais reservatórios da bacia do São Francisco: Retiro Baixo, Três Marias, Queimado, Sobradinho, Itaparica, Complexo Paulo Afonso-Moxotó e Xingó. Segundo esse critério, $62 \%$ do consumo outorgado total ocorre na área incremental de contribuição do reservatório de Sobradinho, conforme mostrado na Figura 5.5. A descrição dos reservatórios está apresentada com maior detalhamento no item 5.3.1. 


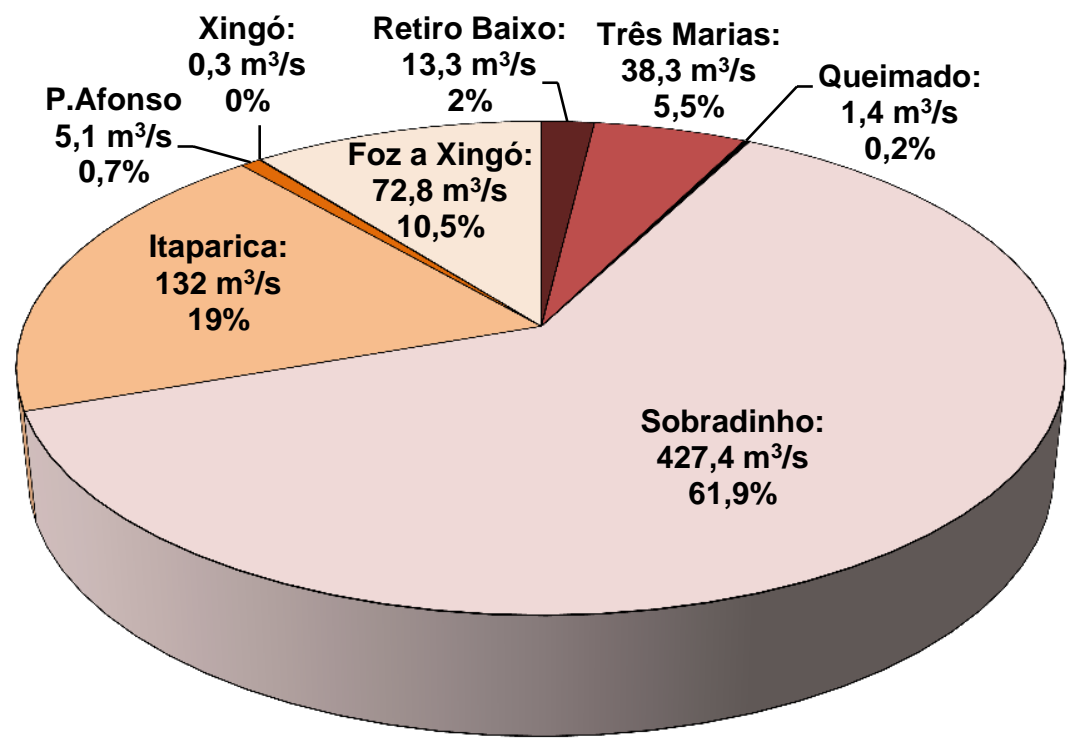

Figura 5.5 - Distribuição do consumo outorgado nas áreas de contribuição dos reservatórios

A vazão de consumo outorgada na área incremental de contribuição dos reservatórios, considerando apenas mananciais superficiais, consta na Tabela 5.7.

Tabela 5.7 - Vazão de consumo outorgada até 2009 nas áreas de contribuição dos reservatórios

\begin{tabular}{|c|c|c|c|c|c|c|c|c|c|c|c|c|c|}
\hline \multirow{2}{*}{ Reservatório } & \multicolumn{13}{|c|}{ Consumo outorgado $\left(\mathrm{m}^{3} / \mathrm{s}\right)$} \\
\hline & Jan & Fev & Mar & Abr & Mai & Jun & Jul & Ago & Set & Out & Nov & Dez & Média \\
\hline Retiro Baixo & 13,3 & 13,3 & 13,3 & 13,3 & 13,3 & 13,3 & 13,3 & 13,3 & 13,3 & 13,3 & 13,3 & 13,3 & 13,3 \\
\hline Três Marias & 35,2 & 35,4 & 35,8 & 36,5 & 40,7 & 40,6 & 40,7 & 40,8 & 40,8 & 40,7 & 36,2 & 35,8 & 38,3 \\
\hline Queimado & 1,3 & 1,3 & 1,3 & 1,3 & 1,5 & 1,5 & 1,5 & 1,5 & 1,5 & 1,4 & 1,3 & 1,5 & 1,4 \\
\hline Sobradinho & 416,7 & 422,6 & 432,3 & 448,7 & 434,2 & 425,9 & 437,2 & 457,1 & 468,3 & 419,8 & 385,8 & 379,9 & 427,4 \\
\hline Itaparica & 139,9 & 142,2 & 136,6 & 128,6 & 120 & 114,6 & 121,5 & 129,8 & 136,5 & 137,9 & 139,9 & 136 & 131,9 \\
\hline P,Afonso-Moxotó & 5,1 & 5,1 & 5,1 & 5,1 & 5,1 & 5,1 & 5,1 & 5,1 & 5,1 & 5,1 & 5,1 & 5,1 & 5,1 \\
\hline Xingó & 0,3 & 0,3 & 0,3 & 0,3 & 0,3 & 0,3 & 0,3 & 0,3 & 0,3 & 0,3 & 0,3 & 0,3 & 0, \\
\hline Total & 611,8 & 620,2 & 624,7 & 633,8 & 615,1 & 601,3 & 619,6 & 647,9 & 665,8 & 618,5 & 581,9 & 571,9 & 617,7 \\
\hline
\end{tabular}

A Tabela 5.8 apresenta uma comparação entre os valores médios de vazão consumida na bacia do rio São Francisco, bem como a vazão consumida por usos prioritários, segundo o ONS, ano-base 2011, e segundo o CNARH, ano-base 2009. Para o cálculo do uso prioritário segundo ONS, supôs-se que sua representatividade no consumo total em 2011 manteve o mesmo percentual observado em 2000.

Tabela 5.8 - Diferença entre os valores de consumo segundo ONS e segundo CNARH

\begin{tabular}{|c|c|c|c|c|c|c|}
\hline \multirow{2}{*}{ Reservatório } & \multicolumn{2}{|c|}{ Consumo total $\left(\mathrm{m}^{3} / \mathrm{s}\right)$} & \multicolumn{2}{|c|}{ Uso prioritário $\left(\mathrm{m}^{3} / \mathrm{s}\right)$} & \multicolumn{2}{|c|}{ Uso prioritário / Total } \\
\hline & ONS & CNARH & ONS & CNARH & ONS & CNARH \\
\hline Retiro Baixo & 1,8 & 13,3 & 1,1 & 1,5 & $59,1 \%$ & $11,0 \%$ \\
\hline Três Marias & 6,4 & 38,3 & 2,8 & 4,2 & $43,3 \%$ & $11,0 \%$ \\
\hline Queimado & 0,9 & 1,4 & 0,1 & 0,0 & $8,9 \%$ & $1,2 \%$ \\
\hline Sobradinho & 58,6 & 427,3 & 7,0 & 39,0 & $12,0 \%$ & $9,1 \%$ \\
\hline Itaparica & 50,9 & 131,9 & 1,5 & 7,4 & $3,3 \%$ & $5,6 \%$ \\
\hline P.Afonso-Moxotó & 2,1 & 1,4 & 0,1 & 0,1 & $3,3 \%$ & $4,6 \%$ \\
\hline Xingó & 0,3 & 3,7 & 0,1 & 0,2 & $45,9 \%$ & $5,3 \%$ \\
\hline Total & 121,0 & 617,4 & 12,7 & 52,3 & $10,5 \%$ & $8,5 \%$ \\
\hline
\end{tabular}


Alguns fatores podem explicar por que a vazão outorgada total na bacia supera a demanda hídrica estimada pelo ONS. Um deles é que os dados de vazão outorgada incluem as outorgas concedidas a empreendimentos que, embora não tenham sido implementados, já têm garantidos seu direito de uso do recurso hídrico, condição exigida em alguns processos de licenciamento como, por exemplo, a obtenção de licenças ambientais. Outro fator é que nem sempre os usuários informam ao Poder Público que deixaram de operar uma captação outorgada, e o registro da captação desativada continua a figurar entre as demais outorgas.

Ressalta-se, também, que são os próprios usuários que informam ao Poder Público os valores que constam em seu cadastro, o que torna algumas informações inconsistentes - notadamente no que se refere à sazonalidade das vazões captadas e lançadas - ou mesmo divergentes - por exemplo, ao se comparar o volume total anual com o volume obtido ao ser considerado o tempo de funcionamento de captações e sua frequência semanal.

Detalham-se, na sequência, os principais usos do recurso hídrico presentes na bacia do rio São Francisco.

\subsubsection{Abastecimento urbano e uso industrial}

A população da bacia do São Francisco, em 2003, era de 13.297.955 habitantes. Sua distribuição pelas regiões fisiográficas é heterogênea: 49\% no Alto, $25 \%$ no Médio, 15\% no Submédio e 11\% no Baixo S. Francisco (ANA, 2004).

Cerca de $40 \%$ da população vive nos 251 municípios da bacia situados dentro do Polígono das Secas, que engloba todo o Submédio e parte do Médio e do Baixo São Francisco. Trata-se de uma área de clima semiárido, caracterizada pela pobreza crítica e pelo êxodo de população (ANA/GEF/PNUMA/OEA, 2004).

Metade da população da bacia vive em 14 municípios maiores que 100.000 habitantes. A principal aglomeração urbana na bacia corresponde à Região Metropolitana de Belo Horizonte (RMBH), situada no Alto São Francisco. Composta por 26 municípios, a RMBH concentra $30 \%$ de toda a população da bacia em uma área de $6.255 \mathrm{~km}^{2}$, o que não chega a $1 \%$ da superfície total da bacia. Outros centros urbanos relevantes na bacia são Divinópolis/MG no Alto São Francisco, 
Montes Claros/MG e Barreiras/BA no Médio São Francisco, Juazeiro/BA e Petrolina/PE no Submédio e Arapiraca/AL no Baixo São Francisco (ANA, 2005).

A Tabela 5.9 apresenta algumas características socioeconômicas das regiões fisiográficas.

Tabela 5.9 - Características socioeconômicas da bacia do São Francisco

\begin{tabular}{lccccc}
\hline \multicolumn{1}{c}{ Característica } & \multicolumn{4}{c}{ Regiões fisiográficas } & \multirow{2}{*}{ Bacia } \\
\cline { 2 - 5 } & Alto & Médio & Submédio & Baixo & \\
\hline População residente $(\mathrm{hab})$ & 6.489 .402 & 3.364 .383 & 2.021 .289 & 1.422 .881 & 13.297 .955 \\
Grau de urbanização $(\%)$ & 93 & 57 & 54 & 51 & 74 \\
Densidade demográfica $\left(\mathrm{hab} / \mathrm{km}^{2}\right)$ & 62,9 & 8,0 & 16,8 & 68,7 & 20,8 \\
IDH dos municípios & 0,55 a 0,80 & 0,34 a 0,72 & 0,44 a 0,66 & 0,36 a 0,53 & 0,34 a 0,80 \\
\hline
\end{tabular}

Fonte: ANA (2005)

O rio São Francisco, em seu percurso de $2.863 \mathrm{~km}$ de extensão, é responsável pelo atendimento de 111 sedes municipais situadas em suas margens. Por meio de extensas linhas de adução, é também a principal solução para o abastecimento de outras 70 sedes municipais, algumas delas localizadas fora da bacia hidrográfica (ANA, 2010). A principal aglomeração urbana abastecida pelo rio São Francisco e que se situa fora da bacia é formada pela capital de Sergipe e dois municípios de seu entorno - Nossa Senhora do Socorro e Barra dos Coqueiros situados na bacia do rio Sergipe (SERGIPE, 2010). O Sistema Adutor São Francisco, por meio de transposição, atende 60\% dos moradores da Grande Aracaju, além de outros três municípios do interior sergipano (DESO, 2011).

Segundo o Plano Decenal, baseado no estudo de usos consuntivos do ONS, a demanda de abastecimento público é responsável pela retirada de $26 \mathrm{~m}^{3} / \mathrm{s}$ dos corpos hídricos superficiais da bacia do São Francisco, dos quais 69\% correspondem às demandas do Alto São Francisco (ANA, 2005). A Tabela 5.10 traz a demanda de abastecimento público entre as regiões segundo o Plano Decenal.

Tabela 5.10 - Demanda média de abastecimento público segundo ONS

\begin{tabular}{lcc}
\hline \multirow{2}{*}{$\begin{array}{c}\text { Região } \\
\text { fisiográfica }\end{array}$} & \multicolumn{2}{c}{ Demanda média } \\
\cline { 2 - 3 } & $\mathbf{( \mathbf { m } ^ { 3 } / \mathbf { s } )}$ & $\%$ \\
\hline Alto & 18,0 & $69 \%$ \\
Médio & 4,4 & $17 \%$ \\
Submédio & 2,6 & $10 \%$ \\
Baixo & 1,0 & $4 \%$ \\
Total & $\mathbf{2 6 , 0}$ & $\mathbf{1 0 0 \%}$ \\
\hline Fonte: ANA (2005) & \multicolumn{2}{l}{}
\end{tabular}


O Atlas Brasil (ANA, 2010), por sua vez, indica uma vazão retirada de $28 \mathrm{~m}^{3} / \mathrm{s}$ para o abastecimento de municípios da própria bacia e de $1,6 \mathrm{~m}^{3} / \mathrm{s}$ para municípios de bacias vizinhas. Segundo o Atlas, os mananciais superficiais da bacia abastecem uma população de 10 milhões de pessoas. A Tabela 5.11 traz, para cada região fisiográfica, as retiradas para abastecimento público, incluindo as destinadas ao atendimento de municípios situados fora dos limites da bacia segundo o Atlas Brasil.

Tabela 5.11 - Demandas de abastecimento público da bacia do São Francisco atendidas por mananciais superficiais segundo Atlas Brasil

\begin{tabular}{lccc}
\hline \multicolumn{1}{c}{$\begin{array}{c}\text { Regiões } \\
\text { fisiográficas }\end{array}$} & \multicolumn{2}{c}{ Demanda média } & $\begin{array}{c}\text { População atendida } \\
\text { (hab) }\end{array}$ \\
\cline { 2 - 3 } Alto & $\mathbf{( \mathbf { m } ^ { 3 } / \mathbf { s } )}$ & $\%$ & 5.852 .165 \\
Médio & 17,1 & $58 \%$ & 1.952 .719 \\
Submédio & 5,4 & $18 \%$ & 1.199 .994 \\
Baixo & 3,4 & $12 \%$ & 731.205 (própria bacia) \\
\hline Total & 3,7 & $12 \%$ & 468.833 (outras bacias) \\
\hline Fonte: ANA (2010) & $\mathbf{2 9 , 6}$ & $\mathbf{1 0 0 \%}$ & $\mathbf{1 0 . 2 0 4 . 9 1 6}$ \\
\hline
\end{tabular}

Fonte: ANA (2010)

O uso da água para fins industriais na bacia do São Francisco ocorre, preponderantemente, na $\mathrm{RMBH}$, na qual o setor industrial é bastante diversificado e apresenta uma demanda hídrica menor apenas que a de abastecimento público. Tal fato faz com que o Alto São Francisco responda por $90 \%$ da vazão retirada em toda a bacia para uso industrial. Nas demais regiões, a atividade industrial é de pequena relevância econômica (ANA/GEF/PNUMA/OEA, 2004).

A Tabela 5.12 apresenta a vazão retirada para uso industrial na bacia.

Tabela 5.12 - Vazão captada para usos industriais na bacia do São Francisco

\begin{tabular}{cccccc}
\hline \multirow{2}{*}{$\begin{array}{c}\text { Regiões } \\
\text { fisiográficas }\end{array}$} & \multicolumn{3}{c}{ Demanda industrial } \\
\cline { 2 - 3 } \cline { 2 - 3 } \cline { 5 - 6 } & estimativa ANA & & estimativa ONS \\
\cline { 2 - 3 }$\left(\mathbf{m}^{\mathbf{3}} / \mathbf{s}\right)$ & $\%$ & & $\%$ \\
\hline Alto & 11,4 & $88,4 \%$ & & 13,8 & $90,8 \%$ \\
Médio & 0,8 & $6,2 \%$ & & 0,6 & $3,9 \%$ \\
Submédio & 0,4 & $3,1 \%$ & & 0,5 & $3,3 \%$ \\
Baixo & 0,3 & $2,3 \%$ & & 0,3 & $2,0 \%$ \\
Total & 12,9 & $100 \%$ & & 15,2 & $100 \%$ \\
\hline
\end{tabular}

Fonte: ANA/GEF/PNUMA/OEA (2004b)

A elevada demanda para abastecimento humano e para uso industrial, notadamente no setor de mineração, faz do Alto Rio das Velhas, no Alto São Francisco, uma das sub-bacias mais críticas em termos de disponibilidade hídrica: 
nas proximidades da $\mathrm{RMBH}$, a demanda hídrica para abastecimento público e para uso industrial ultrapassa $70 \%$ da vazão média de longo termo (ANA, 2005).

\subsubsection{Irrigação}

A principal demanda consuntiva de água na bacia é a irrigação, principalmente no Médio e no Submédio São Francisco. A agricultura irrigada é considerada uma atividade indutora do desenvolvimento regional da bacia ao adotar culturas de maior valor econômico e de melhor eficiência quanto à necessidade de água, notadamente na região de clima semiárido, cujos municípios são os que apresentam os menores indicadores sociais na bacia.

A expansão das áreas irrigadas na bacia ocorreu em ritmo mais acelerado a partir do final da década de 1960. Desde o final do século XIX, contudo, há registros de projetos de irrigação implantados pelo Governo Federal de forma isolada, cujo objetivo era o abastecimento de água no Semiárido sem qualquer integração com outros programas nacionais (ANA/GEF/PNUMA/OEA, 2004a). A evolução da área irrigada no Brasil e na bacia do São Francisco é apresentada na Figura 5.6.

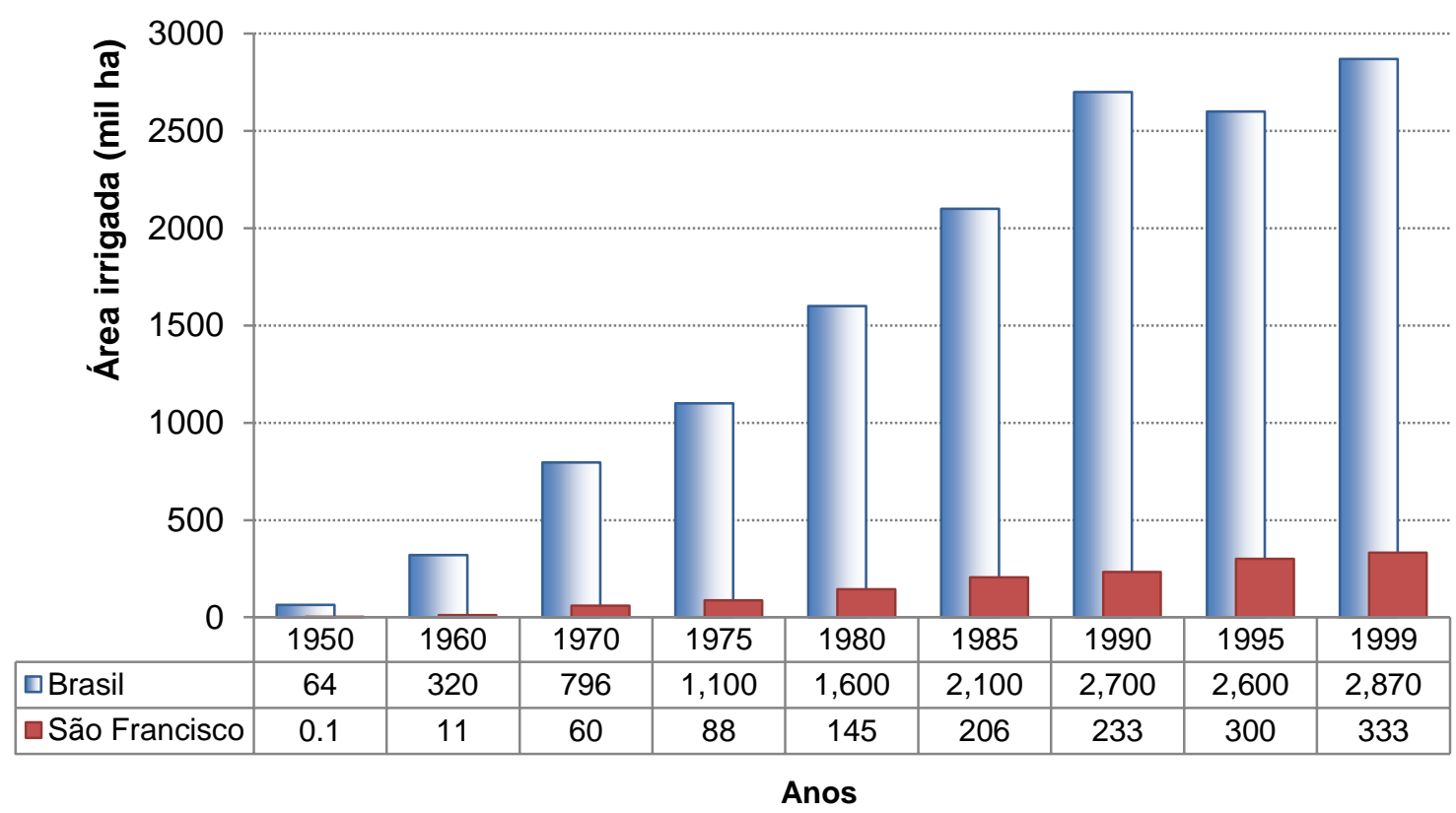

Figura 5.6 - Evolução da área irrigada no Brasil e na bacia do São Francisco 
Os principais polos de irrigação implantados na bacia do São Francisco são Norte de Minas (32.283 ha irrigados), Oeste Baiano (23.334 ha), Irecê (2.166 ha), Guanambi (8.373 ha), Baixo São Francisco (10.507 ha) e Petrolina/Juazeiro (46.279 ha), o mais desenvolvido e voltado à produção de frutas para exportação (ANA/GEF/PNUMA/OEA, 2004a).

A irrigação demanda $114 \mathrm{~m}^{3} / \mathrm{s}$, o que corresponde a $69 \%$ da vazão captada total na bacia (ANA/GEF/PNUMA/OEA, 2004b). A distribuição das demandas de irrigação em cada região fisiográfica é mostrada na Tabela 5.13.

Tabela 5.13 - Área irrigada e demanda de irrigação na bacia do São Francisco

\begin{tabular}{lcclcc}
\hline \multirow{2}{*}{$\begin{array}{c}\text { Região } \\
\text { fisiográfica }\end{array}$} & \multicolumn{2}{c}{ Área irrigada } & & \multicolumn{2}{c}{ Demanda de irrigação } \\
\cline { 2 - 3 } \cline { 5 - 6 } & $\mathbf{( 1 \mathbf { 0 } ^ { 3 } \mathbf { h a } )}$ & $\%$ & & $\mathbf{( \mathbf { m } ^ { 3 } / \mathbf { s } )}$ & $\%$ \\
\hline Alto & 48 & $14 \%$ & & 7,7 & $7 \%$ \\
Médio & 173 & $50 \%$ & & 45,1 & $40 \%$ \\
Submédio & 87 & $25 \%$ & & 50,2 & $44 \%$ \\
Baixo & 35 & $10 \%$ & & 11,0 & $10 \%$ \\
Total & $\mathbf{3 4 3}$ & $\mathbf{1 0 0} \%$ & & $\mathbf{1 1 4}$ & $\mathbf{1 0 0} \%$ \\
\hline
\end{tabular}

Fonte: ANA/GEF/PNUMA/OEA (2004a, 2004b)

Os valores apresentados na Tabela $\mathbf{5 . 1 3}$ para a demanda de irrigação são baseados no estudo realizado pelo ONS para determinação dos usos consuntivos de água na bacia do São Francisco, ano-base 2003. Outras fontes apresentam valores distintos para as retiradas com fins de irrigação na bacia. A resolução no. 145 da Agência Nacional de Águas, de 22 de julho de 2002, estima os valores de vazão captada para irrigação na bacia do São Francisco para o período 2000-2007 apresentados na Tabela 5.14, os quais foram utilizados por Brandão (2004).

Tabela 5.14 - Estimativa da captação $\left(\mathrm{m}^{3} / \mathrm{s}\right)$ para irrigação na bacia

\begin{tabular}{cccccc}
\hline Ano & $\begin{array}{c}\text { Montante de } \\
\text { Sobradinho }\end{array}$ & $\begin{array}{c}\text { Entre Sobradinho } \\
\text { e Itaparica }\end{array}$ & $\begin{array}{c}\text { Entre Itaparica } \\
\text { e Xingó }\end{array}$ & $\begin{array}{c}\text { Jusante } \\
\text { de Xingó }\end{array}$ & Total \\
\hline 1999 & 94,2 & 86,8 & 4,0 & 8,4 & $\mathbf{1 9 3 , 3}$ \\
2000 & 96,5 & 88,9 & 4,1 & 8,6 & $\mathbf{1 9 8 , 0}$ \\
2001 & 98,7 & 90,9 & 4,2 & 8,8 & $\mathbf{2 0 2 , 6}$ \\
2002 & 101,0 & 93,0 & 4,3 & 9,0 & $\mathbf{2 0 7 , 2}$ \\
2003 & 103,2 & 95,1 & 4,4 & 9,2 & $\mathbf{2 1 1 , 9}$ \\
2004 & 105,5 & 97,2 & 4,5 & 9,4 & $\mathbf{2 1 6 , 5}$ \\
2005 & 107,8 & 99,3 & 4,6 & 9,6 & $\mathbf{2 2 1 , 2}$ \\
2006 & 110,0 & 101,4 & 4,7 & 9,8 & $\mathbf{2 2 5 , 8}$ \\
2007 & 112,3 & 103,4 & 4,8 & 10,0 & $\mathbf{2 3 0 , 4}$ \\
\hline
\end{tabular}

Fonte: ANA (2002)

As áreas irrigadas na bacia se localizam, principalmente, ao longo da calha do rio São Francisco e dos afluentes perenes. A rede hidrográfica da bacia compõe-se, majoritariamente, de rios intermitentes. Quase todos os afluentes perenes localizam- 
se em Minas Gerais, dos quais o Velhas, o Gorutuba, o Jequitaí e o Verde Grande servem de manancial dos polos de irrigação. Outros mananciais perenes para irrigação são os rios Grande e Corrente, localizados no oeste da Bahia.

As altas demandas para irrigação de culturas e sua contínua expansão levaram à ocorrência de conflitos entre usuários da água na sub-bacia do Alto Preto, entre Goiás e Minas Gerais, e na do Alto Grande, no Oeste Baiano. O intenso consumo da agricultura irrigada, aliado à baixa precipitação, ocasiona a intermitência do fluxo do rio Salitre, na Bahia (MINAS GERAIS, 2003). Esses mesmos fatores também tornam crítica a disponibilidade hídrica nas sub-bacias dos rios Garças, Terra Nova e Alto Ipanema em Pernambuco e na do rio Verde Grande em Minas Gerais e na Bahia. Em todas essas sub-bacias, a demanda hídrica média chega a ultrapassar 70\% da vazão média de longo termo (ANA/GEF/PNUMA/OEA, 2004a).

Algumas áreas de grande consumo de água para irrigação, identificadas pelo Grupo de Estudos de Relações Intersetoriais (GERI) (UFBA, 2010), são mostradas nas Figuras 5.7, 5.8 e 5.9. A Figura 5.7 mostra a vista aérea das áreas irrigadas na sub-bacia do Alto Rio Grande, no Oeste Baiano. A Figura 5.8 mostra o canal de irrigação do Baixio de Irecê, no Centro Norte Baiano. A Figura 5.9 mostra as áreas irrigadas nas proximidades de Jaíba, sub-bacia do Verde Grande, Norte de Minas.

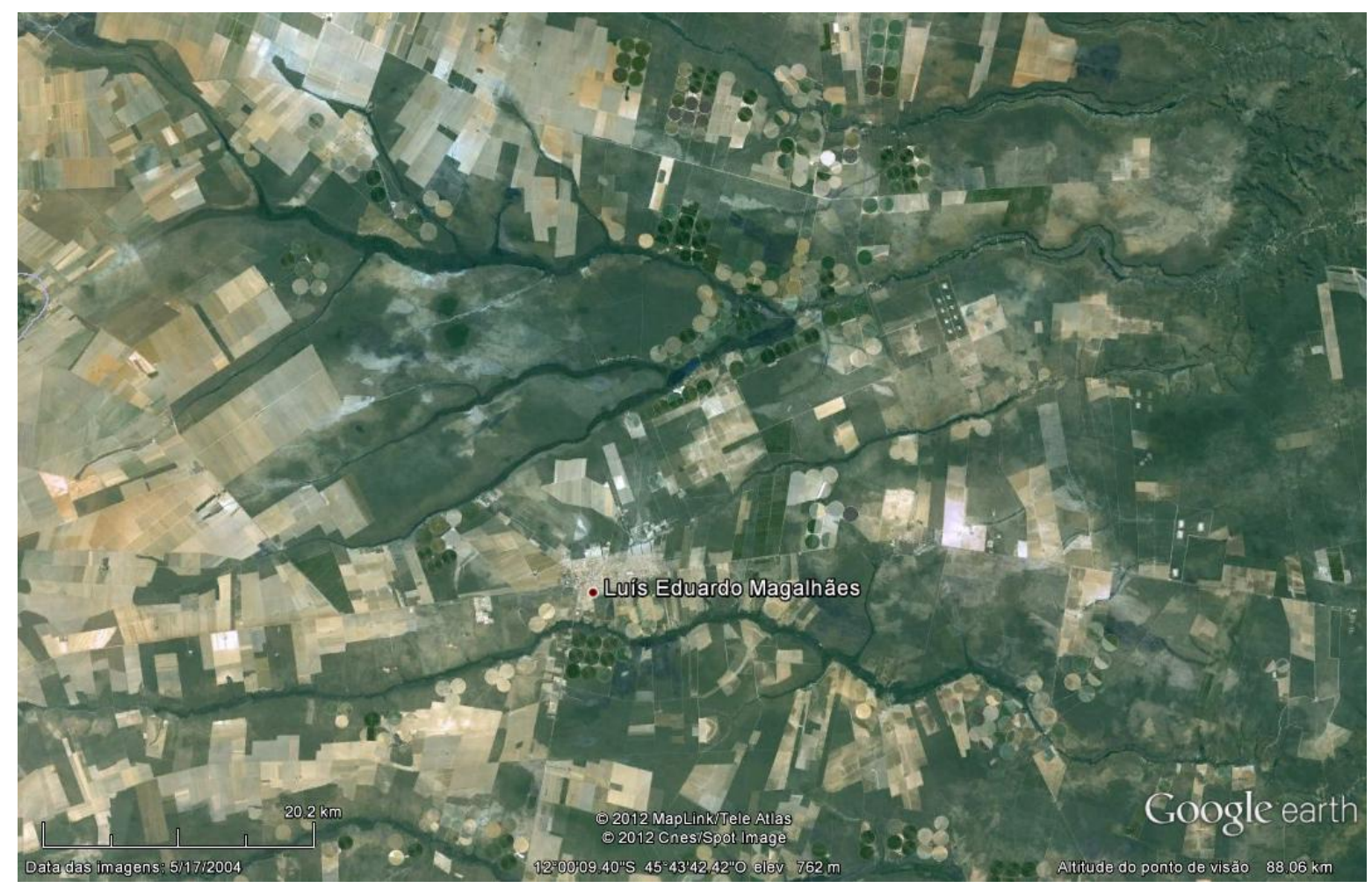

Figura 5.7 - Áreas irrigadas na sub-bacia do Alto Rio Grande, Oeste Baiano 


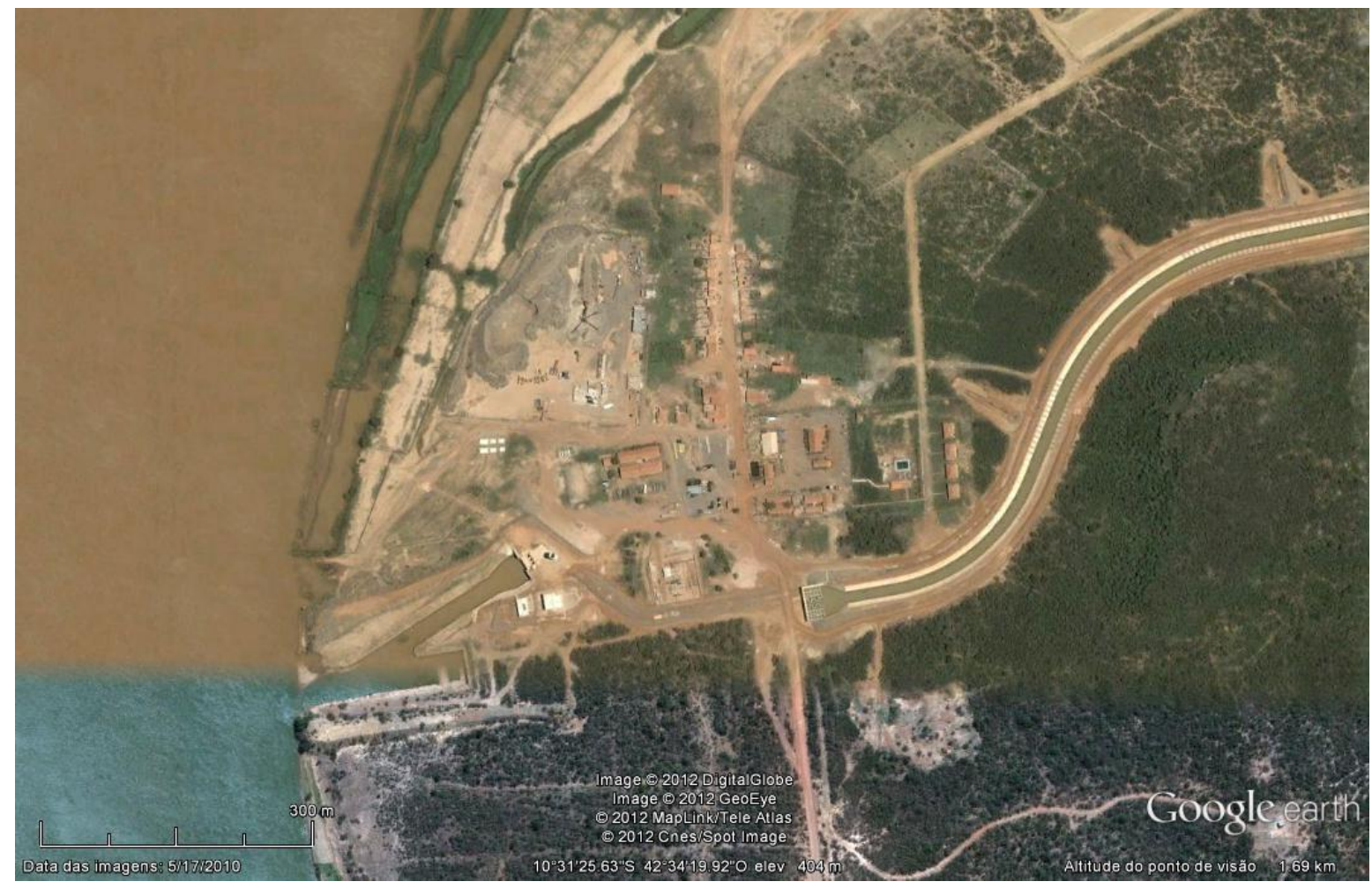

Figura 5.8 - Vista aérea do canal de irrigação do Baixio de Irecê, Bahia

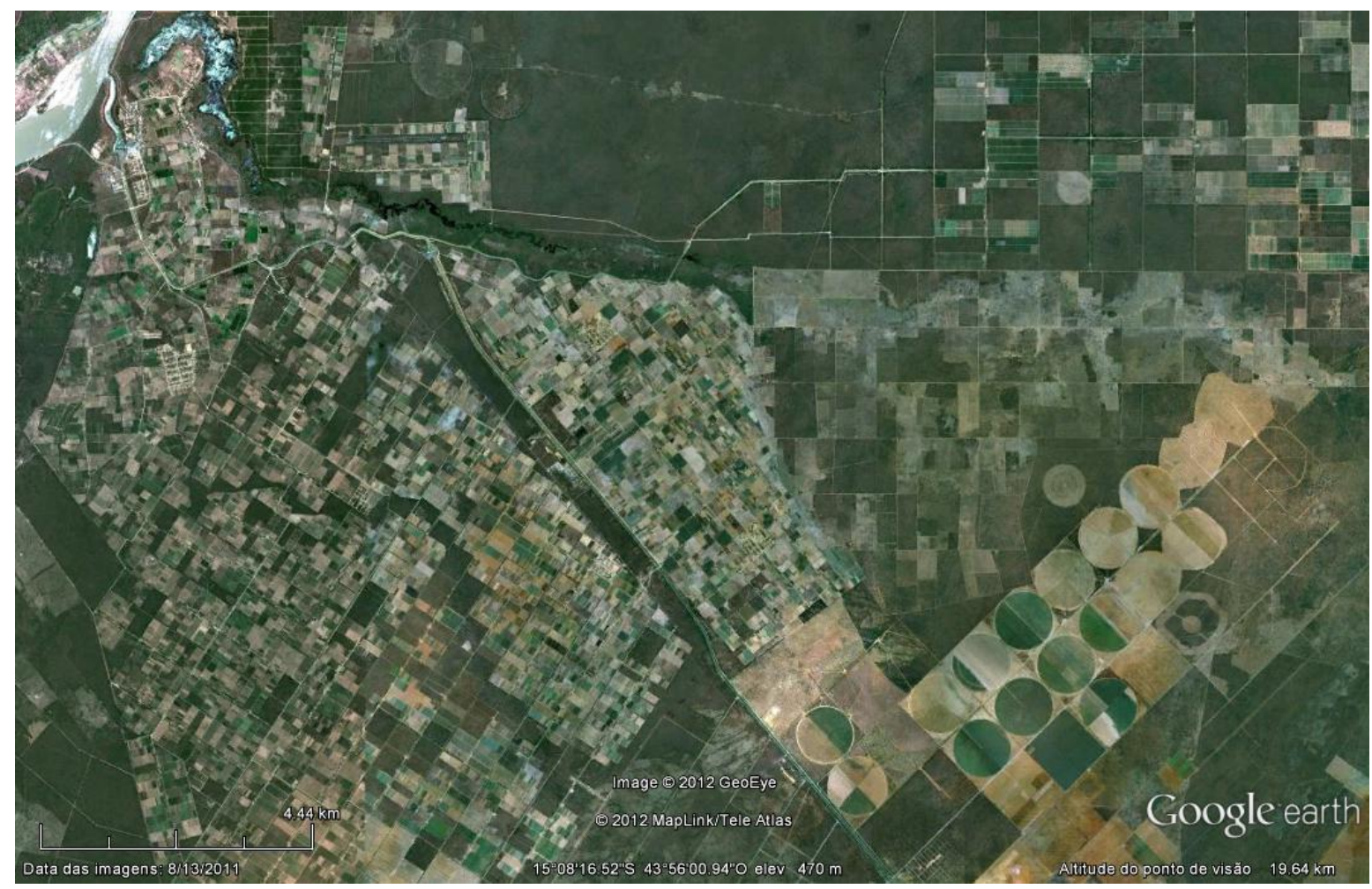

Figura 5.9 - Áreas irrigadas em Jaíba, sub-bacia do Verde Grande, Norte de Minas 
Estima-se que o potencial de áreas irrigadas em toda a bacia do rio São Francisco seja da ordem de 8 milhões de hectares. Estudos realizados em conjunto pela Codevasf e pela Chesf, contudo, concluem que é possível haver prejuízo no atendimento de outros usos da água caso a área irrigada total na bacia supere 800.000 hectares (ANA/GEF/PNUMA/OEA, 2004a).

O fornecimento de água para a irrigação se beneficia de alguns reservatórios construídos na bacia, alguns dos quais utilizados para outros usos como abastecimento humano e geração de energia elétrica. Em algumas sub-bacias, o atendimento das demandas de irrigação pelo reservatório interfere na produção de energia pelas hidrelétricas nos períodos de estiagem prolongada. A porção da bacia que vai do entorno do reservatório de Sobradinho até o reservatório de Xingó é a que registra os principais conflitos entre irrigação e geração de energia elétrica.

\subsubsection{Transposição do rio São Francisco para o Nordeste Setentrional}

A vazão média do rio São Francisco em sua foz, $2.850 \mathrm{~m}^{3} / \mathrm{s}$, corresponde a $70 \%$ da disponibilidade de água doce de toda a Região Nordeste, sendo este um dos motivos apontados para se utilizarem as águas do São Francisco em localidades nordestinas situadas fora da bacia (ANA/GEF/PNUMA/OEA, 2004).

O Projeto de Integração do Rio São Francisco com Bacias Hidrográficas do Nordeste Setentrional (PISF) tem como objetivo aumentar a disponibilidade hídrica das bacias do Semiárido para o abastecimento humano. A versão inicial do projeto, datada de 1981, previa a transposição de $300 \mathrm{~m}^{3} / \mathrm{s}$. Nos estudos realizados em 1994 e 1998, propunha-se que a vazão transposta fosse de $180 \mathrm{~m}^{3} / \mathrm{s}$ e $70 \mathrm{~m}^{3} / \mathrm{s}$, respectivamente (ALVES FILHO, 2000).

Atualmente, prevê-se que a retirada de $26,4 \mathrm{~m}^{3} / \mathrm{s}$ do rio São Francisco regularize as vazões afluentes aos grandes açudes do Nordeste Setentrional, que servem a 390 municípios dos estados de Pernambuco, da Paraíba, do Ceará e do Rio Grande do Norte. Estima-se que em 2025, horizonte do projeto, a população atendida seja de 12 milhões de habitantes, o que inclui as capitais Fortaleza/CE e João Pessoa/PB e cidades-polo como Campina Grande/PB, Crato/CE, Juazeiro do Norte/CE e Mossoró/RN (CODEVASF, 2011). 
O projeto prevê a construção de dois eixos de integração, o Norte e o Leste. A derivação do eixo Norte será na cidade de Cabrobó/PE, a montante do reservatório de Itaparica. Apresentará $402 \mathrm{~km}$ de extensão e atenderá as bacias do rio Jaguaribe e do rio Salgado no Ceará, do rio Piranhas na Paraíba e no Rio Grande do Norte e do rio Apodi no Rio Grande do Norte. Também atenderá 3 sub-bacias do rio São Francisco em Pernambuco: as dos rios Brígida, Terra Nova e Pajeú. A vazão de operação do eixo Norte será de $16,4 \mathrm{~m}^{3} / \mathrm{s}$, a qual poderá variar até a capacidade máxima de $99 \mathrm{~m}^{3} / \mathrm{s}$ em situações de vertimento em Sobradinho.

A derivação do eixo Leste será no reservatório de Itaparica próximo à cidade de Floresta/PE. Com extensão de $220 \mathrm{~km}$, atenderá a bacia do rio Paraíba na Paraíba e 2 sub-bacias do São Francisco em Pernambuco: a do rio Pajeú e a do rio Moxotó. A vazão de operação do eixo Leste será de $10 \mathrm{~m} / \mathrm{s}$, a qual, em situações de vertimento em Sobradinho, poderá variar até a capacidade máxima de $28 \mathrm{~m}^{3} / \mathrm{s}$.

A Figura 5.10 apresenta um mapa de localização dos eixos da transposição do São Francisco, bem como as adutoras previstas no PISF.

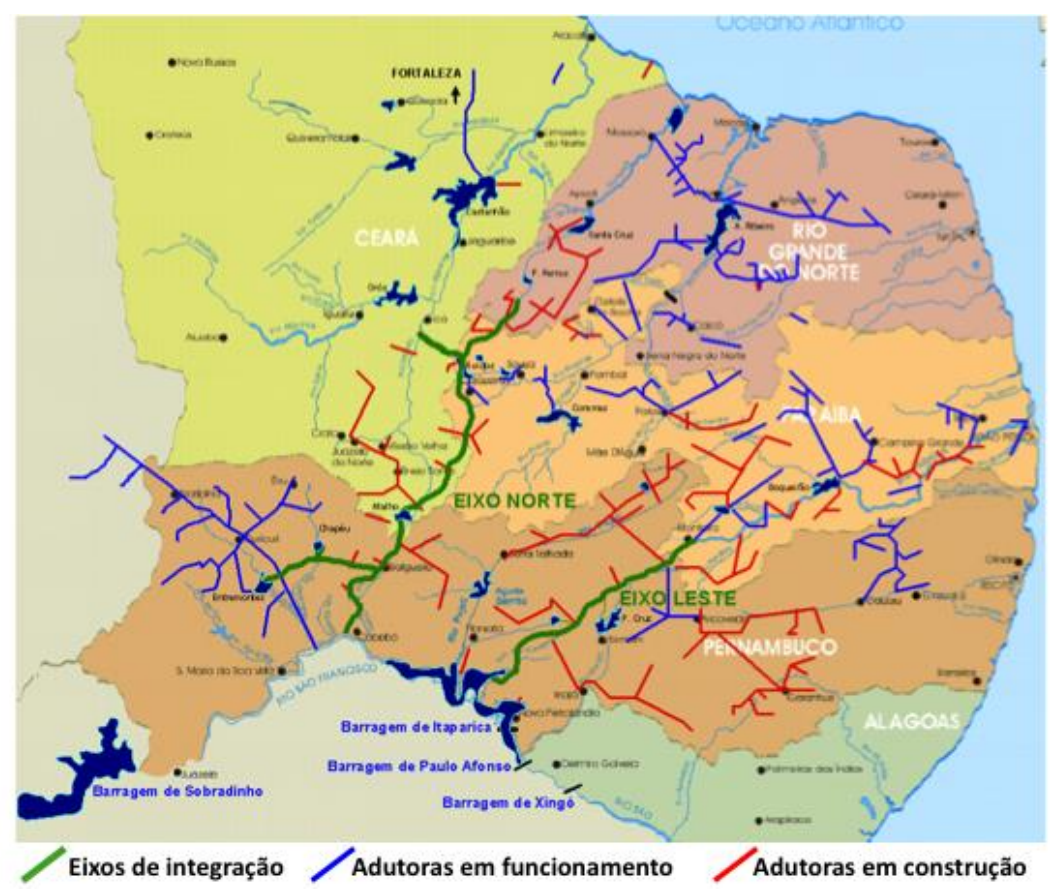

Figura 5.10 - Mapa de localização dos eixos da transposição do rio São Francisco

A Resolução ANA $n^{\circ} .411 / 2005$ outorga à transposição a vazão de operação de $26,4 \mathrm{~m}^{3} / \mathrm{s}$ e estabelece que esse valor pode ser ultrapassado somente quando o nível d'água no reservatório de Sobradinho superar o menor entre os seguintes 
valores: volume de espera para controle de cheias ou $94 \%$ do volume útil. Nesse caso, a vazão máxima instantânea poderá chegar a $127 \mathrm{~m}^{3} / \mathrm{s}$, porém a vazão máxima diária não poderá ultrapassar 114,3 m³/s (ANA, 2005).

Com relação ao impacto da transposição sobre as vazões do rio São Francisco, a vazão de operação contínua da transposição, $26,4 \mathrm{~m}^{3} / \mathrm{s}$, representa $1,4 \%$ da vazão de $1850 \mathrm{~m}^{3} / \mathrm{s}$ garantida pelo reservatório de Sobradinho (CODEVASF, 2011). Segundo as leituras de vazão mensal do posto fluviométrico 48020000, a vazão com permanência de 95\% do tempo em Juazeiro/BA, após o início de operação de Sobradinho, é de $1410 \mathrm{~m}^{3} / \mathrm{s}$. A vazão de operação da transposição corresponderia, assim, a $1,8 \%$ da $Q_{95}$ registrada neste posto. Se comparada à vazão mínima mensal registrada em Juazeiro/BA após a operação de Sobradinho, $906 \mathrm{~m}^{3} / \mathrm{s}$, a vazão de operação equivale a $3 \%$ desse valor.

O impacto da transposição sobre os usos múltiplos da água na bacia foi estimado por Brandão (2004). Para uma vazão de operação de $64 \mathrm{~m}^{3} / \mathrm{s}$, a perda média na geração de energia poderia chegar a 3\% em um cenário de escassez hídrica. Caso não fossem consideradas as demandas de irrigação, a redução média da produção de energia, para o mesmo cenário de escassez e a mesma vazão de operação de $64 \mathrm{~m}^{3} / \mathrm{s}$, seria de $2 \%$ (BRANDÃO, 2004).

\subsection{Descrição dos principais usos não consuntivos na bacia}

\subsubsection{Geração de energia pelas hidrelétricas}

O potencial hidrelétrico da bacia do São Francisco é de $26 \mathrm{GW}$, o que representa $11 \%$ do potencial hidrelétrico do País, estimado em $243 \mathrm{GW}$. Na bacia do São Francisco, encontram-se $13 \%$ do total em operação por hidrelétricas no Brasil (ELETROBRÁS, 2010), conforme mostram os dados da Tabela 5.15.

As maiores usinas hidrelétricas em operação na bacia do São Francisco Retiro Baixo (RBA), Três Marias (TMA), Queimado (QUE), Sobradinho (SOB), Itaparica (ITP), Complexo Paulo Afonso-Moxotó (PAM) e Xingó (XIN) - fazem parte do SIN e somam potência instalada de 10,6 GW. As últimas quatro hidrelétricas 
citadas representam a base do suprimento de energia do subsistema Nordeste, e as três primeiras atendem o subsistema Sudeste.

Tabela 5.15 - Distribuição do potencial hidrelétrico pelas bacias hidrográficas

\begin{tabular}{|c|c|c|c|c|c|c|}
\hline \multirow{2}{*}{ Bacia } & \multicolumn{2}{|c|}{ Operação } & \multicolumn{2}{|c|}{ Disponível } & \multicolumn{2}{|c|}{ Total } \\
\hline & GW & $\%$ & GW & $\%$ & GW & $\%$ \\
\hline Amazonas & 1,09 & $1 \%$ & 88,81 & $55 \%$ & 89,90 & $37 \%$ \\
\hline Paraná & 41,89 & $51 \%$ & 20,41 & $13 \%$ & 62,30 & $26 \%$ \\
\hline São Francisco & 10,69 & $13 \%$ & 15,36 & $10 \%$ & 26,05 & $11 \%$ \\
\hline Tocantins-Araguaia & 13,14 & $16 \%$ & 13,08 & $8 \%$ & 26,22 & $11 \%$ \\
\hline Uruguai & 6,53 & $8 \%$ & 5,78 & $4 \%$ & 12,31 & $5 \%$ \\
\hline Atlântico Norte/Nordeste & 0,32 & $0 \%$ & 2,42 & $1 \%$ & 2,74 & $1 \%$ \\
\hline Atlântico Leste & 4,82 & $6 \%$ & 9,17 & $6 \%$ & 13,99 & $6 \%$ \\
\hline Atlântico Sudeste & 3,46 & $4 \%$ & 6,39 & $4 \%$ & 9,85 & $4 \%$ \\
\hline Total & 81,93 & $100 \%$ & 161,43 & $100 \%$ & 243,36 & $100 \%$ \\
\hline
\end{tabular}

Fonte: SIPOT Dezembro/2010 (ELETROBRÁS, 2010)

Os reservatórios das usinas de Três Marias e de Sobradinho são os que apresentam maior capacidade de acumulação e propiciam a regularização plurianual das vazões do rio São Francisco. Os reservatórios de Retiro Baixo, no rio Paraopeba, de Queimado, no rio Preto, e de Itaparica, no rio São Francisco, têm capacidade de regularização anual. A Figura 5.11 apresenta o diagrama esquemático das principais usinas hidrelétricas da bacia do São Francisco.

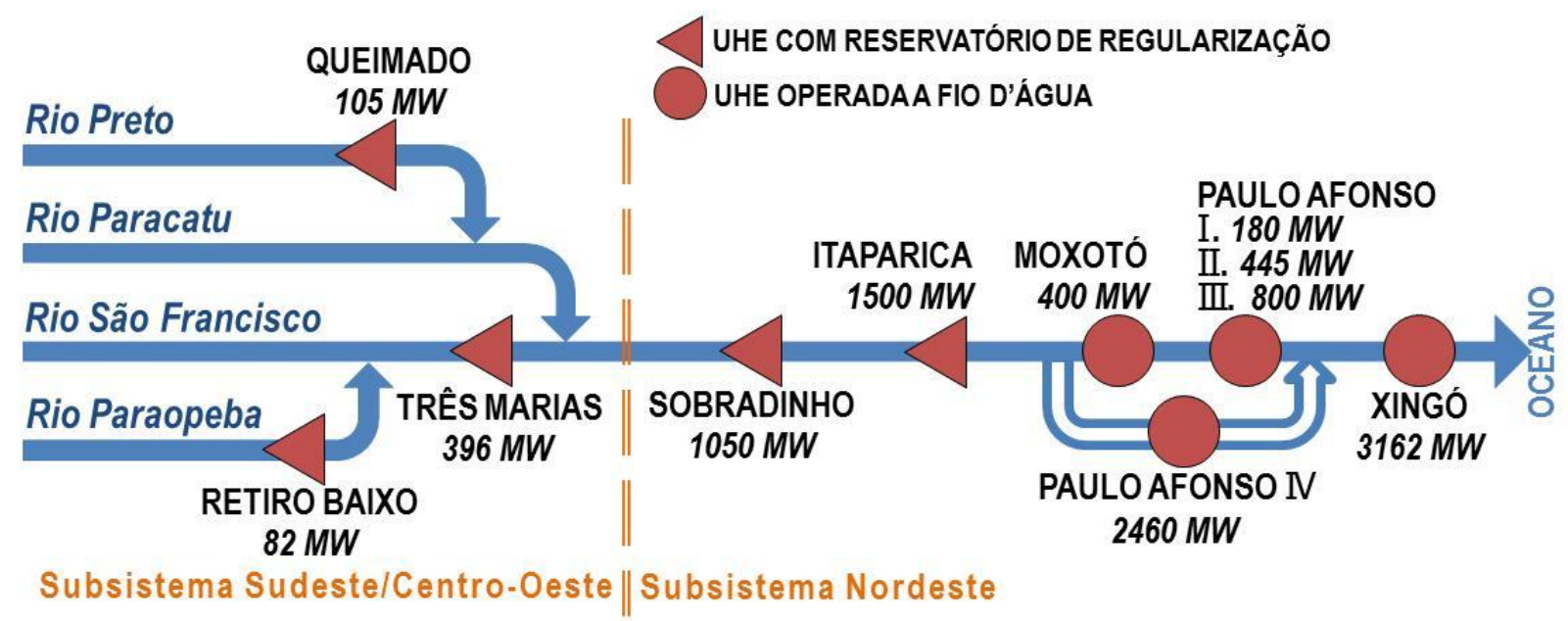

Figura 5.11 - Diagrama esquemático das usinas hidrelétricas da bacia do São Francisco

A Tabela 5.16 apresenta as principais características dos reservatórios como a área de drenagem, o volume útil ( $V U$ ), os níveis d'água mínimo e máximo, a vazão média afluente (Qafl) e a vazão regularizada (Qreg), bem como a potência instalada nas usinas hidrelétricas. A evaporação líquida estimada para esses reservatórios, utilizada pelo setor elétrico (ONS, 2004), consta na Tabela 5.17. A Tabela 5.18 apresenta os coeficientes dos polinômios de quarto grau que geram as curvas cotavolume, cota-área e cota-vazão de jusante de cada aproveitamento. 
Tabela 5.16 - Características dos aproveitamentos hidrelétricos da bacia do S. Francisco

\begin{tabular}{lcccccccc}
\hline $\begin{array}{c}\text { Reservatório / } \\
\text { Usina }\end{array}$ & Operador & $\begin{array}{c}\text { Potência } \\
\text { instalada } \\
(\mathbf{M W})\end{array}$ & $\begin{array}{c}\text { Area de } \\
\left(\mathbf{k m}^{2}\right)\end{array}$ & $\begin{array}{c}\text { VU } \\
\left(\mathbf{h m}^{3}\right)\end{array}$ & $\begin{array}{c}\text { NA mín. } \\
\text { normal } \\
(\mathbf{m})\end{array}$ & $\begin{array}{c}\text { NA máx. } \\
\text { normal } \\
(\mathbf{m})\end{array}$ & $\begin{array}{c}\text { Qafl } \\
\left(\mathbf{m}^{3} / \mathbf{s}\right)\end{array}$ & $\begin{array}{c}\text { Qreg } \\
\left(\mathbf{m}^{\mathbf{3}} / \mathbf{s}\right)\end{array}$ \\
\hline Retiro Baixo & Retiro Baixo & 82 & 11.160 & 40,87 & 614,00 & 616,00 & 159 & \\
Três Marias & Cemig & 396 & 50.732 & 15.278 & 549,20 & 572,50 & 686 & 513 \\
Queimado & Cemig & 105 & 3.760 & 389 & 811,00 & 829,00 & 57 & 34 \\
Sobradinho & Chesf & 1.050 & 499.084 & 28.669 & 380,50 & 392,50 & 2.706 & 1.825 \\
Itaparica & Chesf & 1.500 & 593.384 & 3.549 & 251,50 & 251,50 & 2.791 & 1.875 \\
P. Afonso-Moxotón & Chesf & 4.283 & 606.270 & 158 & 251,00 & 251,50 & 2.810 & 1.875 \\
Xingó & Chesf & 3.162 & 610.544 & 65 & 137,20 & 138,00 & 2.810 & 1.875 \\
\hline
\end{tabular}

Fonte: ANA (2007a), ANA/GEF/PNUMA/OEA (2004c), ONS (2010a).

Tabela 5.17 - Evaporação líquida $(\mathrm{mm})$ dos reservatórios da bacia do S. Francisco

\begin{tabular}{lrrrrrrrrrrrrrr}
\hline Reservatório & Mês Jan & Fev & Mar & Abr & Mai & Jun & Jul & Ago & Set & Out & Nov Dez & $\begin{array}{r}\text { Total } \\
\text { anual }\end{array}$ \\
\hline Retiro Baixo & -21 & -14 & 9 & 30 & 45 & 49 & 69 & 83 & 60 & 30 & 1 & -12 & 329 \\
Três Marias & -1 & -2 & 28 & 47 & 61 & 61 & 58 & 49 & 49 & 35 & 21 & 22 & 428 \\
Queimado & 21 & 4 & 21 & 33 & 59 & 70 & 77 & 79 & 80 & 51 & 17 & 51 & 563 \\
Sobradinho & 171 & 109 & 61 & 56 & 108 & 104 & 165 & 203 & 234 & 267 & 245 & 223 & 1946 \\
Itaparica & 163 & 88 & 47 & 35 & 55 & 41 & 81 & 138 & 190 & 227 & 235 & 202 & 1502 \\
Paulo Afonso-Moxotó & 163 & 88 & 47 & 35 & 55 & 41 & 81 & 138 & 190 & 227 & 235 & 202 & 1502 \\
Xingó & 163 & 88 & 47 & 35 & 55 & 41 & 81 & 138 & 190 & 227 & 235 & 202 & 1502 \\
\hline
\end{tabular}

Fonte: ONS (2004)

Tabela 5.18 - Coeficientes dos polinômios dos reservatórios da bacia do S. Francisco

\begin{tabular}{|c|c|c|c|c|c|}
\hline \multirow{2}{*}{ Reservatório } & \multicolumn{5}{|c|}{ Curva Cota X Volume } \\
\hline & A0 & A1 & A2 & A3 & A4 \\
\hline$\overline{R e t i r o ~ B a i x o ~}$ & 5,915352E-02 & $1,642508 \mathrm{E}-01$ & $-2,607112 \mathrm{E}-04$ & 0 & 0 \\
\hline Três Marias & $5,303318 \mathrm{E}+02$ & $6,075960 \mathrm{E}-03$ & $-4,836150 \mathrm{E}-07$ & $2,203479 \mathrm{E}-11$ & $-3,846500 \mathrm{E}-16$ \\
\hline Queimado & $8,017885 E+02$ & 1,142334E-01 & $-1,977012 \mathrm{E}-04$ & 1,441183E-07 & $-2,488779 E-17$ \\
\hline Sobradinho & $3,741790 \mathrm{E}+02$ & 1,396690E-03 & $-5,351590 \mathrm{E}-08$ & 1,155989E-12 & $-9,545989 E-18$ \\
\hline Itaparica & $2,758130 E+02$ & 6,764889E-03 & $-8,868370 \mathrm{E}-07$ & $7,067909 \mathrm{E}-11$ & $-2,239850 E-15$ \\
\hline P.A.-Moxotó & $2,515000 \mathrm{E}+02$ & 0 & 0 & 0 & 0 \\
\hline Xingó & $1,380000 \mathrm{E}+02$ & 0 & 0 & 0 & 0 \\
\hline \multirow{2}{*}{ Reservatório } & \multicolumn{5}{|c|}{ Curva Área X Cota } \\
\hline & AO & A1 & A2 & A3 & A4 \\
\hline$\overline{R e t i r o ~ B a i x o ~}$ & $-7,237893 E+05$ & $2,350039 E-03$ & $-1,907499 \mathrm{E}+00$ & 0 & 0 \\
\hline Três Marias & $1,207500 \mathrm{E}+07$ & $-8,934369 E+04$ & $2,479890 \mathrm{E}+02$ & $-3,060890 \mathrm{E}-01$ & $1,417750 \mathrm{E}-04$ \\
\hline Queimado & $-7,222561 E+06$ & $2,654824 \mathrm{E}+04$ & $-3,252922 E+01$ & 1,328637E-02 & 0 \\
\hline Sobradinho & $-5,037100 \mathrm{E}+05$ & 4,913789E+03 & $-8,966889 E+00$ & $-1,891690 \mathrm{E}-02$ & 4,653790E-05 \\
\hline Itaparica & $-1,996950 \mathrm{E}+05$ & $1,822240 \mathrm{E}+03$ & $-4,435699 E+00$ & $-1,917610 \mathrm{E}-03$ & 1,292100E-05 \\
\hline P.A.-Moxotó & $2,130000 \mathrm{E}+02$ & 0 & 0 & 0 & 0 \\
\hline Xingó & $6,000000 \mathrm{E}+01$ & 0 & 0 & 0 & 0 \\
\hline \multirow{2}{*}{ Reservatório } & \multicolumn{5}{|c|}{ Curva Cota de jusante X Vazão defluente } \\
\hline & A0 & A1 & A2 & A3 & A4 \\
\hline Retiro Baixo & $5,77 \mathrm{E}+02$ & 6,877187E-03 & $-2,099505 E-06$ & $3,629827 \mathrm{E}-10$ & $-2,35895 E-14$ \\
\hline Três Marias & $5,146558 \mathrm{E}+02$ & $1,606860 \mathrm{E}-03$ & $-2,552750 \mathrm{E}-07$ & $2,885479 \mathrm{E}-11$ & $-1,179780 \mathrm{E}-15$ \\
\hline Queimado & $6,362000 \mathrm{E}+02$ & $3,073000 \mathrm{E}-02$ & $-1,553100 \mathrm{E}-04$ & $5,084740 \mathrm{E}-07$ & $-6,098659 E-10$ \\
\hline Sobradinho & $3,596538 \mathrm{E}+02$ & 1,964010E-03 & $-2,968730 \mathrm{E}-07$ & $2,508280 \mathrm{E}-11$ & $-7,702299 E-16$ \\
\hline Itaparica & $2,515000 \mathrm{E}+02$ & 0 & 0 & 0 & 0 \\
\hline P.A.-Moxotó & $1,380000 \mathrm{E}+02$ & 0 & 0 & 0 & 0 \\
\hline Xingó & $1,003861 \mathrm{E}+01$ & 6,665461E-03 & $-2,454770 \mathrm{E}-06$ & $4,559482 \mathrm{E}-10$ & $-3,144850 E-14$ \\
\hline
\end{tabular}




\subsubsection{Navegação}

Conforme o relatório Conjuntura dos Recursos Hídricos no Brasil (ANA, 2010a), o País conta com 28.834 km de rios navegáveis, dos quais 7\% situam-se na bacia do São Francisco. São $1.578 \mathrm{~km}$ no rio principal, dos quais $1.370 \mathrm{~km}$ entre Pirapora/MG e Juazeiro/BA e 208 km entre Piranhas/AL e a foz, além de $350 \mathrm{~km}$ no rio Grande e $110 \mathrm{~km}$ no rio Corrente, o que totaliza $2.038 \mathrm{~km}$. Durante a estação das chuvas, notam-se condições adequadas à navegação no baixo curso dos afluentes Paracatu, por um trecho de $100 \mathrm{~km}$, Velhas, por $90 \mathrm{~km}$, e Carinhanha, por $80 \mathrm{~km}$ (ANA, 2007).

A bacia tem como principais portos Pirapora/MG, Itacarambi/MG, Ibotirama/BA, Juazeiro/BA e Petrolina/PE. O maior tráfego de embarcações é registrado na Bahia, entre a foz do rio Carinhanha e a foz do rio Grande (MINAS GERAIS, 2003). No trecho Piranhas-foz trafegam embarcações turísticas e de pesca. Nos trechos a montante de Petrolina/PE, realiza-se o escoamento da produção de soja e de milho do Oeste Baiano e o transporte de gesso agrícola para Barreiras/BA e de gipsita para Minas Gerais (ANA, 2007).

Após a construção dos reservatórios para geração de energia elétrica, alguns impactos negativos à navegação passaram a ser observados ao longo do rio São Francisco. No trecho entre os reservatórios de Três Marias e de Sobradinho, o processo de assoreamento causa frequentes encalhes de embarcações durante os meses de estiagem, o que ocasionou o abandono da navegação comercial nos $760 \mathrm{~km}$ entre os portos de Pirapora/MG e Ibotirama/BA (ANA, 2007). A navegação no trecho entre a barragem de Sobradinho e as cidades de Juazeiro/BA e Petrolina/PE fica impossibilitada quando a vazão defluente de Sobradinho baixa a valores próximos de $1.100 \mathrm{~m}^{3} / \mathrm{s}$, por não haver calado mínimo para as embarcações. A construção das barragens provocou impactos também no Baixo São Francisco, onde a modificação das condições de escoamento prejudicou a navegação e a falta de carreamento de sedimentos levou à extinção de algumas espécies da ictiofauna.

A fim de que a calha do São Francisco seja adequada à navegação, impõe-se a restrição de vazão mínima de $500 \mathrm{~m}^{3} / \mathrm{s}$ a jusante de Três Marias para garantia de calado mínimo das embarcações (ANA/GEF/PNUMA/OEA, 2004c). 


\subsubsection{Restrições operativas das usinas}

Conforme estudos do ONS (2010a, 2011), os reservatórios das usinas hidrelétricas estão sujeitos a algumas restrições operativas como, por exemplo, vazão defluente máxima, vazão defluente mínima, taxa de variação máxima da defluência e nível d'água máximo a montante.

A exigência de vazão defluente mínima ou vazão remanescente visa garantir a operação dos sistemas de captação de água para abastecimento público, o calado mínimo para navegação no rio, a proteção à ictiofauna e a manutenção do ecossistema aquático.

As restrições de vazão defluente máxima, por sua vez, são estabelecidas para minimizar inundações em lavouras, áreas residenciais e industriais, bem como evitar danos a estruturas como sistemas de captação para abastecimento público, estações de piscicultura, pontes, diques, portos fluviais, rodovias e ferrovias.

Em algumas sub-bacias, faz-se necessário, também, limitar a taxa de variação da defluência, ou seja, a máxima amplitude permitida ao longo de uma hora ou de um dia à vazão defluente, que é a soma da vazão turbinada com a vazão vertida. O objetivo, geralmente, é evitar danos à calha do rio. Os reservatórios de Queimado, de Três Marias e de Sobradinho apresentam restrições deste tipo.

Alguns reservatórios apresentam restrições quanto ao nível d'água máximo, a fim de impedir inundações de áreas urbanas e de lavouras localizados a montante do aproveitamento hidrelétrico. Restrições deste tipo são impostas aos reservatórios de Três Marias e de Itaparica.

Há outras restrições operativas estabelecias para os reservatórios como, por exemplo, as relacionadas à concentração de oxigênio dissolvido, vazão máxima no vertedor e operações de descargas de fundo, cujo detalhamento foge dos objetivos deste trabalho.

A Tabela 5.19 traz as restrições operativas dos reservatórios da bacia do São Francisco atualmente impostas aos agentes operadores das usinas. 
Tabela 5.19 - Restrições operativas das usinas da bacia do São Francisco

\begin{tabular}{|c|c|c|c|c|}
\hline UHE & $\begin{array}{l}\text { Vazão defluente } \\
\text { mínima }\left(\mathrm{m}^{3} / \mathrm{s}\right)\end{array}$ & $\begin{array}{l}\text { Vazão defluente } \\
\text { máxima }\left(\mathrm{m}^{3} / \mathrm{s}\right)\end{array}$ & $\begin{array}{l}\text { NA máximo } \\
\text { montante }(\mathrm{m})\end{array}$ & $\begin{array}{c}\text { Taxa de variação de } \\
\text { defluência }\end{array}$ \\
\hline RBA & 27,67 & - & - & - \\
\hline TMA & $\begin{array}{c}\text { 300(abastecimento) } \\
500 \text { (navegação) }\end{array}$ & 4.000 & 572,50 & $\begin{array}{c}100 \text { a } 200 \mathrm{~m}^{3} / \mathrm{s} / 0,5 \mathrm{~h} \\
500 \text { a } 700 \mathrm{~m}^{3} / \mathrm{s} / \mathrm{dia}\end{array}$ \\
\hline QUE & 8,8 & 300 & - & $150 \mathrm{~m}^{3} / \mathrm{s} / \mathrm{dia}$ \\
\hline SOB & 1.300 & 8.000 & - & $\begin{array}{l}500 \mathrm{~m}^{3} / \mathrm{s} / \text { dia(operação normal) } \\
1.000 \mathrm{~m}^{3} / \mathrm{s} / \text { dia(contr. de cheia) }\end{array}$ \\
\hline ITP & - & - & 304,00 & - \\
\hline PAM & - & - & - & - \\
\hline XIN & 1.300 & 8.000 & - & $800 \mathrm{~m}^{3} / \mathrm{s} / \mathrm{h}$ \\
\hline
\end{tabular}

Fonte: ONS (2010a, 2011)

Embora as restrições apresentadas na Tabela 5.19 sejam definidas por meio de notas técnicas ou de licenças de operação, outros valores têm sido praticados pelo setor elétrico. É o caso, por exemplo, da vazão defluente mínima de Sobradinho, fixada em $1.300 \mathrm{~m}^{3} / \mathrm{s}$ na licença de operação desta UHE. Pela Resolução ANA no. 434/2003, esse valor foi reduzido, em caráter excepcional, para $1.100 \mathrm{~m}^{3} / \mathrm{s}$, em decorrência do baixo armazenamento verificado nos reservatórios da bacia. Em 2004, a Resolução ANA nº.139 determinou que a redução vigoraria até 30 de abril daquele ano. O ONS, todavia, continua a adotar o valor de $1.100 \mathrm{~m}^{3} / \mathrm{s}$ para determinar as Curvas Bianuais de Aversão ao Risco (CAR), usadas como referência de segurança para o suprimento energético do subsistema Nordeste (ONS, 2010).

Com relação às restrições mostradas na Tabela 5.19, ressalta-se que, nos casos de Três Marias, de Queimado e de Sobradinho, o estudo do ONS (2011) relata que vazões inferiores às fixadas como limite máximo são suficientes para provocar inundações em áreas urbanas e benfeitorias. É o que acontece, por exemplo, quando se atingem $204 \mathrm{~m}^{3} / \mathrm{s}$ a jusante de Queimado, $2.600 \mathrm{~m}^{3} / \mathrm{s}$ a jusante de Três Marias e $7.000 \mathrm{~m}^{3} / \mathrm{s}$ a jusante de Sobradinho.

\subsubsection{Controle de cheias}

$\mathrm{Na}$ bacia do São Francisco, o controle de cheias é exercido pelos reservatórios de Queimado, de Três Marias, de Sobradinho e de Itaparica, operados 
pelo setor elétrico. Para esses reservatórios, o ONS estabelece volumes de espera que sejam adequados ao amortecimento das ondas de cheia e, portanto, evitem a superação das restrições de vazão máxima a jusante desses aproveitamentos, apresentadas anteriormente na Tabela 5.19.

Para o reservatório de Queimado, estabelecem-se volumes de espera associados a um período de retorno $(T R)$ de 10 anos. Para Três Marias, o período de retorno associado aos volumes de espera é de 50 anos. Para Sobradinho e Itaparica, os períodos de retorno são, respectivamente, de 17 e de 18 anos (ONS, 2010a). A Tabela 5.20 traz os volumes de espera (VE) desses reservatórios para o ciclo 2010-2011 (ONS, 2010a).

Tabela 5.20 - Volumes de espera dos reservatórios para 2010-2011

\begin{tabular}{|c|c|c|c|c|c|c|c|c|c|c|c|c|}
\hline \multirow{3}{*}{ Período } & \multicolumn{12}{|c|}{ Aproveitamentos } \\
\hline & \multicolumn{3}{|c|}{$\begin{array}{c}\text { Queimado } \\
\text { (TR=10 anos) }\end{array}$} & \multicolumn{3}{|c|}{$\begin{array}{l}\text { Três Marias } \\
\text { (TR=50 anos) }\end{array}$} & \multicolumn{3}{|c|}{$\begin{array}{l}\text { Sobradinho } \\
\text { (TR=17 anos) }\end{array}$} & \multicolumn{3}{|c|}{$\begin{array}{c}\text { Itaparica } \\
\text { (TR=18 anos) }\end{array}$} \\
\hline & $\begin{array}{c}\text { VE } \\
\left(\mathrm{hm}^{3}\right)\end{array}$ & $\begin{array}{l}\text { Cota } \\
(\mathrm{m})\end{array}$ & $\% V U$ & $\begin{array}{l}\mathrm{VE} \\
\left(\mathrm{hm}^{3}\right)\end{array}$ & $\begin{array}{l}\text { Cota } \\
(\mathrm{m})\end{array}$ & $\% \mathrm{VU}$ & $\begin{array}{l}\mathrm{VE} \\
\left(\mathrm{hm}^{3}\right)\end{array}$ & $\begin{array}{l}\text { Cota } \\
(\mathrm{m})\end{array}$ & $\%$ VU & $\begin{array}{l}\mathrm{VE} \\
\left(\mathrm{hm}^{3}\right)\end{array}$ & $\begin{array}{l}\text { Cota } \\
\text { (m) }\end{array}$ & $\% V U$ \\
\hline 25.09 .10 a 01.10 .10 & 0 & 829,00 & 100,00 & 0 & 572,50 & 100,00 & 0 & 392,50 & 100,00 & 0 & 304,00 & 100,00 \\
\hline 02.10 .10 a 08.10 .10 & 0 & 829,00 & 100,00 & 0 & 572,50 & 100,00 & 0 & 392,50 & 100,00 & 0 & 304,00 & 100,00 \\
\hline 09.10 .10 a 15.10 .10 & 0 & 829,00 & 100,00 & 0 & 572,50 & 100,00 & 0 & 392,50 & 100,00 & 0 & 304,00 & 100,00 \\
\hline 16.10 .10 a 22.10 .10 & 0 & 829,00 & 100,00 & 0 & 572,50 & 100,00 & 0 & 392,50 & 100,00 & 0 & 304,00 & 100,00 \\
\hline 23.10 .10 a 29.10 .10 & 0 & 829,00 & 100,00 & 0 & 572,50 & 100,00 & 159 & 392,46 & 99,45 & 341 & 303,58 & 90,39 \\
\hline 30.10 .10 a 05.11 .10 & 10 & 828,72 & 97,43 & 460 & 572,08 & 96,99 & 3306 & 391,68 & 88,47 & 564 & 303,29 & 84,10 \\
\hline 06.11 .10 a 12.11 .10 & 70 & 826,94 & 82,03 & 670 & 571,87 & 95,61 & 5508 & 391,08 & 80,79 & 752 & 303,05 & 78,80 \\
\hline 13.11 .10 a 19.11 .10 & 100 & 825,98 & 74,32 & 840 & 571,69 & 94,50 & 6234 & 390,87 & 78,26 & 926 & 302,83 & 73,90 \\
\hline 20.11 .10 a 26.11 .10 & 100 & 825,98 & 71,76 & 1880 & 570,61 & 87,69 & 6244 & 390,87 & 78,22 & 1096 & 302,60 & 69,11 \\
\hline 27.11 .10 a 03.12 .10 & 110 & 825,65 & 71,76 & 3110 & 569,22 & 79,64 & 6244 & 390,87 & 78,22 & 1423 & 302,17 & 59,89 \\
\hline 04.12 .10 a 10.12 .10 & 120 & 825,31 & 69,19 & 4070 & 568,09 & 73,36 & 6244 & 390,87 & 78,22 & 1423 & 302,17 & 59,89 \\
\hline 11.12 .10 a 17.12 .10 & 120 & 825,31 & 69,19 & 4020 & 568,15 & 73,69 & 6365 & 390,84 & 77,80 & 1423 & 302,17 & 59,89 \\
\hline 18.12 .10 a 24.12 .10 & 110 & 825,65 & 71,76 & 3830 & 568,37 & 74,93 & 6365 & 390,84 & 77,80 & 1423 & 302,17 & 59,89 \\
\hline 25.12 .10 a 31.12 .10 & 110 & 825,65 & 71,76 & 3400 & 568,88 & 77,75 & 6365 & 390,84 & 77,80 & 1423 & 302,17 & 59,89 \\
\hline 01.01 .11 a 07.01 .11 & 100 & 825,98 & 74,32 & 3270 & 569,03 & 78,60 & 6365 & 390,84 & 77,80 & 1423 & 302,17 & 59,89 \\
\hline 08.01.11 a 14.01 .11 & 100 & 825,98 & 74,32 & 3040 & 569,30 & 80,10 & 6365 & 390,84 & 77,80 & 1423 & 302,17 & 59,89 \\
\hline 15.01 .11 a 21.01 .11 & 90 & 826,31 & 76,89 & 2730 & 569,66 & 82,13 & 6365 & 390,84 & 77,80 & 1485 & 302,08 & 58,15 \\
\hline 22.01 .11 a 28.01 .11 & 90 & 826,31 & 76,89 & 2530 & 569,89 & 83,44 & 6365 & 390,84 & 77,80 & 1534 & 302,01 & 56,76 \\
\hline 29.01.11 a 04.02.11 & 80 & 826,63 & 79,46 & 2300 & 570,16 & 84,95 & 6365 & 390,84 & 77,80 & 1583 & 301,94 & 55,37 \\
\hline 05.02.11 a 11.02 .11 & 80 & 826,63 & 79,46 & 1970 & 570,51 & 87,11 & 6365 & 390,84 & 77,80 & 1633 & 301,88 & 53,99 \\
\hline 12.02 .11 a 18.02 .11 & 70 & 826,94 & 82,03 & 1620 & 570,88 & 89,40 & 6365 & 390,84 & 77,80 & 1682 & 301,81 & 52,60 \\
\hline 19.02 .11 a 25.02 .11 & 70 & 826,94 & 82,03 & 1390 & 571,13 & 90,90 & 6365 & 390,84 & 77,80 & 1731 & 301,74 & 51,22 \\
\hline 26.02.11 a 04.03.11 & 60 & 827,25 & 84,59 & 1280 & 571,24 & 91,62 & 6365 & 390,84 & 77,80 & 1780 & 301,67 & 49,83 \\
\hline 05.03.11 a 11.03 .11 & 60 & 827,25 & 84,59 & 930 & 571,60 & 93,91 & 6365 & 390,84 & 77,80 & 1703 & 301,78 & 51,99 \\
\hline 12.03 .11 a 18.03 .11 & 50 & 827,55 & 87,16 & 710 & 571,83 & 95,35 & 6274 & 390,86 & 78,12 & 1627 & 301,88 & 54,15 \\
\hline 19.03 .11 a 25.03 .11 & 50 & 827,55 & 87,16 & 450 & 572,09 & 97,05 & 6130 & 390,90 & 78,62 & 1550 & 301,99 & 56,31 \\
\hline 26.03.11 a 01.04.11 & 40 & 827,85 & 89,73 & 170 & 572,35 & 98,89 & 5510 & 391,08 & 80,78 & 1390 & 302,21 & 60,82 \\
\hline 02.04.11 a 08.04.11 & 40 & 827,85 & 89,73 & 0 & 572,50 & 100,00 & 5090 & 391,20 & 82,25 & 810 & 302,98 & 77,17 \\
\hline 09.04 .11 a 15.04 .11 & 30 & 828,14 & 92,30 & 0 & 572,50 & 100,00 & 4960 & 391,23 & 82,70 & 790 & 303,00 & 77,73 \\
\hline 16.04 .11 a 22.04 .11 & 30 & 828,14 & 92,30 & 0 & 572,50 & 100,00 & 4960 & 391,23 & 82,70 & 230 & 303,72 & 93,52 \\
\hline 23.04 .11 a 29.04 .11 & 20 & 828,43 & 94,86 & 0 & 572,50 & 100,00 & 4960 & 391,23 & 82,70 & 203 & 303,75 & 94,28 \\
\hline 30.04 .11 a 06.05 .11 & 0 & 829,00 & 100,00 & 0 & 572,50 & 100,00 & 4960 & 391,23 & 82,70 & 35 & 303,96 & 99,01 \\
\hline 07.05 .11 a 13.05 .11 & 0 & 829,00 & 100,00 & 0 & 572,50 & 100,00 & 4215 & 391,44 & 85,30 & 35 & 303,96 & 99,01 \\
\hline 14.05 .11 a 20.05 .11 & 0 & 829,00 & 100,00 & 0 & 572,50 & 100,00 & 1520 & 392,13 & 94,70 & 20 & 303,98 & 99,44 \\
\hline 21.05 .11 a 27.05 .11 & 0 & 829,00 & 100,00 & 0 & 572,50 & 100,00 & 230 & 392,44 & 99,20 & 0 & 304,00 & 100,00 \\
\hline 28.05 .11 a 03.06 .11 & 0 & 829,00 & 100,00 & 0 & 572,50 & 100,00 & 0 & 392,50 & 100,00 & 0 & 304,00 & 100,00 \\
\hline
\end{tabular}




\subsubsection{Manutenção do ecossistema}

A manutenção do ecossistema constitui uma demanda hídrica não consuntiva cuja estimativa pode ser feita a partir de diferentes métodos. Para avaliar a demanda de conservação dos ecossistemas aquáticos naturais e a proteção da ictiofauna em toda a bacia do São Francisco, o Plano Decenal da bacia, em seu Estudo Técnico $\mathrm{n}^{\circ} .16$ (ANA/GEF/PNUMA/OEA, 2004d), estima a demanda ambiental pelo Método de Tennant, o qual define percentuais da vazão média de longo termo para a manutenção do ecossistema. No estudo, foi estabelecido um percentual de $20 \%$ da $Q_{M L T}$ para a defluência mínima de Retiro Baixo e de Três Marias e um percentual de $30 \%$ da $Q_{M L T}$ para a defluência mínima em Sobradinho e em Xingó.

A Tabela 5.21 apresenta a vazão defluente mínima dos reservatórios para a manutenção do ecossistema aquático.

Tabela 5.21 - Vazão mínima para conservação ambiental a jusante dos reservatórios

\begin{tabular}{lrc}
\hline \multirow{2}{*}{ Reservatório } & \multicolumn{2}{c}{ Defluência mínima } \\
\cline { 2 - 3 } & $\left(\mathbf{m}^{\mathbf{3}} / \mathbf{s}\right)$ & $\% \mathbf{Q}_{\mathbf{M L T}}$ \\
\hline Retiro Baixo & 27,67 & $20 \%$ \\
Três Marias & 405,70 & $20 \%$ \\
Sobradinho & 843,80 & $30 \%$ \\
Xingó & 855,00 & $30 \%$ \\
\hline
\end{tabular}

\subsection{Histórico de afluências na bacia}

As informações referentes à disponibilidade hídrica superficial na bacia do São Francisco constam do Estudo Técnico n.1 desenvolvido para o Plano Decenal da bacia e tiveram como base a série histórica de vazões naturais de 1931 a 2001 (ANA/GEF/PNUMA/OEA, 2004b). Segundo esse estudo, a vazão natural média anual do rio São Francisco é de $2850 \mathrm{~m}^{3} / \mathrm{s}$. Em 95\% do tempo, a vazão natural do rio São Francisco em sua foz permaneceu igual ou superior a $853 \mathrm{~m}^{3} / \mathrm{s}$. O mês de maior vazão média é março, com $13.743 \mathrm{~m}^{3} / \mathrm{s}$, e o de menor vazão média é outubro, 
com $644 \mathrm{~m}^{3} / \mathrm{s}$. Considera-se vazão natural a contribuição natural da bacia caso não houvesse qualquer interferência antrópica na região como, por exemplo, regularização de reservatórios, transposição de rios ou captações (ONS, 2009).

A análise da série histórica de vazões naturais afluentes aos reservatórios da bacia do rio São Francisco pode ser feita a partir da energia natural afluente (ENA) aos reservatórios. Define-se ENA como a energia elétrica que pode ser gerada a partir da vazão natural em um aproveitamento hidrelétrico (ONS, 2009). A ENA de uma usina hidrelétrica, portanto, é o produto da vazão natural afluente a esta usina pela produtividade média desta usina. Por sua vez, a ENA de uma bacia hidrográfica é a soma das ENAs de todas as usinas hidrelétricas da bacia.

A série histórica de ENA da bacia do rio São Francisco, publicada pelo ONS, cobre o período de janeiro/1931 a dezembro/2009 e está apresentada no Anexo B deste trabalho. A ENA média da bacia, ou seja, a MLT é de 8.163 MWmed. A menor ENA do histórico, 3.968 MWmed, foi registrada no ano de 2001, e o valor máximo, 14.870 MWmed, foi registrado em 1979. As estatísticas da série histórica de ENA da bacia do rio São Francisco é apresentada na Tabela 5.22.

Tabela 5.22 - Estatísticas da série histórica de ENA da bacia do S. Francisco

\begin{tabular}{lcrl}
\hline & ENA (MWmed) & \%MLT & \\
\hline MLT & 8.163 & $100,0 \%$ & \\
Desvio padrão & 2.360 & $28,9 \%$ & \\
Mínimo & 3.968 & $48,6 \%$ & \\
Mediana & 7.860 & $96,3 \%$ & \\
Máximo & 14.870 & $182,2 \%$ & \\
Coeficiente de Variação & & 0,289 \\
Coeficiente de Assimetria & & 1,031 \\
Coeficiente de Curtose & & 3,804 \\
Excesso de Curtose & & 0,804 \\
\hline
\end{tabular}

As estatísticas mostradas na Tabela 5.22 indicam que, para a bacia do São Francisco, o valor da mediana equivale a 96,3\% da MLT. A série histórica de ENA apresentaria, portanto, assimetria positiva, o que é confirmado pelo valor positivo obtido para o coeficiente de assimetria. Presume-se, assim, que a MLT apresente uma permanência no tempo mais baixa do que a maior parte dos anos do histórico.

De fato, a curva de permanência de ENA da bacia do São Francisco, mostrada na Figura 5.12, indica que a permanência da MLT é de 37,7\%, ou seja, $62,3 \%$ dos anos do histórico registraram afluência média menor do que a MLT. 


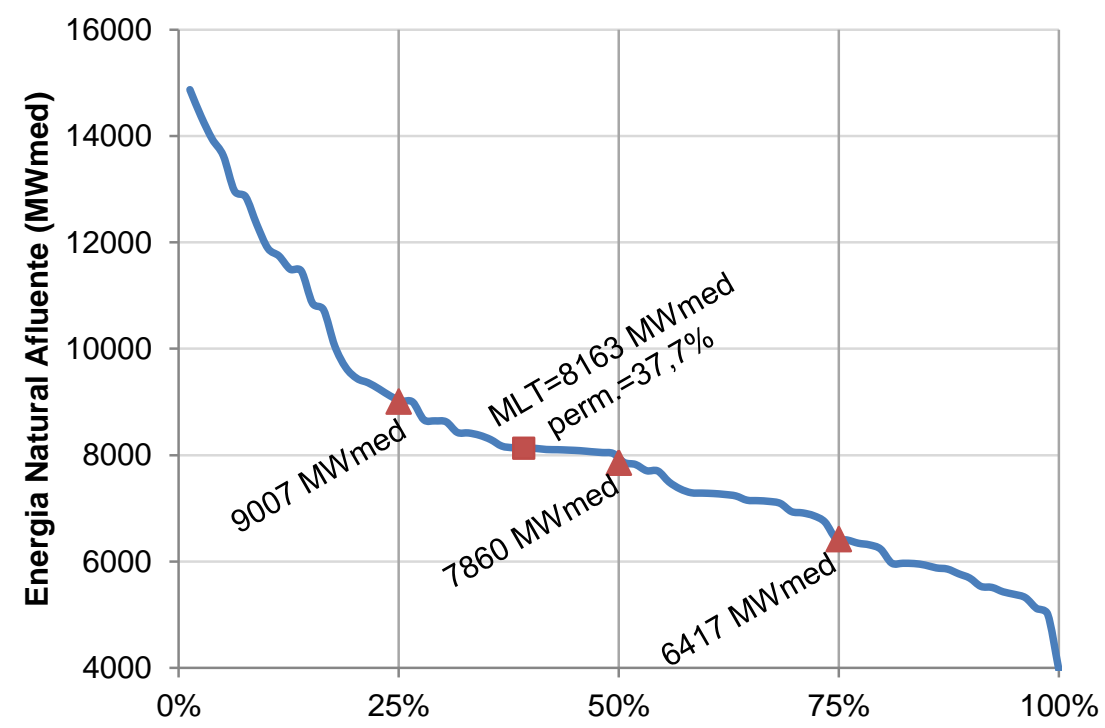

Figura 5.12 - Curva de permanência de ENA na bacia do S. Francisco

Para a identificação dos períodos de hidrologia mais escassa na bacia, foi avaliada a diferença entre a ENA média de cada ano e a mediana (96,3\%MLT). Os valores negativos obtidos em anos consecutivos foram acumulados. A maior diferença acumulada - ou maior intensidade - foi obtida no período de 1998 a 2004. Esse período caracteriza não apenas o de seca mais severa na bacia do rio São Francisco, mas também o de maior duração (7 anos).

A Tabela 5.23 apresenta a classificação dos períodos de seca da bacia do rio São Francisco segundo a intensidade acumulada.

Tabela 5.23 - Classificação dos períodos de seca na bacia do S. Francisco

\begin{tabular}{ccccc}
\hline Ordem & $\begin{array}{c}\text { Ano } \\
\text { inicial }\end{array}$ & $\begin{array}{c}\text { Ano } \\
\text { final }\end{array}$ & $\begin{array}{c}\text { Duração } \\
\text { (anos) }\end{array}$ & $\begin{array}{c}\text { Intensidade } \\
\text { acumulada }\end{array}$ \\
\hline 1 & 1998 & 2004 & 7 & $-5,881$ \\
2 & 1953 & 1956 & 4 & $-3,134$ \\
3 & 1975 & 1977 & 3 & $-2,242$ \\
4 & 1987 & 1990 & 4 & $-2,095$ \\
5 & 1995 & 1996 & 2 & $-1,832$ \\
6 & 1932 & 1934 & 3 & $-1,661$ \\
7 & 1971 & 1972 & 2 & $-1,599$ \\
8 & 1958 & 1959 & 2 & $-1,126$ \\
9 & 2006 & 2008 & 3 & $-0,994$ \\
10 & 1962 & 1963 & 2 & $-0,889$ \\
11 & 1938 & 1939 & 2 & $-0,603$ \\
\hline
\end{tabular}

Procedeu-se, também, à análise das médias-móveis de 7 anos de ENA da bacia do rio São Francisco. Essa análise permite comparar a afluência média do período 1998-2004 com a do período crítico adotado pelo setor elétrico, de 
junho/1949 a novembro/1956, cuja duração também é de 7 anos. Foi construída a curva de duração das médias-móveis de 7 anos, mostrada na Figura 5.13.

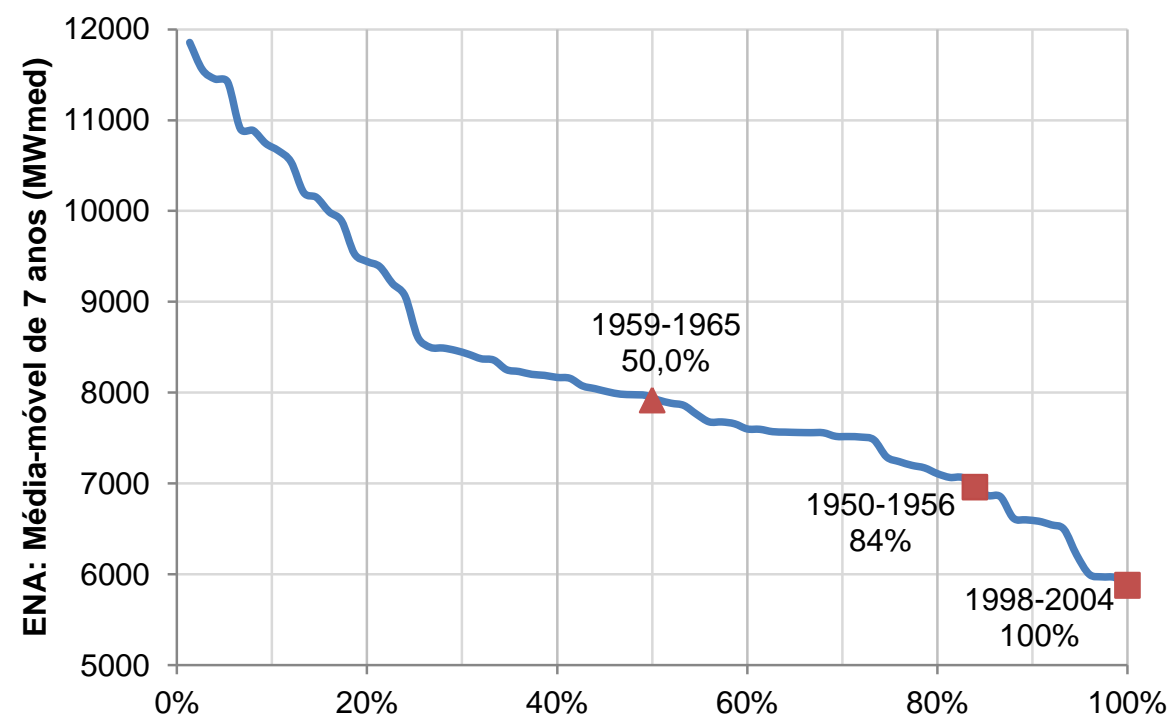

Figura 5.13 - Curva de permanência das médias-móveis de 7 anos de ENA

A média-móvel do período de 1998-2004 vale 5.878 MWmed e constitui a menor média-móvel de 7 anos do histórico, ou seja, sua permanência é de $100 \%$. O período 1950-1956 registra uma média-móvel igual a $6.957 \mathrm{MWmed,} \mathrm{com}$ permanência de $84 \%$.

Percebe-se, de fato, que é inadequado estabelecer como período crítico de afluências para a bacia do rio São Francisco o mesmo comumente adotado pelo setor elétrico quando se deseja proceder a uma avaliação de cenários de escassez. Essa mesma constatação está expressa, também, no Plano Decenal da bacia do São Francisco em seu Estudo Técnico n. 1 (ANA/GEF/PNUMA/OEA, 2004b). 


\section{APLICAÇÃO DO MODELO}

No Capítulo 4 foi discutida a metodologia adotada na abordagem do problema de otimização da operação de um sistema de reservatórios voltados à geração de energia elétrica e ao atendimento de usos consuntivos da água. Foi apresentada uma nova função objetivo para o modelo HIDRO, a qual busca minimizar tanto o deficit de energia como o deficit no fornecimento de água para as demandas consuntivas. No caso específico da bacia do rio São Francisco, também foram acrescentadas as equações de restrição relativas às regras de operação da transposição do rio São Francisco para o Nordeste Setentrional.

O novo equacionamento do modelo HIDRO, baseado nas equações mostradas no Capítulo 4, foi elaborado em linguagem estruturada GAMS, que se mostra uma ferramenta útil para solução de problemas de programação linear, não linear, inteira e inteira mista. A ferramenta é associada a um conjunto de pacotes de otimização - solver - como, por exemplo, o MINOS, o CONOPT e o SNOPT, adequados ao tratamento de problemas de programação não linear.

Os códigos do modelo HIDRO, elaborados em linguagem GAMS e utilizados na otimização da operação do sistema de reservatórios da bacia do São Francisco, estão apresentados no Apêndice deste trabalho.

$\mathrm{Na}$ sequência, apresentam-se as variáveis de entrada do problema e as restrições impostas à otimização. As restrições e os valores das variáveis de entrada são baseados nas características da bacia do rio São Francisco e nas regras operativas de seus reservatórios, conforme a descrição apresentada no Capítulo 5. 


\subsection{Variáveis de entrada e restrições operativas}

\subsubsection{Demanda objetivo}

A demanda objetivo de energia foi estimada como igual à soma das garantias físicas das usinas da bacia. Conforme a Portaria MME $n^{\circ} 258$, de 28 de julho de 2008, a garantia física de um sistema, anteriormente chamada energia assegurada, é definida como a máxima quantidade de energia que este sistema pode suprir sob um dado critério de garantia de suprimento, atualmente fixado em 95\%. O rateio da garantia física de um sistema entre todas as usinas que o compõem determina a garantia física de cada usina (BRASIL, 2008).

As usinas hidrelétricas da bacia do rio São Francisco somam uma garantia física de 6.189,5 MWmed, sendo este o valor adotado como demanda objetivo de energia. Os valores de garantia física de cada usina constam na Tabela 6.1.

Tabela 6.1 - Potência instalada e garantia física das usinas hidrelétricas

\begin{tabular}{lcc}
\hline UHE & $\begin{array}{c}\text { Potência instalada } \\
\text { (MW) }\end{array}$ & $\begin{array}{c}\text { Garantia Física } \\
\text { (MWmed) }\end{array}$ \\
\hline RBA & 82 & 38,5 \\
TMA & 396 & 239,0 \\
QUE & 105 & 58,0 \\
SOB & 1.050 & 531,0 \\
ITP & 1.500 & 959,0 \\
PAM & 4.283 & $2.225,0$ \\
XIN & 3.162 & $2.139,0$ \\
\hline Total & $\mathbf{1 0 . 5 7 8}$ & $\mathbf{6 . 1 8 9 , 5}$ \\
\hline
\end{tabular}

Fonte: ANEEL (2011)

Com relação à demanda hídrica objetivo, não foi estabelecido um único valor a ser atendido. Em função da divergência observada entre as fontes pesquisadas no que se refere à demanda consuntiva na bacia do São Francisco, foram considerados 6 cenários de demanda hídrica objetivo. O cenário I é o de menor demanda consuntiva, considerada igual ao valor de uso consuntivo adotado pelo ONS para o ano de 2011 (UC ONS). O cenário II considera a demanda consuntiva igual a uma vez e meia o valor $U C_{O N S}$. Seguindo essa progressão, foram estabelecidos os cenários III, IV e V, cujas demandas foram calculadas como o valor UCONS multiplicado, respectivamente, por dois, dois e meio e três. Finalmente, o cenário VI é o de maior demanda hídrica consuntiva, considerada igual ao consumo outorgado na bacia até 
outubro/2009, conforme discutido no Capítulo 5. Os cenários de demanda hídrica consuntiva por reservatório são mostrados na Tabela 6.2.

Tabela 6.2 - Cenários de demanda hídrica consuntiva $\left(\mathrm{m}^{3} / \mathrm{s}\right)$

\begin{tabular}{|c|c|c|c|c|c|c|c|c|c|c|c|c|}
\hline \multirow{2}{*}{ Usina } & \multicolumn{12}{|c|}{ Cenário I: Demanda hídrica $\left(\mathrm{m}^{3} / \mathrm{s}\right)=1,0 \times$ UCons } \\
\hline & JAN & FEV & MAR & ABR & MAI & JUN & JUL & AGO & SET & OUT & NOV & DEZ \\
\hline RBA & 1,2 & 2,4 & 1,5 & 2,7 & 1,8 & 2,3 & 2,3 & 2,0 & 2,3 & 1,4 & 1,0 & 1,0 \\
\hline TMA & 4,2 & 8,4 & 5,4 & 9,6 & 6,4 & 8,3 & 8,0 & 7,1 & 8,0 & 4,9 & 3,6 & 3,5 \\
\hline QUE & 0,2 & 0,2 & 0,6 & 1,1 & 1,2 & 1,0 & 1,7 & 2,0 & 2,1 & 0,5 & 0,2 & 0,2 \\
\hline SOB & 50,6 & 62,1 & 30,7 & 71 & 73,9 & 79,4 & 73,5 & 87,7 & 92,4 & 48,9 & 17,7 & 16,9 \\
\hline ITP & 57,1 & 45,7 & 17,9 & 47,9 & 49,1 & 40,1 & 46,5 & 57,6 & 68,5 & 69,3 & 70,4 & 40,9 \\
\hline PAM & 2,6 & 2,2 & 1,0 & 2,2 & 2,1 & 1,4 & 1,3 & 1,9 & 2,7 & 2,6 & 2,9 & 1,8 \\
\hline XIN & 0,3 & 0,3 & 0,2 & 0,3 & 0,3 & 0,2 & 0,2 & 0,2 & 0,3 & 0,3 & 0,4 & 0,3 \\
\hline \multirow{2}{*}{ Usina } & \multicolumn{12}{|c|}{ Cenário II: Demanda hídrica $\left(\mathrm{m}^{3} / \mathrm{s}\right)=1,5 \times$ UC ons } \\
\hline & JAN & FEV & MAR & ABR & MAI & JUN & JUL & AGO & SET & OUT & NOV & DEZ \\
\hline RBA & 1,8 & 3,6 & 2,3 & 4,0 & 2,7 & 3,5 & 3,4 & 3,0 & 3,4 & 2,1 & 1,5 & 1,5 \\
\hline TMA & 6,3 & 12,6 & 8,2 & 14,3 & 9,6 & 12,4 & 10,2 & 10,6 & 12,0 & 7,4 & 5,5 & 5,3 \\
\hline QUE & 0,3 & 0,3 & 0,8 & 1,7 & 1,8 & 1,4 & 2,6 & 3,0 & 3,1 & 0,8 & 0,2 & 0,2 \\
\hline SOB & 75,8 & 93,1 & 46,1 & 106,4 & 110,9 & 119,1 & 110,2 & 131,6 & 138,6 & 73,3 & 26,6 & 25,3 \\
\hline ITP & 85,7 & 68,6 & 26,9 & 71,9 & 73,7 & 60,2 & 69,8 & 86,3 & 102,8 & 104 & 105,6 & 61,3 \\
\hline PAM & 3,8 & 3,3 & 1,5 & 3,3 & 3,1 & 2,0 & 2,0 & 2,8 & 4,0 & 3,8 & 4,3 & 2,7 \\
\hline XIN & 0,5 & 0,5 & 0,3 & 0,5 & 0,4 & 0,3 & 0,3 & 0,3 & 0,4 & 0,5 & 0,6 & 0,4 \\
\hline \multirow{2}{*}{ Usina } & \multicolumn{12}{|c|}{ Cenário III: Demanda hídrica $\left(\mathrm{m}^{3} / \mathrm{s}\right)=2,0 \times \mathrm{UC}_{\mathrm{ONS}}$} \\
\hline & JAN & FEV & MAR & ABR & MAI & JUN & JUL & AGO & SET & OUT & NOV & DEZ \\
\hline RBA & 2,4 & 4,7 & 3,1 & 5,4 & 3,6 & 4,7 & 4,5 & 4,0 & 4,5 & 2,8 & 2,1 & 2,0 \\
\hline TMA & 8,5 & 16,8 & 10,9 & 19,1 & 12,7 & 16,5 & 16,0 & 14,2 & 16,1 & 9,8 & 7,3 & 7,1 \\
\hline QUE & 0,4 & 0,4 & 1,1 & 2,3 & 2,4 & 1,9 & 3,4 & 4,0 & 4,2 & 1,0 & 0,3 & 0,3 \\
\hline SOB & 101,1 & 124,2 & 61,4 & 141,9 & 147,8 & 158,8 & 147,0 & 175,5 & 184,8 & 97,7 & 35,4 & 33,7 \\
\hline ITP & 114,3 & 91,4 & 35,9 & 95,8 & 98,3 & 80,2 & 93,1 & 115,1 & 137 & 138,6 & 140,7 & 81,7 \\
\hline PAM & 5,1 & 4,4 & 1,9 & 4,5 & 4,2 & 2,7 & 2,6 & 3,8 & 5,4 & 5,1 & 5,7 & 3,6 \\
\hline XIN & 0,7 & 0,7 & 0,5 & 0,6 & 0,6 & 0,4 & 0,4 & 0,4 & 0,5 & 0,6 & 0,8 & 0,5 \\
\hline \multirow{2}{*}{ Usina } & \multicolumn{12}{|c|}{ Cenário IV: Demanda hídrica $\left(\mathrm{m}^{3} / \mathrm{s}\right)=2,5 \times$ UCons } \\
\hline & JAN & FEV & MAR & ABR & MAI & JUN & JUL & AGO & SET & OUT & NOV & DEZ \\
\hline RBA & 3,0 & 5,9 & 3,8 & 6,7 & 4,5 & 5,8 & 5,6 & 5,0 & 5,7 & 3,5 & 2,6 & 2,5 \\
\hline TMA & 10,6 & 21,0 & 13,6 & 23,9 & 15,9 & 20,7 & 20,0 & 17,7 & 20,1 & 12,3 & 9,1 & 8,8 \\
\hline QUE & 0,5 & 0,5 & 1,4 & 2,8 & 3,1 & 2,4 & 4,3 & 5,0 & 5,2 & 1,3 & 0,4 & 0,4 \\
\hline SOB & 126,4 & 155,2 & 76,8 & 177,4 & 184,8 & 198,5 & 183,7 & 219,3 & 231,0 & 122,2 & 44,3 & 42,2 \\
\hline ITP & 142,8 & 114,3 & 44,9 & 119,8 & 122,8 & 100,3 & 116,4 & 143,9 & 171,3 & 173,3 & 175,9 & 102,1 \\
\hline PAM & 6,4 & 5,5 & 2,4 & 5,6 & 5,2 & 3,4 & 3,3 & 4,7 & 6,7 & 6,4 & 7,2 & 4,5 \\
\hline XIN & 0,9 & 0,8 & 0,6 & 0,8 & 0,7 & 0,5 & 0,5 & 0,5 & 0,7 & 0,8 & 1,0 & 0,7 \\
\hline \multirow{2}{*}{ Usina } & \multicolumn{12}{|c|}{ Cenário V: Demanda hídrica $\left(\mathrm{m}^{3} / \mathrm{s}\right)=3,0 \times$ UCons } \\
\hline & JAN & FEV & MAR & ABR & MAI & JUN & JUL & AGO & SET & OUT & NOV & DEZ \\
\hline RBA & 3,6 & 7,1 & 4,6 & 8,1 & 5,4 & 7,0 & 6,8 & 6,0 & 6,8 & 4,1 & 3,1 & 3 \\
\hline TMA & 12,7 & 25,2 & 16,3 & 28,7 & 19,1 & 24,8 & 24 & 21,3 & 24,1 & 14,7 & 10,9 & 10,6 \\
\hline QUE & 0,5 & 0,5 & 1,7 & 3,4 & 3,7 & 2,9 & 5,1 & 5,9 & 6,2 & 1,5 & 0,5 & 0,5 \\
\hline SOB & 151,7 & 186,2 & 92,1 & 212,9 & 221,7 & 238,2 & 220,5 & 263,2 & 277,2 & 46,6 & 53,1 & 50,6 \\
\hline ITP & 171,4 & 137,1 & 53,8 & 143,7 & 147,4 & 120,3 & 139,6 & 172,7 & 205,6 & 207,9 & 211,1 & 122,6 \\
\hline PAM & 7,7 & 6,6 & 2,9 & 6,7 & 6,3 & 4,1 & 3,9 & 5,7 & 8,1 & 7,7 & 8,6 & 5,4 \\
\hline XIN & 1,0 & 1,0 & 0,7 & 0,9 & 0,8 & 0,5 & 0,6 & 0,5 & 0,8 & 0,9 & 1,2 & 0,8 \\
\hline \multirow{2}{*}{ Usina } & \multicolumn{12}{|c|}{ Cenário VI: Demanda hídrica $\left(\mathrm{m}^{3} / \mathrm{s}\right)=$ Consumo outorgado } \\
\hline & JAN & FEV & MAR & ABR & MAl & JUN & JUL & AGO & SET & OUT & NOV & DEZ \\
\hline RBA & 13,3 & 13,3 & 13,3 & 13,3 & 13,3 & 13,3 & 13,3 & 13,3 & 13,3 & 13,3 & 13,3 & 13,3 \\
\hline TMA & 35,2 & 35,4 & 35,8 & 36,5 & 40,7 & 40,6 & 40,7 & 40,8 & 40,8 & 40,7 & 36,2 & 35,8 \\
\hline QUE & 1,3 & 1,3 & 1,3 & 1,3 & 1,5 & 1,5 & 1,5 & 1,5 & 1,5 & 1,4 & 1,3 & 1,5 \\
\hline SOB & 416,7 & 422,6 & 432,3 & 448,7 & 434,2 & 425,9 & 437,2 & 457,1 & 468,3 & 419,8 & 385,8 & 379,9 \\
\hline ITP & 139,9 & 142,2 & 136,6 & 128,6 & 120,0 & 114,6 & 121,5 & 129,8 & 136,5 & 137,9 & 139,9 & 136,0 \\
\hline PAM & 1,4 & 1,4 & 1,4 & 1,4 & 1,4 & 1,4 & 1,4 & 1,4 & 1,4 & 1,4 & 1,4 & 1,4 \\
\hline XIN & 3,7 & 3,7 & 3,7 & 3,7 & 3,7 & 3,7 & 3,7 & 3,7 & 3,7 & 3,7 & 3,7 & 3,7 \\
\hline
\end{tabular}


Para se chegar aos valores de consumo outorgado do cenário $\mathrm{VI}$, foram utilizadas as informações relativas às outorgas de uso da água concedidas na bacia do São Francisco até outubro/2009, levantadas pelo Grupo de Estudos de Relações Intersetoriais (GERI) e agregadas por Unidade da Federação (UFBA, 2010).

Neste trabalho, mais importante que a distribuição das outorgas por Unidade da Federação é a sua distribuição pela área de contribuição dos reservatórios. Por meio das coordenadas geográficas dos pontos de captação e de lançamento informadas pelos usuários, cada outorga de captação e de lançamento foi classificada como pertencendo à área de contribuição incremental de algum dos reservatórios considerados nesta pesquisa. Distribuídos todos os pontos de captação e de lançamento para cada reservatório, o consumo outorgado foi calculado como a diferença entre os valores outorgados de vazão captada e de vazão de lançamento, não sendo considerados, portanto, os coeficientes de retorno típicos de cada uso da água.

Nos seis cenários considerados, a demanda hídrica associada a cada usina é representada por um conjunto de 12 valores referentes a cada mês do ano. A partir do $13^{\circ}$ mês da otimização, repetem-se os valores da série. O mesmo ocorre no $25^{\circ}$ mês e assim sucessivamente até o mês final da otimização.

Com relação à sazonalidade das demandas consuntivas, foi obedecida nos cenários I a V a variação mensal dos valores divulgados pelo ONS. No cenário VI, seguiu-se a sazonalidade dos valores outorgados para captação e lançamento.

\subsubsection{Vazão afluente e perdas por evaporação}

O modelo HIDRO foi aplicado para dois cenários de vazão afluente. Trata-se de dois períodos de 7 anos marcados por escassez hídrica na bacia do rio São Francisco, conforme discutido no Capítulo 5 item 5.4:

- Período 1998-2004, que se mostra como o de maior escassez de afluência na bacia em todo o histórico;

- Período 1950-1956, que se mostra como o segundo de escassez mais severa, coincide com o período crítico adotado pelo setor elétrico para todo o País. 
O horizonte da otimização, portanto, foi de 84 meses, com início no mês de abril, marcado pelo fim da estação chuvosa na porção mais úmida da bacia.

Uma vez que as principais usinas hidrelétricas da bacia do rio São Francisco localizam-se no Nordeste Semiárido, onde as perdas por evaporação são relevantes, foi considerado no balanço hídrico dos reservatórios o saldo entre precipitação e evaporação adotado pelo ONS e mostrado no Capítulo 5 item 5.3.1.

\subsubsection{Restrições operativas}

No mês inicial da otimização, os reservatórios de regularização apresentaram volume armazenado igual a $100 \%$ do volume útil menos o volume de espera para controle de cheias no mês. A mesma restrição foi imposta para o volume armazenado no último mês da otimização. Sendo abril e março, respectivamente, os meses de início e de fim da otimização, o volume final exigido em cada reservatório seguiu os valores mostrados na Tabela 6.3.

\begin{tabular}{cc}
\multicolumn{2}{c}{ Tabela 6.3 - Volume final dos reservatório } \\
\hline Reservatório & Volume final $\left(\mathbf{h m}^{3}\right)$ \\
\hline RBA & 241,59 \\
TMA & $18.837,43$ \\
QUE & 485,84 \\
SOB & $27.751,48$ \\
ITP & $9.071,86$ \\
PAM & $1.226,00$ \\
XIN & $3.800,00$ \\
\hline
\end{tabular}

As restrições de vazão defluente mínima de cada reservatório seguiram os valores do ONS discutidos no Capítulo 5 item 5.3.3. Um caso particular é o reservatório de Três Marias, que apresenta duas restrições de vazão defluente mínima pelo ONS. A defluência mínima que garante o abastecimento da população a jusante é de $300 \mathrm{~m}^{3} / \mathrm{s}$. Para garantir as condições de navegação, a defluência mínima deve ser de $500 \mathrm{~m}^{3} / \mathrm{s}$. Também foi considerado o valor intermediário de $400 \mathrm{~m}^{3} / \mathrm{s}$, necessário à manutenção do ecossistema aquático, conforme apresentado no item 5.3.5. 
Assim, definiram-se três conjuntos de restrições operativas, denominados TMA300, TMA400 e TMA500, que foram aplicados aos reservatórios e cujos valores são mostrados na Tabela 6.4 .

Tabela 6.4 - Restrições de defluência mínima dos reservatórios

\begin{tabular}{cccccccc}
\hline \multirow{2}{*}{ Configuração } & \multicolumn{7}{c}{ Vazão defluente mínima $\left(\mathbf{m}^{\mathbf{3}} / \mathbf{s}\right)$} \\
\cline { 2 - 8 } & RBA & TMA & QUE & SOB & ITP & PAM & XIN \\
\hline TMA300 & 27,67 & 300 & 8,8 & 1300 & 1300 & 1300 & 1300 \\
TMA400 & 27,67 & 400 & 8,8 & 1300 & 1300 & 1300 & 1300 \\
TMA500 & 27,67 & 500 & 8,8 & 1300 & 1300 & 1300 & 1300 \\
\hline
\end{tabular}

Foi imposto um limite mínimo para a vazão fornecida aos usos consuntivos como forma de garantir o atendimento dos usos prioritários em caso de indisponibilidade hídrica. Tal limite mínimo foi considerado como um percentual da demanda hídrica total em cada trecho. Conforme discutido no Capítulo 5, os usos prioritários representam percentuais diferentes do consumo total de acordo com a referência utilizada, ONS ou CNARH. Para os cenários I a V, foram considerados os percentuais segundo o ONS e, para o cenário $\mathrm{VI}$, foram considerados os percentuais segundo o $\mathrm{CNARH}$, conforme apresentado na Tabela 6.5 .

Tabela 6.5 - Representatividade dos usos prioritários em relação à demanda hídrica

\begin{tabular}{crr}
\hline Reservatório & Cenários I a V & Cenário VI \\
\hline RBA & $59,1 \%$ & $11,0 \%$ \\
TMA & $43,3 \%$ & $11,0 \%$ \\
QUE & $8,9 \%$ & $1,2 \%$ \\
SOB & $12,0 \%$ & $9,1 \%$ \\
ITP & $3,3 \%$ & $5,6 \%$ \\
PAM & $3,3 \%$ & $4,6 \%$ \\
XIN & $45,9 \%$ & $5,3 \%$ \\
\hline
\end{tabular}

Finalmente, incluem-se entre as restrições as regras de operação da transposição do rio São Francisco para o Nordeste Setentrional. Foram considerados para a vazão de transposição o valor mínimo de $26,4 \mathrm{~m}^{3} / \mathrm{s}$ e o valor máximo de $114,3 \mathrm{~m}^{3} / \mathrm{s}$, o qual pode ser praticado se houver vertimento no reservatório de Sobradinho, conforme apresentado no Capítulo 5 item 5.2.3. Para fins de comparação, também foi feita a otimização para a situação em que não há transposição, ou seja, quando a vazão transposta é igual a zero.

Na sequência, apresentam-se os resultados obtidos na aplicação do modelo. 


\subsection{Análise dos resultados}

Neste item são apresentados os resultados obtidos na aplicação do modelo HIDRO que dão embasamento às seguintes análises:

- Análise dos índices de atendimento por trecho da bacia em períodos de escassez;

- Avaliação das relações de troca - trade-offs - entre geração de energia, usos consuntivos e conservação ambiental;

- Análise de sensibilidade do atendimento das demandas hídrica e de energia quanto à variação dos coeficientes ponderadores $\omega \mathrm{e} \psi$;

- Avaliação da geração de energia para diferentes períodos de afluências ordenados pela curva de permanência de ENA.

\subsubsection{Análise dos índices de atendimento}

Para avaliar os índices de atendimento obtidos em períodos de escassez, procedeu-se à aplicação do modelo HIDRO com prioridades iguais atribuídas tanto à geração de energia como ao atendimento dos usos consuntivos. Dessa forma, os coeficientes ponderadores da função objetivo foram assumidos como $\omega=\psi=0,5$.

No atendimento das demandas hídricas, foi considerado que houve falha no mês em que a vazão destinada aos usos consuntivos, em qualquer reservatório da bacia, foi menor que $95 \%$ da demanda naquele reservatório naquele mês, ou seja, no mês em que o deficit hídrico em um reservatório representar mais que $5 \%$ da demanda consuntiva naquele reservatório.

No atendimento da demanda energética, foi considerado que houve falha no mês em que a geração em toda a bacia foi menor que $95 \%$ da demanda de energia, ou seja, no mês em que o deficit de energia representou mais que $5 \%$ da demanda.

- Resultados do período abril/1998-març/2005 
Os resultados obtidos com as afluências de abr/1998-mar/2005 para os seis cenários de demanda hídrica, com e sem transposição, são resumidos nas Tabelas

6.6, 6.7 e 6.8, respectivamente, para as restrições TMA300, TMA400 e TMA500.

Tabela 6.6 - Resultados do período abr/1998-mar/2005 sob restrição TMA300

\begin{tabular}{|c|c|c|c|c|c|c|c|c|c|c|c|c|}
\hline \multirow{2}{*}{\multicolumn{2}{|c|}{$\begin{array}{r}\text { Cenário de demanda hídrica } \\
\text { Transposição }\end{array}$}} & \multicolumn{2}{|c|}{ (I) $1 \mathrm{xUC}_{\text {ONS }}$} & \multicolumn{2}{|c|}{ (II) $1,5 \times$ UC $_{\text {ONS }}$} & \multicolumn{2}{|c|}{ (III) $2 \times \mathrm{XC}_{\mathrm{ONS}}$} & \multicolumn{2}{|c|}{ (IV) $2,5 \times$ UC $_{\text {ONS }}$} & \multicolumn{2}{|c|}{ (V) $3 \times \mathrm{XC}_{\text {oNs }}$} & (VI) Outorga \\
\hline & & Ativa & Inativa & Ativa & Inativa & Ativa & Inativa & Ativa & Inativa & Ativa & Inativa & Ativa Inativa \\
\hline \multicolumn{2}{|c|}{ Função objetivo } & 1,30 & 1,14 & 1,71 & 1,53 & 2,17 & 1,97 & 2,69 & 2,47 & 3,27 & 3,02 & 7,92 \\
\hline \multirow[t]{2}{*}{$\begin{array}{l}\text { Demanda } \\
\text { Hídrica }\end{array}$} & $\begin{array}{l}\text { Volume }\left(\mathrm{hm}^{3}\right) \\
\text { Vazão }\left(\mathrm{m}^{3} / \mathrm{s}\right)\end{array}$ & \multicolumn{2}{|c|}{26.737} & \multicolumn{2}{|c|}{40.095} & \multicolumn{2}{|c|}{53.463} & \multicolumn{2}{|c|}{66.838} & \multicolumn{2}{|c|}{80.187} & 617,7 \\
\hline & Volume $\left(\mathrm{hm}^{3}\right)$ & 81 & 76 & 209 & 197 & 419 & 399 & 728 & 697 & 1.154 & 1.108 & 21.47615 .967 \\
\hline \multirow{2}{*}{$\begin{array}{l}\text { Deficit } \\
\text { Hídrico }\end{array}$} & Vazão & 0,4 & 0,3 & 0,9 & 0,9 & 1,9 & 1,8 & 3,3 & 3,2 & 5,2 & 5,0 & 97,2 \\
\hline & $\begin{array}{l}\text { Deficit / Demanda } \\
\text { Índice de falhas }\end{array}$ & $\begin{array}{r}0,3 \% \\
0 \%\end{array}$ & $\begin{array}{r}0,3 \% \\
0 \%\end{array}$ & $\begin{array}{r}0,5 \% \\
0 \%\end{array}$ & $\begin{array}{r}0,5 \% \\
0 \%\end{array}$ & $\begin{array}{r}0,8 \% \\
0 \%\end{array}$ & $\begin{array}{r}0,7 \% \\
0 \%\end{array}$ & $\begin{array}{r}1,1 \% \\
0 \%\end{array}$ & $\begin{array}{r}1,0 \% \\
0 \%\end{array}$ & $\begin{array}{r}1,4 \% \\
0 \%\end{array}$ & $\begin{array}{r}1,4 \% \\
0 \%\end{array}$ & \begin{tabular}{|rr}
$15,7 \%$ & $11,7 \%$ \\
$100 \%$ & $100 \%$
\end{tabular} \\
\hline \multicolumn{2}{|c|}{ Transposição média $\left(\mathrm{m}^{3} / \mathrm{s}\right)$} & 26,4 & 0 & 26,4 & 0 & 26,4 & 0 & 26,4 & 0 & 26,4 & 0 & 26,4 \\
\hline & Demanda(MWmed) & \multicolumn{2}{|c|}{6.190} & \multicolumn{2}{|c|}{6.190} & \multicolumn{2}{|c|}{6.190} & \multicolumn{2}{|c|}{6.190} & \multicolumn{2}{|c|}{6.190} & 6.190 \\
\hline $\begin{array}{l}\text { Atendimento } \\
\text { Energético }\end{array}$ & $\begin{array}{l}\text { Deficit (MW) } \\
\text { Deficit / Demanda } \\
\text { Índice de falhas }\end{array}$ & $\begin{array}{r}1.078 \\
17,4 \% \\
100 \%\end{array}$ & $\begin{array}{r}1.011 \\
16,3 \% \\
100 \%\end{array}$ & $\begin{array}{r}1.237 \\
20,0 \% \\
100 \%\end{array}$ & $\begin{array}{r}1.170 \\
18,9 \% \\
100 \%\end{array}$ & $\begin{array}{r}1.395 \\
22,5 \% \\
100 \%\end{array}$ & $\begin{array}{r}1.328 \\
21,5 \% \\
100 \%\end{array}$ & $\begin{array}{r}1.552 \\
25,1 \% \\
100 \%\end{array}$ & $\begin{array}{r}1.485 \\
24,0 \% \\
100 \%\end{array}$ & $\begin{array}{r}1.708 \\
27,6 \% \\
100 \%\end{array}$ & $\begin{array}{r}1.641 \\
26,5 \% \\
100 \%\end{array}$ & \begin{tabular}{|rr}
2.212 & 2.212 \\
$35,7 \%$ & $35,7 \%$ \\
$100 \%$ & $100 \%$
\end{tabular} \\
\hline
\end{tabular}

Tabela 6.7 - Resultados do período abr/1998-mar/2005 sob restrição TMA400

\begin{tabular}{|c|c|c|c|c|c|c|c|c|c|c|c|c|c|}
\hline \multicolumn{2}{|c|}{$\begin{array}{r}\text { Cenário de demanda hídrica } \\
\text { Transposição }\end{array}$} & \multicolumn{2}{|c|}{$\begin{array}{l}\text { (I) } 1 \times U C_{\text {ONS }} \\
\text { Ativa Inativa }\end{array}$} & \multicolumn{2}{|c|}{$\begin{array}{l}\text { (II) } 1,5 \times \text { UCCons } \\
\text { Ativa Inativa }\end{array}$} & \multicolumn{2}{|c|}{$\begin{array}{l}\text { (III) } 2 \times \text { CC }_{\text {ons }} \\
\text { Ativa Inativa }\end{array}$} & \multicolumn{2}{|c|}{$\begin{array}{l}\text { (IV) } 2,5 \times \text { UC }_{\text {ons }} \\
\text { Ativa Inativa }\end{array}$} & \multicolumn{2}{|c|}{$\begin{array}{l}\text { (V) } 3 \times \mathrm{XC}_{\text {ons }} \\
\text { Ativa Inativa }\end{array}$} & \multicolumn{2}{|c|}{$\begin{array}{l}\text { (VI) Outorga } \\
\text { Ativa Inative }\end{array}$} \\
\hline \multicolumn{2}{|c|}{ Função objetivo } & 1,30 & 1,14 & 1,71 & 1,53 & 2,17 & 1,97 & 2,69 & 2,47 & 3,27 & 3,02 & 8,10 & 6,98 \\
\hline \multirow[t]{2}{*}{$\begin{array}{l}\text { Demanda } \\
\text { Hídrica }\end{array}$} & $\begin{array}{l}\text { Volume }\left(\mathrm{hm}^{3}\right) \\
\text { Vazão }\left(\mathrm{m}^{3} / \mathrm{s}\right)\end{array}$ & \multicolumn{2}{|c|}{$\begin{array}{r}26.737 \\
121,0\end{array}$} & \multicolumn{2}{|c|}{$\begin{array}{c}40.095 \\
181,5\end{array}$} & \multicolumn{2}{|c|}{$\begin{array}{c}53.463 \\
242,0\end{array}$} & \multicolumn{2}{|c|}{$\begin{array}{c}66.838 \\
302,5\end{array}$} & \multicolumn{2}{|c|}{$\begin{array}{c}80.187 \\
363,0\end{array}$} & \multicolumn{2}{|c|}{$\begin{array}{c}136.456 \\
617,7\end{array}$} \\
\hline & Volume $\left(\mathrm{hm}^{3}\right)$ & 81 & 76 & 209 & 198 & 419 & 399 & 729 & 697 & 1.155 & 1.109 & 22.646 & 17.17 \\
\hline \multirow{3}{*}{$\begin{array}{l}\text { Deficit } \\
\text { Hídrico }\end{array}$} & Vaz & 0,4 & 0,3 & 0,9 & 0,9 & 1,8 & 1,7 & 3,3 & 3,2 & 5,2 & 5,0 & 102,5 & 77 , \\
\hline & Defi & $0,3 \%$ & $0,3 \%$ & $0,5 \%$ & $0,5 \%$ & $0,8 \%$ & $0,7 \%$ & $1,1 \%$ & $1,0 \%$ & $1,4 \%$ & $1,4 \%$ & $16,6 \%$ & $12,6^{\circ}$ \\
\hline & Índice & $0 \%$ & $0 \%$ & $0 \%$ & $0 \%$ & $0 \%$ & $0 \%$ & $0 \%$ & $0 \%$ & $0 \%$ & $0 \%$ & $100 \%$ & $100 \%$ \\
\hline \multicolumn{2}{|c|}{ Transposição média $\left(\mathrm{m}^{3} / \mathrm{s}\right)$} & 26,4 & 0 & 26,4 & 0 & 26,4 & 0 & 26,4 & 0 & 26,4 & 0 & 26,4 & \\
\hline \multirow{4}{*}{$\begin{array}{l}\text { Atendimento } \\
\text { Energético }\end{array}$} & Demand & \multicolumn{2}{|c|}{6.190} & \multicolumn{2}{|c|}{6.190} & \multicolumn{2}{|c|}{6.190} & \multicolumn{2}{|c|}{6.190} & \multicolumn{2}{|c|}{6.190} & \multicolumn{2}{|c|}{6.190} \\
\hline & Deficit (MW) & 1.078 & 1.011 & 1.237 & 1.170 & 1.395 & 1.329 & 1.553 & 1.486 & 1.708 & 1.641 & 2.190 & 2.19 \\
\hline & Deficit / Dem & $17,4 \%$ & $16,3 \%$ & $20,0 \%$ & $18,9 \%$ & $22,5 \%$ & $21,5 \%$ & $25,1 \%$ & $24,0 \%$ & $27,6 \%$ & $26,5 \%$ & $35,4 \%$ & $35,4 \%$ \\
\hline & Índice d & $100 \%$ & $100 \%$ & $100 \%$ & $100 \%$ & $100 \%$ & $100 \%$ & $100 \%$ & $100 \%$ & $100 \%$ & $100 \%$ & $100 \%$ & 100 \\
\hline
\end{tabular}

Tabela 6.8 - Resultados do período abr/1998-mar/2005 sob restrição TMA500

\begin{tabular}{|c|c|c|c|c|c|c|c|c|c|c|c|c|}
\hline \multirow{2}{*}{\multicolumn{2}{|c|}{$\begin{array}{r}\text { Cenário de demanda hídrica } \\
\text { Transposição }\end{array}$}} & \multirow{2}{*}{\multicolumn{2}{|c|}{$\begin{array}{l}\text { (I) } 1 \times \mathrm{xUC}_{\mathrm{ONS}} \\
\text { Ativa Inativa }\end{array}$}} & \multirow{2}{*}{\multicolumn{2}{|c|}{$\begin{array}{l}\text { (II) } 1,5 \times \mathrm{XC}_{\text {ons }} \\
\text { Ativa Inativa } \\
\end{array}$}} & \multirow{2}{*}{\multicolumn{2}{|c|}{$\begin{array}{l}\text { (III) } 2 \times \text { UCONS }_{\text {ons }} \\
\text { Ativa Inativa }\end{array}$}} & \multicolumn{2}{|c|}{ (IV) $2,5 x U C_{\text {ons }}$} & \multicolumn{2}{|c|}{ (V) $3 \times U_{\text {ons }}$} & (VI) Outorga \\
\hline & & & & & & & & Ativa & Inativa & Ativa & Inativa & Ativa Inativa \\
\hline \multicolumn{2}{|c|}{ Função objetivo } & 1,33 & 1,17 & 1,75 & 1,57 & 2,22 & 2,01 & 2,75 & 2,52 & 3,33 & 3,08 & 9,10 \\
\hline \multirow{3}{*}{$\begin{array}{l}\text { Demanda } \\
\text { Hídrica }\end{array}$} & Volume $\left(\mathrm{hm}^{3}\right)$ & \multirow{2}{*}{\multicolumn{2}{|c|}{$\begin{array}{r}26.737 \\
121,0\end{array}$}} & \multirow{2}{*}{\multicolumn{2}{|c|}{$\begin{array}{c}40.095 \\
181,5\end{array}$}} & \multirow{2}{*}{\multicolumn{2}{|c|}{$\begin{array}{l}53.463 \\
242,0\end{array}$}} & \multirow{2}{*}{\multicolumn{2}{|c|}{$\begin{array}{c}66.838 \\
302,5\end{array}$}} & \multirow{2}{*}{\multicolumn{2}{|c|}{$\begin{array}{c}80.187 \\
363,0\end{array}$}} & \multirow{2}{*}{$\begin{array}{c}136.456 \\
617,7\end{array}$} \\
\hline & Vazão $\left(\mathrm{m}^{3} / \mathrm{s}\right)$ & & & & & & & & & & & \\
\hline & Volume $\left(\mathrm{hm}^{3}\right)$ & 81 & 76 & 210 & 199 & 422 & 402 & 734 & 703 & 1.162 & 1.117 & 26.12420 .926 \\
\hline \multirow{3}{*}{$\begin{array}{l}\text { Deficit } \\
\text { Hídrico }\end{array}$} & Vazão $\left(\mathrm{m}^{3} / \mathrm{s}\right)$ & 0,4 & 0,3 & 1,0 & 0,9 & 1,9 & 1,8 & 3,3 & 3,2 & 5,3 & 5,1 & 118,2 \\
\hline & Deficit / Demanda & $0,3 \%$ & $0,3 \%$ & $0,5 \%$ & $0,5 \%$ & $0,8 \%$ & $0,8 \%$ & $1,1 \%$ & $1,1 \%$ & $1,4 \%$ & $1,4 \%$ & $19,1 \% \quad 15,3 \%$ \\
\hline & Índice de fa & $0 \%$ & $0 \%$ & $0 \%$ & $0 \%$ & $0 \%$ & $0 \%$ & $0 \%$ & $0 \%$ & $0 \%$ & $0 \%$ & $98,8 \% 98,8 \%$ \\
\hline \multicolumn{2}{|c|}{ Transposição média $\left(\mathrm{m}^{3} / \mathrm{s}\right)$} & 26,4 & & 26,4 & 0 & 26,4 & 0 & 26,4 & 0 & 26,4 & 0 & 26,4 \\
\hline \multirow{4}{*}{$\begin{array}{l}\text { Atendimento } \\
\text { Energético }\end{array}$} & Demanda(MWmed) & \multicolumn{2}{|c|}{6.190} & \multicolumn{2}{|c|}{6.190} & \multicolumn{2}{|c|}{6.190} & \multicolumn{2}{|c|}{6.190} & \multicolumn{2}{|c|}{6.190} & 6.190 \\
\hline & Deficit (MWméd) & 1.087 & 1.020 & 1.245 & 1.179 & 1.405 & 1.338 & 1.562 & 1.496 & 1.719 & 1.652 & $2.161 \quad 2.163$ \\
\hline & Deficit / Demanda & $17,6 \%$ & $16,5 \%$ & $20,1 \%$ & $19,0 \%$ & $22,7 \%$ & $21,6 \%$ & $25,2 \%$ & $24,2 \%$ & $27,8 \%$ & $26,7 \%$ & $34,9 \% \quad 35,0 \%$ \\
\hline & Índice de falhas & $98,8 \%$ & $98,8 \%$ & $100 \%$ & $100 \%$ & $100 \%$ & $100 \%$ & $100 \%$ & $100 \%$ & $100 \%$ & $100 \%$ & $100 \% \quad 100 \%$ \\
\hline
\end{tabular}


Nas soluções obtidas para todos os cenários de demanda hídrica, foram respeitados os limites mínimos de vazão a jusante dos aproveitamentos hidrelétricos. Com relação à transposição do São Francisco, a vazão transposta permaneceu igual ao valor mínimo de $26,4 \mathrm{~m}^{3} / \mathrm{s}$ em todos os cenários, uma vez que não houve vertimentos em Sobradinho.

Os resultados demonstram que as baixas afluências do período de abril/1998março/2005 deixaram a energia média gerada abaixo de $90 \%$ da garantia física em, pelo menos, 98,8\% do tempo. No cenário I, o deficit de energia médio para as três restrições de defluência foi de $17,5 \%$ da demanda na situação com transposição e de $16,4 \%$ da demanda quando não houve transposição. À medida que a demanda consuntiva aumentou, diminuiu a energia média gerada, o que fez o deficit de energia atingir, em termos médios, 35,3\% da demanda no cenário $\mathrm{VI}$ tanto para a transposição ativa como inativa.

O índice de falhas no atendimento dos usos consuntivos mostrou-se baixo em quase todos os cenários de demanda hídrica, exceto para o cenário $\mathrm{VI}$, no qual a vazão média fornecida ficou abaixo de $95 \%$ da demanda em $98 \%$ do tempo.

O deficit no atendimento das demandas consuntivas foi muito baixo nos cenários I a V, variando de $0,3 \%$ a 1,4\% da demanda. No cenário VI, o deficit hídrico variou de $11,7 \%$ a $15,3 \%$ da demanda no caso em que não houve transposição, e de $15,7 \%$ a $19,1 \%$ da demanda na situação em que houve transposição. Esses percentuais referem-se ao deficit hídrico em toda a bacia.

É possível proceder a uma análise mais detalhada do atendimento das demandas consuntivas se o percentual de deficit e o índice de falhas forem observados por reservatório. Os resultados são apresentados na Tabela 6.9.

A região da bacia em que o deficit hídrico foi mais significativo é a área de contribuição incremental do reservatório de Sobradinho, na qual o deficit em relação à demanda, em termos médios, foi de 24,7\% com a transposição ativa e de $19 \%$ sem transposição. Como os usos prioritários representam apenas 9,1\% da demanda consuntiva deste trecho, pode-se afirmar que as demandas não prioritárias tiveram um deficit no atendimento de 15,6\% com transposição e de 9,9\% sem transposição. 
Tabela 6.9 - Percentual de deficit e de falhas no atendimento de uso consuntivo no Cenário VI

\begin{tabular}{|c|c|c|c|c|c|c|c|}
\hline & \multirow{2}{*}{ Reservatório } & \multicolumn{3}{|c|}{ Transposição ativa } & \multicolumn{3}{|c|}{ Transposição inativa } \\
\hline & & TMA300 & TMA400 & TMA500 & TMA300 & TMA400 & TMA500 \\
\hline \multirow{7}{*}{ Deficit / Demanda } & RBA & $1,53 \%$ & $1,53 \%$ & $1,53 \%$ & $1,53 \%$ & $1,53 \%$ & $1,53 \%$ \\
\hline & TMA & $0 \%$ & $0 \%$ & $0 \%$ & $0 \%$ & $0 \%$ & $0 \%$ \\
\hline & QUE & $0 \%$ & $0 \%$ & $0 \%$ & $0 \%$ & $0 \%$ & $0 \%$ \\
\hline & SOB & $22,70 \%$ & $23,94 \%$ & $27,62 \%$ & $16,86 \%$ & $18,14 \%$ & $22,12 \%$ \\
\hline & ITP & $0 \%$ & $0 \%$ & $0 \%$ & $0 \%$ & $0 \%$ & $0 \%$ \\
\hline & PAM & $0 \%$ & $0 \%$ & $0 \%$ & $0 \%$ & $0 \%$ & $0 \%$ \\
\hline & XIN & $0 \%$ & $0 \%$ & $0 \%$ & $0 \%$ & $0 \%$ & $0 \%$ \\
\hline \multirow{7}{*}{ Índice de falhas } & RBA & $5,95 \%$ & $5,95 \%$ & $5,95 \%$ & $5,95 \%$ & $5,95 \%$ & $5,95 \%$ \\
\hline & TMA & $0 \%$ & $0 \%$ & $0 \%$ & $0 \%$ & $0 \%$ & $0 \%$ \\
\hline & QUE & $0 \%$ & $0 \%$ & $0 \%$ & $0 \%$ & $0 \%$ & $0 \%$ \\
\hline & SOB & $96,43 \%$ & $96,43 \%$ & $95,24 \%$ & $94,05 \%$ & $94,05 \%$ & $94,05 \%$ \\
\hline & ITP & $0 \%$ & $0 \%$ & $0 \%$ & $0 \%$ & $0 \%$ & $0 \%$ \\
\hline & PAM & $0 \%$ & $0 \%$ & $0 \%$ & $0 \%$ & $0 \%$ & $0 \%$ \\
\hline & XIN & $0 \%$ & $0 \%$ & $0 \%$ & $0 \%$ & $0 \%$ & $0 \%$ \\
\hline
\end{tabular}

A demanda consuntiva outorgada na área de contribuição incremental de Sobradinho totaliza $427,3 \mathrm{~m}^{3} / \mathrm{s}$, o que representa $69,2 \%$ da demanda consuntiva outorgada em toda a bacia do São Francisco. Aliadas a uma demanda tão expressiva, têm-se a baixa afluência ao reservatório - que, no período, foi igual a $70,2 \% \mathrm{MLT}$, a alta taxa de evaporação da região e a restrição de defluência mínima de $1.300 \mathrm{~m}^{3} / \mathrm{s}$ a jusante de Sobradinho como fatores que interferem no balanço hídrico do reservatório de forma a diminuir a retirada média para uso consuntivo.

Com relação aos impactos da transposição do rio São Francisco, nota-se que sua operação afetou o atendimento das demandas consuntivas de Sobradinho por acarretar uma perda média de $23,8 \mathrm{~m}^{3} / \mathrm{s}$ na vazão fornecida a uso consuntivo, o que equivale a $5,7 \%$ da demanda consuntiva do trecho.

Se por um lado a operação da transposição acarretou impacto em termos quantitativos no atendimento do uso consuntivo em Sobradinho, ela não afetou o percentual de meses em que ocorre falha no atendimento hídrico. Houve falha no suprimento de água em $96 \%$ dos meses no caso da transposição ativa e em $94 \%$ dos meses no caso da transposição inativa.

Ainda com referência aos resultados obtidos para o cenário $\mathrm{VI}$, observou-se que o aumento da vazão defluente mínima de Três Marias acarretou impacto no atendimento das demandas consuntivas. Uma avaliação açodada tenderia a associar o aumento da defluência mínima de Três Marias a uma queda no deficit hídrico em Sobradinho. Todavia os resultados apontam para uma situação contrária. Com a transposição inativa, o aumento de $200 \mathrm{~m}^{3} / \mathrm{s}$ na defluência mínima de Três 
Marias levou à redução de $22,5 \mathrm{~m}^{3} / \mathrm{s}$ na retirada média para uso consuntivo. Com a transposição ativa, essa redução foi de $21,0 \mathrm{~m}^{3} / \mathrm{s}$. Ambas as reduções equivalem a cerca de $5 \%$ da demanda. Embora seja um impacto pequeno, é interessante analisar as razões de sua ocorrência.

Como a função objetivo trabalha com dois atendimentos - de água e de energia - espera-se, que tenha havido uma queda no deficit energético com o aumento da defluência mínima. De fato, houve um aumento da energia gerada em Sobradinho, que variou de $309 \mathrm{MWmed}$ na condição TMA300 para 327,4 MWmed na condição TMA500, considerando a transposição ativa. Esse ganho de $18,4 \mathrm{MWmed}$ equivale a $3,5 \%$ da energia assegurada de Sobradinho. No entanto, não foram registradas alterações significativas na vazão turbinada média em Sobradinho, a qual variou de 1462 em TMA300 a 1465 m³ $/ \mathrm{s}$ em TMA500.

Nota-se, assim, que o aumento de defluência de Três Marias foi aproveitado para aumentar o nível do reservatório de Sobradinho - o armazenamento médio subiu de $14.081 \mathrm{hm}^{3}$ em TMA300 para $16.714 \mathrm{hm}^{3}$ em TMA500 - e, dessa forma, incrementar a geração em detrimento ao atendimento das demandas consuntivas.

$\mathrm{Na}$ situação em que a transposição ficou inativa ocorreu efeito semelhante. Nas situações com e sem transposição, gerar mais energia em Sobradinho mostrouse uma solução melhor do que aumentar atendimento hídrico. Ressalta-se que, nesta análise, a geração de energia e os usos consuntivos têm pesos iguais na função objetivo e que é exigido, ao final do período, um volume armazenado igual ao volume útil menos o volume de espera para controle de cheias, o que equivale, no $84^{\circ}$.mês da otimização, a $77,8 \%$ do volume útil do reservatório.

Os valores de energia gerada nos reservatórios, bem como a média do volume armazenado, a vazão turbinada média e a vazão média fornecida para uso consuntivo no cenário $\mathrm{VI}$ em cada reservatório, com e sem a operação da transposição, são apresentados na Tabela 6.10.

Os resultados obtidos em cada cenário de demanda hídrica sob as três restrições de defluência mínima, considerando a transposição ativa e inativa, são apresentados do Anexo $\mathrm{C}$ ao Anexo $\mathrm{H}$ deste trabalho. 
Tabela 6.10 - Vazão média fornecida a uso consuntivo (UC), vazão turbinada média (R'), energia média gerada $(\mathrm{E})$ e volume armazenado médio $(\mathrm{S})$ no cenário $\mathrm{VI}$

\begin{tabular}{|c|c|c|c|c|c|c|c|}
\hline & \multirow{2}{*}{ Reservatório } & \multicolumn{3}{|c|}{ Transposição ativa } & \multicolumn{3}{|c|}{ Transposição inativa } \\
\hline & & TMA300 & TMA400 & TMA500 & TMA300 & TMA400 & TMA500 \\
\hline \multirow{7}{*}{$\begin{array}{c}\text { UC } \\
\text { média } \\
\left(\mathrm{m}^{3} / \mathrm{s}\right)\end{array}$} & RBA & 13,1 & 13,1 & 13,1 & 13,1 & 13,1 & 13,1 \\
\hline & TMA & 38,3 & 38,3 & 38,3 & 38,3 & 38,3 & 38,3 \\
\hline & QUE & 1,4 & 1,4 & 1,4 & 1,4 & 1,4 & 1,4 \\
\hline & SOB & 330,4 & 325,1 & 309,3 & 355,3 & 349,8 & 332,8 \\
\hline & ITP & 131,9 & 131,9 & 131,9 & 131,9 & 131,9 & 131,9 \\
\hline & PAM & 5,1 & 5,1 & 5,1 & 5,1 & 5,1 & 5,1 \\
\hline & XIN & 0,3 & 0,3 & 0,3 & 0,3 & 0,3 & 0,3 \\
\hline \multirow{7}{*}{$\begin{array}{c}\text { R' média } \\
\left(\mathrm{m}^{3} / \mathrm{s}\right)\end{array}$} & RBA & 78,2 & 78,3 & 78,1 & 78,2 & 78,2 & 78,3 \\
\hline & TMA & 409,1 & 454,7 & 503,7 & 419,5 & 459,3 & 503,7 \\
\hline & QUE & 34,1 & 34,1 & 32,4 & 34,1 & 34,1 & 33,1 \\
\hline & SOB & $1.461,8$ & $1.461,8$ & $1.464,7$ & $1.435,2$ & $1.435,2$ & $1.438,4$ \\
\hline & ITP & $1.319,2$ & $1.319,2$ & $1.321,5$ & $1.319,2$ & $1.319,2$ & $1.321,8$ \\
\hline & PAM & $1.309,3$ & $1.309,3$ & $1.311,6$ & $1.309,3$ & $1.309,3$ & $1.311,9$ \\
\hline & XIN & $1.306,2$ & $1.306,2$ & $1.308,5$ & $1.306,2$ & $1.306,2$ & $1.308,8$ \\
\hline \multirow{7}{*}{$\begin{array}{c}E \\
\text { (MWmed) }\end{array}$} & RBA & 25,4 & 25,4 & 25,4 & 25,4 & 25,4 & 25,4 \\
\hline & TMA & 181,9 & 199,4 & 208,4 & 186,9 & 201,8 & 208,4 \\
\hline & QUE & 56,1 & 56,1 & 53,9 & 56,1 & 56,1 & 54,9 \\
\hline & SOB & 309,0 & 313,7 & 327,4 & 304,9 & 309,7 & 324,1 \\
\hline & ITP & 603,2 & 603,1 & 606,5 & 602,5 & 602,4 & 605,9 \\
\hline & PAM & $1.342,7$ & $1.342,7$ & $1.345,0$ & $1.342,7$ & $1.342,7$ & $1.345,3$ \\
\hline & XIN & $1.459,3$ & $1.459,3$ & $1.461,8$ & $1.459,3$ & $1.459,3$ & $1.462,2$ \\
\hline \multirow{5}{*}{$\begin{array}{c}\text { S médio } \\
\left(\mathrm{hm}^{3}\right)\end{array}$} & RBA & 223,43 & 224,84 & 224,15 & 224,51 & 224,32 & 223,12 \\
\hline & TMA & $15.692,70$ & $14.885,04$ & $12.369,69$ & $15.722,39$ & $14.932,11$ & $12.370,48$ \\
\hline & QUE & 366,16 & 367,74 & 436,57 & 370,78 & 377,22 & 428,43 \\
\hline & SOB & $14.080,67$ & $14.787,10$ & $16.714,11$ & $14.263,35$ & $15.010,58$ & $17.092,60$ \\
\hline & ITP & $9.790,83$ & $9.782,57$ & $9.927,85$ & $9.742,42$ & $9.736,30$ & $9.879,21$ \\
\hline
\end{tabular}

- Resultados do período abril/1950-marco/1957

Em todos os cenários de demanda hídrica foram respeitados os limites mínimos de vazão a jusante dos aproveitamentos hidrelétricos nas condições TMA300 e TMA400. Contudo não foi encontrada solução viável para a condição TMA500. O valor mais próximo de $500 \mathrm{~m}^{3} / \mathrm{s}$ para defluência mínima de Três Marias para o qual se encontrou uma solução possível foi $437,5 \mathrm{~m} / \mathrm{s}$, obtido por processo de tentativa e erro. Assim, para este período de afluências, a condição TMA500 passa a ser designada TMA437.

Embora o período de 1950-1957 apresente afluência média superior à do período 1998-2005 no exutório da bacia, mostra-se coerente com a realidade o fato de o modelo não ter encontrado solução viável quando foi imposta a restrição de vazão defluente mínima de Três Marias igual a $500 \mathrm{~m}^{3} / \mathrm{s}$. A área de contribuição do reservatório de Três Marias insere-se na região Sudeste do Brasil, cujo período 
crítico de afluências vai de junho/1949 a novembro/1957. De fato, verifica-se que, para Três Marias, as vazões médias mensais do período 1954-1957 são menores que as do período 2002-2005. A afluência média nos respectivos períodos vale $488 \mathrm{~m}^{3} / \mathrm{s}$ e $687 \mathrm{~m}^{3} / \mathrm{s}$.

Com relação à transposição do São Francisco, a vazão transposta média reduz-se à medida que aumenta a demanda consuntiva. Os maiores valores de vazão transposta média foram obtidos no cenário $\mathrm{I}: 33,8 \mathrm{~m}^{3} / \mathrm{s}$ com a restrição TMA300; 30,7 m³ $/ \mathrm{s}$ com a restrição TMA400; $31,7 \mathrm{~m}^{3} / \mathrm{s}$ com a restrição TMA437. No cenário VI, para as três restrições de defluência de Três Marias, a vazão transposta média permaneceu igual ao valor mínimo de $26,4 \mathrm{~m}^{3} / \mathrm{s}$, uma vez que não houve vertimentos em Sobradinho neste cenário.

Os resultados obtidos com as afluências de abril/1950-março/1957 para os seis cenários de demanda hídrica, com e sem transposição, estão resumidos nas Tabelas 6.11, 6.12 e 6.13, respectivamente para as restrições TMA300, TMA400 e TMA437.

O período de abril/1950-março/1957 registrou índices mais altos de atendimento das demandas consuntivas e da demanda de energia do que o período de abril/1998-março/2005. O cenário VI, no qual o atendimento foi pior, chegou a registrar deficit hídrico de $4,4 \%$ da demanda e deficit de energia de $21 \%$ da demanda. Com relação ao índice de falhas, no cenário VI a vazão fornecida para uso consuntivo ficou abaixo de $95 \%$ da demanda em $60 \%$ do tempo, e a energia gerada ficou abaixo de $90 \%$ da demanda em $67 \%$ do tempo.

Tabela 6.11 - Resultados do período abr/1950-mar/1957 sob restrição TMA300

\begin{tabular}{|c|c|c|c|c|c|c|c|c|c|c|c|c|c|}
\hline \multirow{2}{*}{\multicolumn{2}{|c|}{$\begin{array}{r}\text { Cenário de demanda hídrica } \\
\text { Transposição }\end{array}$}} & \multicolumn{2}{|c|}{ (I) $1 \times \mathrm{xUC}_{\text {ons }}$} & \multicolumn{2}{|c|}{ (II) $1,5 \times$ UC $_{\text {ons }}$} & \multicolumn{2}{|c|}{ (III) $2 \times U_{\text {ONS }}$} & \multirow{2}{*}{\multicolumn{2}{|c|}{$\begin{array}{l}\text { (IV) } 2,5 \times \text { UC }_{\text {ons }} \\
\text { Ativa Inativa }\end{array}$}} & \multirow{2}{*}{\multicolumn{2}{|c|}{\begin{tabular}{|l|} 
(V) $3 \times$ UCONS $_{\text {ons }}$ \\
Ativa Inativa
\end{tabular}}} & \multirow{2}{*}{\multicolumn{2}{|c|}{$\begin{array}{l}\text { (VI) Outorga } \\
\text { Ativa Inativa }\end{array}$}} \\
\hline & & Ativa & Inativa & Ativa & Inativa & Ativa & Inativa & & & & & & \\
\hline \multicolumn{2}{|l|}{ Função objetivo } & 0,21 & 0,16 & 0,34 & 0,28 & 0,52 & 0,44 & 0,74 & 0,64 & 0,99 & 0,88 & 3,01 & 2,82 \\
\hline \multirow{2}{*}{ Demanda Hídrica } & Volume $\left(\mathrm{hm}^{3}\right)$ & \multicolumn{2}{|c|}{26.737} & \multicolumn{2}{|c|}{40.095} & \multicolumn{2}{|c|}{53.463} & \multicolumn{2}{|c|}{66.838} & \multicolumn{2}{|c|}{80.187} & \multicolumn{2}{|c|}{136.456} \\
\hline & Vazão (m3/s) & \multicolumn{2}{|c|}{121,0} & \multicolumn{2}{|c|}{181,5} & \multicolumn{2}{|c|}{242,0} & \multicolumn{2}{|c|}{302,5} & \multicolumn{2}{|c|}{363,0} & \multicolumn{2}{|c|}{617,7} \\
\hline \multirow{4}{*}{ Deficit Hídrico } & Volume $\left(\mathrm{hm}^{3}\right)$ & 25 & 20 & 75 & 67 & 168 & 154 & 316 & 294 & 533 & 501 & 3.437 & 3.286 \\
\hline & Vazão $\left(\mathrm{m}^{3} / \mathrm{s}\right)$ & 0,1 & 0,1 & 0,3 & 0,3 & 0,8 & 0,7 & 1,4 & 1,3 & 2,4 & 2,3 & 15,6 & 14,9 \\
\hline & Deficit / Demanda & $0,1 \%$ & $0,1 \%$ & $0,2 \%$ & $0,2 \%$ & $0,3 \%$ & $0,3 \%$ & $0,5 \%$ & $0,4 \%$ & $0,7 \%$ & $0,6 \%$ & $2,5 \%$ & $2,4 \%$ \\
\hline & Índice de f & $0 \%$ & $0 \%$ & $0 \%$ & $0 \%$ & $0 \%$ & $0 \%$ & $0 \%$ & $0 \%$ & $0 \%$ & $0 \%$ & $51,2 \%$ & $47,6 \%$ \\
\hline \multicolumn{2}{|c|}{ Transposição média $\left(\mathrm{m}^{3} / \mathbf{s}\right)$} & 33,8 & 0 & 32,7 & 0 & 32,8 & 0 & 30,6 & 0 & 29,5 & 0 & 26,4 & \\
\hline \multirow{4}{*}{$\begin{array}{l}\text { Atendimento } \\
\text { Energético }\end{array}$} & Demanda(MWmed) & \multicolumn{2}{|c|}{6.190} & \multicolumn{2}{|c|}{6.190} & \multicolumn{2}{|c|}{6.190} & \multicolumn{2}{|c|}{6.190} & \multicolumn{2}{|c|}{6.190} & \multicolumn{2}{|c|}{6.190} \\
\hline & Deficit(MWmed) & 348 & 318 & 449 & 420 & 554 & 519 & 662 & 627 & 776 & 735 & 1,327 & 1,268 \\
\hline & Deficit / Demanda & $5,6 \%$ & $5,1 \%$ & $7,3 \%$ & $6,8 \%$ & $9,0 \%$ & $8,4 \%$ & $10,7 \%$ & $10,1 \%$ & $12,5 \%$ & $11,9 \%$ & $21,4 \%$ & $20,5 \%$ \\
\hline & Índice de falhas & $54,8 \%$ & $54,8 \%$ & $61,9 \%$ & $59,5 \%$ & $65,5 \%$ & $65,5 \%$ & $65,5 \%$ & $65,5 \%$ & $65,5 \%$ & $65,5 \%$ & $91,7 \%$ & $86,9 \%$ \\
\hline
\end{tabular}


Tabela 6.12 - Resultados do período abr/1950-mar/1957 sob restrição TMA400

\begin{tabular}{|c|c|c|c|c|c|c|c|c|c|c|}
\hline \multicolumn{2}{|c|}{ Cenário de demanda hídrica } & (I) $1 \times \mathrm{xUC}_{\mathrm{ONS}}$ & (II) $1,5 \times \mathrm{XC}_{\text {oNs }}$ & \multicolumn{2}{|c|}{ (III) $2 \times U C_{\text {ONS }}$} & \multicolumn{2}{|c|}{ (IV) $2,5 x \mathrm{XC}_{\text {oNs }}$} & \multicolumn{2}{|c|}{ (V) $3 \times \mathrm{XC}_{\text {ons }}$} & (VI) Outorga \\
\hline & Transposição & Ativa Inativa A & Ativa Inativa $A$ & Ativa I & Inativa & Ativa & Inativa & Ativa & Inativa & Ativa Inativa \\
\hline \multicolumn{2}{|c|}{ Função objetivo } & $\begin{array}{ll}0,23 & 0,19\end{array}$ & \begin{tabular}{ll|}
0,38 & 0,32
\end{tabular} & 0,56 & 0,49 & 0,79 & 0,69 & 1,05 & 0,94 & 3,26 \\
\hline \multirow{3}{*}{$\begin{array}{c}\text { Demanda } \\
\text { Hídrica }\end{array}$} & Jolume & 26.737 & 40.095 & \multicolumn{2}{|c|}{53.463} & \multicolumn{2}{|c|}{66.838} & \multicolumn{2}{|c|}{80.187} & 136.456 \\
\hline & Vazã & 121,0 & 181,5 & \multicolumn{2}{|c|}{242,0} & \multicolumn{2}{|c|}{302,5} & \multicolumn{2}{|c|}{363,0} & 617,7 \\
\hline & Volu & 27 & 78 & 174 & 160 & 326 & 303 & 548 & 516 & $6 \quad 1,662 \quad 1,501$ \\
\hline \multirow{3}{*}{$\begin{array}{l}\text { Deficit } \\
\text { Hídrico }\end{array}$} & Va & 0,1 & 0,3 & 0,8 & 0,7 & 1,5 & 1,4 & 2,5 & 2,3 & 7,5 \\
\hline & $D \epsilon$ & $0,1 \% \quad 0,1 \%$ & $0,2 \% \quad 0,2 \%$ & $0,3 \%$ & $0,3 \%$ & $0,5 \%$ & $0,5 \%$ & $0,7 \%$ & \% $0,6 \%$ & $1,2 \% \quad 1,1 \%$ \\
\hline & & $0 \%$ & $0 \%$ & $0 \%$ & $0 \%$ & $0 \%$ & $0 \%$ & $0 \%$ & $0 \%$ & $60,7 \% \quad 60,7 \%$ \\
\hline \multicolumn{2}{|c|}{ Transposição média $\left(\mathrm{m}^{3} / \mathrm{s}\right)$} & 30,7 & 32,7 & 29,6 & 0 & 28,4 & 0 & 26,4 & & 26,4 \\
\hline \multirow{4}{*}{$\begin{array}{l}\text { Atendimento } \\
\text { Energético }\end{array}$} & Dem & 6.190 & 6.190 & \multicolumn{2}{|c|}{6.190} & \multicolumn{2}{|c|}{6.190} & \multicolumn{2}{|c|}{6.190} & 6.190 \\
\hline & Defic & 365 & 465 & 572 & 537 & 679 & 645 & 793 & 754 & \begin{tabular}{l|ll}
4 & 1,364 & 1,305
\end{tabular} \\
\hline & $D e$ & $5,9 \% \quad 5,4 \%$ & $7,5 \% \quad 7,1 \%$ & $9,2 \%$ & $8,7 \%$ & $11,0 \%$ & $10,4 \%$ & $12,8 \%$ & $12,2 \%$ & $22,0 \% 21,1 \%$ \\
\hline & Íno & $\begin{array}{llll}54,8 \% & 54,8 \% & 6 \\
\end{array}$ & $60,7 \% 54,8 \%$ & $65,5 \%$ & $65,5 \%$ & $65,5 \%$ & $65,5 \%$ & $65,5 \%$ & $65,5 \%$ & $86,9 \% \quad 82,1 \%$ \\
\hline & & esuitaus a & PETा & 100 & all & 15 & & do $1 \mathrm{IV}$ & 1 & \\
\hline C & de den & (I) $1 \times \mathrm{xUC}_{\text {ONS }}$ & (II) $1,5 \times \mathrm{xUC}_{\text {ONS }}$ & (III) $2 x$ & $\mathrm{xUC}_{\text {ONs }}$ & (IV) $2,5 x$ & $\mathrm{XUC}_{\text {ONS }}$ & (V) $3 \times U$ & JCons & (VI) Outorga \\
\hline & Trar & Ativa Inativa & Ativa Inativa & Ativa & Inativa & Ativa I & tiva & Ativa Ir & Inativa & Ativa Inativa \\
\hline Função objeti & tivo & $0,26 \quad 0,21$ & $0,59 \quad 0,53$ & 4,10 & 4,02 & 8,85 & 8,75 & 25,18 & 25,10 & $48,45 \quad 48,29$ \\
\hline & Vo & 26.737 & 40.095 & 53. & 463 & 66.8 & 338 & 80.18 & & 136.456 \\
\hline & Vazã & 121,0 & 181,5 & & 2,0 & 302 & & 363 , & & 617,7 \\
\hline & Volt & 23 & 116 & 67 & 675 & 1.244 & 1.239 & 1.821 & 1.816 & $6.033 \quad 5.977$ \\
\hline & $\mathrm{Va}$ & 0,1 & 0,5 & 3,1 & 3,1 & 5,6 & 5,6 & 8,2 & 8,2 & 27,3 \\
\hline & & $0,1 \% \quad 0,1 \%$ & $0,3 \% \quad 0,3 \%$ & $1,3 \%$ & $1,3 \%$ & $1,9 \%$ & $1,9 \%$ & $2,3 \%$ & $2,3 \%$ & $4,4 \% \quad 4,4 \%$ \\
\hline & IÍndice & $0 \%$ & $51,2 \% 51,2 \%$ & $60,7 \%$ & $60,7 \%$ & $60,7 \%$ & $60,7 \%$ & $60,7 \%$ & $60,7 \%$ & $60,7 \% \quad 60,7 \%$ \\
\hline Transposição & o mé & 31,7 & 29,6 & 27,5 & 0 & 28,5 & 0 & 30,5 & 0 & 26,4 \\
\hline & Dem & 6.190 & 6.190 & & 190 & 6.19 & 90 & 6.19 & & 6.190 \\
\hline Aten & Deficit(MWmed) & 376 & 477 & 574 & 541 & 676 & 642 & 783 & 744 & $1.302 \quad 1.242$ \\
\hline Co & Deficit / Demanda & $6,1 \% \quad 5,7 \%$ & $7,7 \% \quad 7,2 \%$ & $9,3 \%$ & $8,7 \%$ & $10,9 \%$ & $10,4 \%$ & $12,6 \%$ & $12,0 \%$ & $21,0 \% \quad 20,1 \%$ \\
\hline & Índice de falhas & $54,8 \% 54,8 \%$ & $59,5 \% 54,8 \%$ & $65,5 \%$ & $65,5 \%$ & $65,5 \%$ & $65,5 \%$ & $65,5 \%$ & $65,5 \%$ & $85,7 \% \quad 81,0 \%$ \\
\hline
\end{tabular}

Diferentemente do que foi registrado no período 1998-2005, no qual o deficit hídrico da bacia foi registrado na área de contribuição de Sobradinho, para o período de 1950-1957 o deficit hídrico afetou com maior intensidade a área de contribuição do reservatório de Três Marias.

Nos cenários de demanda hídrica I a V, o baixo deficit hídrico concentrou-se na área de contribuição de Sobradinho quando valiam as restrições TMA300 e TMA400, com percentuais sempre menores que 1\%. Sob a restrição TMA437, passa a ocorrer deficit com grande intensidade na área de contribuição de Três Marias e de Retiro Baixo, cujos valores no cenário $V$ foram, respectivamente, de $34 \%$ e $25 \%$ da demanda. 
No cenário VI, Sobradinho e Retiro Baixo apresentaram percentuais de deficit comparáveis sob as restrições TMA300 e TMA437, ambos próximos de $2 \%$. Sob a restrição TMA437, enquanto Sobradinho registrou deficit percentual de apenas 0,7\% da demanda, Retiro Baixo e Três Marias registraram deficit de $27 \%$ e $53 \%$ da demanda, respectivamente. Uma vez que os usos prioritários correspondem a 11\% do consumo outorgado nestas duas áreas, tem-se que apenas $16 \%$ e $42 \%$ das demandas não prioritárias foram atendidas em Retiro Baixo e Três Marias, respectivamente. Esses valores não apresentaram alterações se comparadas as situações com transposição e sem transposição.

Observou-se que, diferentemente do ocorrido no período de abr/1998mar/2005, quando o aumento da defluência mínima de Três Marias acarretou queda no atendimento do uso consuntivo em Sobradinho, no período de abr/1950mar/1957 ocorreu melhora no atendimento das demandas consuntivas neste reservatório. Em 1998-2005, o aumento do deficit hídrico foi compensado por uma maior geração de energia em Sobradinho. Em 1950-1957, também houve aumento da energia média gerada em Sobradinho, embora de pequena magnitude - menos de 7,5 MWmed adicionais.

Contudo o aumento da energia gerada e a melhora do atendimento de uso consuntivo em Sobradinho foram compensados por uma queda expressiva da vazão fornecida a uso consuntivo em Três Marias e em Retiro Baixo. Ressalta-se que, com defluência mínima de $437,5 \mathrm{~m}^{3} / \mathrm{s}$ em Três Marias, a energia média gerada nesta usina também foi maior em 10,6 MWmed do que a energia média gerada sob a restrição TMA300.

Os resultados obtidos em cada cenário de demanda hídrica sob as três restrições de defluência mínima, considerando a transposição ativa e inativa, são apresentados do Anexo I ao Anexo N deste trabalho.

\section{- $\quad$ Custo da queda na geração devido ao aumento dos usos consuntivos}

Em ambos os períodos de afluência avaliados, observou-se que o deficit na geração de energia é significativo quando comparadas os cenários de demanda hídrica I, cujos valores são os adotados pelo ONS, e VI, cujos valore são iguais ao consumo outorgado na bacia. No período crítico de afluência (1998-2005), em que houve maiores impactos na geração de energia, registrou-se uma perda de 
1134 MWmed na restrição TMA300 e de 1074 MWmed na restrição TMA500, o que resulta uma perda média de $1104 \mathrm{MWmed} \mathrm{no} \mathrm{período.} \mathrm{Esse} \mathrm{valor} \mathrm{equivale,} \mathrm{ao} \mathrm{longo}$ de um ano, a 9671 GWh a menos de energia.

Tomando-se por base o preço médio de comercialização de $1 \mathrm{MWh}$ como igual a $\mathrm{R} \$ 72$ no mercado livre, essa perda de energia representa, ao longo de um ano, uma perda de $\mathrm{R} \$ 696,3$ milhões. O preço médio de $\mathrm{R} \$ 72 / \mathrm{MWh}$ pode ser calculado a partir do histórico de preços semanais da energia, divulgado pela CCEE para o período de 30/06/2001 a 01/06/2012 (CCEE, 2012a).

Se for adotada como referência uma empresa como a Companhia Hidro Elétrica do São Francisco (Chesf), cujo parque gerador possui 10,6 MW de potência instalada, equiparável a toda a potência instalada na bacia do São Francisco, é possível estabelecer um referencial para as perdas calculadas no período 19982005. No ano de 2011, a Chesf gerou 48.663 GWh e registrou uma receita operacional bruta de $\mathrm{R} \$ 6,5$ bilhões (CHESF, 2012).

Dessa forma, se as demandas consuntivas na bacia do São Francisco equivalessem ao consumo outorgado na bacia, haveria uma queda na geração equivalente a $20 \%$ da produção de uma empresa do porte da Chesf, ou a $11 \%$ da sua receita operacional bruta, em relação aos valores de uso consuntivo adotado pelo ONS.

Ressalta-se que esses custos referem-se apenas às perdas para o agente gerador. Não se incluem os prejuízos econômicos em que incorreram os demais usuários do recurso hídrico, uma vez que suas demandas foram atendidas em apenas $17 \%$, se for considerada toda a bacia. Tal custo é de estimativa muito complexa, dada a dificuldade de se atribuir valor econômico ao recurso hídrico, o qual é insumo relevante em diversos processos de produção e indispensável à vida.

\subsubsection{Análise das relações de troca entre geração de energia, uso consuntivo e conservação ambiental}

Procedeu-se ao estabelecimento das relações de troca entre diferentes usos da água por meio da análise dos resultados obtidos para todo o âmbito da bacia do rio São Francisco, em vez de serem considerados os reservatórios isoladamente. 
- Período de afluência: abril/1998 a março/2005

Com relação ao trade-off entre geração de energia e uso consuntivo, deve-se observar que o deficit de energia é tanto maior quanto mais alta for a demanda hídrica consuntiva a ser atendida.

A Tabela 6.14 apresenta o gradiente médio das curvas de Pareto obtidas para geração de energia e uso consuntivo (UC) considerando as afluências do período de abril/1998-março/2005.

Tabela 6.14 - Relação de troca entre geração de energia e uso consuntivo na bacia do São Francisco para o período abr/1998-mar/2005

\begin{tabular}{|c|c|c|c|c|c|c|}
\hline \multicolumn{7}{|c|}{ Restrição TMA300 } \\
\hline \multirow[b]{2}{*}{ Cenário } & \multicolumn{3}{|c|}{ Transposição ativa } & \multicolumn{3}{|c|}{ Transposição inativa } \\
\hline & $\underset{\left(\mathrm{m}^{3} / \mathrm{s}\right)}{\mathrm{UC}}$ & $\begin{array}{l}\text { Energia } \\
\text { (MWmed) }\end{array}$ & $\begin{array}{c}\text { Gradiente } \\
\left(\mathrm{MWmed} / \mathrm{m}^{3} / \mathrm{s}\right)\end{array}$ & $\underset{\left(\mathrm{m}^{3} / \mathrm{s}\right)}{\mathrm{UC}}$ & $\begin{array}{c}\text { Energia } \\
\text { (MWmed) }\end{array}$ & $\begin{array}{c}\text { Gradiente } \\
\left(\mathrm{MWmed} / \mathrm{m}^{3} / \mathrm{s}\right)\end{array}$ \\
\hline I & 120,7 & 5.111 & & 120,7 & 5.178 & \\
\hline II & 180,5 & 4.952 & $-2,66$ & 180,6 & 5.019 & $-2,66$ \\
\hline III & 240,1 & 4.795 & $-2,64$ & 240,2 & 4.862 & $-2,65$ \\
\hline IV & 299,2 & 4.638 & $-2,65$ & 299,4 & 4.704 & $-2,66$ \\
\hline V & 357,7 & 4.482 & $-2,67$ & 357,9 & 4.549 & $-2,66$ \\
\hline VI & 520,4 & 3.978 & $-3,10$ & 545,4 & 3.978 & $-3,05$ \\
\hline \multicolumn{4}{|c|}{ Gradiente médio $\left(\mathrm{MWmed} / \mathrm{m}^{3} / \mathrm{s}\right)$} & & & $-2,73$ \\
\hline \multicolumn{7}{|c|}{ Restrição TMA400 } \\
\hline & \multicolumn{3}{|c|}{ Transposição ativa } & \multicolumn{3}{|c|}{ Transposição inativa } \\
\hline Cenário & $\begin{array}{l}\mathrm{UC} \\
\left(\mathrm{m}^{3} / \mathrm{s}\right)\end{array}$ & $\begin{array}{l}\text { Energia } \\
\text { (MWmed) }\end{array}$ & $\begin{array}{c}\text { Gradiente } \\
\left(\mathrm{MWmed} / \mathrm{m}^{3} / \mathrm{s}\right)\end{array}$ & $\underset{\left(\mathrm{m}^{3} / \mathrm{s}\right)}{\mathrm{UC}}$ & $\begin{array}{l}\text { Energia } \\
\text { (MWmed) }\end{array}$ & $\begin{array}{c}\text { Gradiente } \\
\left(\mathrm{MWmed} / \mathrm{m}^{3} / \mathrm{s}\right)\end{array}$ \\
\hline $\mathbf{I}$ & 120,7 & 5.111 & & 120,7 & 5.178 & \\
\hline II & 180,5 & 4.952 & $-2,66$ & 180,6 & 5.019 & $-2,66$ \\
\hline III & 240,1 & 4.795 & $-2,65$ & 240,2 & 4.861 & $-2,66$ \\
\hline IV & 299,2 & 4.637 & $-2,67$ & 299,4 & 4.704 & $-2,65$ \\
\hline V & 357,7 & 4.481 & $-2,67$ & 357,9 & 4.548 & $-2,66$ \\
\hline VI & 515,2 & 4.000 & $-3,06$ & 539,9 & 3.997 & $-3,03$ \\
\hline \multicolumn{4}{|c|}{ Gradiente médio (MWmed $/ \mathrm{m}^{3} / \mathrm{s}$ ) } & & & $-2,73$ \\
\hline \multicolumn{7}{|c|}{ Restrição TMA500 } \\
\hline & \multicolumn{3}{|c|}{ Transposição ativa } & \multicolumn{3}{|c|}{ Transposição inativa } \\
\hline Cenário & $\underset{\left(\mathrm{m}^{3} / \mathrm{s}\right)}{\mathrm{UC}}$ & $\begin{array}{l}\text { Energia } \\
\text { (MWmed) }\end{array}$ & $\begin{array}{c}\text { Gradiente } \\
\left(\mathrm{MWmed} / \mathrm{m}^{3} / \mathrm{s}\right)\end{array}$ & $\underset{\left(\mathrm{m}^{3} / \mathrm{s}\right)}{\mathrm{UC}}$ & $\begin{array}{c}\text { Energia } \\
\text { (MWmed) }\end{array}$ & $\begin{array}{c}\text { Gradiente } \\
\left(\mathrm{MWmed} / \mathrm{m}^{3} / \mathrm{s}\right)\end{array}$ \\
\hline $\mathbf{I}$ & 120,7 & 5.103 & & 120,7 & 5.169 & \\
\hline II & 180,5 & 4.944 & $-2,65$ & 180,6 & 5.011 & $-2,65$ \\
\hline III & 240,1 & 4.785 & $-2,68$ & 240,2 & 4.852 & $-2,67$ \\
\hline IV & 299,2 & 4.627 & $-2,67$ & 299,4 & 4.693 & $-2,68$ \\
\hline V & 357,7 & 4.471 & $-2,67$ & 357,9 & 4.537 & $-2,67$ \\
\hline VI & 499,4 & 4.028 & $-3,12$ & 522,9 & 4.026 & $-3,10$ \\
\hline \multicolumn{3}{|c|}{ Gradiente médio $\left(\mathrm{MWmed} / \mathrm{m}^{3} / \mathrm{s}\right.$ ) } & $-2,76$ & & & $-2,75$ \\
\hline
\end{tabular}


Os resultados da Tabela 6.14 mostram que o gradiente médio das curvas de Pareto é de $-2,7 \mathrm{MWmed}$ para cada $\mathrm{m}^{3} / \mathrm{s}$ destinado aos usos consuntivos e não apresenta alterações significativas entre as condições de defluência TMA300, TMA400 e TMA500, esteja a transposição em funcionamento ou inativa.

A obtenção de gradientes maiores que a unidade indicam que a geração de energia é mais sensível à variação da demanda consuntiva do que da vazão fornecida a uso consuntivo.

Uma perda de 2,7 MWmed totaliza, ao longo de um ano, 23.652 MWh a menos de energia. Tomando-se por base o preço médio de comercialização de $1 \mathrm{MWh}$ como igual a $\mathrm{R} \$ 72$, essa perda de energia representa, ao longo de um ano, uma perda de $\mathrm{R} \$ 1,7$ milhão.

A operação da transposição só afeta significativamente o atendimento dos usos consuntivos quando a demanda é considerada igual ao consumo outorgado. Neste caso, ou seja, para o cenário VI, a transposição reduz em $24,4 \mathrm{~m}^{3} / \mathrm{s}$ em média o fornecimento para uso consuntivo, o que equivale a $4 \%$ da demanda total da bacia. Para os demais cenários de demanda hídrica, a transposição reduz em apenas $0,1 \mathrm{~m}^{3} / \mathrm{s}$ a vazão média fornecida para usos consuntivos. Os resultados são mostrados na Tabela 6.15.

Tabela 6.15 - Variação da vazão fornecida a usos consuntivos pela transposição do São Francisco no período abr/1998-mar/2005

\begin{tabular}{|c|c|c|c|c|c|c|c|c|c|}
\hline \multirow{3}{*}{ Cenário } & \multicolumn{3}{|c|}{ TMA300 } & \multicolumn{3}{|c|}{ TMA400 } & \multicolumn{3}{|c|}{ TMA500 } \\
\hline & \multicolumn{2}{|c|}{$\mathrm{UC}\left(\mathrm{m}^{3} / \mathrm{s}\right)$} & \multirow{2}{*}{ Variação } & \multicolumn{2}{|c|}{$\mathrm{UC}\left(\mathrm{m}^{3} / \mathrm{s}\right)$} & \multirow{2}{*}{ Variação } & \multicolumn{2}{|c|}{$\mathrm{UC}\left(\mathrm{m}^{3} / \mathrm{s}\right)$} & \multirow{2}{*}{ Variação } \\
\hline & Tr.Ativa & Tr.Inativa & & Tr.Ativa & Tr.Inativa & & Tr.Ativa & Tr.Inativa & \\
\hline I & 120,7 & 120,7 & $0,0 \%$ & 120,7 & 120,7 & $0,0 \%$ & 120,7 & 120,7 & $0,0 \%$ \\
\hline II & 180,5 & 180,6 & $0,0 \%$ & 180,5 & 180,6 & $0,0 \%$ & 180,5 & 180,6 & $0,0 \%$ \\
\hline III & 240,1 & 240,2 & $0,0 \%$ & 240,1 & 240,2 & $0,0 \%$ & 240,1 & 240,2 & $0,0 \%$ \\
\hline IV & 299,2 & 299,4 & $0,0 \%$ & 299,2 & 299,4 & $0,0 \%$ & 299,2 & 299,4 & $0,0 \%$ \\
\hline V & 357,7 & 357,9 & $-0,1 \%$ & 357,7 & 357,9 & $-0,1 \%$ & 357,7 & 357,9 & $-0,1 \%$ \\
\hline VI & 520,4 & 545,3 & $-4,6 \%$ & 515,2 & 539,9 & $-4,6 \%$ & 499,4 & 522,9 & $-4,5 \%$ \\
\hline
\end{tabular}

A transposição também não afetou de forma relevante a geração de energia pelas usinas hidrelétricas da bacia. Para os cenários I a V de demanda hídrica, a operação da transposição diminuiu a energia gerada em 66,7 MWmed, o que representa $1,1 \%$ da demanda de energia. Ao longo de um ano, essa perda de energia chega a $584 \mathrm{GWh}$ ou $\mathrm{R} \$ 42$ milhões, considerando o preço médio de 
$\mathrm{R} \$ 72 / \mathrm{MWh}$. Para o cenário $\mathrm{VI}$, a variação de energia gerada com e sem transposição ficou abaixo de $0,1 \%$ da demanda.

Na média dos seis cenários, a perda na geração foi de 55,3 MWmed, o que equivale, ao longo de um ano, a $\mathrm{R} \$ 34,7$ milhões considerando o preço médio de $\mathrm{R} \$ 72 / \mathrm{MWh}$. Uma vez que a vazão transposta foi de $26,4 \mathrm{~m}^{3} / \mathrm{s}$, tem-se uma perda na geração de energia de 2,1 MWmed para cada $\mathrm{m}^{3} / \mathrm{s}$ da transposição. Os resultados estão apresentados na Tabela 6.16.

Tabela 6.16 - Variação da geração de energia pela transposição do São Francisco no período abr/1998-mar/2005

\begin{tabular}{|c|c|c|c|c|c|c|c|c|c|}
\hline \multirow{3}{*}{ Cenário } & \multicolumn{3}{|c|}{ TMA300 } & \multicolumn{3}{|c|}{ TMA400 } & \multicolumn{3}{|c|}{ TMA500 } \\
\hline & \multicolumn{2}{|c|}{ Energia (MWmed) } & \multirow{2}{*}{ Variação } & \multicolumn{2}{|c|}{ Energia (MWmed) } & \multirow{2}{*}{ Variação } & \multicolumn{2}{|c|}{ Energia (MWmed) } & \multirow{2}{*}{ Variação } \\
\hline & Tr.Ativa & Tr.Inativa & & Tr.Ativa & Tr.Inativa & & Tr.Ativa & Tr.Inativa & \\
\hline I & 5.111 & 5.178 & $-1,3 \%$ & 5.111 & 5.178 & $-1,3 \%$ & 5.103 & 5.169 & $-1,3 \%$ \\
\hline II & 4.952 & 5.019 & $-1,3 \%$ & 4.952 & 5.019 & $-1,3 \%$ & 4.944 & 5.011 & $-1,3 \%$ \\
\hline III & 4.795 & 4.862 & $-1,4 \%$ & 4.795 & 4.861 & $-1,4 \%$ & 4.785 & 4.852 & $-1,4 \%$ \\
\hline IV & 4.638 & 4.704 & $-1,4 \%$ & 4.637 & 4.704 & $-1,4 \%$ & 4.627 & 4.693 & $-1,4 \%$ \\
\hline V & 4.482 & 4.549 & $-1,5 \%$ & 4.481 & 4.548 & $-1,5 \%$ & 4.471 & 4.537 & $-1,5 \%$ \\
\hline VI & 3.978 & 3.978 & $0 \%$ & 4.000 & 3.997 & $0,1 \%$ & 4.028 & 4.026 & $0,1 \%$ \\
\hline
\end{tabular}

Esses resultados justificam as curvas de Pareto entre geração de energia e usos consuntivos, para as três condições de jusante em Três Marias, mostrarem-se muito próximas, conforme apresentado na Figura 6.1.

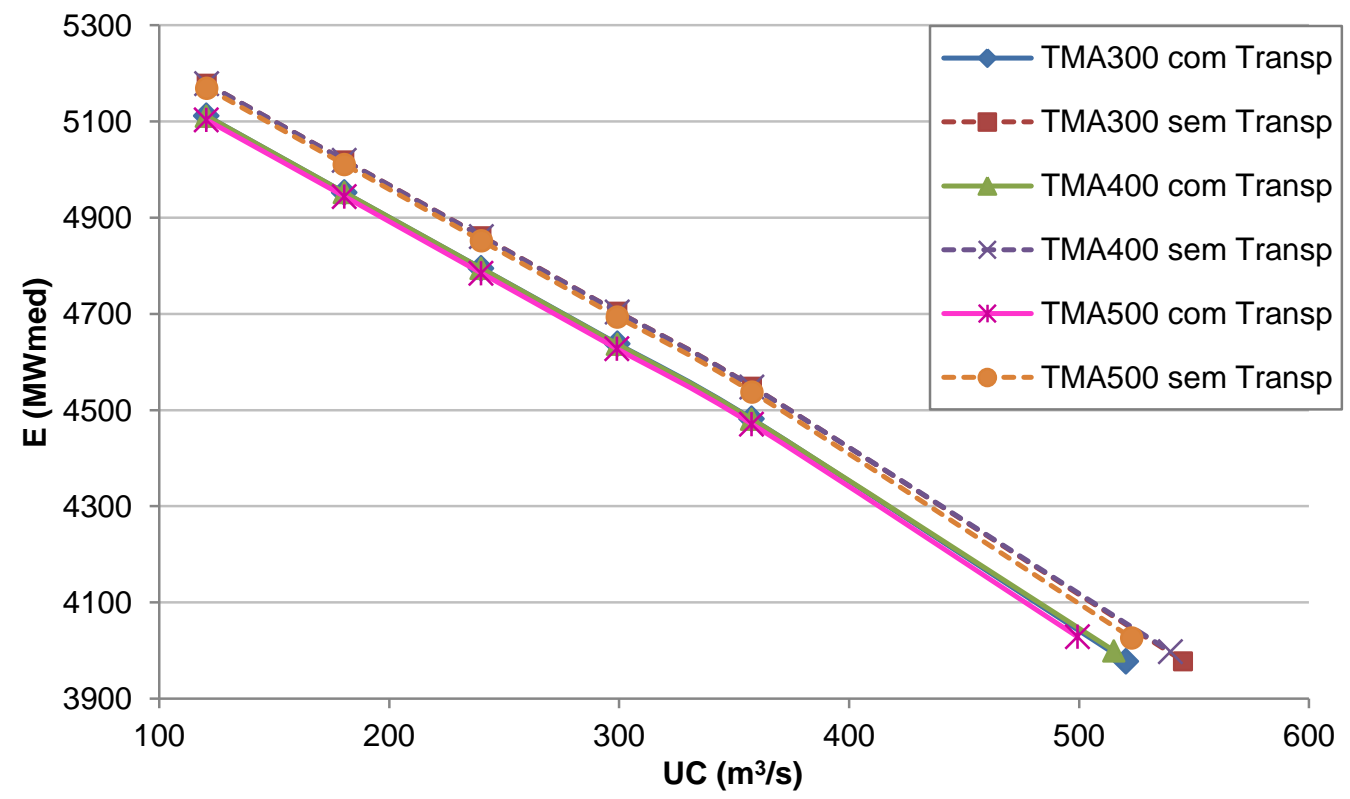

Figura 6.1 - Curvas de Pareto entre geração de energia e uso consuntivo no período abr/1998mar/2005 
Em cada cenário de demanda hídrica de I a $\mathrm{V}$, a mudança das condições de defluência mínima de Três Marias não alterou a vazão média retirada para uso consuntivo, esteja a transposição ativa ou inativa. Apenas no cenário VI foi registrado impacto da defluência de Três Marias sobre a retirada média para uso consuntivo. Para este cenário, tem-se que o aumento de $1 \mathrm{~m}^{3} / \mathrm{s}$ na exigência de vazão mínima a jusante de Três Marias implica uma diminuição média de $0,11 \mathrm{~m}^{3} / \mathrm{s}$ no fornecimento de água para uso consuntivo em toda a bacia. A perda de $21,1 \mathrm{~m}^{3} / \mathrm{s}$ na vazão fornecida, observada entre as restrições TMA300 e TMA500 com transposição, representa $3,4 \%$ da demanda hídrica. A variação observada sem a transposição foi semelhante, com perda de $22,4 \mathrm{~m}^{3} / \mathrm{s}$. As razões para o aumento do deficit hídrico com o aumento da defluência de Três Marias foram discutidas no item anterior.

A Tabela 6.17 apresenta os gradientes entre conservação ambiental a jusante de Três Marias e uso consuntivo. A Figura 6.2 apresenta as curvas de Pareto entre conservação ambiental e usos consuntivos.

Tabela 6.17 - Relação de troca entre conservação ambiental e uso consuntivo no período abr/1998mar/2005

\begin{tabular}{|c|c|c|c|c|c|c|c|c|c|}
\hline \multirow{2}{*}{\multicolumn{2}{|c|}{$\begin{array}{l}\text { Qmín a jusante de } \\
\text { Três Marias }\left(\mathrm{m}^{3} / \mathrm{s}\right)\end{array}$}} & \multicolumn{4}{|c|}{ Transposição ativa } & \multicolumn{4}{|c|}{ Transposição inativa } \\
\hline & & 300 & 400 & 500 & $\begin{array}{l}\text { Gradiente } \\
\text { médio }\end{array}$ & 300 & 400 & 500 & $\begin{array}{c}\text { Gradiente } \\
\text { médio }\end{array}$ \\
\hline \multirow{6}{*}{$\mathrm{UC}\left(\mathrm{m}^{3} / \mathrm{s}\right)$} & Cenário I & 120,7 & 120,7 & 120,7 & 0 & 120,7 & 120,7 & 120,7 & 0 \\
\hline & Cenário II & 180,5 & 180,5 & 180,5 & 0 & 180,6 & 180,6 & 180,6 & 0 \\
\hline & Cenário III & 240,1 & 240,1 & 240,1 & 0 & 240,2 & 240,2 & 240,2 & 0 \\
\hline & Cenário IV & 299,2 & 299,2 & 299,2 & 0 & 299,4 & 299,4 & 299,4 & 0 \\
\hline & Cenário V & 357,7 & 357,7 & 357,7 & 0 & 357,9 & 357,9 & 357,9 & 0 \\
\hline & Cenário VI & 520,5 & 515,2 & 499,4 & 0,11 & 545,4 & 539,9 & 522,9 & 0,11 \\
\hline
\end{tabular}




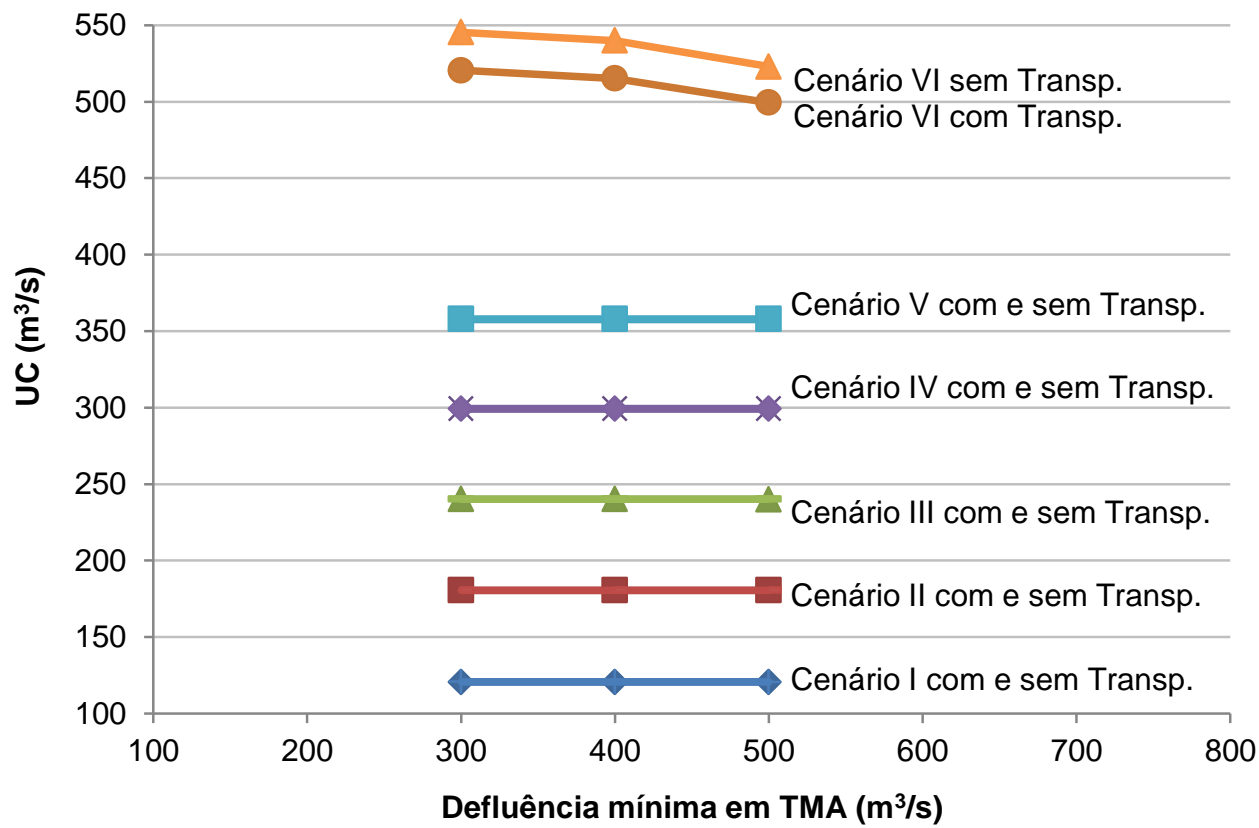

Figura 6.2 - Curvas de Pareto entre conservação ambiental e uso consuntivo no período abr/1998mar/2005

A mudança da defluência mínima de Três Marias também não ocasionou impacto significativo na geração de energia pelas usinas hidrelétricas da bacia. Para os cenários I a V, o gradiente entre energia e vazão defluente mínima é próximo de zero, ocorrendo ou não a transposição. Para o cenário VI, o aumento de $200 \mathrm{~m}^{3} / \mathrm{s}$ na defluência mínima de Três Marias implicou um aumento de $51 \mathrm{MWmed}$ na geração de energia, ou seja, um gradiente de $0,25 \mathrm{MWmed} / \mathrm{m}^{3} / \mathrm{s}$. Esse aumento de $51 \mathrm{MWmed}$ na geração totaliza, ao longo de um ano, $446 \mathrm{GWh}$, o que representa um ganho de $R \$ 32$ milhões, considerando o preço médio de $R \$ 72 / M W h$.

A Tabela 6.18 apresenta os gradientes entre conservação ambiental a jusante de Três Marias e geração de energia.

Tabela 6.18 - Relação de troca entre conservação ambiental e geração de energia no período abr/1998-mar/2005

\begin{tabular}{|c|c|c|c|c|c|c|c|c|c|}
\hline \multirow{2}{*}{\multicolumn{2}{|c|}{$\begin{array}{l}\text { Qmín a jusante de } \\
\text { Três Marias }\left(\mathrm{m}^{3} / \mathrm{s}\right)\end{array}$}} & \multicolumn{4}{|c|}{ Transposição ativa } & \multicolumn{4}{|c|}{ Transposição inativa } \\
\hline & & 300 & 400 & 500 & $\begin{array}{l}\text { Gradiente } \\
\text { médio }\end{array}$ & 300 & 400 & 500 & $\begin{array}{l}\text { Gradiente } \\
\text { médio }\end{array}$ \\
\hline \multirow{6}{*}{$\begin{array}{l}\text { Energia } \\
\text { (MWmed) }\end{array}$} & Cenário I & $5.111,4$ & $5.111,4$ & $5.103,0$ & $-0,04$ & $5.178,3$ & $5.178,2$ & $5.169,2$ & $-0,05$ \\
\hline & Cenário II & $4.952,2$ & $4.952,3$ & $4.944,2$ & $-0,04$ & $5.019,2$ & $5.019,0$ & $5.010,7$ & $-0,04$ \\
\hline & Cenário III & $4.794,7$ & $4.794,7$ & $4.784,7$ & $-0,05$ & $4.861,5$ & $4.860,8$ & $4.851,8$ & $-0,05$ \\
\hline & Cenário IV & $4.637,9$ & $4.636,9$ & $4.627,1$ & $-0,05$ & $4.704,3$ & $4.703,8$ & $4.693,5$ & $-0,05$ \\
\hline & Cenário V & $4.481,7$ & $4.481,0$ & $4.470,9$ & $-0,05$ & $4.548,6$ & $4.548,2$ & $4.537,3$ & $-0,06$ \\
\hline & Cenário VI & $3.977,6$ & $4.000,0$ & $4.028,5$ & 0,25 & $3.977,8$ & $3.977,4$ & $4.026,2$ & 0,24 \\
\hline
\end{tabular}


A Figura 6.3 apresenta as curvas de Pareto entre conservação ambiental e geração de energia.

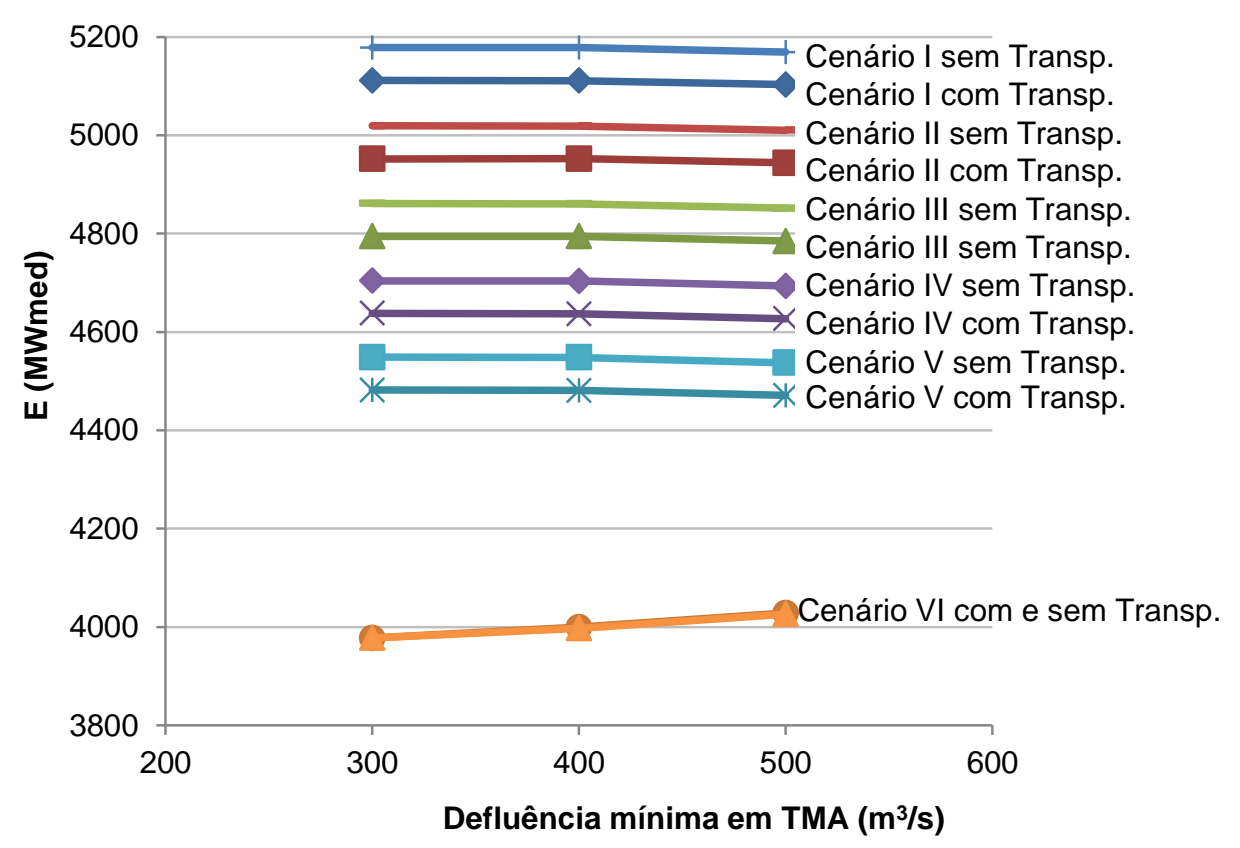

Figura 6.3 - Curvas de Pareto entre conservação ambiental e geração de energia no período abr/1998-mar/2005

- Período de afluência: abril/1950 a março/1957

A Tabela 6.19 apresenta o gradiente médio das curvas de Pareto obtidas para geração de energia e uso consuntivo considerando as afluências do período abril/1950-março/1957.

Os resultados mostram que o gradiente médio das curvas de Pareto é de 1,8 MWmed para cada $\mathrm{m}^{3} / \mathrm{s}$ destinado aos usos consuntivos e não apresenta alterações significativas entre as condições de defluência TMA300, TMA400 e TMA437, esteja a transposição em funcionamento ou inativa.

Os gradientes obtidos maiores que a unidade indicam que a geração e energia mostrou-se mais sensível à variação da demanda consuntiva do que a vazão fornecida a uso consuntivo. 
Tabela 6.19 - Relação de troca entre geração de energia e uso consuntivo na bacia do São Francisco para o período abr/1950-mar/1957

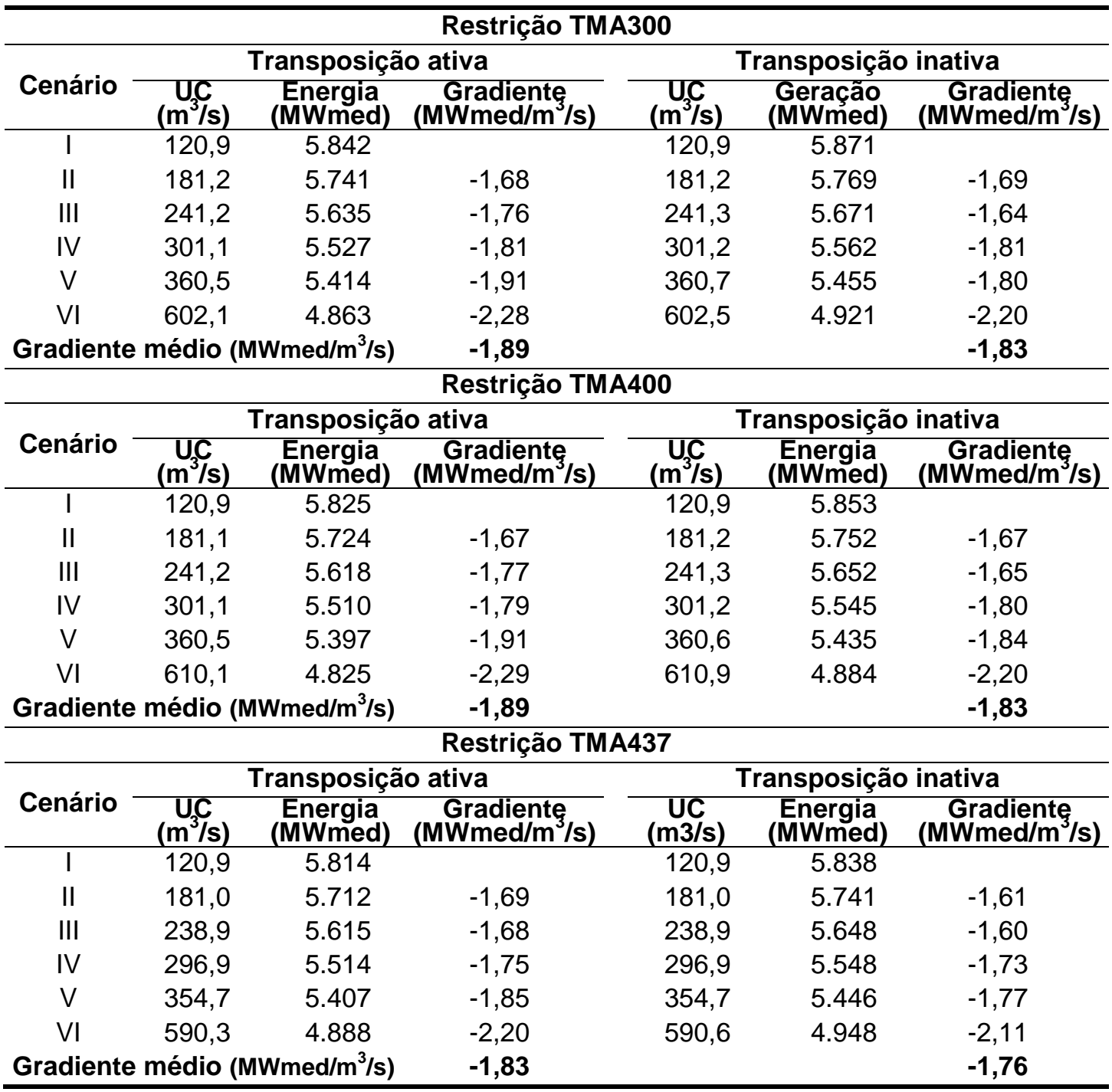

Uma perda de 1,8 MWmed totaliza, ao longo de um ano, 15.768 MWh a menos de energia. Tomando-se por base o preço médio de comercialização de 1 MWh como igual a $R \$ 72$, essa queda na geração representa, ao longo de um ano, uma perda de $\mathrm{R} \$ 1,1$ milhão. Trata-se de um gradiente menor em termos absolutos que o obtido para o período 1998-2005, em razão da menor afluência média registrada na bacia naquele período.

A operação da transposição não afetou significativamente o atendimento dos usos consuntivos em nenhum dos cenários analisados para este período de afluência. $\mathrm{O}$ impacto maior foi observado no cenário $\mathrm{VI}$, com redução de $1,7 \mathrm{~m}^{3} / \mathrm{s}$ na vazão média fornecida às demandas consuntivas, o que representa apenas $0,1 \%$ da demanda hídrica total da bacia. Os resultados são mostrados na Tabela 6.20. 
Tabela 6.20 - Variação da vazão fornecida a usos consuntivos pela transposição do São Francisco no período abr/1950-mar/1957

\begin{tabular}{|c|c|c|c|c|c|c|c|c|c|}
\hline \multirow{3}{*}{ Cenário } & \multicolumn{3}{|c|}{ TMA300 } & \multicolumn{3}{|c|}{ TMA400 } & \multicolumn{3}{|c|}{ TMA437 } \\
\hline & \multicolumn{2}{|c|}{$\mathrm{UC}\left(\mathrm{m}^{3} / \mathrm{s}\right)$} & \multirow[t]{2}{*}{ Variação } & \multicolumn{2}{|c|}{ UC $\left(\mathrm{m}^{3} / \mathrm{s}\right)$} & \multirow[t]{2}{*}{ Variação } & \multicolumn{2}{|c|}{$\mathrm{UC}\left(\mathrm{m}^{3} / \mathrm{s}\right)$} & \multirow[t]{2}{*}{ Variação } \\
\hline & Tr.ativa & Tr.inativa & & Tr.ativa & Tr.inativa & & Tr.ativa & inativa & \\
\hline I & 120,9 & 120,9 & $0 \%$ & 120,9 & 120,9 & $0 \%$ & 120,9 & 120,9 & $0 \%$ \\
\hline II & 181,2 & 181,2 & $0 \%$ & 181,1 & 181,2 & $0 \%$ & 181,0 & 181,0 & $0 \%$ \\
\hline III & 241,2 & 241,3 & $0 \%$ & 241,2 & 241,3 & $0 \%$ & 238,9 & 238,9 & $0 \%$ \\
\hline IV & 301,1 & 301,2 & $0 \%$ & 301,1 & 301,2 & $0 \%$ & 296,9 & 296,9 & $0 \%$ \\
\hline V & 360,5 & 360,7 & $0 \%$ & 360,5 & 360,6 & $0 \%$ & 354,7 & 354,7 & $0 \%$ \\
\hline $\mathrm{VI}$ & 602,1 & 602,8 & $-0,1 \%$ & 610,1 & 610,9 & $-0,1 \%$ & 590,3 & 590,6 & $0 \%$ \\
\hline
\end{tabular}

Tal como no período de 1998-2005, a transposição também não afetou de forma relevante a geração de energia pelas usinas hidrelétricas da bacia. Contudo, diferentemente do observado naquele período, quando o maior impacto da transposição se fez sentir nos cenários de I a V, neste período de 1950-1957 o maior impacto da transposição sobre a geração de energia ocorreu nos cenários VI e V respectivamente.

No cenário $\mathrm{VI}$, a operação da transposição ocasionou uma queda de $59 \mathrm{MWmed}$ na geração de energia, o que representa $1 \%$ da demanda. Ao longo de um ano, essa perda de energia chega a $517 \mathrm{GWh}$ ou $\mathrm{R} \$ 37,2$ milhões, considerando o preço médio de $\mathrm{R} \$ 72 / \mathrm{MWh}$. Para os cenários I a IV, a transposição acarretou uma perda de 32,8 MW médio na geração de energia. Considerando o preço médio de $\mathrm{R} \$ 72 / \mathrm{MWh}$, essa perda representa, ao longo de um ano, $\mathrm{R} \$ 20,6$ milhões.

Considerando a média dos seis cenários, registrou-se uma perda de $37,1 \mathrm{MWmed}$. A vazão transposta, na média dos seis cenários, foi de $29,7 \mathrm{~m}^{3} / \mathrm{s}$. Tem-se, então que cada $\mathrm{m}^{3} / \mathrm{s}$ da transposição acarreta uma perda de 1,25 MWmed na geração de energia. Os resultados do impacto da transposição na geração de energia estão apresentados na Tabela 6.21.

Tabela 6.21 - Variação da geração de energia pela transposição do São Francisco no período abr/1950-mar/1957

\begin{tabular}{|c|c|c|c|c|c|c|c|c|c|}
\hline \multirow{3}{*}{ Cenário } & \multicolumn{3}{|c|}{ TMA300 } & \multicolumn{3}{|c|}{ TMA400 } & \multicolumn{3}{|c|}{ TMA437 } \\
\hline & \multicolumn{2}{|c|}{ Energia (MWmed) } & \multirow{2}{*}{$\begin{array}{l}\text { Variação } \\
\text { a }\end{array}$} & \multicolumn{2}{|c|}{ Energia (MWmed) } & \multirow[t]{2}{*}{ Variação } & \multicolumn{2}{|c|}{ Energia (MWmed) } & \multirow[t]{2}{*}{ Variação } \\
\hline & Tr.ativa & Tr.inativa & & Tr.ativa & Tr.inativa & & Tr.ativa & Tr.inativa & \\
\hline 1 & 5.842 & 5.871 & $-0,5 \%$ & 5.825 & 5.853 & $-0,5 \%$ & 5.814 & 5.838 & $-0,4 \%$ \\
\hline II & 5.741 & 5.769 & $-0,5 \%$ & 5.724 & 5.752 & $-0,5 \%$ & 5.712 & 5.741 & $-0,5 \%$ \\
\hline III & 5.635 & 5.671 & $-0,6 \%$ & 5.618 & 5.652 & $-0,6 \%$ & 5.615 & 5.648 & $-0,6 \%$ \\
\hline IV & 5.527 & 5.562 & $-0,6 \%$ & 5.510 & 5.545 & $-0,6 \%$ & 5.514 & 5.548 & $-0,6 \%$ \\
\hline V & 5.414 & 5.455 & $-0,8 \%$ & 5.397 & 5.435 & $-0,7 \%$ & 5.407 & 5.446 & $-0,7 \%$ \\
\hline VI & 4.863 & 4.921 & $-1,2 \%$ & 4.825 & 4.884 & $-1,2 \%$ & 4.888 & 4.948 & $-1,2 \%$ \\
\hline
\end{tabular}


Esses resultados justificam as curvas de Pareto entre geração de energia e usos consuntivos, para as três condições de jusante em Três Marias, mostram-se muito próximas, conforme é apresentado na Figura 6.4.

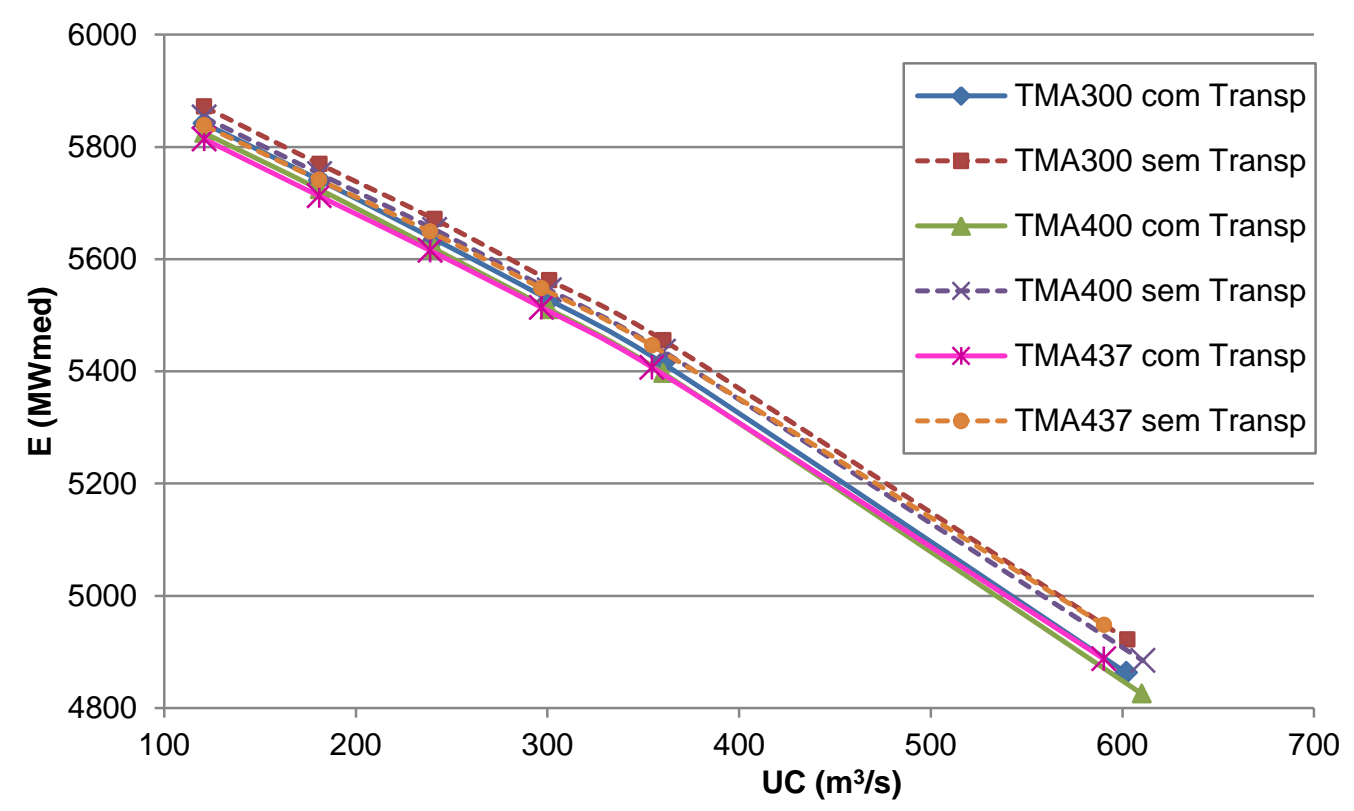

Figura 6.4 - Curvas de Pareto entre geração de energia e uso consuntivo no período abr/1950mar/1957

Em cada cenário de demanda hídrica de I a V, a mudança das condições de defluência de Três Marias não alterou a vazão média retirada para uso consuntivo, esteja a transposição ativa ou inativa. Tal como no período de 1998-2005, apenas no cenário VI foi registrado impacto do aumento da defluência de Três Marias sobre a retirada para uso consuntivo. Para este cenário, tem-se que o aumento de $1 \mathrm{~m}^{3} / \mathrm{s}$ na exigência de vazão mínima a jusante de Três Marias implica uma diminuição média de $0,09 \mathrm{~m}^{3} / \mathrm{s}$ na vazão para uso consuntivo em toda a bacia. A perda de $11,8 \mathrm{~m} 3 / \mathrm{s}$ na vazão fornecida, observada entre as restrições TMA300 e TMA437 com transposição, representa $1,9 \%$ da demanda hídrica. A variação observada sem a transposição foi semelhante, com perda de $12,2 \mathrm{~m}^{3} / \mathrm{s}$.

A Tabela 6.22 apresenta os gradientes entre conservação ambiental a jusante de Três Marias e uso consuntivo. A Figura 6.5 apresenta as curvas de Pareto entre conservação ambiental e usos consuntivos. 
Tabela 6.22 - Relação de troca entre conservação ambiental e uso consuntivo no período abr/1950mar/1957

\begin{tabular}{|c|c|c|c|c|c|c|c|c|c|}
\hline \multirow{2}{*}{\multicolumn{2}{|c|}{$\begin{array}{l}\text { Qmín a jusante de } \\
\text { Três Marias }\left(\mathrm{m}^{3} / \mathrm{s}\right)\end{array}$}} & \multicolumn{4}{|c|}{ Transposição ativa } & \multicolumn{4}{|c|}{ Transposição inativa } \\
\hline & & 300 & 400 & 437 & $\begin{array}{l}\text { Gradiente } \\
\text { médio }\end{array}$ & 300 & 400 & 437 & $\begin{array}{l}\text { Gradiente } \\
\text { médio }\end{array}$ \\
\hline \multirow{6}{*}{$\mathrm{UC}\left(\mathrm{m}^{3} / \mathrm{s}\right)$} & Cenário I & 120,9 & 120,9 & 120,9 & 0 & 120,9 & 120,9 & 120,9 & 0 \\
\hline & Cenário II & 181,2 & 181,1 & 181,0 & 0 & 181,0 & 181,2 & 181,0 & 0 \\
\hline & Cenário III & 241,2 & 241,2 & 238,9 & 0,02 & 241,3 & 241,3 & 238,9 & 0,02 \\
\hline & Cenário IV & 301,1 & 301,1 & 296,9 & 0,03 & 301,2 & 301,2 & 296,9 & 0,03 \\
\hline & Cenário V & 360,5 & 360,5 & 354,7 & 0,04 & 360,7 & 360,6 & 354,7 & 0,04 \\
\hline & Cenário VI & 602,1 & 610,1 & 590,3 & 0,09 & 602,8 & 610,9 & 590,6 & 0,09 \\
\hline
\end{tabular}

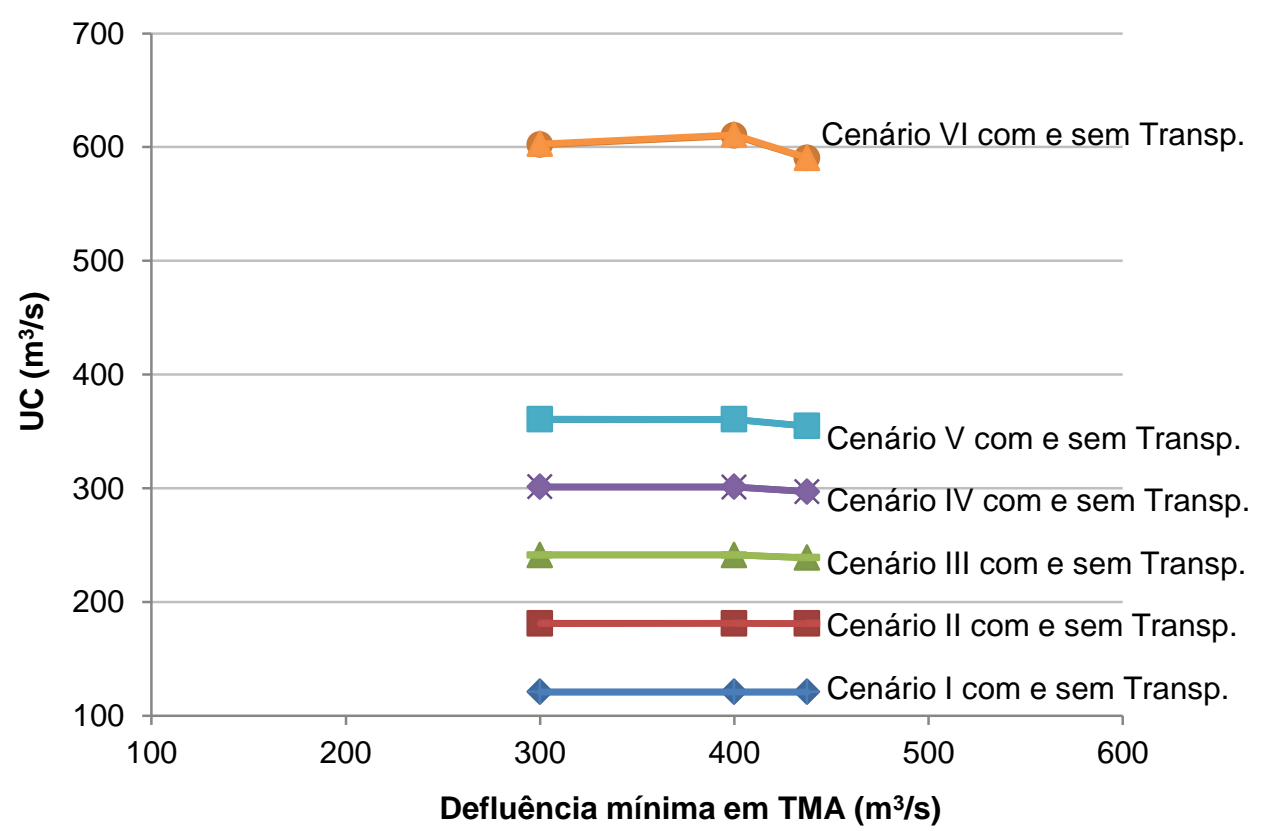

Figura 6.5 - Curvas de Pareto entre conservação ambiental e uso consuntivo no período abr/1950mar/1957

A mudança da defluência mínima de Três Marias também não ocasionou impacto significativo na geração de energia pelas usinas hidrelétricas da bacia. $\mathrm{O}$ gradiente mais expressivo foi obtido para o cenário $\mathrm{VI}$, no qual o aumento de $137 \mathrm{~m}^{3} / \mathrm{s}$ na defluência mínima de Três Marias implicou um aumento de 24,8 MWmed na geração de energia, ou seja, um gradiente de $0,18 \mathrm{MWmed} / \mathrm{m}^{3} / \mathrm{s}$. Esse aumento de 24,8 MWmed na geração totaliza, ao longo de um ano, $217 \mathrm{GWh}$, o que equivale a um ganho de $R \$ 15,6$ milhões, considerando o preço médio de $\mathrm{R} \$ 72 / \mathrm{MWh}$. Na situação sem transposição, o gradiente médio obtido foi semelhante.

A Tabela 6.23 apresenta os gradientes entre conservação ambiental a jusante de Três Marias e geração de energia. A Figura 6.6 apresenta as curvas de Pareto entre conservação ambiental e geração de energia. 
Tabela 6.23 - Relação de troca entre conservação ambiental e geração de energia no período abr/1950-mar/1957

\begin{tabular}{|c|c|c|c|c|c|c|c|c|c|}
\hline \multirow{2}{*}{\multicolumn{2}{|c|}{$\begin{array}{l}\text { Qmín a jusante de } \\
\text { Três Marias }\left(\mathrm{m}^{3} / \mathrm{s}\right)\end{array}$}} & \multicolumn{4}{|c|}{ Transposição ativa } & \multicolumn{4}{|c|}{ Transposição inativa } \\
\hline & & 300 & 400 & 437 & $\begin{array}{l}\text { Gradiente } \\
\text { médio }\end{array}$ & 300 & 400 & 437 & $\begin{array}{l}\text { Gradiente } \\
\text { médio }\end{array}$ \\
\hline \multirow{6}{*}{$\begin{array}{l}\text { Energia } \\
\text { (MWmed) }\end{array}$} & Cenário I & 5842 & 5825 & 5814 & $-0,20$ & 5871 & 5853 & 5838 & $-0,24$ \\
\hline & Cenário II & 5741 & 5724 & 5712 & $-0,21$ & 5769 & 5752 & 5741 & $-0,20$ \\
\hline & Cenário III & 5635 & 5618 & 5615 & $-0,15$ & 5671 & 5652 & 5648 & $-0,17$ \\
\hline & Cenário IV & 5527 & 5510 & 5514 & $-0,09$ & 5562 & 5545 & 5548 & $-0,10$ \\
\hline & Cenário V & 5414 & 5397 & 5407 & $-0,05$ & 5455 & 5435 & 5446 & $-0,06$ \\
\hline & Cenário VI & 4863 & 4825 & 4888 & 0,18 & 4921 & 4884 & 4948 & 0,19 \\
\hline
\end{tabular}

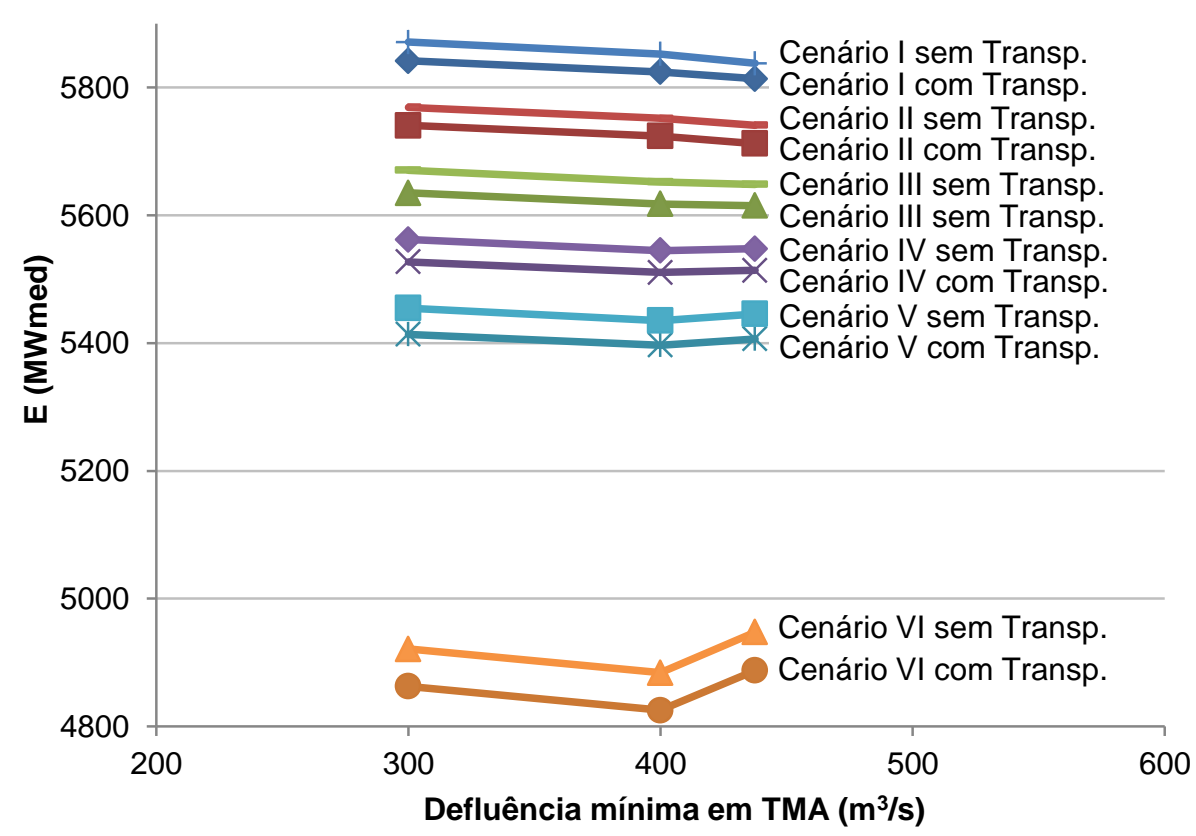

Figura 6.6 - Curvas de Pareto entre conservação ambiental e geração de energia no período abr/1950-mar/1957

\subsubsection{Análise de sensibilidade à variação de prioridade}

Procedeu-se à análise de sensibilidade das variáveis energia gerada e vazão destinada a uso consuntivo mediante a variação dos coeficientes ponderadores $\omega \mathrm{e}$ $\psi$ na função objetivo, os quais assumiram valores complementares. Foram adotados os seguintes valores de $(\omega, \psi):(0,1 ; 0,9),(0,25 ; 0,75),(0,5 ; 0,5),(0,75 ; 0,25)$ e $(0,9 ; 0,1)$. No caso dos valores $(0,1 ; 0,9)$ é dada prioridade máxima ao atendimento 
das demandas consuntivas. Para os valores $(0,9 ; 0,1)$ tem-se a situação oposta, isto é, dá-se máxima prioridade à geração de energia.

Dentre os cenários de demanda hídrica objetivo utilizados neste trabalho, foram escolhidos para a análise de sensibilidade os cenários I e VI. Em ambos os cenários, foi considerada a operação da transposição do rio São Francisco. A demanda objetivo de energia foi considerada igual à garantia física das usinas.

O período de afluências adotado na análise de sensibilidade foi de abril/1998 a março/2005. De forma análoga à análise anterior, foi imposto que os reservatórios chegassem ao final do período com volume armazenado igual ao volume útil menos o volume de espera para controle de cheias.

Uma vez que, para esta análise de sensibilidade, não foi levado em consideração o aumento da defluência mínima em Três Marias, apenas os valores do conjunto de restrições TMA500 foram adotados como limite de vazão mínima a jusante dos reservatórios da bacia.

A Figura 6.7 apresenta os resultados obtidos para o cenário I e a Figura 6.8 apresenta os resultados para o cenário VI.

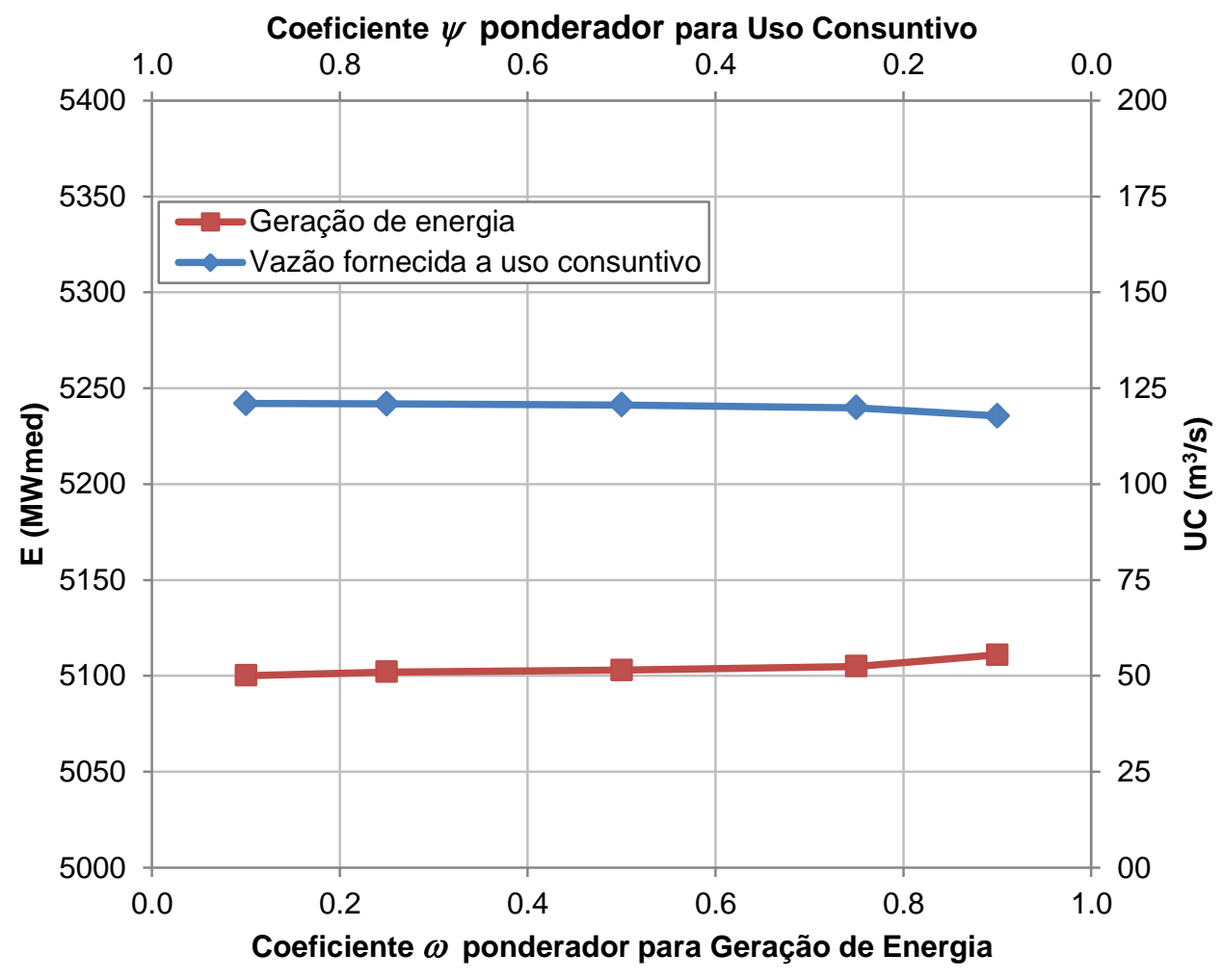

Figura 6.7 - Curvas de Pareto entre geração de energia e uso consuntivo com variação dos coeficientes ponderadores $\omega$ e $\psi$-Cenário I 


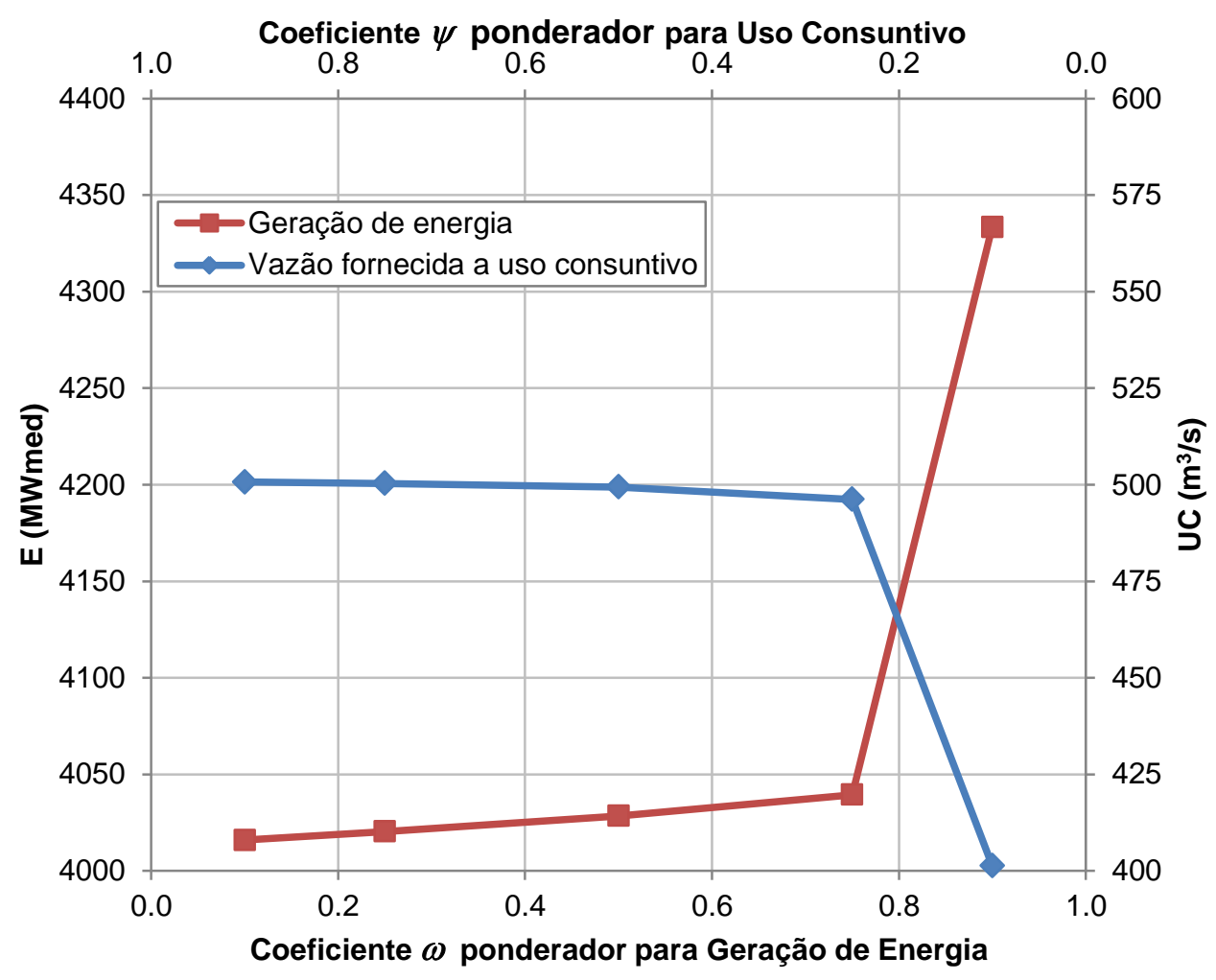

Figura 6.8 - Curvas de Pareto entre geração de energia e uso consuntivo com variação dos coeficientes ponderadores $\omega$ e $\psi$-Cenário VI

Os resultados demonstram que as relações de troca entre geração de energia e uso consuntivo tornam-se mais intensas quanto maior for a demanda hídrica.

No cenário I, em que as demandas consuntivas somam $121 \mathrm{~m}^{3} / \mathrm{s}$ em toda a bacia, não se observa uma variação significativa do gradiente à medida que se prioriza o atendimento de uma das demandas. Percebe-se que o limite mínimo do atendimento das demandas consuntivas é muito próximo do limite máximo, 117 e $121 \mathrm{~m}^{3} / \mathrm{s}$ respectivamente. O mesmo se observa com relação aos limites mínimo e máximo da geração de energia, 5100 e 5111 MWmed respectivamente.

Ao contrário, as relações de troca mostram-se intensas no cenário $\mathrm{VI}$, em que as demandas consuntivas da bacia somam $617 \mathrm{~m}^{3} / \mathrm{s}$. O limite máximo de atendimento dos usos consuntivos mantém-se próximo de $500 \mathrm{~m}^{3} / \mathrm{s}$ para valores de $\omega$ entre 0,1 e 0,75 , isto é, para valores de $\psi$ entre 0,9 e 0,25 . No entanto, para valores de $\omega$ maiores que 0,75 , a vazão fornecida aos usos consuntivos reduz-se até atingir o valor de $401 \mathrm{~m}^{3} / \mathrm{s}$, que representa apenas $65 \%$ da demanda. À medida que o atendimento das demandas consuntivas deixa de ser priorizado em favor do 
atendimento da demanda energética, a geração de energia eleva-se de 4016 MWmed para 4334 MWmed.

Esse incremento de 317,5 MWmed totaliza 2785 GWh de energia ao longo de um ano, o que representa $\mathrm{R} \$ 200$ milhões, considerando-se o preço médio de R\$72/MWh. Ainda assim, o valor máximo obtido na geração equivale a apenas $70 \%$ da demanda objetivo de energia adotada na análise.

\subsubsection{Avaliação da geração de energia ao longo da curva de duração das afluências}

$\mathrm{Na}$ análise da série histórica de afluências na bacia do São Francisco apresentada no Capítulo 5, foi levantada a curva de duração da ENA média de 7 anos. Uma vez que, para os períodos mais severos de escassez analisados, a geração de energia ficou abaixo da demanda objetivo, procedeu-se à avaliação do desempenho do sistema de reservatórios quanto à geração para outros períodos de 7 anos nos quais a escassez hídrica é menos intensa.

Com essa finalidade, foi aplicado o modelo HIDRO considerando diferentes afluências aos reservatórios da bacia. A escolha dos períodos de afluência seguiu o ordenamento da curva de duração apresentada no Capítulo 5, iniciando-se pelo período com ENA média de 7 anos com $100 \%$ de permanência até o período de ENA média de 7 anos com $50 \%$ de permanência. Os períodos selecionados estão apresentados na Tabela 6.24 .

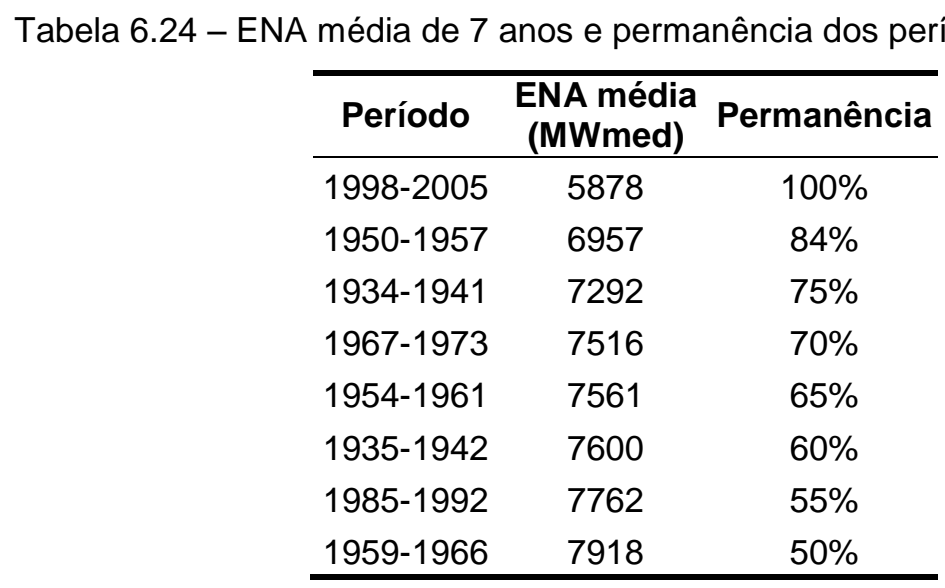


A demanda hídrica objetivo foi considerada igual à do cenário I, ou seja, 0 mesmo valor adotado pelo ONS em 2011. A demanda objetivo de energia foi considerada igual à energia assegurada das usinas. Os pesos atribuídos à geração de energia e aos usos consuntivos foram iguais, isto é, $\omega=\psi=0,5$. Novamente foi imposto que os reservatórios apresentassem ao fim do período um volume armazenado igual ao volume útil menos o volume de espera para controle de cheias. Além disso, a vazão defluente mínima das usinas seguiu os valores definidos na condição TMA300.

Em todos os períodos, as demandas consuntivas foram atendidas praticamente em sua plenitude. A vazão fornecida ficou acima de $99,7 \%$ da demanda objetivo no período de 1998-2005 e acima de 99,9\% nos demais períodos.

Com relação à geração de energia, o atendimento da demanda objetivo foi distinto em cada período analisado. A Figura 6.9 apresenta a geração de energia ao longo dos 84 meses de cada período em comparação com a demanda objetivo de energia. Acumulando-se os valores do deficit mensal de energia em GWh, obtêm-se os valores apresentados na Figura 6.10.

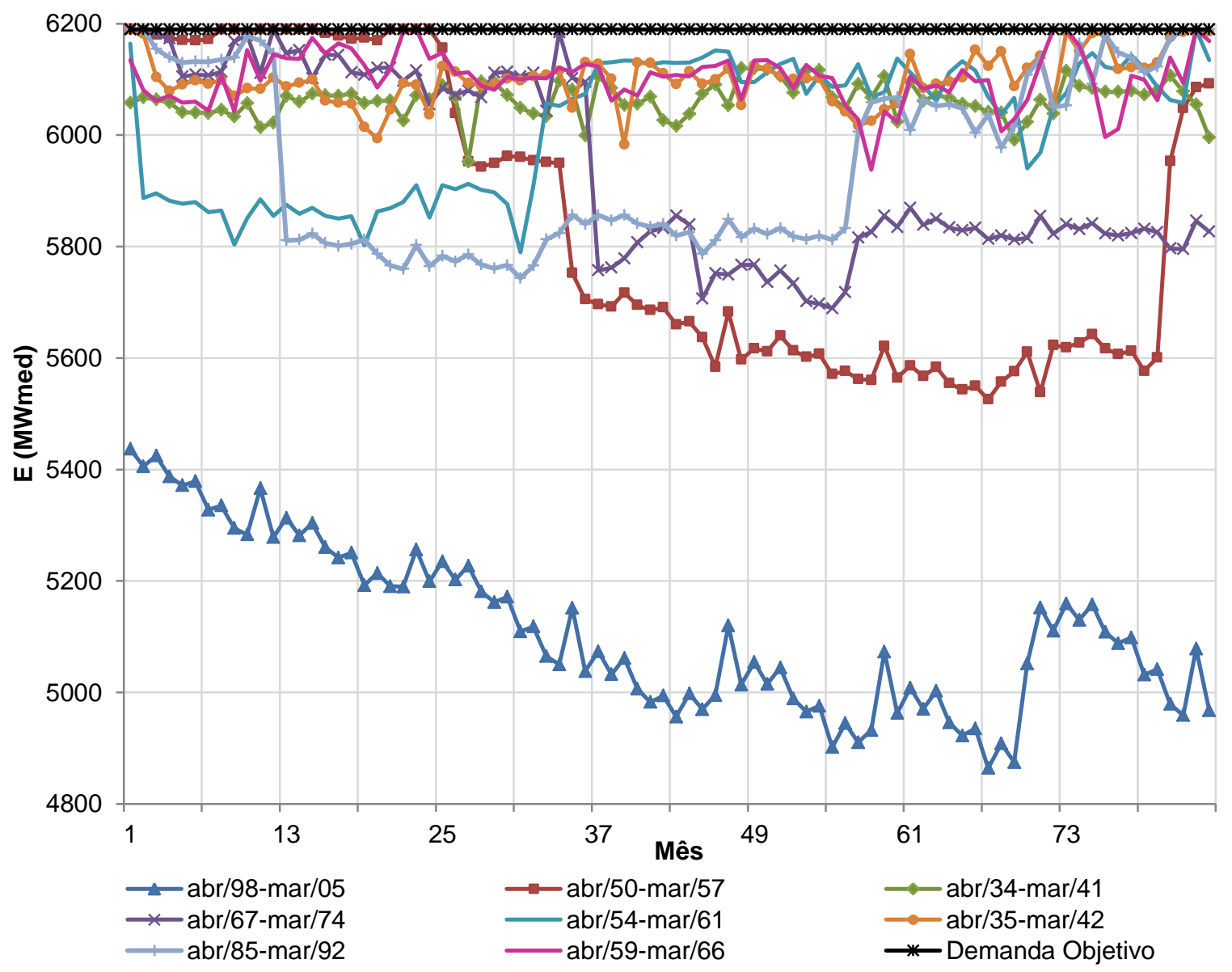

Figura 6.9 - Geração de energia para os diferentes períodos 


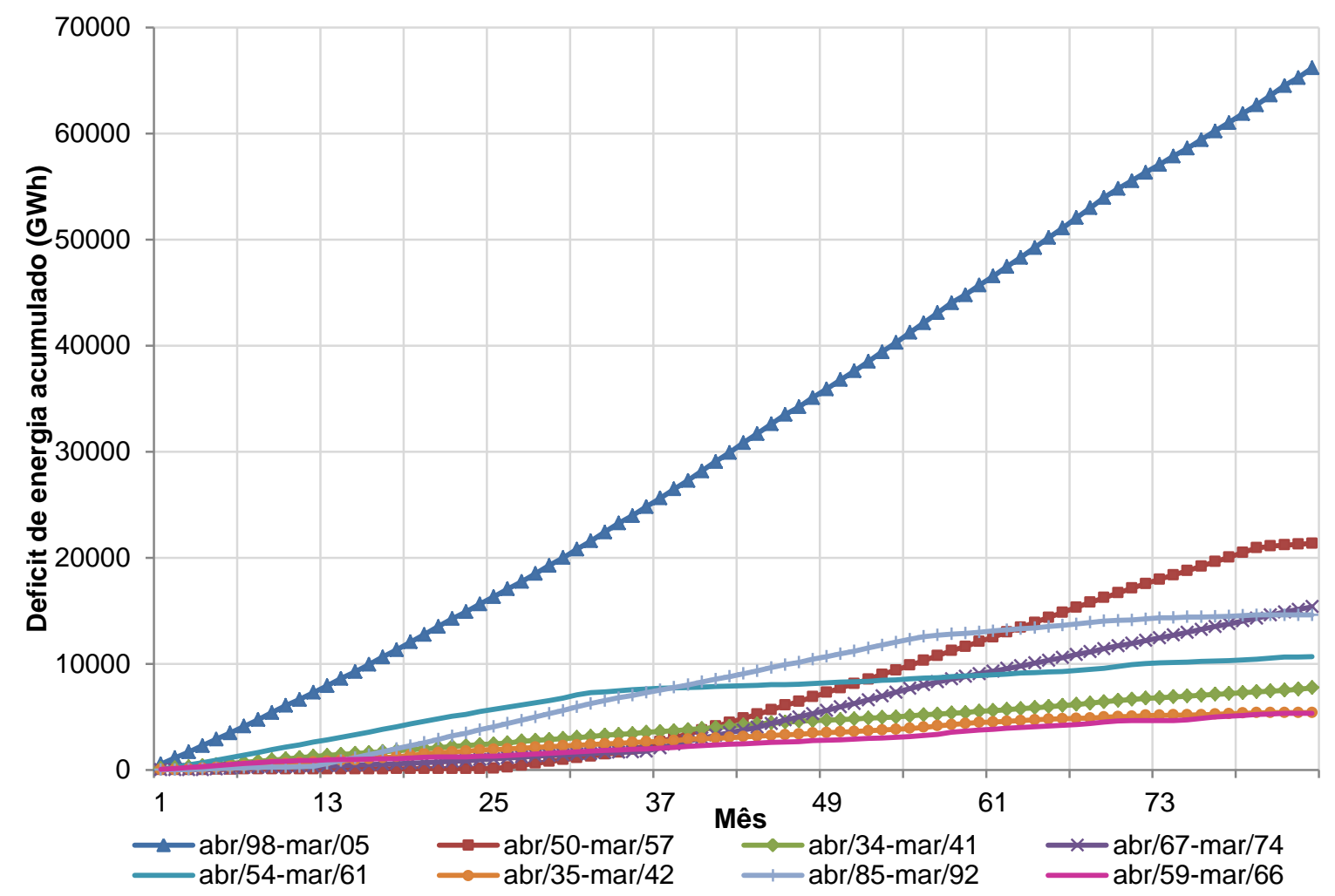

Figura 6.10 - Deficit de energia acumulado para os diferentes períodos de afluência

A Tabela 6.25 apresenta um resumo dos resultados obtidos para os períodos de análise classificados em ordem crescente de permanência de ENA.

Tabela 6.25 - Atendimento energético para cada permanência de ENA

\begin{tabular}{cccccr}
\hline Período & $\begin{array}{c}\text { Permanência } \\
\text { de ENA }\end{array}$ & $\begin{array}{c}\text { Função } \\
\text { objetivo }\end{array}$ & $\begin{array}{c}\text { Energia } \\
\text { (MWmed) }\end{array}$ & Deficit/Demanda & Falhas \\
\hline abr/59-mar/66 & $50 \%$ & 0,01 & 6103 & $1,4 \%$ & $0 \%$ \\
abr/85-mar/92 & $55 \%$ & 0,09 & 5952 & $3,8 \%$ & $0 \%$ \\
abr/35-mar/42 & $60 \%$ & 0,01 & 6102 & $1,4 \%$ & $0 \%$ \\
abr/54-mar/61 & $65 \%$ & 0,05 & 6016 & $2,8 \%$ & $27 \%$ \\
abr/67-mar/74 & $70 \%$ & 0,10 & 5939 & $4,0 \%$ & $57 \%$ \\
abr/34-mar/41 & $75 \%$ & 0,02 & 6063 & $2,0 \%$ & $0 \%$ \\
abr/50-mar/57 & $84 \%$ & 0,21 & 5842 & $5,6 \%$ & $55 \%$ \\
abr/98-mar/05 & $100 \%$ & 1,30 & 5111 & $17,4 \%$ & $100 \%$ \\
\hline
\end{tabular}

Os resultados mostram que 0 atendimento da demanda de energia, ao contrário do que se esperaria, não é estritamente crescente com a diminuição da ENA média de 7 anos. Os maiores deficit foram observados nos períodos de maior permanência, ou seja, 1998-2005 e 1950-1957, e o menor deficit foi observado para a mediana, isto é, 1959-1966. No entanto, para os demais períodos, tal correspondência não foi seguida rigorosamente. 
O período de 1934-1941, por exemplo, cuja ENA média de 7 anos tem permanência de $75 \%$, está entre os três períodos de menor deficit acumulado. Este foi o primeiro dos períodos analisados em que a geração de energia manteve-se acima de $95 \%$ da demanda objetivo em todos os 84 meses da otimização. O maior deficit percentual observado no período representou $4 \%$ da demanda objetivo.

Por outro lado, o período de 1985-1992, cuja permanência de ENA é de 55\%, registrou um deficit acumulado semelhante ao do período de 1967-1971, cuja permanência de ENA é de 70\%. Em ambos os períodos o desempenho mostrou-se pior que o do período de 1934-1941. E o período de 1935-1942, cuja permanência de ENA é de 60\%, apresentou um desempenho quase idêntico ao da mediana.

Essa variação pode ser explicada pelas diferenças observadas entre as regiões fisiográficas da bacia, discutidas no Capítulo 5. Os valores da ENA média podem ocultar a ocorrência, em um mesmo período, de chuvas muito acima da média em uma região fisiográfica e de chuvas muito abaixo do esperado em outra região. O Alto São Francisco segue um regime hidrológico que difere muito do regime do Médio e Submédio São Francisco. Além disso, a capacidade instalada na bacia distribui-se de forma muito desigual entre essas regiões.

Obviamente, essa observação acerca da variação da geração média com a variação da ENA média de 7 anos reflete as restrições impostas ao problema nesta análise, principalmente no que se refere ao armazenamento exigido no último mês da otimização, considerado igual ao volume útil menos o volume de espera para controle de cheias.

Percebe-se, contudo, que, sob as restrições definidas neste estudo, as usinas hidrelétricas da bacia do São Francisco não conseguiram, em conjunto, gerar nem o equivalente a $95 \%$ de sua garantia física com o regime de vazões registrado em 1998-2005, período crítico da bacia, e em 1950-1957, período tido como crítico para o SIN. Uma vez que, nesta análise, foi considerado o valor de uso consuntivo adotado pelo ONS em 2011, entende-se que o desempenho das usinas seria ainda mais impactado negativamente se as demandas consuntivas fossem consideradas iguais ao consumo outorgado na bacia. 


\section{CONCLUSÕES}

Neste trabalho foi desenvolvida uma nova função objetivo para o modelo HIDRO adequada à aplicação da programação não linear para avaliar o impacto das demandas hídricas consuntivas na operação de um sistema de reservatórios para geração de energia elétrica situados em uma bacia hidrográfica marcada por múltiplos usos do recurso hídrico. O conjunto de variáveis de decisão do modelo inclui não apenas a vazão turbinada e a vazão vertida em cada usina hidrelétrica, como também a vazão retirada para suprimento dos usos consuntivos.

Novas restrições também foram adicionadas ao modelo HIDRO de forma a contemplar o atendimento dos usos da água considerados prioritários abastecimento urbano e rural e criação animal - em situações de indisponibilidade hídrica. A demanda de energia foi agregada em um único valor, de modo a permitir que todas as usinas hidrelétricas da região de estudo contribuam para o atendimento global. As demandas hídricas consuntivas foram agregadas por usina, segundo a localização dos usuários nas áreas de contribuição incremental de cada reservatório.

O novo equacionamento foi implementado no modelo HIDRO com o uso da ferramenta de programação GAMS, de forma que a metodologia pode ser adaptada e aplicada a sistemas de reservatórios quaisquer. As aplicações do modelo foram realizadas para a bacia hidrográfica do rio São Francisco, utilizando-se o pacote de otimização MINOS para a solução do problema.

Face à discrepância das informações referentes à vazão consumida na bacia, foram criados seis cenários de demanda hídrica consuntiva. As vazões afluentes aos reservatórios assumiram os valores observados nos períodos da série histórica de afluência em que foram registradas as estiagens mais intensas na bacia.

Observou-se que o período crítico de afluência na bacia do São Francisco foi registrado entre os anos de 1998 e 2005, diferentemente do que o setor elétrico adota para o SIN, que é entre 1950 e 1956. Em decorrência disso, o deficit no atendimento da demanda objetivo de recurso hídrico mostrou-se 2 a 5 vezes menor no período 1950-1956 em relação ao período 1998-2005, dependendo do cenário de 
demanda consuntiva considerado. No atendimento da demanda objetivo de energia, essa relação variou de 1,5 a 3 vezes.

A escassez do período 1950-1956 mostrou-se mais intensa apenas na área da bacia situada a montante de Três Marias, a qual apresenta o regime de chuvas típico do Sudeste brasileiro, cujo histórico de afluências tem como período crítico a primeira metade da década de 1950. Para este período de afluência, o modelo HIDRO não obteve solução viável para defluência mínima de $500 \mathrm{~m}^{3} / \mathrm{s}$ de Três Marias, além de ter sido fornecida uma vazão equivalente a apenas $40 \%$ da demanda consuntiva na área a montante desta usina. Ressalta-se que a navegação entre Três Marias e Sobradinho só se realiza se a vazão no trecho for superior a $500 \mathrm{~m}^{3} / \mathrm{s}$.

Observou-se também que, no período crítico de 1998-2005, para valores de demanda hídrica consuntiva próximos aos adotados pelo ONS em 2011, não se registra deficit significativo no atendimento dos usos consuntivos. No entanto a geração de energia pelas usinas hidrelétricas no período não alcançou o valor de suas respectivas garantias físicas, variando de $73 \%$ a $83 \%$ da energia assegurada.

Caso o valor das demandas consuntivas seja igual ao consumo outorgado na bacia até outubro/2009, os índices de atendimento caem consideravelmente. A geração de energia alcança apenas $65 \%$ da garantia física e a vazão fornecida a usos consuntivos só atende de $81 \%$ a $89 \%$ da demanda.

Esses resultados demonstram que, sob condições de afluência mínima já registradas no histórico, a bacia do São Francisco não apresenta disponibilidade hídrica suficiente para atender todos os usos devidamente outorgados pelo Poder Público e, ao mesmo tempo, gerar, em suas usinas hidrelétricas, o equivalente à garantia física dessas usinas.

Neste cenário de indisponibilidade hídrica, a região da bacia que registra maior deficit de atendimento dos usos consuntivos, tanto em termos absolutos como em relação à demanda, é a área de contribuição incremental do reservatório de Sobradinho. Trata-se da porção da bacia que contribui com $54 \%$ da $Q_{M L T}$ e com $62 \%$ da $Q_{95}$ do rio São Francisco. Ao mesmo tempo, conforme discutido no Capítulo 5, nela se concentra a maior parte dos usos consuntivos da bacia, majoritariamente representados pela irrigação de lavouras.

Esse resultado indica que o ritmo de expansão da irrigação no Médio São Francisco registrado nas últimas décadas pode acarretar impactos na geração de 
energia e também oferecer riscos ao atendimento dos usuários outorgados que, teoricamente, têm garantido seu direito de acesso ao recurso hídrico.

Observou-se também que a operação da transposição das águas do São Francisco para as bacias do Nordeste Setentrional não causa impacto relevante na geração de energia. Cada $\mathrm{m}^{3} / \mathrm{s}$ derivado na transposição representou, em média, uma perda de 2,1 MWmed no período crítico de afluências.

O impacto da transposição sobre o atendimento dos usos consuntivos da própria bacia só é significativo se as demandas hídricas consuntivas forem consideradas iguais ao consumo outorgado. Neste caso, para o período crítico de afluências, registrou-se uma redução média de $24,4 \mathrm{~m}^{3} / \mathrm{s}$ na vazão fornecida aos usos consuntivos, o que representa $4 \%$ do consumo outorgado total na bacia.

Concomitantemente, a operação da transposição não afetou a obediência do limite de vazão defluente mínima em Xingó de $1.300 \mathrm{~m}^{3} / \mathrm{s}$, mesmo na consideração do pior cenário de demanda consuntiva no período de afluência mais escassa.

Ressalta-se que, no período crítico de afluências, por não ter sido registrado vertimento em Sobradinho, a transposição operou em seu limite mínimo de $26,4 \mathrm{~m}^{3} / \mathrm{s}$ em todos os meses da otimização.

No período de 1950-1957, houve meses em que, a despeito da ocorrência de vertimento em Sobradinho, a vazão transposta permaneceu no limite mínimo. Isso mostra que o modelo realizou a operação da transposição submetendo-a a um melhor atendimento das demandas hídrica e de energia da própria bacia do São Francisco, em vez de operá-la de forma isolada.

Finalmente, foram estabelecidas as curvas de Pareto que descrevem a relação de troca entre geração de energia, uso consuntivo e conservação ambiental. As curvas de Pareto entre geração de energia e uso consuntivo mostraram-se praticamente coincidentes tanto no período de afluência crítica de 1998-2005 como no período de 1950-1957. O gradiente obtido foi de $-2,7 \mathrm{MWmed}$ para cada $\mathrm{m}^{3} / \mathrm{s}$ destinado a usos consuntivos no período 1998-2005 e de -1,8 MWmed no período 1950-1957. As curvas obtidas com a transposição inativa mantiveram os mesmo gradientes observados nas curvas levantadas com a operação da transposição.

A geração de energia mostrou-se mais sensível à variação da demanda consuntiva do que a vazão fornecida aos usos consuntivos quando a demanda consuntiva variou de 1 a 3 vezes o valor adotado pelo ONS. A vazão fornecida a uso consuntivo só se mostrou mais sensível do que a geração de energia quando a 
demanda hídrica variou de 3 vezes o valor do ONS para o valor de consumo outorgado.

Observou-se também que essa relação de troca entre geração de energia e uso consuntivo torna-se mais intensa quando se atribui à geração de energia uma preferência relativa de $75 \%$ a $90 \%$, isto é, quando se atribui aos usos consuntivos uma preferência relativa de $10 \%$ a $25 \%$.

Foi observado que a conservação ambiental não estabelece trade-off significativo com a geração de energia nem com os usos consuntivos, principalmente no período 1998-2005. No período 1950-157, no qual se registra escassez no trecho da bacia a montante de Três Marias, os trade-offs foram um pouco mais expressivos. Ainda assim, só foram obtidos gradientes significativos quando a demanda consuntiva foi considerada igual ao consumo outorgado. Neste caso, foi observado que o aumento de $1 \mathrm{~m}^{3} / \mathrm{s}$ no limite mínimo de defluência de Três Marias implica uma diminuição de $0,2 \mathrm{~m}^{3} / \mathrm{s}$ no atendimento dos usos consuntivos. Por outro lado, para cada $\mathrm{m}^{3} / \mathrm{s}$ adicionado ao limite mínimo de defluência em Três Marias, ocorre um aumento de 0,7 MWmed na geração de energia.

Todas essas considerações demonstram que a bacia do rio São Francisco está exposta a uma situação de conflito pelo uso do recurso hídrico que pode acarretar custos significativos no futuro por conta da expansão das demandas consuntivas nas áreas que mais contribuem para a disponibilidade hídrica superficial. Observou-se que, se as demandas consuntivas alcançarem valores iguais ao consumo outorgado até outubro/2009 na bacia, a perda média na geração de energia no período crítico de afluências pode chegar a $1134 \mathrm{MWmed}$ em relação à geração obtida com uso consuntivo igual ao adotado pelo ONS. Essa perda equivale a $\mathrm{R} \$ 693$ milhões ao ano, considerando o preço médio de $\mathrm{R} \$ 72 / \mathrm{MWh}$. Somam-se ainda a essa perda os custos associados ao despacho de usinas térmicas e também ao deficit no atendimento dos usos consuntivos, cuja estimativa é complexa em razão das dificuldades de se associar valor econômico a um recurso indispensável a diversas atividades econômicas e à vida.

O equacionamento proposto para o modelo HIDRO mostrou-se uma ferramenta adequada à avaliação dos impactos que as demandas hídricas consuntivas impõem à operação dos reservatórios para geração de energia elétrica em uma bacia hidrográfica marcada por conflitos entre os múltiplos usos da água. 
No que se refere à metodologia, a introdução da vazão retirada para uso consuntivo na função objetivo, em vez de considerá-la uma restrição do problema, como atualmente procede o ONS, permitiu não apenas avaliar as relações de compromisso entre diferentes usos da água, como também se mostrou uma técnica interessante para estudos de alocação de água em cenários de escassez.

No que se refere ao esforço computacional requerido pelo modelo, o tempo de processamento dos períodos de 84 meses em um computador equipado com processador Intel $\AA^{\circledR}$ Core ${ }^{\mathrm{TM}}$ Duo $2,4 \mathrm{GHz}$ e memória RAM de 4,0 Gbytes variou de 5 a 30 segundos, chegando poucas vezes ultrapassar esta marca. O tempo de processamento variou conforme a configuração do problema - período de afluência, cenário de demanda consuntiva, restrições de defluência mínima e pesos relativos atribuídos a geração de energia e a uso consuntivo.

Como sugestões para estudos futuros, podem ser considerados:

- Avaliar o impacto dos usos consuntivos na geração de energia considerando diferentes níveis de armazenamento nos reservatórios ao fim do período para estabelecer as melhores regras de deplecionamento e reenchimento em função também das demandas hídricas consuntivas e não apenas do melhor aproveitamento da cascata;

- Expandir a avaliação de impactos na bacia do São Francisco para diferentes cenários futuros, que contemplem projetos em discussão no Governo Federal para reforço da vazão do São Francisco pela transposição de bacias vizinhas, como a do Tocantins e a do Paraná;

- Desagregar a vazão destinada às demandas consuntivas com um todo em vazões fornecidas a usos consuntivos específicos, de forma a avaliar as relações de troca entre geração de energia e cada tipo de uso consuntivo;

- Avaliar o impacto dos usos consuntivos na geração de energia considerando a estocasticidade associada à precipitação e, por consequência, às vazões afluentes aos reservatórios;

- A ampliação da área de estudo com aplicação da metodologia às demais regiões hidrográficas brasileiras, abrangendo não somente as usinas hidrelétricas do SIN, como também as usinas termelétricas e nucleares que integram o sistema, avaliando de forma integrada o impacto do uso consuntivo na geração e no intercâmbio de energia entre os subsistemas. 


\section{REFERÊNCIAS}

ALVES FILHO, J. Transposição das Águas do São Francisco: agressão à natureza x solução ecológica. 2a. ed. Maceió: Edições Catavento, 2000. 192 p.

ANA - Agência Nacional de Águas. Resolução №.145, de 22 de julho de 2002. Dispõe sobre a estimativa da área irrigada e da vazão para irrigação na bacia do rio São Francisco. Disponível em: <http://arquivos.ana.gov.br/resolucoes/2002/1452002.pdf> Acesso em: 5 mar. 2011.

. Resolução nํ.434, de 9 de dezembro de 2003. Dispõe sobre a reducão temporária da descarga mínima defluente dos reservatórios de Sobradinho e Xingó, no rio São Francisco. Disponível em:

<http://arquivos.ana.gov.br/resolucoes/2003/434-2003.pdf> Acesso em: 5 mar. 2011.

. São Francisco River Basin: Physiographic Regions - New Limits 2003. [S.I.], 2003a. 1 mapa. Escala gráfica. Disponível em: < http://archive.iwlearn.net/www.ana.gov.br/www.ana.gov.br/gefsf/Arquivos/NovosLim2 003.jpg > Acesso em: 20 mai. 2012.

. Resolução ํo.139, de 8 de março de 2004. Altera a Resolução $n^{\circ} .434$, que dispõe sobre a reducão temporária da descarga mínima defluente dos reservatórios de Sobradinho e Xingó, no rio São Francisco. Disponível em:

<http://arquivos.ana.gov.br/resolucoes/2004/139-2004.pdf> Acesso em: 5 mar. 2011.

. Resolução $n^{\circ} .411$, de 22 de setembro de 2005. Outorga ao Ministério da Integração Nacional o direito de uso de recursos hídricos do Rio São Francisco para a execução do Projeto de Integração do Rio São Francisco com as Bacias Hidrográficas do Nordeste Setentrional. Disponível em: <http://www.mi.gov.br/saofrancisco/documentos/index.asp> Acesso: 5 mar. 2011.

. Plano Decenal de Recursos Hídricos da Bacia Hidrográfica do Rio São Francisco (2004-2013): síntese executiva com apreciação das deliberações do CBHSF aprovadas na III Reunião Plenária de 28 a 31 de julho de 2004. Brasília: 2005. $152 \mathrm{p}$.

A Navegação Interior e sua Interface com o Setor de Recursos Hídricos e Aproveitamento do Potencial Hidráulico para a Geração de Energia no Brasil. Brasília: 2007. 170 p. (Caderno de Recursos Hídricos; 3).

. Disponibilidade e Demandas de Recursos Hídricos no Brasil. Brasília:

2007a. 123 p. (Caderno de Recursos Hídricos; 2). 
ANA. Atlas Brasil: abastecimento urbano de água. Brasília: 2010. Disponível em: <http://atlas.ana.gov.br/Atlas/forms/Home.aspx> Acesso em 04 abr. 2011.

2010a. 76 p.

Conjuntura dos recursos hídricos no Brasil: informe 2010. Brasília:

ANA/GEF/PNUMA/OEA. Projeto de Gerenciamento Integrado das Atividades Desenvolvidas em Terra na Bacia do Rio São Francisco: Programa de Ações Estratégicas para o Gerenciamento Integrado da Bacia do Rio São Francisco e da sua Zona Costeira - Síntese Executiva. Brasília: TDA, 2004. 48 p.

Projeto de Gerenciamento Integrado das Atividades Desenvolvidas em Terra na Bacia do São Francisco: Sub-projeto 4.5C - Plano Decenal de Recursos Hídricos da Bacia do Rio São Francisco (2004-2013): Agricultura irrigada. Estudo Técnico de Apoio no 12. Brasília: 2004a. 128 p.

Projeto de Gerenciamento Integrado das Atividades Desenvolvidas em Terra na Bacia do Rio São Francisco: Subprojeto 4.5C - Plano Decenal de Recursos Hídricos da Bacia Hidrográfica do Rio São Francisco (2004-2013): Disponibilidade Hídrica Quantitativa e Usos Consuntivos. Estudo Técnico de Apoio № 1. Brasília: 2004b. 63 p.

Projeto de Gerenciamento Integrado das Atividades Desenvolvidas em Terra na Bacia do Rio São Francisco: Subprojeto 4.5C - Plano Decenal de Recursos Hídricos da Bacia Hidrográfica do Rio São Francisco (2004-2013): Aproveitamento do potencial hidráulico para geração de energia elétrica. Estudo Técnico de Apoio no 9. Brasília: 2004c. 58 p.

Projeto de Gerenciamento Integrado das Atividades Desenvolvidas em Terra na Bacia do Rio São Francisco: Subprojeto 4.5C - Plano Decenal de Recursos Hídricos da Bacia Hidrográfica do Rio São Francisco (2004-2013): Alocação de água. Estudo Técnico de Apoio no 16. Brasília: 2004d. 53 p.

ANEEL - Agência Nacional de Energia Elétrica. Atlas de Energia Elétrica do Brasil. Brasília: 2008. 236 p.

Banco de Informações de Geração. 2012. Disponível em: <http://www.aneel.gov.br> Acesso em: 03 mai. 2012.

AZEVEDO, L.G.T.; PORTO, R.L.L.; ZAHED FILHO, K. Modelos de Simulação e de Rede de Fluxo. In: PORTO, R.L.L. (Org.). Técnicas quantitativas para 0 gerenciamento de Recursos Hídricos. Porto Alegre: Editora da UFRGS/ABRH, 2002. P. 165-227. 
BARROS, M.T.L. et al. Otimização de sistemas de adução de água: o modelo SISAGUA. In: SIMPÓSIO BRASILEIRO DE RECURSOS HÍDRICOS, 16., 2005, João Pessoa. Anais... João Pessoa: Associação Brasileira de Recursos Hídricos (ABRH), 2005.

. Model to Optimize Large Hydrothermal System Operation Considering Water and Environment Sustainability. In: WORLD ENVIRONMENTAL \& WATER RESOURCES CONGRESS, 2008, Honolulu. Procedures... Honolulu: American Society of Civil Engineers (ASCE), 2008.

. Impacts of the Upstream Storage Reservoirs on Itaipu Hydropower Plant Operation. In: WORLD ENVIRONMENTAL \& WATER RESOURCES CONGRESS, 2009, Kansas City. Procedures... Kansas City: ASCE, 2009.

BRANDÃO, J.L.B. Modelo para operação de sistemas de reservatórios com usos múltiplos. 2004. 160 p. Tese (Doutorado) - Escola Politécnica, Universidade de São Paulo, São Paulo, 2004.

BRASIL. Decreto ํ․ 24.643, de 10 de julho de 1934. Decreta o Código de Águas. Disponível em: <http://www.planalto.gov.br> Acesso em: 04 jun. 2006.

. Constituição (1988). Constituição da República Federativa do Brasil. São Paulo: Editora Escala, [2006].

. Lei Federal no. 9.433, de 8 de janeiro de 1997. Institui a Política Nacional de Recursos Hídricos, cria o Sistema Nacional de Gerenciamento dos Recursos Hídricos, regulamenta o inciso XIX do artigo $21 \mathrm{da} \mathrm{CF}$, e altera o artigo 1․ da Lei 8.001 de 13.03.1990 que modificou a Lei 7.990, de 28.12.1989. Disponível em: <http://www.mma.gov.br> Acesso em: 04 jun. 2006.

. Ministério de Minas e Energia (MME). Portaria no. 258, de 28 de julho de 2008. Define a metodologia de cálculo da garantia física de novos empreendimentos de geração de energia elétrica do Sistema Interligado Nacional - SIN, conforme metodologia constante do Anexo I. Disponível em: <http://www.mme.gov.br> Acesso em: 04 dez. 2011.

MME/EPE, 2010. 2 v.

Plano Nacional de Expansão de Energia 2019. Brasília:

. Resenha Energética Brasileira: Exercício de 2010 (Preliminar).

Brasília: 2011. Disponível em:<http://www.portalpch.com.br>Acesso em:19 jul.2011. 
BURTON, R. Viagem de canoa de Sabará ao Oceano Atlântico. Tradução de David Jardim Júnior. Belo Horizonte: Ed. Itatiaia; São Paulo: EDUSP, 1977. 359 p.

CABRAL, B.; KELMAN, J. Quem é responsável pela administração dos rios? Revista Justiça e Cidadania, Rio de Janeiro, ํo. 36, jul. 2003. Disponível em: <http://www.kelman.com.br> Acesso em: 04 jun. 2006.

CBHSF - Comitê da Bacia Hidrográfica do Rio São Francisco. Disponível em: <http://www.saofrancisco.cbh.gov.br> Acesso em: 25 mar. 2011.

CCEE - Câmara de Comercialização de Energia Elétrica. Deck de Preços. 2011. Disponível em: $<$ http://www.ccee.org.br/StaticFile/Arquivo/biblioteca_virtual/NW201101.zip > Acesso em: 03 mai. 2012.

. Deck de Preços. 2012. Disponível em:

<http://www.ccee.org.br/StaticFile/Arquivo/biblioteca_virtual/NW201205.zip> Acesso em: 03 mai. 2012.

Comercialização de Energia: Preços. 2012a. Disponível em:

<http://www.ccee.org.br> Acesso em: 27 mai. 2012.

CEPEL - Centro de Pesquisa de Energia Elétrica. Manual de referência: modelo NEWAVE. Disponível em: <http://www.cose.fee.unicamp.br> Acesso em: 11 fev. 2011.

CHESF - Companhia Hidro Elétrica do São Francisco. Demonstrações Financeiras 2011. [S.I.]: 2012. Disponível em: < http://www.chesf.gov.br/portal/page/portal/chesf_portal/conteudos_portal/docs/CHES F_Demonstracoes_Financeiras_2011x.pdf> Acesso em: 02 mai. 2012.

CIRILO, J.A. Programação Não Linear Aplicada a Recursos Hídricos. In: PORTO, R.L.L. (Org.). Técnicas quantitativas para o gerenciamento de Recursos Hídricos. Porto Alegre: Editora da UFRGS/ABRH, 2002. p. 305-359.

CODEVASF - Companhia de Desenvolvimento dos Vales do São Francisco e do Parnaíba. Disponível em: <http://www.codevasf.gov.br> Acesso em: 25 mar. 2011.

DESO - Companhia de Saneamento de Sergipe. Adutora do São Francisco -

Deso. Disponível em: <http://www.deso-se.com.br> Acesso em: 30 mar. 2011. 
ELETROBRÁS - Centrais Elétricas Brasileiras S.A. Sistema de Informações do Potencial Hidrelétrico Brasileiro (SIPOT). Disponível em:

<http://www.eletrobras.com> Acesso em: 30 mar. 2011.

EPE - Empresa de Pesquisa Energética. Balanço Energético Nacional 2007: Ano base 2006. Rio de Janeiro: EPE, 2007. 60 p.

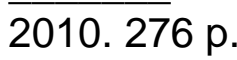

Balanço Energético Nacional 2010: Ano base 2009. Rio de Janeiro:

KELMAN, J. et al. Hidreletricidade. In: REBOUÇAS, A.C.; BRAGA, B.; TUNDISI, J.G. (Org.). Águas Doces no Brasil: capital ecológico, uso e conservação. 3a . ed. São Paulo: Escrituras Editora, 2006. cap. 16, p. 507-543.

LABADIE, J.W. Optimal Operation of Multireservoir Systems: State-of-the-Art Review. ASCE: Journal of Water Resources Planning and Management, v.130, n.2, p. 93-111, março/abril 2004.

LOPES, J.E.G. Otimização de Sistemas Hidroenergéticos. 2001. 85 p.

Dissertação (Mestrado) - Escola Politécnica, Universidade de São Paulo, São Paulo, 2001.

. Modelo de planejamento da operação de sistemas hidrotérmicos de produção de energia elétrica. 2007. 141 p. Tese (Doutorado) - Escola Politécnica, Universidade de São Paulo, São Paulo, 2007.

MENDES, L.A. Análise dos critérios de outorga de direito de usos consuntivos dos recursos hídricos baseados em vazões mínimas e em vazões de permanência. 2007. 187 p. Dissertação (Mestrado) - Escola Politécnica, Universidade de São Paulo, São Paulo, 2007.

MINAS GERAIS. Assembleia Legislativa. Rio São Francisco: patrimônio cultural e natural. Belo Horizonte: ALMG, 2003. 182 p.

MOLION, L.C.B. Águas do Tocantins para o São Francisco. Ciência Hoje, v.33, n.197, p. 58-61, fev. 2003. Disponível em:

<http://www.sfrancisco.bio.br/arquivos/Molion\%20LCB001.pdf> Acesso em: 30 mar. 2011.

ONS - Operador Nacional do Sistema Elétrico. Evaporações líquidas nas usinas hidrelétricas. Rio de Janeiro: 2004. 61 p. (Relatório RE 3/214/2004) 
ONS. Glossário de termos técnicos. Rio de Janeiro: 2009. 46 p. (Procedimentos de Rede - Submódulo 20.1)

. Curva bianual de aversão ao risco para a Região Nordeste: biênio 2011/2012. Rio de Janeiro: 2010. 16 p. (Nota Técnica NT 128/2010)

. Diretrizes para as regras de operação de controle de cheias: bacia do rio São Francisco (ciclo 2010-2011). Rio de Janeiro: 2010a. 164 p. (Relatório RE $3 / 175 / 2010)$

. Inventário das restrições operativas hidráulicas dos aproveitamentos hidrelétricos. Revisão 1. Rio de Janeiro: 2011. 149 p. (Relatório RE 3/039/2011)

Série de vazões naturais médias mensais. 2011a. Disponível em: <http://www.ons.org.br/operacao/vazoes_naturais.aspx> Acesso em: 01 fev. 2011.

. Diagrama Esquemático das Usinas Hidrelétricas do SIN. $2011 \mathrm{~b}$.

Disponível em: <http://www.ons.org.br/conheca_sistema/mapas_sin.aspx\#> Acesso em: 25 mai 2011.

ROBERTO, A.N.; PORTO, R.L.L. Alocação de água entre múltiplos usos em uma bacia hidrográfica. In: SIMPÓSIO BRASILEIRO DE RECURSOS HÍDRICOS, 13., 1999, Belo Horizonte. Anais... Belo Horizonte: ABRH, 1999.

SCHARDONG, A. et al. Aplicação de técnicas de programação linear e extensões para otimização da alocação da água em sistemas de recursos hídricos considerando amortecimento em canais. In: SIMPÓSIO DE RECURSOS HÍDRICOS DO SUL-SUDESTE, 1., 2006, Curitiba. Anais... Curitiba: ABRH, 2006.

SERGIPE. Secretaria de Estado do Meio Ambiente e Recursos Hídricos. Gestão Integrada das Águas Urbanas em Aracaju-SE/Brasil: Relatório do Diagnóstico Qualitativo. Aracaju: 2010.54 p.

UFBA - Universidade Federal da Bahia. Regime de vazões ecológicas como condicionantes da cadeia produtiva: um estudo de cenários no baixo curso do rio São Francisco - Relatório Final. Salvador: 2010. 342 p.

ZAMBON, R.C. Planejamento da operação de sistemas hidrotérmicos de grande porte. 2008. 104 p. Tese (Doutorado) - Escola Politécnica, Universidade de São Paulo, São Paulo, 2008. 
ZAMBON, R.C. et al. Economical Impacts on the Brazilian Hydrothermal System Production due to the Newly Imposed Constraints on Storage Reservoirs. In: WORLD ENVIRONMENTAL \& WATER RESOURCES CONGRESS, 2010,

Providence. Procedures... Providence: ASCE, 2010.

. Planning Operation of Large-Scale Hydrothermal System. In: WORLD ENVIRONMENTAL \& WATER RESOURCES CONGRESS, 2011, Palm Springs. Procedures... Palm Springs: ASCE, 2011.

\section{REFERÊNCIAS COMPLEMENTARES}

ANA. Resolução no ${ }^{131}$, de 11 de março de 2003. Dispõe sobre procedimentos referentes à emissão de declaração de reserva de disponibilidade hídrica e de outorga de direito de uso de recursos hídricos, para uso de potencial de energia hidráulica superior a $1 \mathrm{MW}$ em corpo de água de domínio da União e dá outras providências. Disponível em: <http://www.ana.gov.br> Acesso em: 07 jan. 2008.

\section{ANEEL. Compensação financeira pela utilização de recursos hídricos.}

Disponível em: <http://www.aneel.com.br> Acesso em: 07 jan. 2008.

BRASIL. Lei Federal no. 7.990, de 28 de dezembro de 1989. Institui, para os Estados, Distrito Federal e Municípios, compensação financeira pelo resultado da exploração de petróleo ou gás natural, de recursos hídricos para fins de geração de energia elétrica, de recursos minerais em seus respectivos territórios, plataforma continental, mar territorial ou zona econômica exclusiva, e dá outras providências. Disponível em: <http://www.lei.adv.br> Acesso em: 07 jan. 2008.

. Lei Federal no. 8.001, de 13 de março de 1990. Define os percentuais da distribuição da compensação financeira de que trata a Lei 7.990 de 28.12 .1989 e dá outras providências. Disponível em: <http://www.lei.adv.br> Acesso em: 07 jan.2008.

Decreto ํo.1, de 11 de janeiro de 1991. Regulamenta o pagamento da compensação financeira instituída pela Lei 7.990 de 28.12.1989 e dá outras providências. Disponível em: <http://www.planalto.gov.br> Acesso em: 07 jan. 2008.

. Lei Federal no. 9.984, de 17 de julho de 2000. Dispõe sobre a criação da Agência Nacional de Águas (ANA), entidade federal de implementação da Política Nacional de Recursos Hídricos e de coordenação do Sistema Nacional de Gerenciamento de Recursos Hídricos, e dá outras providências. Disponível em: <http://www.planalto.gov.br> Acesso em: 04 jun. 2006. 
BRASIL. Ministério do Meio Ambiente (MMA). Plano Nacional de Recursos Hídricos - Síntese Executiva. Brasília: MMA, 2006. 135 p.

HENKES, S.L. Histórico legal e institucional dos recursos hídricos no Brasil. Jus Navigandi. Teresina, a. 7, n. 66, jun. 2003. Disponível em:

<http://jus2.uol.com.br/doutrina/texto.asp?id=4146> Acesso em: 04 jun. 2006.

LANNA, A.E. Gestão dos recursos hídricos. In: TUCCI, C.E.M. (Org.). Hidrologia: ciência e aplicação. Porto Alegre: Editora da UFRGS/ABRH, 1993. p. 727-768.

OLIVE, D.J. Applied Robust Statistics. Carbondale: Southern Illinois University, 2008. 588 p. Disponível em: < http://www.math.siu.edu/olive/ol-bookp.htm> Acesso em: 28 jul. 2010.

SILVA, D.D.; PRUSKI, F.F. Gestão de recursos hídricos: aspectos legais, econômicos, administrativos e sociais. Viçosa-MG: Ed. Folha de Viçosa, 2000. 659p. 


\section{APÊNDICE}

Código do modelo HIDRO em linguagem GAMS 


\section{Código do modelo HIDRO com a operação da transposição do São Francisco}

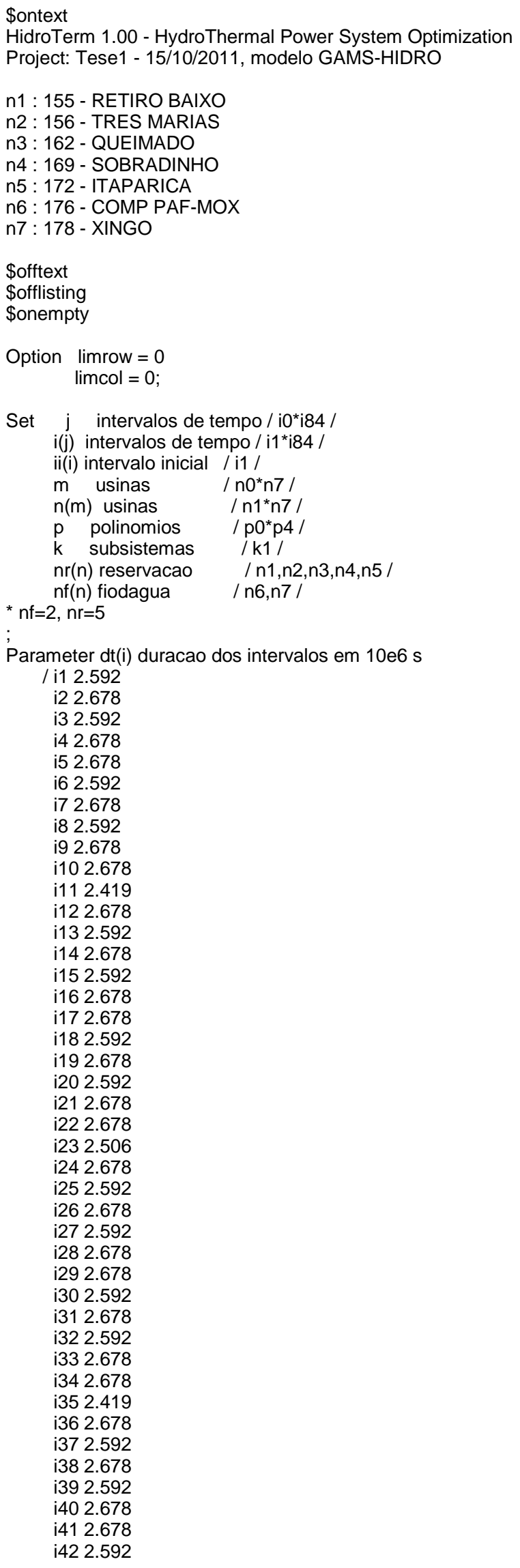




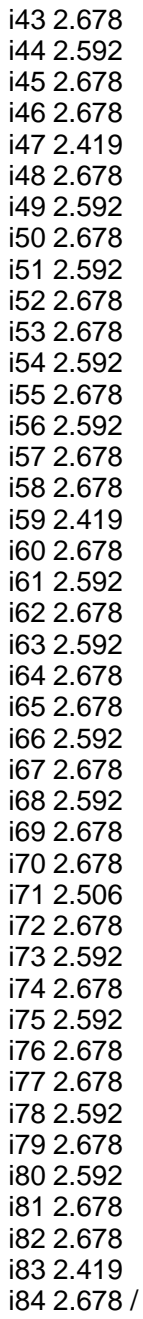

Table DD $(k, i)$ demanda energetica objetivo \$ondelim

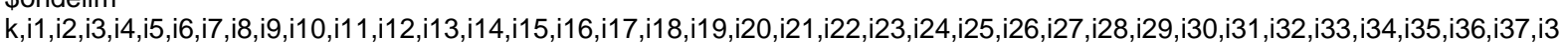

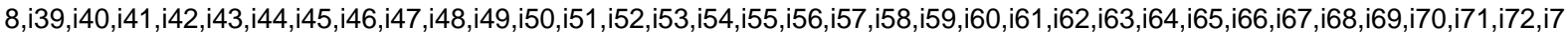
$3, i 74, i 75, i 76, i 77, i 78, i 79, i 80, i 81, i 82, i 83, i 84$

k1,6189.5,6189.5,6189.5,6189.5,6189.5,6189.5,6189.5,6189.5,6189.5,6189.5,6189.5,6189.5,6189.5,6189.5,6189.5,6189.5,618 $9.5,6189.5,6189.5,6189.5,6189.5,6189.5,6189.5,6189.5,6189.5,6189.5,6189.5,6189.5,6189.5,6189.5,6189.5,6189.5,6189.5,61$ $89.5,6189.5,6189.5,6189.5,6189.5,6189.5,6189.5,6189.5,6189.5,6189.5,6189.5,6189.5,6189.5,6189.5,6189.5,6189.5,6189.5,6$ $189.5,6189.5,6189.5,6189.5,6189.5,6189.5,6189.5,6189.5,6189.5,6189.5,6189.5,6189.5,6189.5,6189.5,6189.5,6189.5,6189.5$, $6189.5,6189.5,6189.5,6189.5,6189.5,6189.5,6189.5,6189.5,6189.5,6189.5,6189.5,6189.5,6189.5,6189.5,6189.5,6189.5,6189.5$ \$offdelim

Table $\mathrm{DH}(\mathrm{n}, \mathrm{i})$ demanda hidrica objetivo

\$ondelim

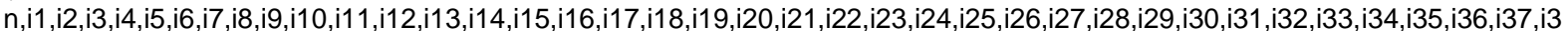

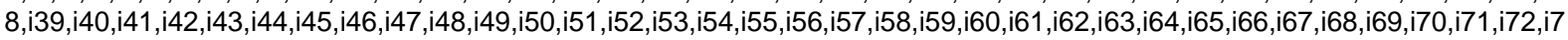
$3, \mathrm{i} 74, \mathrm{i} 75, \mathrm{i} 76, \mathrm{i} 77, \mathrm{i} 78, \mathrm{i} 79, \mathrm{i} 80, \mathrm{i} 81, \mathrm{i} 82, \mathrm{i} 83, \mathrm{i} 84$

${ }^{*} \mathrm{DH}=$ ons

n1,2.7,1.8,2.3,2.3,2,2.3,1.4,1,1,1.2,2.4,1.5,2.7,1.8,2.3,2.3,2,2.3,1.4,1,1,1.2,2.4,1.5,2.7,1.8,2.3,2.3,2,2.3,1.4,1,1,1.2,2.4,1.5,2.7,1. $8,2.3,2.3,2,2.3,1.4,1,1,1.2,2.4,1.5,2.7,1.8,2.3,2.3,2,2.3,1.4,1,1,1.2,2.4,1.5,2.7,1.8,2.3,2.3,2,2.3,1.4,1,1,1.2,2.4,1.5,2.7,1.8,2.3,2.3$ $, 2,2.3,1.4,1,1,1.2,2.4,1.5$

n2,9.6,6.4,8.3,8,7.1,8,4.9,3.6,3.5,4.2,8.4,5.4,9.6,6.4,8.3,8,7.1,8,4.9,3.6,3.5,4.2,8.4,5.4,9.6,6.4,8.3,8,7.1,8,4.9,3.6,3.5,4.2,8.4,5.4, 9.6,6.4,8.3,8,7.1,8,4.9,3.6,3.5,4.2,8.4,5.4,9.6,6.4,8.3,8,7.1,8,4.9,3.6,3.5,4.2,8.4,5.4,9.6,6.4,8.3,8,7.1,8,4.9,3.6,3.5,4.2,8.4,5.4,9.6 $6.4,8.3,8,7.1,8,4.9,3.6,3.5,4.2,8.4,5.4$

n3,1.1,1.2,1,1.7,2,2.1,0.5,0.2,0.2,0.2,0.2,0.6,1.1,1.2,1,1.7,2,2.1,0.5,0.2,0.2,0.2,0.2,0.6,1.1,1.2,1,1.7,2,2.1,0.5,0.2,0.2,0.2,0.2,0.6, $1.1,1.2,1,1.7,2,2.1,0.5,0.2,0.2,0.2,0.2,0.6,1.1,1.2,1,1.7,2,2.1,0.5,0.2,0.2,0.2,0.2,0.6,1.1,1.2,1,1.7,2,2.1,0.5,0.2,0.2,0.2,0.2,0.6,1.1$ $1.2,1,1.7,2,2.1,0.5,0.2,0.2,0.2,0.2,0.6$

n4,71,73.9,79.4,73.5,87.7,92.4,48.9,17.7,16.9,50.6,62.1,30.7,71,73.9,79.4,73.5,87.7,92.4,48.9,17.7,16.9,50.6,62.1,30.7,71,73.9 $, 79.4,73.5,87.7,92.4,48.9,17.7,16.9,50.6,62.1,30.7,71,73.9,79.4,73.5,87.7,92.4,48.9,17.7,16.9,50.6,62.1,30.7,71,73.9,79.4,73.5$, $87.7,92.4,48.9,17.7,16.9,50.6,62.1,30.7,71,73.9,79.4,73.5,87.7,92.4,48.9,17.7,16.9,50.6,62.1,30.7,71,73.9,79.4,73.5,87.7,92.4$, $48.9,17.7,16.9,50.6,62.1,30.7$

n5,47.9,49.1,40.1,46.5,57.6,68.5,69.3,70.4,40.9,57.1,45.7,17.9,47.9,49.1,40.1,46.5,57.6,68.5,69.3,70.4,40.9,57.1,45.7,17.9,47. $9,49.1,40.1,46.5,57.6,68.5,69.3,70.4,40.9,57.1,45.7,17.9,47.9,49.1,40.1,46.5,57.6,68.5,69.3,70.4,40.9,57.1,45.7,17.9,47.9,49.1$, 
$40.1,46.5,57.6,68.5,69.3,70.4,40.9,57.1,45.7,17.9,47.9,49.1,40.1,46.5,57.6,68.5,69.3,70.4,40.9,57.1,45.7,17.9,47.9,49.1,40.1,4$ $6.5,57.6,68.5,69.3,70.4,40.9,57.1,45.7,17.9$

n6,2.2.2.1,1.4,1.3,1.9,2.7,2.6,2.9,1.8,2.6,2.2,1,2.2,2.1,1.4,1.3,1.9,2.7,2.6.2.9,1.8,2.6,2.2,1,2.2,2.1,1.4,1.3,1.9,2.7,2.6,2.9,1.8,2.6,

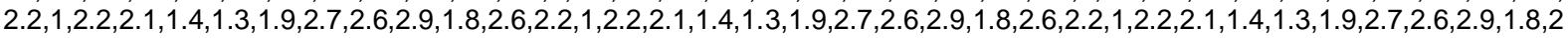
$6,2.2,1,2.2,2.1,1.4,1.3,1.9,2.7,2.6,2.9,1.8,2.6,2.2,1$

n7, $0.3,0.3,0.2,0.2,0.2,0.3,0.3,0.4,0.3,0.3,0.3,0.2,0.3,0.3,0.2,0.2,0.2,0.3,0.3,0.4,0.3,0.3,0.3,0.2,0.3,0.3,0.2,0.2,0.2,0.3,0.3,0.4,0.3$, $0.3,0.3,0.2,0.3,0.3,0.2,0.2,0.2,0.3,0.3,0.4,0.3,0.3,0.3,0.2,0.3,0.3,0.2,0.2,0.2,0.3,0.3,0.4,0.3,0.3,0.3,0.2,0.3,0.3,0.2,0.2,0.2,0.3,0.3$ $, 0.4,0.3,0.3,0.3,0.2,0.3,0.3,0.2,0.2,0.2,0.3,0.3,0.4,0.3,0.3,0.3,0.2$

\$offdelim

Table QI(n,i) vazao afluente

\$ondelim

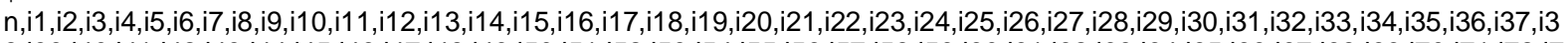

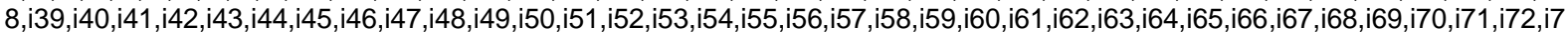
$3, \mathrm{i} 74, \mathrm{i} 75, \mathrm{i} 76, \mathrm{i} 77, \mathrm{i} 78, \mathrm{i} 79, \mathrm{i} 80, \mathrm{i} 81, \mathrm{i} 82, \mathrm{i} 83, \mathrm{i} 84$

n1 $116,92,109,68,68,42,72,151,153,207,103,289,117,84,58,50,42,40,49,110,157,255,380,242,140,89,71,59,50,73,48,140,252$, $166,68,98,46,39,38,32,32,34,51,94,183,292,361,200,100,76,58,51,42,55,38,101,245,502,269,224,131,80,65,58,53,44,38,65,16$ $3,350,284,231,208,129,89,79,62,42,47,50,218,340,263,384$

n2,511,457,379,256,248,196,262,681,698,907,600,1637,533,343,216,193,106,104,133,608,759,1069,2131,1451,688,419,310, $239,166,240,112,570,915,741,322,445,215,158,138,117,111,119,199,428,796,1329,1808,961,428,304,233,187,112,159,86,34$ $5,860,1656,1178,883,488,327,249,218,169,151,101,220,718,1288,1791,1838,1050,477,394,332,261,195,196,210,1009,1721,1$ 247,1617

n3,33,27,23,19,15,12,17,54,73,52,38,71,36,29,24,21,17, 15,18,27,53,64,72,90,56,42,34,29,22,25,17,35,72,52,36,55,35,27, 22, 1 $7,14,13,16,45,46,61,62,48,41,29,24,20,15,14,9,18,37,52,41,54,57,37,27,21,19,19,15,21,25,78,167,126,115,76,59,47,43,37,35$, $38,55,53,82,129$

n4,1536,1122,950,838,751,620,704,1994,3241,3013,1827,4212,2245,1201,874,787,663,695,570,1601,2990,4169,5271,4455,3 $316,1730,1188,930,923,918,703,1823,3655,3158,1695,1719,1096,845,824,645,632,659,714,1201,2187,4440,4761,3516,2234$, $1074,883,851,644,506,665,936,1871,4118,4387,2737,2604,1374,983,890,747,680,506,843,1611,3233,5002,6786,5329,2737,1$ $493,1304,1010,899,889,1063,1841,4123,4915,4807$

n5,1636,1226,974,839,785,660,684,1852,3209,3166,1922,4005,2595,1329,914,797,689,793,597,1516,3186,4332,5182,4516,3 $676,1828,1231,960,1011,936,806,1717,3668,3465,1803,1795,1326,847,836,680,631,657,750,1156,2171,5244,4766,3671,236$ $2,1110,894,847,662,501,672,909,1783,4087,4574,2720,2712,1406,998,896,755,687,507,823,1582,3017,4910,6771,5422,2941$ $, 1526,1316,1027,905,883,1044,1734,4052,4988,4912$

n6,1686,1252,983,851,787,719,709,1842,3204,3196,1957,3892,2714,1336,933,797,697,782,619,1479,3223,4364,5092,4530,3 $789,1855,1243,964,1018,934,852,1653,3616,3553,1826,1767,1377,862,850,685,631,668,737,1135,2147,5244,4766,3671,236$ $2,1110,894,847,662,501,672,909,1783,4087,4574,2720,2712,1406,998,896,755,687,507,823,1582,3017,4910,6771,5422,2941$ $, 1526,1316,1027,905,883,1044,1734,4052,4988,4912$

n7,1686,1252,983,851,787,719,710,1843,3204,3196,1957,3892,2714,1336,933,797,697,782,619,1480,3224,4364,5092,4530,3 $789,1855,1243,964,1018,934,852,1654,3616,3553,1826,1767,1377,862,850,685,631,668,737,1135,2147,5244,4766,3671,236$ $2,1110,894,847,662,501,672,909,1783,4087,4574,2720,2712,1406,998,896,755,687,507,823,1582,3017,4910,6771,5422,2941$ $, 1526,1316,1027,905,883,1044,1734,4052,4988,4912$

\$offdelim

Table Ev(n,i) evaporacao

\$ondelim

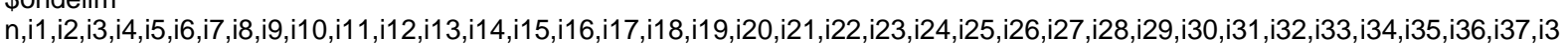

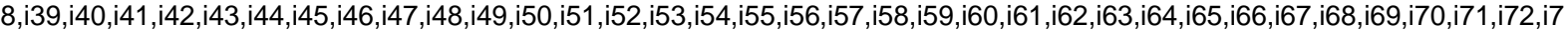
$3, \mathrm{i} 74, \mathrm{i} 75, \mathrm{i} 76, \mathrm{i} 77, \mathrm{i} 78, \mathrm{i} 79, \mathrm{i} 80, \mathrm{i} 81, \mathrm{i} 82, \mathrm{i} 83, \mathrm{i} 84$

$\mathrm{n} 1,0.03,0.045,0.049,0.069,0.083,0.06,0.03,0.001,-0.012,-0.021,-0.014,0.009,0.03,0.045,0.049,0.069,0.083,0.06,0.03,0.001$,$0.012,-0.021,-0.014,0.009,0.03,0.045,0.049,0.069,0.083,0.06,0.03,0.001,-0.012,-0.021,-$

$0.014,0.009,0.03,0.045,0.049,0.069,0.083,0.06,0.03,0.001,-0.012,-0.021,-$

$0.014,0.009,0.03,0.045,0.049,0.069,0.083,0.06,0.03,0.001,-0.012,-0.021,-$

$0.014,0.009,0.03,0.045,0.049,0.069,0.083,0.06,0.03,0.001,-0.012,-0.021,-$

$0.014,0.009,0.03,0.045,0.049,0.069,0.083,0.06,0.03,0.001,-0.012,-0.021,-0.014,0.009$

n2, $0.047,0.061,0.061,0.058,0.049,0.049,0.035,0.021,0.022,-0.001$

$0.002,0.028,0.047,0.061,0.061,0.058,0.049,0.049,0.035,0.021,0.022,-0.001$,

$0.002,0.028,0.047,0.061,0.061,0.058,0.049,0.049,0.035,0.021,0.022,-0.001$,

$0.002,0.028,0.047,0.061,0.061,0.058,0.049,0.049,0.035,0.021,0.022,-0.001,-$

$0.002,0.028,0.047,0.061,0.061,0.058,0.049,0.049,0.035,0.021,0.022,-0.001$,-

$0.002,0.028,0.047,0.061,0.061,0.058,0.049,0.049,0.035,0.021,0.022,-0.001$

$0.002,0.028,0.047,0.061,0.061,0.058,0.049,0.049,0.035,0.021,0.022,-0.001,-0.002,0.028$

$\mathrm{n} 3,0.033,0.059,0.07,0.077,0.079,0.08,0.051,0.017,0.051,0.021,0.004,0.021,0.033,0.059,0.07,0.077,0.079,0.08,0.051,0.017,0.0$ $51,0.021,0.004,0.021,0.033,0.059,0.07,0.077,0.079,0.08,0.051,0.017,0.051,0.021,0.004,0.021,0.033,0.059,0.07,0.077,0.079,0$. $08,0.051,0.017,0.051,0.021,0.004,0.021,0.033,0.059,0.07,0.077,0.079,0.08,0.051,0.017,0.051,0.021,0.004,0.021,0.033,0.059,0$ $.07,0.077,0.079,0.08,0.051,0.017,0.051,0.021,0.004,0.021,0.033,0.059,0.07,0.077,0.079,0.08,0.051,0.017,0.051,0.021,0.004,0$. 021

n4,0.056,0.108,0.104,0.165,0.203,0.234,0.267,0.245,0.223,0.171,0.109,0.061,0.056,0.108,0.104,0.165,0.203,0.234,0.267,0.24 $5,0.223,0.171,0.109,0.061,0.056,0.108,0.104,0.165,0.203,0.234,0.267,0.245,0.223,0.171,0.109,0.061,0.056,0.108,0.104,0.165$, $0.203,0.234,0.267,0.245,0.223,0.171,0.109,0.061,0.056,0.108,0.104,0.165,0.203,0.234,0.267,0.245,0.223,0.171,0.109,0.061,0$. $056,0.108,0.104,0.165,0.203,0.234,0.267,0.245,0.223,0.171,0.109,0.061,0.056,0.108,0.104,0.165,0.203,0.234,0.267,0.245,0.2$ $23,0.171,0.109,0.061$

n5,0.035,0.055,0.041, $0.081,0.138,0.19,0.227,0.235,0.202,0.163,0.088,0.047,0.035,0.055,0.041,0.081,0.138,0.19,0.227,0.235,0$ $.202,0.163,0.088,0.047,0.035,0.055,0.041,0.081,0.138,0.19,0.227,0.235,0.202,0.163,0.088,0.047,0.035,0.055,0.041,0.081,0.13$ $8,0.19,0.227,0.235,0.202,0.163,0.088,0.047,0.035,0.055,0.041,0.081,0.138,0.19,0.227,0.235,0.202,0.163,0.088,0.047,0.035,0$. $055,0.041,0.081,0.138,0.19,0.227,0.235,0.202,0.163,0.088,0.047,0.035,0.055,0.041,0.081,0.138,0.19,0.227,0.235,0.202,0.163$, $0.088,0.047$ 
n6,0.035,0.055,0.041,0.081,0.138,0.19,0.227, $0.235,0.202,0.163,0.088,0.047,0.035,0.055,0.041,0.081,0.138,0.19,0.227,0.235,0$ $.202,0.163,0.088,0.047,0.035,0.055,0.041,0.081,0.138,0.19,0.227,0.235,0.202,0.163,0.088,0.047,0.035,0.055,0.041,0.081,0.13$ $8,0.19,0.227,0.235,0.202,0.163,0.088,0.047,0.035,0.055,0.041,0.081,0.138,0.19,0.227,0.235,0.202,0.163,0.088,0.047,0.035,0$. $055,0.041,0.081,0.138,0.19,0.227,0.235,0.202,0.163,0.088,0.047,0.035,0.055,0.041,0.081,0.138,0.19,0.227,0.235,0.202,0.163$, $0.088,0.047$

n7, $0.035,0.055,0.041,0.081,0.138,0.19,0.227,0.235,0.202,0.163,0.088,0.047,0.035,0.055,0.041,0.081,0.138,0.19,0.227,0.235,0$ $.202,0.163,0.088,0.047,0.035,0.055,0.041,0.081,0.138,0.19,0.227,0.235,0.202,0.163,0.088,0.047,0.035,0.055,0.041,0.081,0.13$ $8,0.19,0.227,0.235,0.202,0.163,0.088,0.047,0.035,0.055,0.041,0.081,0.138,0.19,0.227,0.235,0.202,0.163,0.088,0.047,0.035,0$. $055,0.041,0.081,0.138,0.19,0.227,0.235,0.202,0.163,0.088,0.047,0.035,0.055,0.041,0.081,0.138,0.19,0.227,0.235,0.202,0.163$ $0.088,0.047$

\$offdelim

Table FC(n,i) controle de cheias

\$ondelim

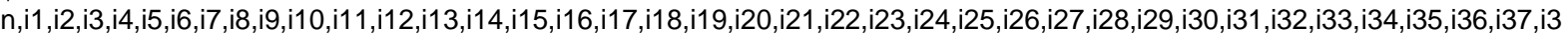

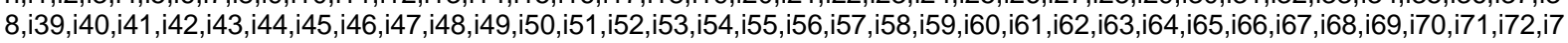
$3, \mathrm{i} 74, \mathrm{i} 75, \mathrm{i} 76, \mathrm{i} 77, \mathrm{i} 78, \mathrm{i} 79, \mathrm{i} 80, \mathrm{i} 81, \mathrm{i} 82, \mathrm{i} 83, \mathrm{i} 84$

n1 $1,1,1,1,1,1,1,1,1,1,1,1,1,1,1,1,1,1,1,1,1,1,1,1,1,1,1,1,1,1,1,1,1,1,1,1,1,1,1,1,1,1,1,1,1,1,1,1,1,1,1,1,1,1,1,1,1,1,1,1,1,1,1,1,1,1$, $1,1,1,1,1,1,1,1,1,1,1,1,1,1,1,1,1,1$

n2,1,1,1,1,1,1,1,0.9594,0.7945,0.8311,0.892,0.9548,1,1,1,1,1,1,1,0.9594,0.7945,0.8311,0.892,0.9548,1,1,1,1,1,1,1,0.9594,0.79 $45,0.8311,0.892,0.9548,1,1,1,1,1,1,1,0.9594,0.7945,0.8311,0.892,0.9548,1,1,1,1,1,1,1,0.9594,0.7945,0.8311,0.892,0.9548,1,1$, $1,1,1,1,1,0.9594,0.7945,0.8311,0.892,0.9548,1,1,1,1,1,1,1,0.9594,0.7945,0.8311,0.892,0.9548$

n3,0.9486,1,1,1,1,1,1,0.7689,0.6919,0.7432,0.7946,0.8459,0.9486,1,1,1,1,1,1,0.7689,0.6919,0.7432,0.7946,0.8459,0.9486,1,1, $1,1,1,1,0.7689,0.6919,0.7432,0.7946,0.8459,0.9486,1,1,1,1,1,1,0.7689,0.6919,0.7432,0.7946,0.8459,0.9486,1,1,1,1,1,1,0.7689$ $0.6919,0.7432,0.7946,0.8459,0.9486,1,1,1,1,1,1,0.7689,0.6919,0.7432,0.7946,0.8459,0.9486,1,1,1,1,1,1,0.7689,0.6919,0.743$ $2,0.7946,0.8459$

n4,0.827,0.9405,1,1,1,1,1,0.8559,0.778,0.778,0.778,0.778,0.827,0.9405,1,1,1,1,1,0.8559,0.778,0.778,0.778,0.778,0.827,0.940 $5,1,1,1,1,1,0.8559,0.778,0.778,0.778,0.778,0.827,0.9405,1,1,1,1,1,0.8559,0.778,0.778,0.778,0.778,0.827,0.9405,1,1,1,1,1,0.85$ $59,0.778,0.778,0.778,0.778,0.827,0.9405,1,1,1,1,1,0.8559,0.778,0.778,0.778,0.778,0.827,0.9405,1,1,1,1,1,0.8559,0.778,0.778$, $0.778,0.778$

n5,0.938,0.9901,1,1,1,1,1,1,0.5677,0.5215,0.518,0.518,0.938,0.9901,1,1,1,1,1,1,0.5677,0.5215,0.518,0.518,0.938,0.9901,1,1,1 $, 1,1,1,0.5677,0.5215,0.518,0.518,0.938,0.9901,1,1,1,1,1,1,0.5677,0.5215,0.518,0.518,0.938,0.9901,1,1,1,1,1,1,0.5677,0.5215$, $0.518,0.518,0.938,0.9901,1,1,1,1,1,1,0.5677,0.5215,0.518,0.518,0.938,0.9901,1,1,1,1,1,1,0.5677,0.5215,0.518,0.518$

n6,1,1,1,1,1,1,1,1,1,1,1,1,1,1,1,1,1,1,1,1,1,1,1,1,1,1,1,1,1,1,1,1,1,1,1,1,1,1,1,1,1,1,1,1,1,1,1,1,1,1,1,1,1,1,1,1,1,1,1,1,1,1,1,1,1,1, $1,1,1,1,1,1,1,1,1,1,1,1,1,1,1,1,1,1$

n7,1,1,1,1,1,1,1,1,1,1,1,1,1,1,1,1,1,1,1,1,1,1,1,1,1,1,1,1,1,1,1,1,1,1,1,1,1,1,1,1,1,1,1,1,1,1,1,1,1,1,1,1,1,1,1,1,1,1,1,1,1,1,1,1,1,1, $1,1,1,1,1,1,1,1,1,1,1,1,1,1,1,1,1,1$

\$offdelim

Table Rtini(n,i) vazao turbinada inicial

\$ondelim

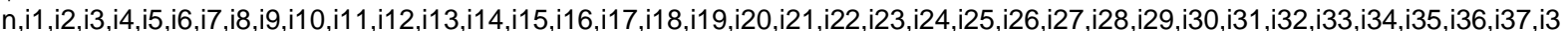

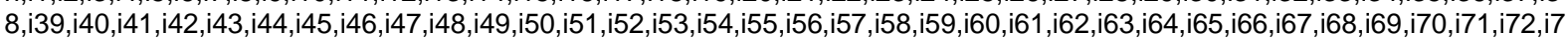
$3, \mathrm{i} 74, \mathrm{i} 75, \mathrm{i} 76, \mathrm{i} 77, \mathrm{i} 78, \mathrm{i} 79, \mathrm{i} 80, \mathrm{i} 81, \mathrm{i} 82, \mathrm{i} 83, \mathrm{i} 84$

n1,115.736,91.617,108.569,67.413,67.294,41.473,71.745,150.991,153.102,207.179,103.132,234.319,116.736,83.617,57.569,4 $9.413,41.294,39.473,48.745,109.991,157.102,233.089,237.577,232.602,139.736,88.617,70.569,58.413,49.294,72.473,47.745$, $139.991,232.976,166.179,68.132,97.923,45.736,38.617,37.569,31.413,31.294,33.473,50.745,93.991,183.102,234.437,236.907$ ,199.923,99.736,75.617,57.569,50.413,41.294,54.473,37.745,100.991,232.719,238.119,233.599,223.923,130.736,79.617,64.5 $69,57.413,52.294,43.473,37.745,64.991,163.102,236.518,234.145,230.923,207.736,128.617,88.569,78.413,61.294,41.473,46$. $745,49.991,218.102,236.162,233.38,237.711$

n2,491.267,432.164,353.301,232.162,227.651,175.175,247.714,672.292,689.283,718.437,601.019,728.501,513.267,318.164,1 $90.301,169.162,85.651,83.175,118.714,599.292,715.977,720.868,734.632,726.063,668.267,394.164,284.301,215.162,145.651$ ,219.175,97.714,561.292,718.417,715.838,323.019,433.699,195.267,133.164,112.301,93.162,90.651,98.175,184.714,419.292, $716.565,724.567,730.801,719.079,408.267,279.164,207.301,163.162,91.651,138.175,71.714,336.292,717.568,728.895,722.45$ $5,717.885,468.267,302.164,223.301,194.162,148.651,130.175,86.714,211.292,709.283,724,730.592,731.018,720.288,452.164$ ,368.301,308.162,240.651,174.175,181.714,201.292,719.841,729.716,723.433,728.244

n3,32.231,25.67,21.369,17.264,13.219,10.136,15.85,52.231,52.315,51.527,37.9,52.309,35.231,27.67,22.369,19.264,15.219,13 $.136,16.85,26.604,51.85,52.278,52.315,52.385,52.239,40.67,32.369,27.264,20.219,23.136,15.85,34.604,52.311,51.527,35.9,5$ 2.236,34.231,25.67,20.369,15.264,12.219,11.136,14.85,44.604,44.85,52.265,52.271,47.527,40.231,27.67,22.369, 18.264,13.21 $9,12.136,7.85,17.604,35.85,51.527,40.9,52.231,52.244,35.67,25.369,19.264,17.219,17.136,13.85,20.604,23.85,52.338,52.623$, $52.504,52.469,52.327,52.25,45.264,41.219,35.136,33.85,37.604,52.233,52.226,52.356,52.513$

n4,1434.721,945.075,772.655,582.1,445.499,259.778,315.854,1631.496,2919.843,2774.404,1659.462,4011.599,2143.721,102 $4.075,696.655,531.1,357.499,334.778,181.854,1238.496,2668.843,3930.404,4011.599,4011.599,3214.721,1553.075,1010.655$ ,674.1,617.499,557.778,314.854,1460.496,3333.843,2919.404,1527.462,1622.075,994.721,668.075,646.655,389.1,326.499,29 $8.778,325.854,838.496,1865.843,4011.599,4011.599,3419.075,2132.721,897.075,705.655,595.1,338.499,145.778,276.854,57$ $3.496,1549.843,3879.404,4011.599,2640.075,2502.721,1197.075,805.655,634.1,441.499,319.778,117.854,480.496,1289.843$, $2994.404,4011.599,4011.599,4011.599,2560.075,1315.655,1048.1,704.499,538.778,500.854,700.496,1519.843,3884.404,401$ $1.599,4011.599$

n5,1523.866,1032.567,783.939,558.789,438.079,240.851,227.722,1416.612,2827.215,2878.481,1725.22,3007.147,2482.866,1 $135.567,723.939,516.789,342.079,373.851,140.722,1080.612,2804.215,3007.147,3007.147,3007.147,3007.147,1634.567,104$ $0.939,679.789,664.079,516.851,349.722,1281.612,3007.147,3007.147,1606.22,1683.968,1213.866,653.567,645.939,399.789$ 284.079,237.851,293.722,720.612,1789.215,3007.147,3007.147,3007.147,2249.866,916.567,703.939,566.789,315.079,81.851 ,215.722,473.612,1401.215,3007.147,3007.147,2608.968,2599.866,1212.567,807.939,615.789,408.079,267.851,50.722,387.6 $12,1200.215,2729.481,3007.147,3007.147,3007.147,2747.567,1335.939,1035.789,680.079,485.851,426.722,608.612,1352.21$ $5,3007.147,3007.147,3007.147$

n6,1683.124,1247.626,979.631,844.558,776.026,703.387,690.948,1822.689,3187.936,3183.037,1949.252,3718.343,2711.124, $1331.626,929.631,790.558,686.026,766.387,600.948,1459.689,3206.936,3718.343,3718.343,3718.343,3718.343,1850.626,12$ 
39.631,957.558,1007.026,918.387,833.948,1633.689,3599.936,3540.037,1818.252,1763.262,1374.124,857.626,846.631,678.5 $58,620.026,652.387,718.948,1115.689,2130.936,3718.343,3718.343,3667.262,2359.124,1105.626,890.631,840.558,651.026,4$ 85.387,653.948,889.689,1766.936,3718.343,3718.343,2716.262,2709.124,1401.626,994.631,889.558,744.026,671.387,488.94 $8,803.689,1565.936,3004.037,3718.343,3718.343,3718.343,2936.626,1522.631,1309.558,1016.026,889.387,864.948,1024.68$ $9,1717.936,3718.343,3718.343,3718.343$

n7,1570.18,1052.961,788.621,562.532,426.013,279.839,230.585,1382.861,2763.105,2764.912,1750.289,2782.217,2598.18,11 $36.961,738.621,508.532,336.013,342.839,139.585,1019.861,2763.509,2787.907,2803.456,2794.947,2780.17,1655.961,1048.6$ $21,675.532,657.013,494.839,372.585,1193.861,2771.195,2771.878,1619.289,1651.177,1261.18,662.961,655.621,396.532,270$ $013,228.839,257.585,674.861,1744.626,2804.175,2797.711,2777.842,2246.18,910.961,699.621,558.532,301.013,61.839,192$. $585,448.861,1380.626,2782.35,2794.033,2604.177,2596.18,1206.961,803.621,607.532,394.013,247.839,27.585,362.861,1179$ $.626,2712.867,2800.446,2782.612,2808.451,2741.961,1331.621,1027.532,666.013,465.839,403.585,583.861,1331.626,2781.6$ $53,2801.661,2801.91$

\$offdelim

Table Rvini(n,i) vazao vertida inicial

\$ondelim

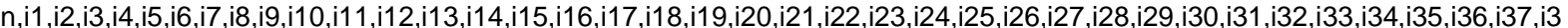
8,i39,i40,i41,i42,i43,i44,i45,i46,i47,i48,i49,i50,i51,i52,i53,i54,i55,i56,i57,i58,i59, i60,i61,i62,i63,i64,i65,i66,i67,i68,i69,i70,i71,i72,i7 $3, \mathrm{i} 74, \mathrm{i75}, \mathrm{i76}, \mathrm{i77}, \mathrm{i78}, \mathrm{i79}, \mathrm{i} 80, \mathrm{i} 81, \mathrm{i} 82, \mathrm{i} 83, \mathrm{i} 84$

$\mathrm{n} 1,0,0,0,0,0,0,0,0,0,0,0,54.605,0,0,0,0,0,0,0,0,0,22.09,142.55,9.321,0,0,0,0,0,0,0,0,19.126,0,0,0,0,0,0,0,0,0,0,0,0,57.742,124.2$ $25,0,0,0,0,0,0,0,0,0,12.383,264.059,35.533,0,0,0,0,0,0,0,0,0,0,113.661,49.983,0,0,0,0,0,0,0,0,0,0,104.017,29.752,146.212$ n2, $0,0,0,0,0,0,0,0,0,189.142,0,897.198,0,0,0,0,0,0,0,0,34.306,348.711,1397.352,713.636,0,0,0,0,0,0,0,0,187.866,25.742,0,0,0$, $0,0,0,0,0,0,0,70.718,605.012,1078.218,230.62,0,0,0,0,0,0,0,0,133.715,927.684,456.565,153.814,0,0,0,0,0,0,0,0,0,564.58,1061$. $393,1095.681,309.98,0,0,0,0,0,0,0,280.442,991.863,524.587,877.455$

n3,0,0,0,0,0,0,0,1.372,19.535,0,0,18.217, $0,0,0,0,0,0,0,0,0,11.248,19.588,37.142,2.992,0,0,0,0,0,0,0,18.539,0,0,2.29,0,0,0,0,0,0$ $, 0,0,0,8.262,9.629,0,0,0,0,0,0,0,0,0,0,0,0,1.295,3.987,0,0,0,0,0,0,0,0,25.188,114.281,73.023,61.762,22.343,5.119,0,0,0,0,0,1.6$ $17,0.3,29.545,76.014$

$\mathrm{n} 4,0,0,0,0,0,0,0,0,0,0,0,103.475,0,0,0,0,0,0,0,0,0,0,1097.64,346.475,0,0,0,0,0,0,0,0,0,0,0,0,0,0,0,0,0,0,0,0,0,189.805,581.863,0$ $, 0,0,0,0,0,0,0,0,0,0,207.863,0,0,0,0,0,0,0,0,0,0,0,828.64,2677.475,1216.122,0,0,0,0,0,0,0,0,0,735.863,698.475$

n5, $0,0,0,0,0,0,0,0,0,0,0,886.82,0,0,0,0,0,0,0,0,0,1037.334,1984.858,1397.82,556.719,0,0,0,0,0,0,0,279.067,170.334,0,0,0,0,0,0$ $0,0,0,0,0,1949.334,1562.073,552.82,0,0,0,0,0,0,0,0,0,792.334,1370.073,0,0,0,0,0,0,0,0,0,0,0,1712.858,3652.82,2302.719,0,0$ $0,0,0,0,0,0,757.334,1784.073,1793.82$

n6, $0,0,0,0,0,0,0,0,0,0,0,169.92,0,0,0,0,0,0,0,0,0,632.695,1366.176,807.92,67.781,0,0,0,0,0,0,0,0,0,0,0,0,0,0,0,0,0,0,0,0,1512.6$ $95,1039.909,0,0,0,0,0,0,0,0,0,0,355.695,847.909,0,0,0,0,0,0,0,0,0,0,0,1184.176,3048.92,1700.781,0,0,0,0,0,0,0,0,320.695,126$ $1.909,1189.92$

n7, $0,0,0,0,0,0,0,0,38.52,126.955,0,993.961,0,0,0,0,0,0,0,0,58.117,1271.96,2088.961,1619.231,893.01,0,0,0,0,0,0,0,442.431,47$ $6.99,0,0,0,0,0,0,0,0,0,0,0,2135.692,1761.578,777.335,0,0,0,0,0,0,0,0,0,1000.517,1573.257,0,0,0,0,0,0,0,0,0,0,0,1909.971,3872$ $.565,2497.729,0,0,0,0,0,0,0,0,966.215,1979.628,1994.268$

\$offdelim

Table Sini(n,j) armazenamento inicial

\$ondelim

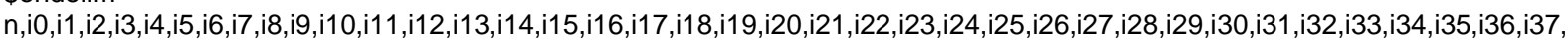

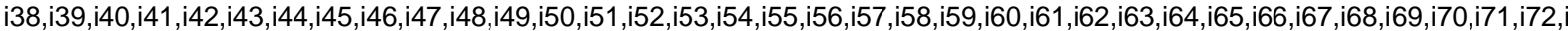
$73, \mathrm{i} 74, \mathrm{i} 75, \mathrm{i} 76, \mathrm{i} 77, \mathrm{i} 78, \mathrm{i} 79, \mathrm{i} 80, \mathrm{i} 81, \mathrm{i} 82, \mathrm{i} 83, \mathrm{i} 84$

$\mathrm{n} 1,241.59,241.59,241.59,241.59,241.59,241.59,241.59,241.59,241.59,241.59,241.59,241.59,241.59,241.59,241.59,241.59,241$ $.59,241.59,241.59,241.59,241.59,241.59,241.59,241.59,241.59,241.59,241.59,241.59,241.59,241.59,241.59,241.59,241.59,24$ $1.59,241.59,241.59,241.59,241.59,241.59,241.59,241.59,241.59,241.59,241.59,241.59,241.59,241.59,241.59,241.59,241.59,2$ $41.59,241.59,241.59,241.59,241.59,241.59,241.59,241.59,241.59,241.59,241.59,241.59,241.59,241.59,241.59,241.59,241.59$, $241.59,241.59,241.59,241.59,241.59,241.59,241.59,241.59,241.59,241.59,241.59,241.59,241.59,241.59,241.59,241.59,241.59$ ,241.59

n2,19528,19528,19528,19528,19528,19528,19528,19528,19528,19528,19528,19528,19528,19528,19528,19528,19528,19528, $19528,19528,19528,19528,19528,19528,19528,19528,19528,19528,19528,19528,19528,19528,19528,19528,19528,19528,19$ $528,19528,19528,19528,19528,19528,19528,19528,19528,19528,19528,19528,19528,19528,19528,19528,19528,19528,1952$ $8,19528,19528,19528,19528,19528,19528,19528,19528,19528,19528,19528,19528,19528,19528,19528,19528,19528,19528,1$ $9528,19528,19528,19528,19528,19528,19528,19528,19528,19528,19528,19528$

n3,533.266,533.266,533.266,533.266,533.266,533.266,533.266,533.266,533.266,533.266,533.266,533.266,533.266,533.266,5

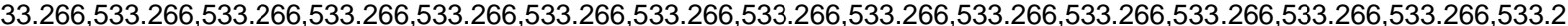
$66,533.266,533.266,533.266,533.266,533.266,533.266,533.266,533.266,533.266,533.266,533.266,533.266,533.266,533.266,5$ 33.266,533.266,533.266,533.266,533.266,533.266,533.266,533.266,533.266,533.266,533.266,533.266,533.266,533.266, 533.2 $66,533.266,533.266,533.266,533.266,533.266,533.266,533.266,533.266,533.266,533.266,533.266,533.266,533.266,533.266,5$ $33.266,533.266,533.266,533.266,533.266,533.266,533.266,533.266,533.266,533.266,533.266,533.266,533.266$ n4,29156.263,29156.263,29156.263,29156.263,29156.263,29156.263,29156.263,29156.263,29156.263,29156.263,29156.263, 29156.263,29156.263,29156.263,29156.263,29156.263,29156.263,29156.263,29156.263,29156.263,29156.263,29156.263,29 156.263,29156.263,29156.263,29156.263,29156.263,29156.263,29156.263,29156.263,29156.263,29156.263,29156.263,2915 6.263,29156.263,29156.263,29156.263,29156.263,29156.263,29156.263,29156.263,29156.263,29156.263,29156.263,29156.2 $63,29156.263,29156.263,29156.263,29156.263,29156.263,29156.263,29156.263,29156.263,29156.263,29156.263,29156.263$, 29156.263,29156.263,29156.263,29156.263,29156.263,29156.263,29156.263,29156.263,29156.263,29156.263,29156.263,29 156.263,29156.263,29156.263,29156.263,29156.263,29156.263,29156.263,29156.263,29156.263,29156.263,29156.263,2915 $6.263,29156.263,29156.263,29156.263,29156.263,29156.263,29156.263$

n5,10562.024,10562.024,10562.024,10562.024,10562.024,10562.024,10562.024,10562.024,10562.024,10562.024,10562.024, $10562.024,10562.024,10562.024,10562.024,10562.024,10562.024,10562.024,10562.024,10562.024,10562.024,10562.024,10$ $562.024,10562.024,10562.024,10562.024,10562.024,10562.024,10562.024,10562.024,10562.024,10562.024,10562.024,1056$ $2.024,10562.024,10562.024,10562.024,10562.024,10562.024,10562.024,10562.024,10562.024,10562.024,10562.024,10562.0$ $24,10562.024,10562.024,10562.024,10562.024,10562.024,10562.024,10562.024,10562.024,10562.024,10562.024,10562.024$, $10562.024,10562.024,10562.024,10562.024,10562.024,10562.024,10562.024,10562.024,10562.024,10562.024,10562.024,10$ 
$562.024,10562.024,10562.024,10562.024,10562.024,10562.024,10562.024,10562.024,10562.024,10562.024,10562.024,1056$ $2.024,10562.024,10562.024,10562.024,10562.024,10562.024,10562.024$

n6,1226,1226,1226,1226,1226,1226,1226,1226,1226,1226,1226,1226,1226,1226,1226,1226,1226,1226,1226,1226,1226,1226, $1226,1226,1226,1226,1226,1226,1226,1226,1226,1226,1226,1226,1226,1226,1226,1226,1226,1226,1226,1226,1226,1226,12$ $26,1226,1226,1226,1226,1226,1226,1226,1226,1226,1226,1226,1226,1226,1226,1226,1226,1226,1226,1226,1226,1226,1226$, $1226,1226,1226,1226,1226,1226,1226,1226,1226,1226,1226,1226,1226,1226,1226,1226,1226,1226$

n7,3800,3800,3800,3800,3800,3800,3800,3800,3800,3800,3800,3800,3800,3800,3800,3800,3800,3800,3800,3800,3800,3800, $3800,3800,3800,3800,3800,3800,3800,3800,3800,3800,3800,3800,3800,3800,3800,3800,3800,3800,3800,3800,3800,3800,38$ $00,3800,3800,3800,3800,3800,3800,3800,3800,3800,3800,3800,3800,3800,3800,3800,3800,3800,3800,3800,3800,3800,3800$, $3800,3800,3800,3800,3800,3800,3800,3800,3800,3800,3800,3800,3800,3800,3800,3800,3800,3800$ \$offdelim

Table UCini(n,i) uso consuntivo inicial

\$ondelim

n,i1,i2,i3,i4,i5,i6,i7, i8,i9,i10,i11,i12,i13,i14,i15,i16,i17,i18,i19,i20,i21,i22,i23,i24,i25,i26,i27,i28,i29,i30,i31,i32,i33,i34,i35,i36,i37, i3

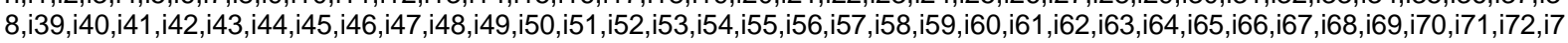
$3, \mathrm{i} 74, \mathrm{i} 75, \mathrm{i} 76, \mathrm{i} 77, \mathrm{i} 78, \mathrm{i} 7 \mathrm{i}, \mathrm{i} 80, \mathrm{i} 81, \mathrm{i} 82, \mathrm{i} 83, \mathrm{i} 84$

$\mathrm{n} 1,0,0,0,0,0,0,0,0,0,0,0,0,0,0,0,0,0,0,0,0,0,0,0,0,0,0,0,0,0,0,0,0,0,0,0,0,0,0,0,0,0,0,0,0,0,0,0,0,0,0,0,0,0,0,0,0,0,0,0,0,0,0,0,0,0,0$, $0,0,0,0,0,0,0,0,0,0,0,0,0,0,0,0,0,0$

n2, $0,0,0,0,0,0,0,0,0,0,0,0,0,0,0,0,0,0,0,0,0,0,0,0,0,0,0,0,0,0,0,0,0,0,0,0,0,0,0,0,0,0,0,0,0,0,0,0,0,0,0,0,0,0,0,0,0,0,0,0,0,0,0,0,0,0$, $0,0,0,0,0,0,0,0,0,0,0,0,0,0,0,0,0,0$

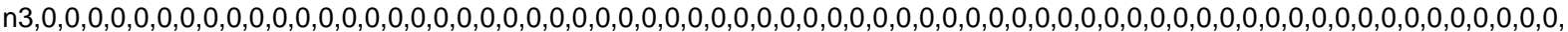
$0,0,0,0,0,0,0,0,0,0,0,0,0,0,0,0,0,0$

n4, $0,0,0,0,0,0,0,0,0,0,0,0,0,0,0,0,0,0,0,0,0,0,0,0,0,0,0,0,0,0,0,0,0,0,0,0,0,0,0,0,0,0,0,0,0,0,0,0,0,0,0,0,0,0,0,0,0,0,0,0,0,0,0,0,0,0$, $0,0,0,0,0,0,0,0,0,0,0,0,0,0,0,0,0,0$

n5, $0,0,0,0,0,0,0,0,0,0,0,0,0,0,0,0,0,0,0,0,0,0,0,0,0,0,0,0,0,0,0,0,0,0,0,0,0,0,0,0,0,0,0,0,0,0,0,0,0,0,0,0,0,0,0,0,0,0,0,0,0,0,0,0,0,0$, $0,0,0,0,0,0,0,0,0,0,0,0,0,0,0,0,0,0$

n6, $0,0,0,0,0,0,0,0,0,0,0,0,0,0,0,0,0,0,0,0,0,0,0,0,0,0,0,0,0,0,0,0,0,0,0,0,0,0,0,0,0,0,0,0,0,0,0,0,0,0,0,0,0,0,0,0,0,0,0,0,0,0,0,0,0,0$, $0,0,0,0,0,0,0,0,0,0,0,0,0,0,0,0,0,0$

n7 $, 0,0,0,0,0,0,0,0,0,0,0,0,0,0,0,0,0,0,0,0,0,0,0,0,0,0,0,0,0,0,0,0,0,0,0,0,0,0,0,0,0,0,0,0,0,0,0,0,0,0,0,0,0,0,0,0,0,0,0,0,0,0,0,0,0,0$, $0,0,0,0,0,0,0,0,0,0,0,0,0,0,0,0,0,0$

\$offdelim

Table DEini(n,i) desvio de transposicao inicial

\$ondelim

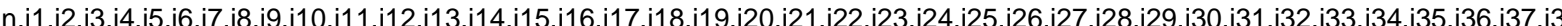

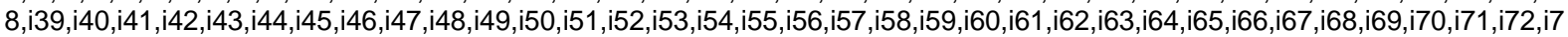
$3, \mathrm{i} 74, \mathrm{i} 75, \mathrm{i} 76, \mathrm{i} 77, \mathrm{i} 78, \mathrm{i} 79, \mathrm{i} 80, \mathrm{i} 81, \mathrm{i} 82, \mathrm{i} 83, \mathrm{i} 84$

$\mathrm{n} 1,0,0,0,0,0,0,0,0,0,0,0,0,0,0,0,0,0,0,0,0,0,0,0,0,0,0,0,0,0,0,0,0,0,0,0,0,0,0,0,0,0,0,0,0,0,0,0,0,0,0,0,0,0,0,0,0,0,0,0,0,0,0,0,0,0,0$, $0,0,0,0,0,0,0,0,0,0,0,0,0,0,0,0,0,0$

n2 $0,0,0,0,0,0,0,0,0,0,0,0,0,0,0,0,0,0,0,0,0,0,0,0,0,0,0,0,0,0,0,0,0,0,0,0,0,0,0,0,0,0,0,0,0,0,0,0,0,0,0,0,0,0,0,0,0,0,0,0,0,0,0,0,0,0$, $0,0,0,0,0,0,0,0,0,0,0,0,0,0,0,0,0,0$

n3 $0,0,0,0,0,0,0,0,0,0,0,0,0,0,0,0,0,0,0,0,0,0,0,0,0,0,0,0,0,0,0,0,0,0,0,0,0,0,0,0,0,0,0,0,0,0,0,0,0,0,0,0,0,0,0,0,0,0,0,0,0,0,0,0,0,0$, $0,0,0,0,0,0,0,0,0,0,0,0,0,0,0,0,0,0$

n4 $0,0,0,0,0,0,0,0,0,0,0,0,0,0,0,0,0,0,0,0,0,0,0,0,0,0,0,0,0,0,0,0,0,0,0,0,0,0,0,0,0,0,0,0,0,0,0,0,0,0,0,0,0,0,0,0,0,0,0,0,0,0,0,0,0,0$, $0,0,0,0,0,0,0,0,0,0,0,0,0,0,0,0,0,0$

$\mathrm{n} 5,0,0,0,0,0,0,0,0,0,0,0,0,0,0,0,0,0,0,0,0,0,0,0,0,0,0,0,0,0,0,0,0,0,0,0,0,0,0,0,0,0,0,0,0,0,0,0,0,0,0,0,0,0,0,0,0,0,0,0,0,0,0,0,0,0,0$, $0,0,0,0,0,0,0,0,0,0,0,0,0,0,0,0,0,0$

n6, $0,0,0,0,0,0,0,0,0,0,0,0,0,0,0,0,0,0,0,0,0,0,0,0,0,0,0,0,0,0,0,0,0,0,0,0,0,0,0,0,0,0,0,0,0,0,0,0,0,0,0,0,0,0,0,0,0,0,0,0,0,0,0,0,0,0$, $0,0,0,0,0,0,0,0,0,0,0,0,0,0,0,0,0,0$

n7 $0,0,0,0,0,0,0,0,0,0,0,0,0,0,0,0,0,0,0,0,0,0,0,0,0,0,0,0,0,0,0,0,0,0,0,0,0,0,0,0,0,0,0,0,0,0,0,0,0,0,0,0,0,0,0,0,0,0,0,0,0,0,0,0,0,0$, $0,0,0,0,0,0,0,0,0,0,0,0,0,0,0,0,0,0$

\$offdelim

Table pvini $(m, i)$ fracao do vertimento para transposicao

\$ondelim

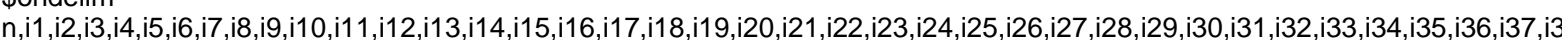

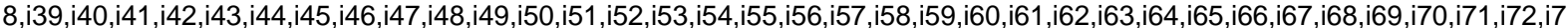
$3, \mathrm{i} 74, \mathrm{i} 75, \mathrm{i} 76, \mathrm{i} 77, \mathrm{i} 78, \mathrm{i} 79, \mathrm{i} 80, \mathrm{i} 81, \mathrm{i} 82, \mathrm{i} 83, \mathrm{i} 84$

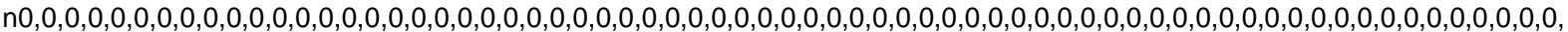
$0,0,0,0,0,0,0,0,0,0,0,0,0,0,0,0,0,0$

$\mathrm{n} 1,0,0,0,0,0,0,0,0,0,0,0,0,0,0,0,0,0,0,0,0,0,0,0,0,0,0,0,0,0,0,0,0,0,0,0,0,0,0,0,0,0,0,0,0,0,0,0,0,0,0,0,0,0,0,0,0,0,0,0,0,0,0,0,0,0,0$, $0,0,0,0,0,0,0,0,0,0,0,0,0,0,0,0,0$

n2 $0,0,0,0,0,0,0,0,0,0,0,0,0,0,0,0,0,0,0,0,0,0,0,0,0,0,0,0,0,0,0,0,0,0,0,0,0,0,0,0,0,0,0,0,0,0,0,0,0,0,0,0,0,0,0,0,0,0,0,0,0,0,0,0,0,0$, $0,0,0,0,0,0,0,0,0,0,0,0,0,0,0,0,0,0$

n3, $0,0,0,0,0,0,0,0,0,0,0,0,0,0,0,0,0,0,0,0,0,0,0,0,0,0,0,0,0,0,0,0,0,0,0,0,0,0,0,0,0,0,0,0,0,0,0,0,0,0,0,0,0,0,0,0,0,0,0,0,0,0,0,0,0,0$, $0,0,0,0,0,0,0,0,0,0,0,0,0,0,0,0,0,0$

n4 $4,0,0,0,0,0,0,0,0,0,0,0,0,0,0,0,0,0,0,0,0,0,0,0,0,0,0,0,0,0,0,0,0,0,0,0,0,0,0,0,0,0,0,0,0,0,0,0,0,0,0,0,0,0,0,0,0,0,0,0,0,0,0,0,0,0,0$, $0,0,0,0,0,0,0,0,0,0,0,0,0,0,0,0,0,0$

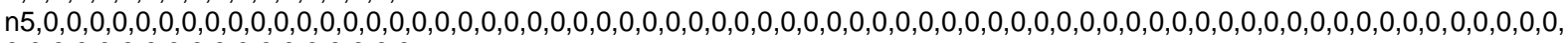
$0,0,0,0,0,0,0,0,0,0,0,0,0,0,0,0,0,0$

n6, $0,0,0,0,0,0,0,0,0,0,0,0,0,0,0,0,0,0,0,0,0,0,0,0,0,0,0,0,0,0,0,0,0,0,0,0,0,0,0,0,0,0,0,0,0,0,0,0,0,0,0,0,0,0,0,0,0,0,0,0,0,0,0,0,0,0$, $0,0,0,0,0,0,0,0,0,0,0,0,0,0,0,0,0,0$

n7 $0,0,0,0,0,0,0,0,0,0,0,0,0,0,0,0,0,0,0,0,0,0,0,0,0,0,0,0,0,0,0,0,0,0,0,0,0,0,0,0,0,0,0,0,0,0,0,0,0,0,0,0,0,0,0,0,0,0,0,0,0,0,0,0,0,0$, $0,0,0,0,0,0,0,0,0,0,0,0,0,0,0,0,0,0$

\$offdelim 
Table edpini(k,i) deficit de energia inicial

\$ondelim

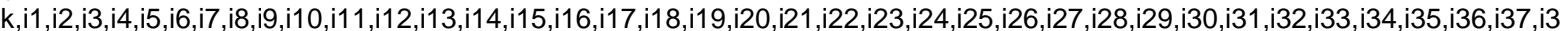

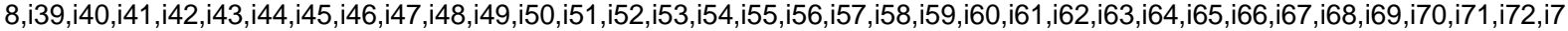
$3, \mathrm{i} 74, \mathrm{i} 75, \mathrm{i} 76, \mathrm{i} 77, \mathrm{i} 78, \mathrm{i} 79, \mathrm{i} 80, \mathrm{i} 81, \mathrm{i} 82, \mathrm{i} 83, \mathrm{i} 84$

$\mathrm{k} 1,0,0,0,0,0,0,0,0,0,0,0,0,0,0,0,0,0,0,0,0,0,0,0,0,0,0,0,0,0,0,0,0,0,0,0,0,0,0,0,0,0,0,0,0,0,0,0,0,0,0,0,0,0,0,0,0,0,0,0,0,0,0,0,0,0,0$, $0,0,0,0,0,0,0,0,0,0,0,0,0,0,0,0,0,0$

\$offdelim

Table hdpini(n,i) deficit hidrico inicial

\$ondelim

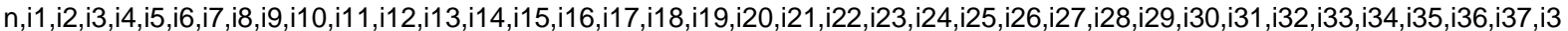

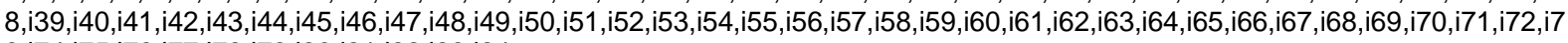
$3, \mathrm{i} 74, \mathrm{i} 75, \mathrm{i} 76, \mathrm{i} 77, \mathrm{i} 78, \mathrm{i} 7 \mathrm{i}, \mathrm{i} 80, \mathrm{i} 81, \mathrm{i} 82, \mathrm{i} 83, \mathrm{i} 84$

n1 $1,1,1,1,1,1,1,1,1,1,1,1,1,1,1,1,1,1,1,1,1,1,1,1,1,1,1,1,1,1,1,1,1,1,1,1,1,1,1,1,1,1,1,1,1,1,1,1,1,1,1,1,1,1,1,1,1,1,1,1,1,1,1,1,1,1$, $1,1,1,1,1,1,1,1,1,1,1,1,1,1,1,1,1,1$

n2,1,1,1,1,1,1,1,1,1,1,1,1,1,1,1,1,1,1,1,1,1,1,1,1,1,1,1,1,1,1,1,1,1,1,1,1,1,1,1,1,1,1,1,1,1,1,1,1,1,1,1,1,1,1,1,1,1,1,1,1,1,1,1,1,1,1, $1,1,1,1,1,1,1,1,1,1,1,1,1,1,1,1,1,1$

n3,1,1,1,1,1,1,1,1,1,1,1,1,1,1,1,1,1,1,1,1,1,1,1,1,1,1,1,1,1,1,1,1,1,1,1,1,1,1,1,1,1,1,1,1,1,1,1,1,1,1,1,1,1,1,1,1,1,1,1,1,1,1,1,1,1,1, $1,1,1,1,1,1,1,1,1,1,1,1,1,1,1,1,1,1$

n $4,1,1,1,1,1,1,1,1,1,1,1,1,1,1,1,1,1,1,1,1,1,1,1,1,1,1,1,1,1,1,1,1,1,1,1,1,1,1,1,1,1,1,1,1,1,1,1,1,1,1,1,1,1,1,1,1,1,1,1,1,1,1,1,1,1,1$, $1,1,1,1,1,1,1,1,1,1,1,1,1,1,1,1,1,1$

n5,1,1,1,1,1,1,1,1,1,1,1,1,1,1,1,1,1,1,1,1,1,1,1,1,1,1,1,1,1,1,1,1,1,1,1,1,1,1,1,1,1,1,1,1,1,1,1,1,1,1,1,1,1,1,1,1,1,1,1,1,1,1,1,1,1,1, $1,1,1,1,1,1,1,1,1,1,1,1,1,1,1,1,1,1$

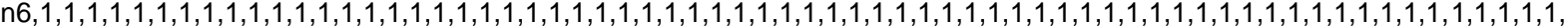
$1,1,1,1,1,1,1,1,1,1,1,1,1,1,1,1,1,1$

n7,1,1,1,1,1,1,1,1,1,1,1,1,1,1,1,1,1,1,1,1,1,1,1,1,1,1,1,1,1,1,1,1,1,1,1,1,1,1,1,1,1,1,1,1,1,1,1,1,1,1,1,1,1,1,1,1,1,1,1,1,1,1,1,1,1,1, $1,1,1,1,1,1,1,1,1,1,1,1,1,1,1,1,1,1$

\$offdelim

Table a(n,p) cota volume

\$ondelim

$\mathrm{n}, \mathrm{p} 0, \mathrm{p} 1, \mathrm{p} 2, \mathrm{p} 3, \mathrm{p} 4$

$\mathrm{n} 1,591.5352,0.1642508,-0.0002607112,0,0$

n2,530.3318,0.00607596,-4.83615E-7,2.203479E-11,-3.84658E-16 n3,801.7885,0.1142334,-0.0001977012,1.44183E-7,-2.488779E-17 n4,374.179,0.00139669,-5.35159E-8,1.155989E-12,-9.545989E-18 n5,275.813,0.006764889,-8.86837E-7,7.067909E-11,-2.23985E-15 $\mathrm{n} 6,251.5,0,0,0,0$

$\mathrm{n} 7,138,0,0,0,0$

\$offdelim

Table $b(n, p)$ cota descarga

\$ondelim

$\mathrm{n}, \mathrm{p} 0, \mathrm{p} 1, \mathrm{p} 2, \mathrm{p} 3, \mathrm{p} 4$

n1,577,0.006877187,-2.099505E-6,3.629827E-10,-2.35895E-14 n2,514.6558,0.00160686,-2.55275E-7,2.885479E-11,-1.17978E-15 n3,636.2,0.03073,-0.00015531,5.08474E-7,-6.098659E-10 $\mathrm{n} 4,359.6538,0.00196401,-2.96873 \mathrm{E}-7,2.50828 \mathrm{E}-11,-7.702299 \mathrm{E}-16$ $\mathrm{n} 5,251.5,0,0,0,0$

$\mathrm{n} 6,138,0,0,0,0$

n7,10.03861,0.006665461,-2.45477E-6,4.559482E-10,-3.14485E-14

\$offdelim

Table $c(n, p)$ area volume

\$ondelim

$\mathrm{n}, \mathrm{p} 0, \mathrm{p} 1, \mathrm{p} 2, \mathrm{p} 3, \mathrm{p} 4$

n1,-289.439596294675,2.62315600176686, $-0.00550845875916944,0,0$

n2,167.268809758092,0.0464019164104526,7.63833651889608E-10,0,0

n3,12.2522148884643,0.03023106774999489,0.000112582321601188,0,0

n4,433.599867164179,0.130635932930397,-5.92442501252507E-7,0,0

n5,86.8069999061546,0.0818037408509336,-1.317045866333E-6,0,0

$\mathrm{n} 6,213,0,0,0,0$

$\mathrm{n} 7,60,0,0,0,0$

\$offdelim

Parameter SSmin(n) limite de armazenamento

/ n1 200.72

n2 4250

n3 95.25

n4 5447

n5 7234

n6 1226

n7 $3800 /$

Parameter SSmax(n) limite de armazenamento / n1 241.59 
n2 19528

n3 557

n4 34116

n5 10782

n6 1226

n7 $3800 /$

Parameter SSend(n) armazenamento final

/ n1 241.59

n2 18837.43

n3 485.84

n4 27751.48

n5 9071.86

n6 1226

n7 $3800 /$

Parameter Rtmin(n) limite de turbinamento

*limite de vazao minima jusante das usinas

/ n1 27.67

n2 500

n3 8.8

n4 1300

n5 1300

n6 1300

n7 $1300 /$

Parameter Rtmax(n) limite de turbinamento

/ n1 238.1192656896

n2 815.2588694712

n3 60.3581901696

n4 4011.599151936

n5 3091.947670974

n6 3741.2783470587

n7 2856.8045941728

Parameter Pmax(n) limite de potencia

${ }^{*}$ Considerado igual à demanda máxima

/ n1 38.5

n2 239

n3 58

n4 531

n5 959

n6 2225

n7 2139 /

Parameter $\mathrm{nn}(\mathrm{n})$ produtividade especifica

/ n1 0.008755

n2 0.008564

n3 0.008829

n4 0.009023

n5 0.008931

n6 0.009035

n7 0.009119 /

Parameter Af(nf) area

/ n6 213

n7 $60 /$

Parameter $\mathrm{Hf}(\mathrm{nf})$ cota do reservatorio / n6 251.5

n7 $138 /$

Parameter DEmin(n) limite do desvio de transposicao

/ n1 0

n2 0

n4 0

n5 26.4

n6 0

n7 $0 /$

Parameter DEmax(n) limite do desvio de transposicao / n1 0

n2 0

n3 0

n4 0

n5 114.3 
n6 0

n7 $0 /$

Parameter pvmin $(m)$ porcentagem do vertimento para transposicao

$$
\begin{array}{lll}
\text { / n0 } & 0 \\
\text { n1 } & 0 \\
\text { n2 } & 0 \\
\text { n3 } & 0 \\
\text { n4 } & 0 \\
\text { n5 } & 0 \\
\text { n6 } & 0 \\
\text { n7 } & 0
\end{array}
$$

Positive Variable

$\operatorname{Rt}(\mathrm{n}, \mathrm{i})$ vazao turbinada

$\operatorname{Rv}(n, i)$ vazao vertida

$\mathrm{R}(\mathrm{n}, \mathrm{i})$ vazao total

$\mathrm{S}(\mathrm{nr}, \mathrm{j})$ volume

$\mathrm{Hr}(n r, j)$ cota no reservatorio

$\mathrm{Ht}(\mathrm{n}, \mathrm{i})$ cota no canal de fuga

$\mathrm{Hg}(\mathrm{n}, \mathrm{i})$ queda

$\operatorname{Ar}(\mathrm{nr}, \mathrm{j})$ area

$\mathrm{pv}(\mathrm{m}, \mathrm{i})$ porcent de vertimento na defluencia

Pot $(n, i)$ potencia

UC $(n, i)$ vazao para uso consuntivo

$h d p(n, i)$ deficit hidrico percentual

Variable

$\mathrm{DE}(\mathrm{n}, \mathrm{i})$ desvio de transposicao

edp $(k, i)$ deficit percentual de energia

$\mathrm{Z}$ objetivo

; Limites

Rt.lo(n,i) = Rtmin (n);

$\operatorname{Rt} \cdot u p(n, i)=R \operatorname{tmax}(n)$;

R.lo(n,i) = Rtmin (n);

S.lo(nr,i) $=S S \min (\mathrm{nr})$;

S.up $(n r, i)=S S m i n(n r)+(S S m a x(n r)-S S \min (n r))^{*} F C(n r, i)$;

S.fx(nr,"i0") = Sini(nr,"i0");

S.fx(nr,"i84") = SSend(nr);

$\operatorname{DE} . \mathrm{lo}(\mathrm{n}, \mathrm{i})=\mathrm{DEmin}(\mathrm{n})$;

$\operatorname{DE} \cdot \operatorname{up}(\mathrm{n}, \mathrm{i})=\operatorname{DEmax}(\mathrm{n})$;

$\operatorname{pv} . \operatorname{lo}(\mathrm{m}, \mathrm{i})=\operatorname{pvmin}(\mathrm{m})$;

$\operatorname{Pot} . u p(n, i)=\operatorname{Pmax}(n)$

UC.up $(n, i)=D H(n, i)$;

* Solucao inicial

S.I(nr,j) = Sini(nr,j);

Hr.I(nr,j) $=a(n r, " p 0 ")+S . I(n r, j)^{\star}\left(a(n r, " p 1 ")+S . I(n r, j)^{\star}\left(a(n r, " p 2 ")+S . I(n r, j)^{\star}(a(n r, " p 3 ")+S . I(n r, j) * a(n r, " p 4 "))\right)\right)$;

Ar.l(nr,j) $=c(n r, " p 0 ")+H r . I(n r, j)^{\star}\left(c(n r, " p 1 ")+H r . I(n r, j)^{\star}\left(c(n r, " p 2 ")+H r . I(n r, j)^{\star}\left(c(n r, " p 3 ")+H r . I(n r, j)^{*} c(n r, " p 4 ")\right)\right)\right)$;

Rt.l(n,i) = Rtini $(n, i)$;

$\operatorname{Rv} .1(n, i)=\operatorname{Rvini}(n, i)$

R.I(n,i) = Rtini $(n, i)+\operatorname{Rvini}(n, i)$

$H t . I(n, i)=b(n, " p 0 ")+R . I(n, i)^{*}\left(b(n, " p 1 ")+R . I(n, i)^{\star}\left(b(n, " p 2 ")+R . I(n, i)^{*}\left(b(n, " p 3 ")+R . I(n, i)^{*} b(n, " p 4 ")\right)\right)\right)$;

Hg.I(nr,i) $=(H r . I(n r, i-1)+H r . I(n r, " i 0 ") \$ i(i)+H r . I(n r, i))^{*} 0.5-H t . I(n r, i) ;$

$H g . I(n f, i)=H f(n f)-H t . I(n f, i)$;

$\operatorname{DE} . I(n, i)=\operatorname{DEini}(\mathrm{n}, \mathrm{i})$

pv.l(m,i) = pvini $(m, i)$;

Pot.I $(n, i)=n n(n)^{*} H g . I(n, i){ }^{*} R t . I(n, i)$;

UC.I(n,i) = UCini $(n, i)$;

edp.l(k,i) = edpini $(k, i)$;

hdp.l(n,i) = hdpini $(n, i)$;

Equation
C1(i) continuidade
C2(i) continuidade
C3(i) continuidade
C4(i) continuidade
C5(i) continuidade
C6(i) continuidade
C7(i) continuidade
$\mathrm{QQ}(\mathrm{n}, \mathrm{i})$ vazao
$\mathrm{CV}(\mathrm{nr}, \mathrm{j})$ cota no reservatorio
$\mathrm{CT}(\mathrm{n}, \mathrm{i})$ cota no canal de fuga
CQr(nr,i) queda
CQf(nf,i) queda
$\mathrm{AA}(\mathrm{nr}, \mathrm{j})$ area 
$\operatorname{DESV}(\mathrm{n}, \mathrm{i})$ transposicao

QUC1 $(n, i)$ derivacao consuntiva minima

QUC2(n,i) derivacao consuntiva minima

QUC3(n,i) derivacao consuntiva minima

QUC4 $(n, i)$ derivacao consuntiva minima

QUC5(n,i) derivacao consuntiva minima

QUC6(n,i) derivacao consuntiva minima

QUC7 $(n, i)$ derivacao consuntiva minima

GERA(n,i) potencia

$\mathrm{AE}(\mathrm{k}, \mathrm{i})$ adimensional

$\mathrm{A} \cup \mathrm{C}(\mathrm{n}, \mathrm{i})$ adimensional

OBJ objetivo

C1(i).. S("n1",i) =e= S("n1",i-1)+S("n1","i0")\$ii(i) + dt(i)

+QI("n1",i)-R("n1",i)-UC("n1",i)-DE("n1",i) )

-Ev("n1",i)*(Ar("n1",i-1)+Ar("n1","i0")\$ii(i));

C2(i).. S("n2",i) =e= S("n2",i-1)+S("n2","i0")\$ii(i) + dt(i)*

-QI("n1",i)+R("n1",i)

+QI("n2",i)-R("n2",i)-UC("n2",i)-DE("n2",i) )

-Ev("n2",ii)*(Ar("n2",i-1)+Ar("n2","i0")\$ii(i));

C3(i).. S("n3",i) =e= S("n3",i-1)+S("n3","i0")\$ii(i) + dt(i)*(

+QI("n3",i)-R("n3",i)-UC("n3",i)-DE("n3",i) )

-Ev("n3",i)*(Ar("n3",i-1)+Ar("n3","i0")\$ii(i));

C4(i).. S("n4",i) =e= S("n4",i-1)+S("n4","i0")\$ii(i) + dt(i)*( -QI("n2",i)+R("n2",i)

-QI("n3",i)+R("n3",i)

+QI("n4",i)-R("n4",i)-UC("n4",i)-DE("n4",i) )

-Ev("n4",i)*(Ar("n4",i-1)+Ar("n4","i0")\$ii(i)):

C5(i).. S("n5",i) =e= S("n5",i-1)+S("n5","i0")\$ii(i) + dt(i)*( -QI("n4",i)+R("n4",i)

+QI("n5",i)-R("n5",i)-UC("n5",i)-DE("n5",i) )

- $\operatorname{Ev}(" n 5 ", i)^{\star}(\operatorname{Ar}(" n 5 ", i-1)+\operatorname{Ar}(" n 5 "$, "i0")\$ii(i));

C6(i).. $0=\mathrm{e}=\mathrm{dt}(\mathrm{i})^{*}($

-QI("n5",i)+R("n5",i)

+QI("n6",i)-R("n6",i)-UC("n6",i)-DE("n6",i) )

$-E v(" n 6 ", i){ }^{\star} A f(" n 6 ")$;

C7(i).. $0=e=d t(i)^{*}($

-QI("n6",i)+R("n6",i)

+QI("n7",i)-R("n7",i)-UC("n7",i)-DE("n7",i) )

$-\operatorname{Ev}(" n 7 ", i)^{\star} A f(" n 7 ")$;

$Q Q(n, i) . . R(n, i)=e=R t(n, i)+\operatorname{Rv}(n, i)$;

$\operatorname{DESV}(n, i) . . D E(n, i)=e=\operatorname{DEmin}(n)+p v(n-1, i)^{\star} R v(n-1, i)^{\star} \operatorname{DEmin}(n) / D E m i n(" n 5 ")$;

$\left.C V(n r, j) . . H r(n r, j)=e=a(n r, " p 0 ")+S(n r, j)^{\star}\left(a(n r, " p 1 ")+S(n r, j)^{\star}\left(a(n r, " p 2 ")+S(n r, j)^{\star}(a(n r, " p 3 ")+S(n r, j))^{*} a(n r, " p 4 ")\right)\right)\right)$; $C T(n, i) . . H t(n, i)=e=b(n, " p 0 ")+R(n, i)^{*}\left(b(n, " p 1 ")+R(n, i)^{*}\left(b(n, " p 2 ")+R(n, i)^{*}\left(b(n, " p 3 ")+R(n, i)^{*} b(n, " p 4 ")\right)\right)\right)$;

$\operatorname{CQr}(n r, i) . . \mathrm{Hg}(\mathrm{nr}, \mathrm{i})=\mathrm{e}=(\mathrm{Hr}(\mathrm{nr}, \mathrm{i}-1)+\mathrm{Hr}(\mathrm{nr}, " \mathrm{i} 0 ") \$ \mathrm{ii}(\mathrm{i})+\mathrm{Hr}(\mathrm{nr}, \mathrm{i}))^{*} 0.5-\mathrm{Ht}(\mathrm{nr}, \mathrm{i})$;

$\mathrm{CQf}(\mathrm{nf}, \mathrm{i}) . . \mathrm{Hg}(\mathrm{nf}, \mathrm{i})=\mathrm{e}=\mathrm{Hf}(\mathrm{nf})-\mathrm{Ht}(\mathrm{nf}, \mathrm{i})$;

$A A(n r, j) . . A r(n r, j)=e=c(n r, " p 0 ")+S(n r, j)^{\star}\left(c(n r, " p 1 ")+S(n r, j)^{*} c(n r, " p 2 ")\right) ;$

*QUC usos prioritários segundo ONS

QUC1 $(n, i) . . \cup C(" n 1 ", i)=g=0.59^{*} D H(" n 1 ", i)$;

QUC2(n,i).. UC("n2",i) =g=0.43*DH("n2",i);

QUC3(n,i).. UC("n3",i) $=g=0.09^{*} \mathrm{DH}(" n 3 ", i)$;

QUC4(n,i).. UC("n4",i) $=\mathrm{g}=0.12^{*} \mathrm{DH}(" \mathrm{n} 4 ", \mathrm{i})$

QUC5(n,i).. UC("n5",i) $=\mathrm{g}=0.03^{*} \mathrm{DH}(" \mathrm{n} 5 ", \mathrm{i})$;

$\operatorname{QUC6}(n, i) . . \cup C(" n 6 ", i)=g=0.03^{*} \mathrm{DH}(" n 6 ", i)$;

QUC7 (n,i).. UC("n7",i) =g= 0.46* DH("n7",i);

$\operatorname{GERA}(n, i) .$. Pot $(n, i)=e=n n(n)^{\star} H g(n, i)^{\star} \operatorname{Rt}(n, i)$;

$A E(k, i) . . \operatorname{edp}(k, i)=e=(D D(k, i)-\operatorname{sum}(n, \operatorname{Pot}(n, i))) / D D(k, i)$;

$\operatorname{AUC}(n, i) . . h d p(n, i)=e=(D H(n, i)-U C(n, i)) / D H(n, i)$;

OBJ.. Z =e = sum(i, $\left.\left(0.5^{*} \operatorname{sqr}(\operatorname{sum}(k, \operatorname{edp}(k, i)))+0.5^{*} \operatorname{sqr}(\operatorname{sum}(n, \operatorname{hdp}(n, i)))\right)\right)$;

Model

HIDRO

C1,C2,C3,C4,C5,C6,C7,QQ,CV,CT,CQr,CQf,AA,DESV,QUC1,QUC2,QUC3,QUC4,QUC5,QUC6,QUC7,GERA,AE,AUC,OBJ/;

Option NLP = MINOS;

HIDRO.nodlim = 10000;

HIDRO. workspace = 200;

HIDRO.optfile $=1$ 
file opt /C:IUsersILudmilson|Documentslgamsdirlprojdirlminos.opt/

put opt;

put 'superbasics limit 7050' /;

put 'scale nonlinear variables' /;

put 'optimality tolerance 0.000001 ' /;

putclose;

Option reslim $=36000$

Option iterlim $=200000$;

Solve HIDRO using NLP minimizing Z;

\section{Código do modelo HIDRO sem a transposição do São Francisco}

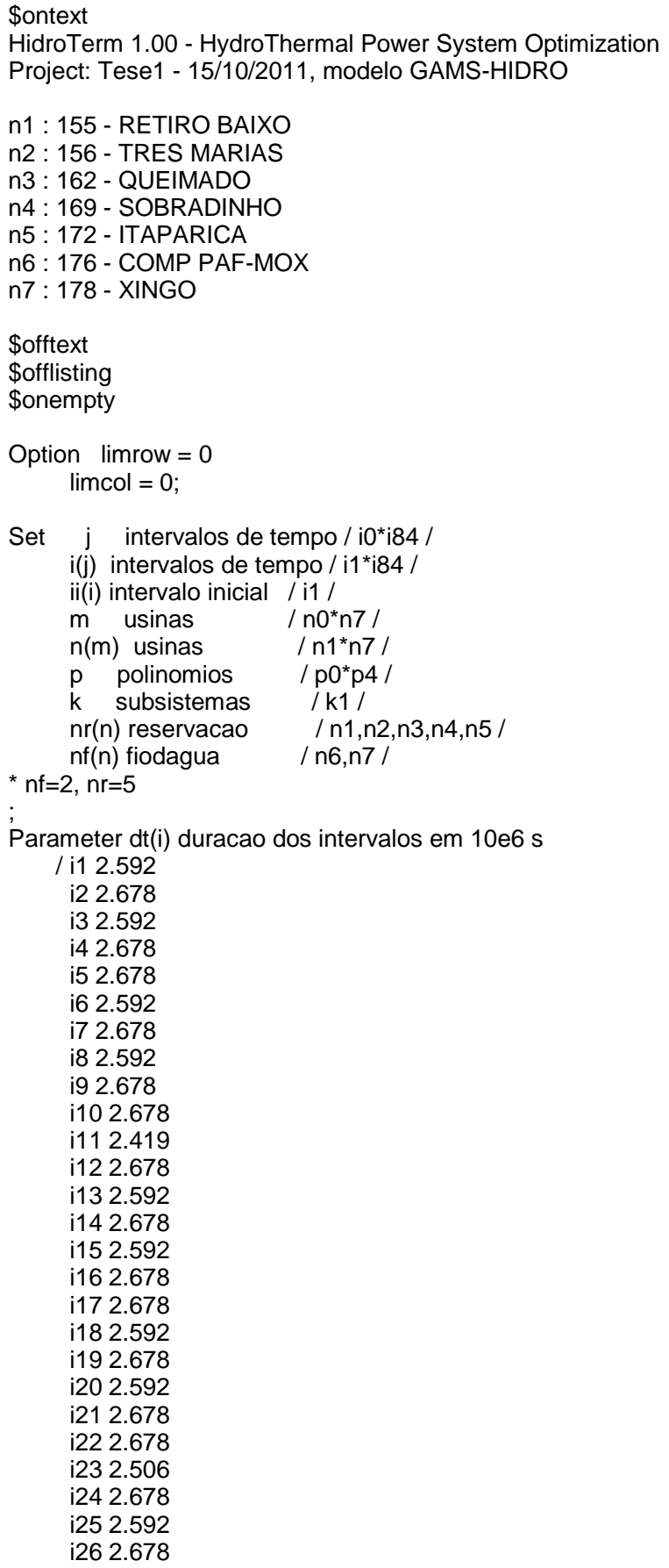




$$
\begin{aligned}
& \text { i27 } 2.592 \\
& \text { i28 } 2.678 \\
& \text { i29 } 2.678 \\
& \text { i30 } 2.592 \\
& \text { i31 } 2.678 \\
& \text { i32 } 2.592 \\
& \text { i33 } 2.678 \\
& \text { i34 } 2.678 \\
& \text { i35 } 2.419 \\
& \text { i36 } 2.678 \\
& \text { i37 } 2.592 \\
& \text { i38 } 2.678 \\
& \text { i39 } 2.592 \\
& \text { i40 } 2.678 \\
& \text { i41 } 2.678 \\
& \text { i42 } 2.592 \\
& \text { i43 } 2.678 \\
& \text { i44 } 2.592 \\
& \text { i45 } 2.678 \\
& \text { i46 } 2.678 \\
& \text { i47 } 2.419 \\
& \text { i48 } 2.678 \\
& \text { i49 } 2.592 \\
& \text { i50 } 2.678 \\
& \text { i51 } 2.592 \\
& \text { i52 } 2.678 \\
& \text { i53 } 2.678 \\
& \text { i54 } 2.592 \\
& \text { i55 } 2.678 \\
& \text { i56 } 2.592 \\
& \text { i57 } 2.678 \\
& \text { i58 } 2.678 \\
& \text { i59 } 2.419 \\
& \text { i60 } 2.678 \\
& \text { i61 } 2.592 \\
& \text { i62 } 2.678 \\
& \text { i63 } 2.592 \\
& \text { i64 } 2.678 \\
& \text { i65 } 2.678 \\
& \text { i66 } 2.592 \\
& \text { i67 } 2.678 \\
& \text { i68 } 2.592 \\
& \text { i69 } 2.678 \\
& \text { i70 } 2.678 \\
& \text { i712.506 } \\
& \text { i72 } 2.678 \\
& \text { i73 } 2.592 \\
& \text { i74 } 2.678 \\
& \text { i75 } 2.592 \\
& \text { i76 } 2.678 \\
& \text { i77 } 2.678 \\
& \text { i78 } 2.592 \\
& \text { i79 } 2.678 \\
& \text { i80 } 2.592 \\
& \text { i81 } 2.678 \\
& \text { i82 } 2.678 \\
& \text { i83 } 2.419 \\
& \text { i84 2.678 / }
\end{aligned}
$$

Table DD(k,i) demanda energetica objetivo

\$ondelim

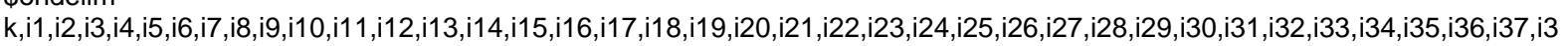

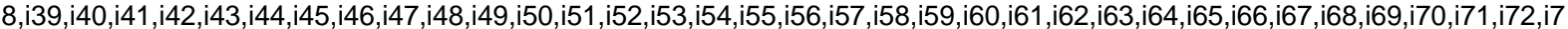
$3, \mathrm{i} 74, \mathrm{i} 75, \mathrm{i} 76, \mathrm{i} 77, \mathrm{i} 78, \mathrm{i} 79, \mathrm{i} 80, \mathrm{i} 81, \mathrm{i} 82, \mathrm{i} 83, \mathrm{i} 84$

k1,6189.5,6189.5,6189.5,6189.5,6189.5,6189.5,6189.5,6189.5,6189.5,6189.5,6189.5,6189.5,6189.5,6189.5,6189.5,6189.5,618 $9.5,6189.5,6189.5,6189.5,6189.5,6189.5,6189.5,6189.5,6189.5,6189.5,6189.5,6189.5,6189.5,6189.5,6189.5,6189.5,6189.5,61$ $89.5,6189.5,6189.5,6189.5,6189.5,6189.5,6189.5,6189.5,6189.5,6189.5,6189.5,6189.5,6189.5,6189.5,6189.5,6189.5,6189.5,6$ $189.5,6189.5,6189.5,6189.5,6189.5,6189.5,6189.5,6189.5,6189.5,6189.5,6189.5,6189.5,6189.5,6189.5,6189.5,6189.5,6189.5$, $6189.5,6189.5,6189.5,6189.5,6189.5,6189.5,6189.5,6189.5,6189.5,6189.5,6189.5,6189.5,6189.5,6189.5,6189.5,6189.5,6189.5$ \$offdelim

Table $\mathrm{DH}(\mathrm{n}, \mathrm{i})$ demanda hidrica objetivo \$ondelim

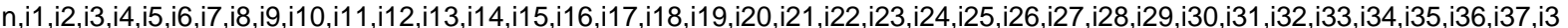
8,i39,i40,i41,i42,i43,i44,i45,i46,i47,i48,i49,i50,i51,i52,i53,i54,i55,i56,i57,i58,i59, i60, i61, i62,i63,i64,i65,i66,i67,i68,i69,i70,i71,i72,i7 $3, i 74, i 75, i 76, i 77, i 78, i 79, i 80, i 81, i 82, i 83, i 84$ 
${ }^{*} \mathrm{DH}=$ ons

$\mathrm{n} 1,2.7,1.8,2.3,2.3,2,2.3,1.4,1,1,1.2,2.4,1.5,2.7,1.8,2.3,2.3,2,2.3,1.4,1,1,1.2,2.4,1.5,2.7,1.8,2.3,2.3,2,2.3,1.4,1,1,1.2,2.4,1.5,2.7,1$. $8,2.3,2.3,2,2.3,1.4,1,1,1.2,2.4,1.5,2.7,1.8,2.3,2.3,2,2.3,1.4,1,1,1.2,2.4,1.5,2.7,1.8,2.3,2 \cdot 3,2,2 \cdot 3,1.4,1,1,1.2,2.4,1.5,2.7,1.8,2.3,2.3$ $2,2.3,1.4,1,1,1.2,2.4,1.5$

n2,9.6,6.4,8.3,8,7.1,8,4.9,3.6,3.5,4.2,8.4,5.4,9.6,6.4,8.3,8,7.1,8,4.9,3.6,3.5,4.2,8.4,5.4,9.6,6.4,8.3,8,7.1,8,4.9,3.6,3.5,4.2,8.4,5.4, $9.6,6.4,8.3,8,7.1,8,4.9,3.6,3.5,4.2,8.4,5.4,9.6,6.4,8.3,8,7.1,8,4.9,3.6,3.5,4.2,8.4,5.4,9.6,6.4,8.3,8,7.1,8,4.9,3.6,3.5,4.2,8.4,5.4,9.6$ ,6.4,8.3,8,7.1,8,4.9,3.6,3.5,4.2,8.4,5.4

n3,1.1,1.2,1,1.7,2,2.1,0.5,0.2,0.2,0.2,0.2,0.6,1.1,1.2,1,1.7,2,2.1,0.5,0.2,0.2,0.2,0.2,0.6,1.1,1.2,1,1.7,2,2.1,0.5,0.2,0.2,0.2,0.2,0.6, $1.1,1.2,1,1.7,2,2.1,0.5,0.2,0.2,0.2,0.2,0.6,1.1,1.2,1,1.7,2,2.1,0.5,0.2,0.2,0.2,0.2,0.6,1.1,1.2,1,1.7,2,2.1,0.5,0.2,0.2,0.2,0.2,0.6,1.1$ $1.2,1,1.7,2,2.1,0.5,0.2,0.2,0.2,0.2,0.6$

n $4,71,73.9,79.4,73.5,87.7,92.4,48.9,17.7,16.9,50.6,62.1,30.7,71,73.9,79.4,73.5,87.7,92.4,48.9,17.7,16.9,50.6,62.1,30.7,71,73.9$ $79.4,73.5,87.7,92.4,48.9,17.7,16.9,50.6,62.1,30.7,71,73.9,79.4,73.5,87.7,92.4,48.9,17.7,16.9,50.6,62.1,30.7,71,73.9,79.4,73.5$, $87.7,92.4,48.9,17.7,16.9,50.6,62.1,30.7,71,73.9,79.4,73.5,87.7,92.4,48.9,17.7,16.9,50.6,62.1,30.7,71,73.9,79.4,73.5,87.7,92.4$, $48.9,17.7,16.9,50.6,62.1,30.7$

$\mathrm{n} 5,47.9,49.1,40.1,46.5,57.6,68.5,69.3,70.4,40.9,57.1,45.7,17.9,47.9,49.1,40.1,46.5,57.6,68.5,69.3,70.4,40.9,57.1,45.7,17.9,47$ $9,49.1,40.1,46.5,57.6,68.5,69.3,70.4,40.9,57.1,45.7,17.9,47.9,49.1,40.1,46.5,57.6,68.5,69.3,70.4,40.9,57.1,45.7,17.9,47.9,49.1$ $40.1,46.5,57.6,68.5,69.3,70.4,40.9,57.1,45.7,17.9,47.9,49.1,40.1,46.5,57.6,68.5,69.3,70.4,40.9,57.1,45.7,17.9,47.9,49.1,40.1,4$ $6.5,57.6,68.5,69.3,70.4,40.9,57.1,45.7,17.9$

n6,2.2,2.1 1.4,1.3,1.9,2.7,2.6,2.9,1.8,2.6,2.2,1,2.2,2.1,1.4,1.3,1.9,2.7,2.6.2.9,1.8,2.6,2.2,1,2.2,2.1,1.4,1.3,1.9,2.7,2.6.2.9.1.8,2.6, $2.2,1,2.2,2.1,1.4,1.3,1.9,2.7,2.6,2.9,1.8,2.6,2.2,1,2.2,2.1,1.4,1.3,1.9,2.7,2.6,2.9,1.8,2.6,2.2,1,2.2,2.1,1.4,1.3,1.9,2.7,2.6,2.9,1.8,2$ $6,2.2,1,2.2,2.1,1.4,1.3,1.9,2.7,2.6,2.9,1.8,2.6,2.2,1$

n7,0.3,0.3,0.2,0.2,0.2,0.3,0.3,0.4,0.3,0.3,0.3,0.2,0.3,0.3,0.2,0.2,0.2,0.3,0.3,0.4,0.3,0.3,0.3,0.2,0.3,0.3,0.2,0.2,0.2,0.3,0.3,0.4,0.3, $0.3,0.3,0.2,0.3,0.3,0.2,0.2,0.2,0.3,0.3,0.4,0.3,0.3,0.3,0.2,0.3,0.3,0.2,0.2,0.2,0.3,0.3,0.4,0.3,0.3,0.3,0.2,0.3,0.3,0.2,0.2,0.2,0.3,0.3$ , $0.4,0.3,0.3,0.3,0.2,0.3,0.3,0.2,0.2,0.2,0.3,0.3,0.4,0.3,0.3,0.3,0.2$

\$offdelim

Table QI(n,i) vazao afluente

\$ondelim

n,i1 ,i2,i3,i4,i5,i6,i7,i8,i9,i10,i11,i12,i13,i14,i15,i16,i17,i18,i19,i20,i21,i22,i23,i24,i25,i26,i27,i28,i29,i30,i31,i32,i33,i34,i35,i36,i37,i3 $8, \mathrm{i} 39, \mathrm{i} 40, \mathrm{i} 41, \mathrm{i} 42, \mathrm{i} 43, \mathrm{i} 44, \mathrm{i} 45, \mathrm{i} 46, \mathrm{i} 47, \mathrm{i} 48, \mathrm{i} 49, \mathrm{i} 50, \mathrm{i} 51, \mathrm{i} 52, \mathrm{i} 53, \mathrm{i} 54, \mathrm{i} 55, \mathrm{i} 56, \mathrm{i} 57, \mathrm{i} 58, \mathrm{i} 59, \mathrm{i} 60, \mathrm{i} 61, \mathrm{i} 62, \mathrm{i} 63, \mathrm{i} 64, \mathrm{i} 65, \mathrm{i} 66, \mathrm{i} 67, \mathrm{i} 68, \mathrm{i} 69 \mathrm{j}, \mathrm{i} 70, \mathrm{i} 71, \mathrm{i} 72, \mathrm{i} 7$ $3, \mathrm{i} 74, \mathrm{i} 75, \mathrm{i} 76, \mathrm{i} 77, \mathrm{i} 78, \mathrm{i} 79, \mathrm{i} 80, \mathrm{i} 81, \mathrm{i} 82, \mathrm{i} 83, \mathrm{i} 84$

$\mathrm{n} 1,116,92,109,68,68,42,72,151,153,207,103,289,117,84,58,50,42,40,49,110,157,255,380,242,140,89,71,59,50,73,48,140,252$, $166,68,98,46,39,38,32,32,34,51,94,183,292,361,200,100,76,58,51,42,55,38,101,245,502,269,224,131,80,65,58,53,44,38,65,16$ $3,350,284,231,208,129,89,79,62,42,47,50,218,340,263,384$

n2,511,457,379,256,248,196,262,681,698,907,600,1637,533,343,216,193,106,104,133,608,759,1069,2131,1451,688,419,310, $239,166,240,112,570,915,741,322,445,215,158,138,117,111,119,199,428,796,1329,1808,961,428,304,233,187,112,159,86,34$ $5,860,1656,1178,883,488,327,249,218,169,151,101,220,718,1288,1791,1838,1050,477,394,332,261,195,196,210,1009,1721,1$ 247,1617

n3,33,27,23,19,15,12,17,54,73,52,38,71,36,29,24,21,17,15,18,27,53,64,72,90,56,42,34,29,22,25,17,35,72,52,36,55,35,27,22,1 $7,14,13,16,45,46,61,62,48,41,29,24,20,15,14,9,18,37,52,41,54,57,37,27,21,19,19,15,21,25,78,167,126,115,76,59,47,43,37,35$, $38,55,53,82,129$

n4,1536,1122,950,838,751,620,704,1994,3241,3013,1827,4212,2245,1201,874,787,663,695,570,1601,2990,4169,5271,4455,3 $316,1730,1188,930,923,918,703,1823,3655,3158,1695,1719,1096,845,824,645,632,659,714,1201,2187,4440,4761,3516,2234$, $1074,883,851,644,506,665,936,1871,4118,4387,2737,2604,1374,983,890,747,680,506,843,1611,3233,5002,6786,5329,2737,1$ $493,1304,1010,899,889,1063,1841,4123,4915,4807$

n5,1636,1226,974,839,785,660,684,1852,3209,3166,1922,4005,2595,1329,914,797,689,793,597,1516,3186,4332,5182,4516,3 $676,1828,1231,960,1011,936,806,1717,3668,3465,1803,1795,1326,847,836,680,631,657,750,1156,2171,5244,4766,3671,236$ $2,1110,894,847,662,501,672,909,1783,4087,4574,2720,2712,1406,998,896,755,687,507,823,1582,3017,4910,6771,5422,2941$ ,1526,1316,1027,905,883,1044,1734,4052,4988,4912

n6,1686,1252,983,851,787,719,709,1842,3204,3196,1957,3892,2714,1336,933,797,697,782,619,1479,3223,4364,5092,4530,3 $789,1855,1243,964,1018,934,852,1653,3616,3553,1826,1767,1377,862,850,685,631,668,737,1135,2147,5244,4766,3671,236$ $2,1110,894,847,662,501,672,909,1783,4087,4574,2720,2712,1406,998,896,755,687,507,823,1582,3017,4910,6771,5422,2941$ $, 1526,1316,1027,905,883,1044,1734,4052,4988,4912$

n7,1686,1252,983,851,787,719,710,1843,3204,3196,1957,3892,2714,1336,933,797,697,782,619,1480,3224,4364,5092,4530,3 $789,1855,1243,964,1018,934,852,1654,3616,3553,1826,1767,1377,862,850,685,631,668,737,1135,2147,5244,4766,3671,236$ $2,1110,894,847,662,501,672,909,1783,4087,4574,2720,2712,1406,998,896,755,687,507,823,1582,3017,4910,6771,5422,2941$ $, 1526,1316,1027,905,883,1044,1734,4052,4988,4912$

\$offdelim

Table Ev(n,i) evaporacao

\$ondelim

n,i1 ,i2,i3,i4,i5,i6,i7,i8,i9,i10,i11,i12,i13,i14,i15,i16,i17,i18,i19,i20,i21,i22,i23,i24,i25,i26,i27,i28,i29,i30,i31,i32,i33,i34,i35,i36,i37,i3 8,i39,i40,i41,i42,i43,i44,i45,i46,i47,i48,i49, i50,i51,i52,i53,i54,i55,i56,i57,i58,i59,i60,i61,i62,i63,i64,i65,i66,i67,i68,i69,i70,i71,i72,i7 $3, \mathrm{i} 74, \mathrm{i} 75, \mathrm{i} 76, \mathrm{i} 77, \mathrm{i} 78, \mathrm{i} 79, \mathrm{i} 80, \mathrm{i} 81, \mathrm{i} 82, \mathrm{i} 83, \mathrm{i} 84$

n1,0.03,0.045,0.049,0.069,0.083,0.06,0.03,0.001,-0.012,-0.021,-0.014,0.009,0.03,0.045,0.049,0.069,0.083,0.06,0.03,0.001, $0.012,-0.021,-0.014,0.009,0.03,0.045,0.049,0.069,0.083,0.06,0.03,0.001,-0.012,-0.021$

$0.014,0.009,0.03,0.045,0.049,0.069,0.083,0.06,0.03,0.001,-0.012,-0.021,-$

$0.014,0.009,0.03,0.045,0.049,0.069,0.083,0.06,0.03,0.001,-0.012,-0.021$,

$0.014,0.009,0.03,0.045,0.049,0.069,0.083,0.06,0.03,0.001,-0.012,-0.021,-$

$0.014,0.009,0.03,0.045,0.049,0.069,0.083,0.06,0.03,0.001,-0.012,-0.021,-0.014,0.009$

n2,0.047, $0.061,0.061,0.058,0.049,0.049,0.035,0.021,0.022,-0.001$,

$0.002,0.028,0.047,0.061,0.061,0.058,0.049,0.049,0.035,0.021,0.022,-0.001$,

$0.002,0.028,0.047,0.061,0.061,0.058,0.049,0.049,0.035,0.021,0.022,-0.001$,

$0.002,0.028,0.047,0.061,0.061,0.058,0.049,0.049,0.035,0.021,0.022,-0.001$,

$0.002,0.028,0.047,0.061,0.061,0.058,0.049,0.049,0.035,0.021,0.022,-0.001$,

$0.002,0.028,0.047,0.061,0.061,0.058,0.049,0.049,0.035,0.021,0.022,-0.001$,

$0.002,0.028,0.047,0.061,0.061,0.058,0.049,0.049,0.035,0.021,0.022,-0.001,-0.002,0.028$ 
n3,0.033,0.059,0.07, 0.077, $0.079,0.08,0.051,0.017,0.051,0.021,0.004,0.021,0.033,0.059,0.07,0.077,0.079,0.08,0.051,0.017,0.0$ $51,0.021,0.004,0.021,0.033,0.059,0.07,0.077,0.079,0.08,0.051,0.017,0.051,0.021,0.004,0.021,0.033,0.059,0.07,0.077,0.079,0$. $08,0.051,0.017,0.051,0.021,0.004,0.021,0.033,0.059,0.07,0.077,0.079,0.08,0.051,0.017,0.051,0.021,0.004,0.021,0.033,0.059,0$ $.07,0.077,0.079,0.08,0.051,0.017,0.051,0.021,0.004,0.021,0.033,0.059,0.07,0.077,0.079,0.08,0.051,0.017,0.051,0.021,0.004,0$. 021

n4,0.056,0.108,0.104,0.165,0.203,0.234,0.267,0.245,0.223,0.171,0.109,0.061,0.056,0.108,0.104,0.165,0.203,0.234,0.267,0.24 $5,0.223,0.171,0.109,0.061,0.056,0.108,0.104,0.165,0.203,0.234,0.267,0.245,0.223,0.171,0.109,0.061,0.056,0.108,0.104,0.165$, $0.203,0.234,0.267,0.245,0.223,0.171,0.109,0.061,0.056,0.108,0.104,0.165,0.203,0.234,0.267,0.245,0.223,0.171,0.109,0.061,0$. $056,0.108,0.104,0.165,0.203,0.234,0.267,0.245,0.223,0.171,0.109,0.061,0.056,0.108,0.104,0.165,0.203,0.234,0.267,0.245,0.2$ $23,0.171,0.109,0.061$

n5,0.035,0.055,0.041,0.081,0.138,0.19,0.227, 0.235,0.202,0.163,0.088,0.047, 0.035,0.055,0.041,0.081,0.138,0.19,0.227,0.235,0 $202,0.163,0.088,0.047,0.035,0.055,0.041,0.081,0.138,0.19,0.227,0.235,0.202,0.163,0.088,0.047,0.035,0.055,0.041,0.081,0.13$ $8,0.19,0.227,0.235,0.202,0.163,0.088,0.047,0.035,0.055,0.041,0.081,0.138,0.19,0.227,0.235,0.202,0.163,0.088,0.047,0.035,0$. $055,0.041,0.081,0.138,0.19,0.227,0.235,0.202,0.163,0.088,0.047,0.035,0.055,0.041,0.081,0.138,0.19,0.227,0.235,0.202,0.163$, $0.088,0.047$

$\mathrm{n} 6,0.035,0.055,0.041,0.081,0.138,0.19,0.227,0.235,0.202,0.163,0.088,0.047,0.035,0.055,0.041,0.081,0.138,0.19,0.227,0.235,0$ $202,0.163,0.088,0.047,0.035,0.055,0.041,0.081,0.138,0.19,0.227,0.235,0.202,0.163,0.088,0.047,0.035,0.055,0.041,0.081,0.13$ $8,0.19,0.227,0.235,0.202,0.163,0.088,0.047,0.035,0.055,0.041,0.081,0.138,0.19,0.227,0.235,0.202,0.163,0.088,0.047,0.035,0$. $055,0.041,0.081,0.138,0.19,0.227,0.235,0.202,0.163,0.088,0.047,0.035,0.055,0.041,0.081,0.138,0.19,0.227,0.235,0.202,0.163$, $0.088,0.047$

n7,0.035,0.055,0.041,0.081,0.138,0.19,0.227,0.235,0.202,0.163,0.088,0.047,0.035,0.055,0.041,0.081,0.138,0.19,0.227,0.235,0 $.202,0.163,0.088,0.047,0.035,0.055,0.041,0.081,0.138,0.19,0.227,0.235,0.202,0.163,0.088,0.047,0.035,0.055,0.041,0.081,0.13$ $8,0.19,0.227,0.235,0.202,0.163,0.088,0.047,0.035,0.055,0.041,0.081,0.138,0.19,0.227,0.235,0.202,0.163,0.088,0.047,0.035,0$. $055,0.041,0.081,0.138,0.19,0.227,0.235,0.202,0.163,0.088,0.047,0.035,0.055,0.041,0.081,0.138,0.19,0.227,0.235,0.202,0.163$, $0.088,0.047$

\$offdelim

Table FC(n,i) controle de cheias

\$ondelim

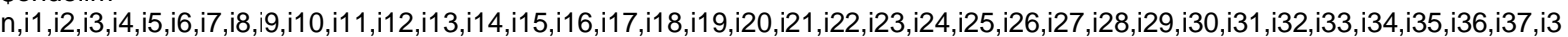

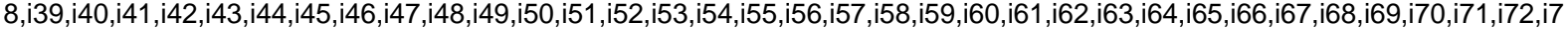
$3, \mathrm{i74}, \mathrm{i75}, \mathrm{i76}, \mathrm{i} 77, \mathrm{i78}, \mathrm{i} 79, \mathrm{i} 80, \mathrm{i} 81, \mathrm{i} 82, \mathrm{i} 83, \mathrm{i} 84$

$\mathrm{n} 1,1,1,1,1,1,1,1,1,1,1,1,1,1,1,1,1,1,1,1,1,1,1,1,1,1,1,1,1,1,1,1,1,1,1,1,1,1,1,1,1,1,1,1,1,1,1,1,1,1,1,1,1,1,1,1,1,1,1,1,1,1,1,1,1,1,1$, $1,1,1,1,1,1,1,1,1,1,1,1,1,1,1,1,1,1$

n2,1,1,1,1,1,1,1,0.9594,0.7945,0.8311,0.892,0.9548,1,1,1,1,1,1,1,0.9594,0.7945,0.8311,0.892,0.9548,1,1,1,1,1,1,1,0.9594,0.79 $45,0.8311,0.892,0.9548,1,1,1,1,1,1,1,0.9594,0.7945,0.8311,0.892,0.9548,1,1,1,1,1,1,1,0.9594,0.7945,0.8311,0.892,0.9548,1,1$, $1,1,1,1,1,0.9594,0.7945,0.8311,0.892,0.9548,1,1,1,1,1,1,1,0.9594,0.7945,0.8311,0.892,0.9548$

n3,0.9486,1,1,1,1,1,1,0.7689,0.6919,0.7432,0.7946,0.8459,0.9486,1,1,1,1,1,1,0.7689,0.6919,0.7432,0.7946,0.8459,0.9486,1,1, $1,1,1,1,0.7689,0.6919,0.7432,0.7946,0.8459,0.9486,1,1,1,1,1,1,0.7689,0.6919,0.7432,0.7946,0.8459,0.9486,1,1,1,1,1,1,0.7689$ $, 0.6919,0.7432,0.7946,0.8459,0.9486,1,1,1,1,1,1,0.7689,0.6919,0.7432,0.7946,0.8459,0.9486,1,1,1,1,1,1,0.7689,0.6919,0.743$ $2,0.7946,0.8459$

n4,0.827,0.9405, 1, 1, 1, 1, 1,0.8559,0.778,0.778,0.778,0.778,0.827,0.9405,1,1,1,1,1,0.8559,0.778,0.778, $0.778,0.778,0.827,0.940$ $5,1,1,1,1,1,0.8559,0.778,0.778,0.778,0.778,0.827,0.9405,1,1,1,1,1,0.8559,0.778,0.778,0.778,0.778,0.827,0.9405,1,1,1,1,1,0.85$ $59,0.778,0.778,0.778,0.778,0.827,0.9405,1,1,1,1,1,0.8559,0.778,0.778,0.778,0.778,0.827,0.9405,1,1,1,1,1,0.8559,0.778,0.778$, $0.778,0.778$

n5,0.938,0.9901,1,1,1,1,1,1,0.5677,0.5215,0.518,0.518,0.938,0.9901,1,1,1,1,1,1,0.5677,0.5215,0.518,0.518,0.938,0.9901,1,1,1 $, 1,1,1,0.5677,0.5215,0.518,0.518,0.938,0.9901,1,1,1,1,1,1,0.5677,0.5215,0.518,0.518,0.938,0.9901,1,1,1,1,1,1,0.5677,0.5215$, $0.518,0.518,0.938,0.9901,1,1,1,1,1,1,0.5677,0.5215,0.518,0.518,0.938,0.9901,1,1,1,1,1,1,0.5677,0.5215,0.518,0.518$

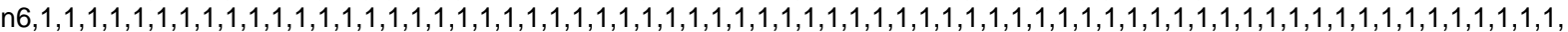
$1,1,1,1,1,1,1,1,1,1,1,1,1,1,1,1,1,1$

n7,1,1,1,1,1,1,1,1,1,1,1,1,1,1,1,1,1,1,1,1,1,1,1,1,1,1,1,1,1,1,1,1,1,1,1,1,1,1,1,1,1,1,1,1,1,1,1,1,1,1,1,1,1,1,1,1,1,1,1,1,1,1,1,1,1,1, $1,1,1,1,1,1,1,1,1,1,1,1,1,1,1,1,1,1$

\$offdelim

Table Rtini(n,i) vazao turbinada inicial

\$ondelim

n, i1 ,i2,i3,i4,i5,i6,i7,i8,i9,i10,i11,i12,i13,i14,i15,i16,i17,i18,i19,i20,i21,i22,i23,i24,i25,i26,i27,i28,i29,i30,i31,i32,i33,i34,i35,i36,i37,i3

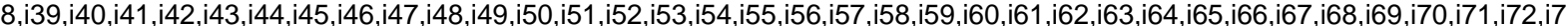
$3, \mathrm{i} 74, \mathrm{i} 75, \mathrm{i} 76, \mathrm{i} 77, \mathrm{i} 78, \mathrm{i} 79, \mathrm{i} 80, \mathrm{i} 81, \mathrm{i} 82, \mathrm{i} 83, \mathrm{i} 84$

n1,115.736,91.617,108.569,67.413,67.294,41.473,71.745,150.991,153.102,207.179,103.132,234.319,116.736,83.617,57.569,4 $9.413,41.294,39.473,48.745,109.991,157.102,233.089,237.577,232.602,139.736,88.617,70.569,58.413,49.294,72.473,47.745$, $139.991,232.976,166.179,68.132,97.923,45.736,38.617,37.569,31.413,31.294,33.473,50.745,93.991,183.102,234.437,236.907$ $199.923,99.736,75.617,57.569,50.413,41.294,54.473,37.745,100.991,232.719,238.119,233.599,223.923,130.736,79.617,64.5$ $69,57.413,52.294,43.473,37.745,64.991,163.102,236.518,234.145,230.923,207.736,128.617,88.569,78.413,61.294,41.473,46$. $745,49.991,218.102,236.162,233.38,237.711$

n2,491.267,432.164,353.301,232.162,227.651,175.175,247.714,672.292,689.283,718.437,601.019,728.501,513.267,318.164,1 $90.301,169.162,85.651,83.175,118.714,599.292,715.977,720.868,734.632,726.063,668.267,394.164,284.301,215.162,145.651$ ,219.175,97.714,561.292,718.417,715.838,323.019,433.699,195.267,133.164,112.301,93.162,90.651,98.175,184.714,419.292, $716.565,724.567,730.801,719.079,408.267,279.164,207.301,163.162,91.651,138.175,71.714,336.292,717.568,728.895,722.45$ $5,717.885,468.267,302.164,223.301,194.162,148.651,130.175,86.714,211.292,709.283,724,730.592,731.018,720.288,452.164$ $368.301,308.162,240.651,174.175,181.714,201.292,719.841,729.716,723.433,728.244$ n3,32.231,25.67,21.369,17.264,13.219,10.136,15.85,52.231,52.315,51.527,37.9.52.309,35.231,27.67,22.369,19.264,15.219,13 $.136,16.85,26.604,51.85,52.278,52.315,52.385,52.239,40.67,32.369,27.264,20.219,23.136,15.85,34.604,52.311,51.527,35.9,5$ $2.236,34,231,25.67,20.369,15.264,12.219,11.136,14.85,44.604,44.85,52,265,52,271,47.527,40.231,27,67,22,369,18.264,13.21$ $9,12.136,7.85,17.604,35.85,51.527,40.9,52.231,52.244,35.67,25.369,19.264,17.219,17.136,13.85,20.604,23.85,52.338,52.623$, $52.504,52.469,52.327,52.25,45.264,41.219,35.136,33.85,37.604,52.233,52.226,52.356,52.513$ 
n4,1434.721,945.075,772.655,582.1,445.499,259.778,315.854,1631.496,2919.843,2774.404,1659.462,4011.599,2143.721,102 4.075,696.655,531.1,357.499,334.778,181.854,1238.496,2668.843,3930.404,4011.599,4011.599,3214.721,1553.075,1010.655 ,674.1,617.499,557.778,314.854,1460.496,3333.843,2919.404,1527.462,1622.075,994.721,668.075,646.655,389.1,326.499,29 $8.778,325.854,838.496,1865.843,4011.599,4011.599,3419.075,2132.721,897.075,705.655,595.1,338.499,145.778,276.854,57$ $3.496,1549.843,3879.404,4011.599,2640.075,2502.721,1197.075,805.655,634.1,441.499,319.778,117.854,480.496,1289.843$, $2994.404,4011.599,4011.599,4011.599,2560.075,1315.655,1048.1,704.499,538.778,500.854,700.496,1519.843,3884.404,401$ $1.599,4011.599$

n5,1523.866,1032.567,783.939,558.789,438.079,240.851,227.722,1416.612,2827.215,2878.481,1725.22,3007.147,2482.866,1 135.567,723.939,516.789,342.079,373.851,140.722,1080.612,2804.215,3007.147,3007.147,3007.147,3007.147,1634.567,104 $0.939,679.789,664.079,516.851,349.722,1281.612,3007.147,3007.147,1606.22,1683.968,1213.866,653.567,645.939,399.789$, $284.079,237.851,293.722,720.612,1789.215,3007.147,3007.147,3007.147,2249.866,916.567,703.939,566.789,315.079,81.851$ ,215.722,473.612,1401.215,3007.147,3007.147,2608.968,2599.866,1212.567,807.939,615.789,408.079,267.851,50.722,387.6 $12,1200.215,2729.481,3007.147,3007.147,3007.147,2747.567,1335.939,1035.789,680.079,485.851,426.722,608.612,1352.21$ $5,3007.147,3007.147,3007.147$

n6,1683.124,1247.626,979.631,844.558,776.026,703.387,690.948,1822.689,3187.936,3183.037,1949.252,3718.343,2711.124, $1331.626,929.631,790.558,686.026,766.387,600.948,1459.689,3206.936,3718.343,3718.343,3718.343,3718.343,1850.626,12$ $39.631,957.558,1007.026,918.387,833.948,1633.689,3599.936,3540.037,1818.252,1763.262,1374.124,857.626,846.631,678.5$ $58,620.026,652.387,718.948,1115.689,2130.936,3718.343,3718.343,3667.262,2359.124,1105.626,890.631,840.558,651.026,4$ $85.387,653.948,889.689,1766.936,3718.343,3718.343,2716.262,2709.124,1401.626,994.631,889.558,744.026,671.387,488.94$ $8,803.689,1565.936,3004.037,3718.343,3718.343,3718.343,2936.626,1522.631,1309.558,1016.026,889.387,864.948,1024.68$ $9,1717.936,3718.343,3718.343,3718.343$

n7,1570.18,1052.961,788.621,562.532,426.013,279.839,230.585,1382.861,2763.105,2764.912,1750.289,2782.217,2598.18,11 $36.961,738.621,508.532,336.013,342.839,139.585,1019.861,2763.509,2787.907,2803.456,2794.947,2780.17,1655.961,1048.6$ $21,675.532,657.013,494.839,372.585,1193.861,2771.195,2771.878,1619.289,1651.177,1261.18,662.961,655.621,396.532,270$ $013,228.839,257.585,674.861,1744.626,2804.175,2797.711,2777.842,2246.18,910.961,699.621,558.532,301.013,61.839,192$. $585,448.861,1380.626,2782.35,2794.033,2604.177,2596.18,1206.961,803.621,607.532,394.013,247.839,27.585,362.861,1179$ $.626,2712.867,2800.446,2782.612,2808.451,2741.961,1331.621,1027.532,666.013,465.839,403.585,583.861,1331.626,2781.6$ $53,2801.661,2801.91$

\$offdelim

Table Rvini(n,i) vazao vertida inicial

\$ondelim

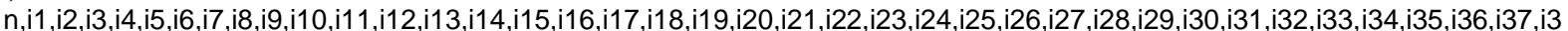

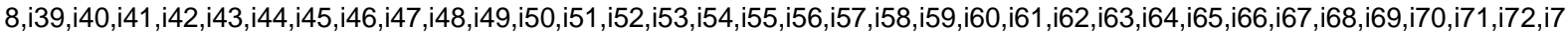
$3, \mathrm{i} 74, \mathrm{i} 75, \mathrm{i}, \mathrm{7} 6, \mathrm{i} 77, \mathrm{i} 78, \mathrm{i} 79, \mathrm{i} 80, \mathrm{i} 81, \mathrm{i} 82, \mathrm{i} 83, \mathrm{i} 84$

$\mathrm{n} 1,0,0,0,0,0,0,0,0,0,0,0,54.605,0,0,0,0,0,0,0,0,0,22.09,142.55,9.321,0,0,0,0,0,0,0,0,19.126,0,0,0,0,0,0,0,0,0,0,0,0,57.742,124.2$ $25,0,0,0,0,0,0,0,0,0,12.383,264.059,35.533,0,0,0,0,0,0,0,0,0,0,113.661,49.983,0,0,0,0,0,0,0,0,0,0,104.017,29.752,146.212$

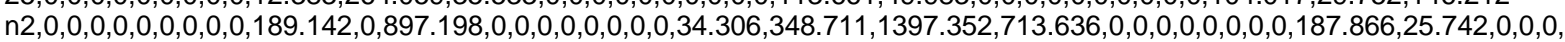
$0,0,0,0,0,0,0,70.718,605.012,1078.218,230.62,0,0,0,0,0,0,0,0,133.715,927.684,456.565,153.814,0,0,0,0,0,0,0,0,0,564.58,1061$. $393,1095.681,309.98,0,0,0,0,0,0,0,280.442,991.863,524.587,877.455$

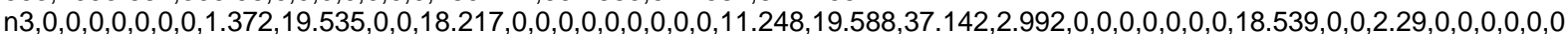
$, 0,0,0,8.262,9.629,0,0,0,0,0,0,0,0,0,0,0,0,1.295,3.987,0,0,0,0,0,0,0,0,25.188,114.281,73.023,61.762,22.343,5.119,0,0,0,0,0,1.6$ $17,0.3,29.545,76.014$

n $4,0,0,0,0,0,0,0,0,0,0,0,103.475,0,0,0,0,0,0,0,0,0,0,1097.64,346.475,0,0,0,0,0,0,0,0,0,0,0,0,0,0,0,0,0,0,0,0,0,189.805,581.863,0$ $, 0,0,0,0,0,0,0,0,0,0,207.863,0,0,0,0,0,0,0,0,0,0,0,828.64,2677.475,1216.122,0,0,0,0,0,0,0,0,0,735.863,698.475$

$\mathrm{n} 5,0,0,0,0,0,0,0,0,0,0,0,886.82,0,0,0,0,0,0,0,0,0,1037.334,1984.858,1397.82,556.719,0,0,0,0,0,0,0,279.067,170.334,0,0,0,0,0,0$ $0,0,0,0,0,1949.334,1562.073,552.82,0,0,0,0,0,0,0,0,0,792.334,1370.073,0,0,0,0,0,0,0,0,0,0,0,1712.858,3652.82,2302.719,0,0$ $0,0,0,0,0,0,757.334,1784.073,1793.82$

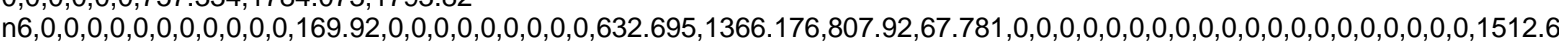
$95,1039.909,0,0,0,0,0,0,0,0,0,0,355.695,847.909,0,0,0,0,0,0,0,0,0,0,0,1184.176,3048.92,1700.781,0,0,0,0,0,0,0,0,320.695,126$ $1.909,1189.92$

n7,0,0,0,0,0,0,0,0,38.52,126.955,0,993.961,0,0,0,0,0,0,0,0,58.117,1271.96,2088.961,1619.231, 893.01,0,0,0,0,0,0,0,442.431,47 $6.99,0,0,0,0,0,0,0,0,0,0,0,2135.692,1761.578,777.335,0,0,0,0,0,0,0,0,0,1000.517,1573.257,0,0,0,0,0,0,0,0,0,0,0,1909.971,3872$ $.565,2497.729,0,0,0,0,0,0,0,0,966.215,1979.628,1994.268$

\$offdelim

Table Sini(n,j) armazenamento inicial

\$ondelim

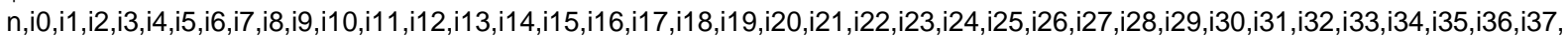

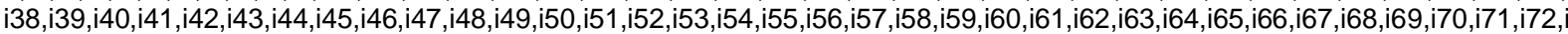
$73, \mathrm{i} 74, \mathrm{i} 75, \mathrm{i} 76, \mathrm{i} 77, \mathrm{i} 78, \mathrm{i} 79, \mathrm{i} 80, \mathrm{i} 81, \mathrm{i} 82, \mathrm{i} 83, \mathrm{i} 84$

$\mathrm{n} 1,241.59,241.59,241.59,241.59,241.59,241.59,241.59,241.59,241.59,241.59,241.59,241.59,241.59,241.59,241.59,241.59,241$ $.59,241.59,241.59,241.59,241.59,241.59,241.59,241.59,241.59,241.59,241.59,241.59,241.59,241.59,241.59,241.59,241.59,24$ $1.59,241.59,241.59,241.59,241.59,241.59,241.59,241.59,241.59,241.59,241.59,241.59,241.59,241.59,241.59,241.59,241.59,2$ $41.59,241.59,241.59,241.59,241.59,241.59,241.59,241.59,241.59,241.59,241.59,241.59,241.59,241.59,241.59,241.59,241.59$, $241.59,241.59,241.59,241.59,241.59,241.59,241.59,241.59,241.59,241.59,241.59,241.59,241.59,241.59,241.59,241.59,241.59$ ,241.59

n2,19528,19528,19528,19528,19528,19528,19528,19528,19528,19528,19528,19528,19528,19528,19528,19528,19528,19528, $19528,19528,19528,19528,19528,19528,19528,19528,19528,19528,19528,19528,19528,19528,19528,19528,19528,19528,19$ $528,19528,19528,19528,19528,19528,19528,19528,19528,19528,19528,19528,19528,19528,19528,19528,19528,19528,1952$ $8,19528,19528,19528,19528,19528,19528,19528,19528,19528,19528,19528,19528,19528,19528,19528,19528,19528,19528,1$ $9528,19528,19528,19528,19528,19528,19528,19528,19528,19528,19528,19528$

n3,533.266,533.266,533.266,533.266,533.266,533.266,533.266,533.266,533.266,533.266,533.266,533.266,533.266,533.266,5 $33.266,533,266,533,266,533,266,533,266,533,266,533,266,533,266,533,266,533,266,533,266,533,266,533,266,533.266,533.2$ $66,533.266,533.266,533.266,533.266,533.266,533.266,533.266,533.266,533.266,533.266,533.266,533.266,533.266,533.266,5$ 33.266,533.266,533.266,533.266,533.266,533.266,533.266,533.266,533.266,533.266,533.266,533.266,533.266,533.266,533.2 
$66,533.266,533.266,533.266,533.266,533.266,533.266,533.266,533.266,533.266,533.266,533.266,533.266,533.266,533.266,5$ 33.266,533.266,533.266,533.266,533.266,533.266,533.266,533.266,533.266,533.266,533.266,533.266,533.266 n4,29156.263,29156.263,29156.263,29156.263,29156.263,29156.263,29156.263,29156.263,29156.263,29156.263,29156.263, 29156.263,29156.263,29156.263,29156.263,29156.263,29156.263,29156.263,29156.263,29156.263,29156.263,29156.263,29 156.263,29156.263,29156.263,29156.263,29156.263,29156.263,29156.263,29156.263,29156.263,29156.263,29156.263,2915 $6.263,29156.263,29156.263,29156.263,29156.263,29156.263,29156.263,29156.263,29156.263,29156.263,29156.263,29156.2$ $63,29156.263,29156.263,29156.263,29156.263,29156.263,29156.263,29156.263,29156.263,29156.263,29156.263,29156.263$, 29156.263,29156.263,29156.263,29156.263,29156.263,29156.263,29156.263,29156.263,29156.263,29156.263,29156.263,29 156.263,29156.263,29156.263,29156.263,29156.263,29156.263,29156.263,29156.263,29156.263,29156.263,29156.263,2915 6.263,29156.263,29156.263,29156.263,29156.263,29156.263,29156.263

n5,10562.024,10562.024,10562.024,10562.024,10562.024,10562.024,10562.024,10562.024,10562.024,10562.024,10562.024, $10562.024,10562.024,10562.024,10562.024,10562.024,10562.024,10562.024,10562.024,10562.024,10562.024,10562.024,10$ $562.024,10562.024,10562.024,10562.024,10562.024,10562.024,10562.024,10562.024,10562.024,10562.024,10562.024,1056$ $2.024,10562.024,10562.024,10562.024,10562.024,10562.024,10562.024,10562.024,10562.024,10562.024,10562.024,10562.0$ $24,10562.024,10562.024,10562.024,10562.024,10562.024,10562.024,10562.024,10562.024,10562.024,10562.024,10562.024$, $10562.024,10562.024,10562.024,10562.024,10562.024,10562.024,10562.024,10562.024,10562.024,10562.024,10562.024,10$ $562.024,10562.024,10562.024,10562.024,10562.024,10562.024,10562.024,10562.024,10562.024,10562.024,10562.024,1056$ $2.024,10562.024,10562.024,10562.024,10562.024,10562.024,10562.024$

n6,1226,1226,1226,1226,1226,1226,1226,1226,1226,1226,1226,1226,1226,1226,1226,1226,1226,1226,1226,1226,1226,1226, $1226,1226,1226,1226,1226,1226,1226,1226,1226,1226,1226,1226,1226,1226,1226,1226,1226,1226,1226,1226,1226,1226,12$ $26,1226,1226,1226,1226,1226,1226,1226,1226,1226,1226,1226,1226,1226,1226,1226,1226,1226,1226,1226,1226,1226,1226$, $1226,1226,1226,1226,1226,1226,1226,1226,1226,1226,1226,1226,1226,1226,1226,1226,1226,1226$

n7, $3800,3800,3800,3800,3800,3800,3800,3800,3800,3800,3800,3800,3800,3800,3800,3800,3800,3800,3800,3800,3800,3800$, $3800,3800,3800,3800,3800,3800,3800,3800,3800,3800,3800,3800,3800,3800,3800,3800,3800,3800,3800,3800,3800,3800,38$ $00,3800,3800,3800,3800,3800,3800,3800,3800,3800,3800,3800,3800,3800,3800,3800,3800,3800,3800,3800,3800,3800,3800$, $3800,3800,3800,3800,3800,3800,3800,3800,3800,3800,3800,3800,3800,3800,3800,3800,3800,3800$ \$offdelim

Table UCini(n,i) uso consuntivo inicial

\$ondelim

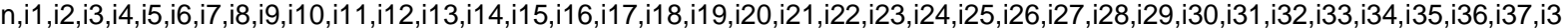
8 ,i39,i40,i41,i42,i43,i44,i45,i46,i47,i48,i49,i50,i51,i52,i53,i54,i55,i56,i57, i58,i59,i60,i61,i62,i63,i64,i65,i66,i67,i68,i69,i70,i71,i72,i7 $3, \mathrm{i} 74, \mathrm{i} 75, \mathrm{i} 76, \mathrm{i} 77, \mathrm{i} 78, \mathrm{i} 79, \mathrm{i} 80, \mathrm{i} 81, \mathrm{i} 82, \mathrm{i} 83, \mathrm{i} 84$

$\mathrm{n} 1,0,0,0,0,0,0,0,0,0,0,0,0,0,0,0,0,0,0,0,0,0,0,0,0,0,0,0,0,0,0,0,0,0,0,0,0,0,0,0,0,0,0,0,0,0,0,0,0,0,0,0,0,0,0,0,0,0,0,0,0,0,0,0,0,0,0$, $0,0,0,0,0,0,0,0,0,0,0,0,0,0,0,0,0,0$

n2, $0,0,0,0,0,0,0,0,0,0,0,0,0,0,0,0,0,0,0,0,0,0,0,0,0,0,0,0,0,0,0,0,0,0,0,0,0,0,0,0,0,0,0,0,0,0,0,0,0,0,0,0,0,0,0,0,0,0,0,0,0,0,0,0,0,0$, $0,0,0,0,0,0,0,0,0,0,0,0,0,0,0,0,0,0$

n3 $3,0,0,0,0,0,0,0,0,0,0,0,0,0,0,0,0,0,0,0,0,0,0,0,0,0,0,0,0,0,0,0,0,0,0,0,0,0,0,0,0,0,0,0,0,0,0,0,0,0,0,0,0,0,0,0,0,0,0,0,0,0,0,0,0,0,0$, $0,0,0,0,0,0,0,0,0,0,0,0,0,0,0,0,0,0$

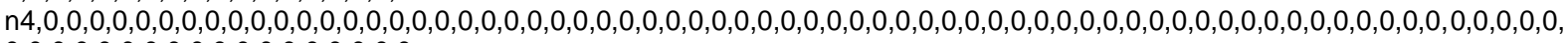
$0,0,0,0,0,0,0,0,0,0,0,0,0,0,0,0,0,0$

n5 $0,0,0,0,0,0,0,0,0,0,0,0,0,0,0,0,0,0,0,0,0,0,0,0,0,0,0,0,0,0,0,0,0,0,0,0,0,0,0,0,0,0,0,0,0,0,0,0,0,0,0,0,0,0,0,0,0,0,0,0,0,0,0,0,0,0$, $0,0,0,0,0,0,0,0,0,0,0,0,0,0,0,0,0,0$

n6, $0,0,0,0,0,0,0,0,0,0,0,0,0,0,0,0,0,0,0,0,0,0,0,0,0,0,0,0,0,0,0,0,0,0,0,0,0,0,0,0,0,0,0,0,0,0,0,0,0,0,0,0,0,0,0,0,0,0,0,0,0,0,0,0,0,0$, $0,0,0,0,0,0,0,0,0,0,0,0,0,0,0,0,0,0$

n7 $0,0,0,0,0,0,0,0,0,0,0,0,0,0,0,0,0,0,0,0,0,0,0,0,0,0,0,0,0,0,0,0,0,0,0,0,0,0,0,0,0,0,0,0,0,0,0,0,0,0,0,0,0,0,0,0,0,0,0,0,0,0,0,0,0,0$, $0,0,0,0,0,0,0,0,0,0,0,0,0,0,0,0,0,0$

\$offdelim

Table DEini(n,i) desvio de transposicao inicial

\$ondelim

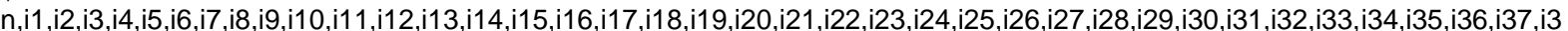

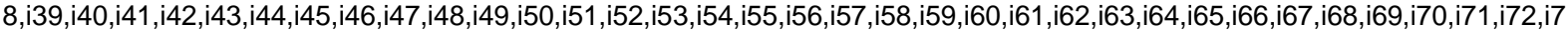
$3, \mathrm{i} 74, \mathrm{i} 75, \mathrm{i} 76, \mathrm{i} 77, \mathrm{i} 78, \mathrm{i} 79, \mathrm{i} 80, \mathrm{i} 81, \mathrm{i} 82, \mathrm{i} 83, \mathrm{i} 84$

$\mathrm{n} 1,0,0,0,0,0,0,0,0,0,0,0,0,0,0,0,0,0,0,0,0,0,0,0,0,0,0,0,0,0,0,0,0,0,0,0,0,0,0,0,0,0,0,0,0,0,0,0,0,0,0,0,0,0,0,0,0,0,0,0,0,0,0,0,0,0,0$, $0,0,0,0,0,0,0,0,0,0,0,0,0,0,0,0,0,0$

n2 $20,0,0,0,0,0,0,0,0,0,0,0,0,0,0,0,0,0,0,0,0,0,0,0,0,0,0,0,0,0,0,0,0,0,0,0,0,0,0,0,0,0,0,0,0,0,0,0,0,0,0,0,0,0,0,0,0,0,0,0,0,0,0,0,0,0$, $0,0,0,0,0,0,0,0,0,0,0,0,0,0,0,0,0,0$

n3 $0,0,0,0,0,0,0,0,0,0,0,0,0,0,0,0,0,0,0,0,0,0,0,0,0,0,0,0,0,0,0,0,0,0,0,0,0,0,0,0,0,0,0,0,0,0,0,0,0,0,0,0,0,0,0,0,0,0,0,0,0,0,0,0,0,0$, $0,0,0,0,0,0,0,0,0,0,0,0,0,0,0,0,0,0$

n4, $0,0,0,0,0,0,0,0,0,0,0,0,0,0,0,0,0,0,0,0,0,0,0,0,0,0,0,0,0,0,0,0,0,0,0,0,0,0,0,0,0,0,0,0,0,0,0,0,0,0,0,0,0,0,0,0,0,0,0,0,0,0,0,0,0,0$, $0,0,0,0,0,0,0,0,0,0,0,0,0,0,0,0,0,0$

n5 $0,0,0,0,0,0,0,0,0,0,0,0,0,0,0,0,0,0,0,0,0,0,0,0,0,0,0,0,0,0,0,0,0,0,0,0,0,0,0,0,0,0,0,0,0,0,0,0,0,0,0,0,0,0,0,0,0,0,0,0,0,0,0,0,0,0$, $0,0,0,0,0,0,0,0,0,0,0,0,0,0,0,0,0,0$

n6, $0,0,0,0,0,0,0,0,0,0,0,0,0,0,0,0,0,0,0,0,0,0,0,0,0,0,0,0,0,0,0,0,0,0,0,0,0,0,0,0,0,0,0,0,0,0,0,0,0,0,0,0,0,0,0,0,0,0,0,0,0,0,0,0,0,0$, $0,0,0,0,0,0,0,0,0,0,0,0,0,0,0,0,0,0$

n7 $0,0,0,0,0,0,0,0,0,0,0,0,0,0,0,0,0,0,0,0,0,0,0,0,0,0,0,0,0,0,0,0,0,0,0,0,0,0,0,0,0,0,0,0,0,0,0,0,0,0,0,0,0,0,0,0,0,0,0,0,0,0,0,0,0,0$, $0,0,0,0,0,0,0,0,0,0,0,0,0,0,0,0,0,0$

\$offdelim

Table edpini(k,i) deficit de energia inicial

\$ondelim

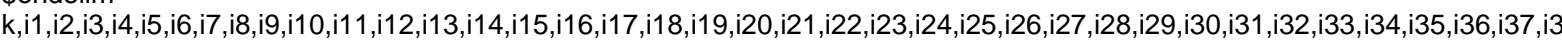

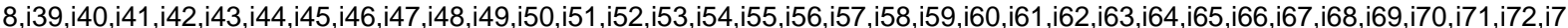
$3, \mathrm{i} 74, \mathrm{i} 75, \mathrm{i} 76, \mathrm{i} 77, \mathrm{i} 78, \mathrm{i} 79, \mathrm{i} 80, \mathrm{i} 81, \mathrm{i} 82, \mathrm{i} 83, \mathrm{i} 84$

k1 $0,0,0,0,0,0,0,0,0,0,0,0,0,0,0,0,0,0,0,0,0,0,0,0,0,0,0,0,0,0,0,0,0,0,0,0,0,0,0,0,0,0,0,0,0,0,0,0,0,0,0,0,0,0,0,0,0,0,0,0,0,0,0,0,0,0$, $0,0,0,0,0,0,0,0,0,0,0,0,0,0,0,0,0,0$ 
\$offdelim

Table hdpini(n,i) deficit hidrico inicial

\$ondelim

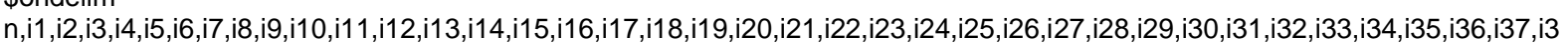

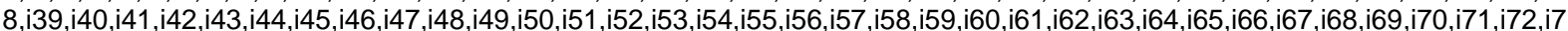
$3, \mathrm{i} 74, \mathrm{i} 75, \mathrm{i} 76, \mathrm{i} 77, \mathrm{i} 78, \mathrm{i} 79, \mathrm{i} 80, \mathrm{i} 81, \mathrm{i} 82, \mathrm{i} 83, \mathrm{i} 84$

n1 $1,1,1,1,1,1,1,1,1,1,1,1,1,1,1,1,1,1,1,1,1,1,1,1,1,1,1,1,1,1,1,1,1,1,1,1,1,1,1,1,1,1,1,1,1,1,1,1,1,1,1,1,1,1,1,1,1,1,1,1,1,1,1,1,1,1$, $1,1,1,1,1,1,1,1,1,1,1,1,1,1,1,1,1,1$

n2,1,1,1,1,1,1,1,1,1,1,1,1,1,1,1,1,1,1,1,1,1,1,1,1,1,1,1,1,1,1,1,1,1,1,1,1,1,1,1,1,1,1,1,1,1,1,1,1,1,1,1,1,1,1,1,1,1,1,1,1,1,1,1,1,1,1, $1,1,1,1,1,1,1,1,1,1,1,1,1,1,1,1,1,1$

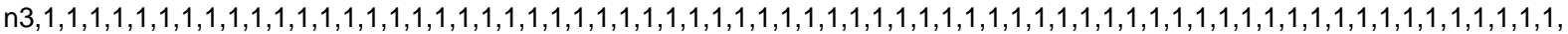
$1,1,1,1,1,1,1,1,1,1,1,1,1,1,1,1,1,1$

n $4,1,1,1,1,1,1,1,1,1,1,1,1,1,1,1,1,1,1,1,1,1,1,1,1,1,1,1,1,1,1,1,1,1,1,1,1,1,1,1,1,1,1,1,1,1,1,1,1,1,1,1,1,1,1,1,1,1,1,1,1,1,1,1,1,1,1$, $1,1,1,1,1,1,1,1,1,1,1,1,1,1,1,1,1,1$

n $5,1,1,1,1,1,1,1,1,1,1,1,1,1,1,1,1,1,1,1,1,1,1,1,1,1,1,1,1,1,1,1,1,1,1,1,1,1,1,1,1,1,1,1,1,1,1,1,1,1,1,1,1,1,1,1,1,1,1,1,1,1,1,1,1,1,1$, $1,1,1,1,1,1,1,1,1,1,1,1,1,1,1,1,1,1$

n6,1,1,1,1,1,1,1,1,1,1,1,1,1,1,1,1,1,1,1,1,1,1,1,1,1,1,1,1,1,1,1,1,1,1,1,1,1,1,1,1,1,1,1,1,1,1,1,1,1,1,1,1,1,1,1,1,1,1,1,1,1,1,1,1,1,1, $1,1,1,1,1,1,1,1,1,1,1,1,1,1,1,1,1,1$

n7,1,1,1,1,1,1,1,1,1,1,1,1,1,1,1,1,1,1,1,1,1,1,1,1,1,1,1,1,1,1,1,1,1,1,1,1,1,1,1,1,1,1,1,1,1,1,1,1,1,1,1,1,1,1,1,1,1,1,1,1,1,1,1,1,1,1,

$1,1,1,1,1,1,1,1,1,1,1,1,1,1,1,1,1,1$

\$offdelim

Table $a(n, p)$ cota volume

\$ondelim

$\mathrm{n}, \mathrm{p} 0, \mathrm{p} 1, \mathrm{p} 2, \mathrm{p} 3, \mathrm{p} 4$

$\mathrm{n} 1,591.5352,0.1642508,-0.0002607112,0,0$

n2,530.3318,0.00607596,-4.83615E-7,2.203479E-11,-3.84658E-16

n3,801.7885,0.1142334,-0.0001977012,1.44183E-7,-2.488779E-17

$\mathrm{n} 4,374.179,0.00139669,-5.35159 \mathrm{E}-8,1.155989 \mathrm{E}-12,-9.545989 \mathrm{E}-18$

n5,275.813,0.006764889,-8.86837E-7,7.067909E-11,-2.23985E-15

n6,251.5,0,0,0,0

$\mathrm{n} 7,138,0,0,0,0$

\$offdelim

Table $b(n, p)$ cota descarga

\$ondelim

$\mathrm{n}, \mathrm{p} 0, \mathrm{p} 1, \mathrm{p} 2, \mathrm{p} 3, \mathrm{p} 4$

n1,577,0.006877187,-2.099505E-6,3.629827E-10,-2.35895E-14

$\mathrm{n} 2,514.6558,0.00160686,-2.55275 \mathrm{E}-7,2.885479 \mathrm{E}-11,-1.17978 \mathrm{E}-15$

n3,636.2,0.03073,-0.00015531,5.08474E-7,-6.098659E-10

n4,359.6538,0.00196401,-2.96873E-7,2.50828E-11,-7.702299E-16

$\mathrm{n} 5,251.5,0,0,0,0$

$\mathrm{n} 6,138,0,0,0,0$

n7,10.03861,0.006665461,-2.45477E-6,4.559482E-10,-3.14485E-14

\$offdelim

Table $\mathrm{c}(\mathrm{n}, \mathrm{p})$ area volume

\$ondelim

$\mathrm{n}, \mathrm{p} 0, \mathrm{p} 1, \mathrm{p} 2, \mathrm{p} 3, \mathrm{p} 4$

$\mathrm{n} 1,-289.439596294675,2.62315600176686,-0.00550845875916944,0,0$

n2,167.268809758092,0.0464019164104526,7.63833651889608E-10,0,0

n3,12.2522148884643,0.03023106774999489,0.000112582321601188,0,0

$\mathrm{n} 4,433.599867164179,0.130635932930397,-5.92442501252507 \mathrm{E}-7,0,0$

n5,86.8069999061546,0.0818037408509336,-1.317045866333E-6,0,0

$\mathrm{n} 6,213,0,0,0,0$

$\mathrm{n} 7,60,0,0,0,0$

\$offdelim

Parameter SSmin(n) limite de armazenamento

/ n1 200.72

n2 4250

n3 95.25

n4 5447

n5 7234

n6 1226

n7 $3800 /$

Parameter SSmax(n) limite de armazenamento

/ n1 241.59

n2 19528

n3 557

n4 34116

n5 10782

n6 1226

n7 3800 
Parameter SSend(n) armazenamento final

/ n1 241.59

n2 18837.43

n3 485.84

n4 27751.48

n5 9071.86

n6 1226

n7 $3800 /$

Parameter Rtmin(n) limite de turbinamento *limite de vazao minima jusante das usinas

/ n1 27.67

n2 500

n3 8.8

n4 1300

n5 1300

n6 1300

n7 $1300 /$

Parameter Rtmax (n) limite de turbinamento / n1 238.1192656896

n2 815.2588694712

n3 60.3581901696

n4 4011.599151936

n5 3091.947670974

n6 3741.2783470587

n7 2856.8045941728

Parameter Pmax(n) limite de potencia

*Considerado igual à demanda máxima

/ n1 38.5

n2 239

n3 58

n4 531

n5 959

n6 2225

n7 2139 /

Parameter $\mathrm{nn}(\mathrm{n})$ produtividade especifica

/ n1 0.008755

n2 0.008564

n3 0.008829

n4 0.009023

n5 0.008931

n6 0.009035

n7 0.009119 /

Parameter Af(nf) area

/ n6 213

n7 $60 /$

Parameter $\mathrm{Hf}(\mathrm{nf})$ cota do reservatorio

/ n6 251.5

n7 138 /

Parameter DEmin(n) limite do desvio de transposicao

/ $\mathrm{n} 10$

n2 0

n3 0

n4 0

n5 0

n6 0

n7 $0 /$

Positive Variable

$R t(n, i)$ vazao turbinada

$\operatorname{Rv}(n, i)$ vazao vertida

$R(n, i)$ vazao total

$\mathrm{S}(\mathrm{nr}, \mathrm{j})$ volume

$\mathrm{Hr}(\mathrm{nr}, \mathrm{j})$ cota no reservatorio

$\mathrm{Ht}(\mathrm{n}, \mathrm{i})$ cota no canal de fuga

$\mathrm{Hg}(\mathrm{n}, \mathrm{i})$ queda

$\operatorname{Ar}(n r, j)$ area

Pot $(n, i)$ potencia

UC $(n, i)$ vazao para uso consuntivo

$\mathrm{hdp}(\mathrm{n}, \mathrm{i})$ deficit hidrico percentual 


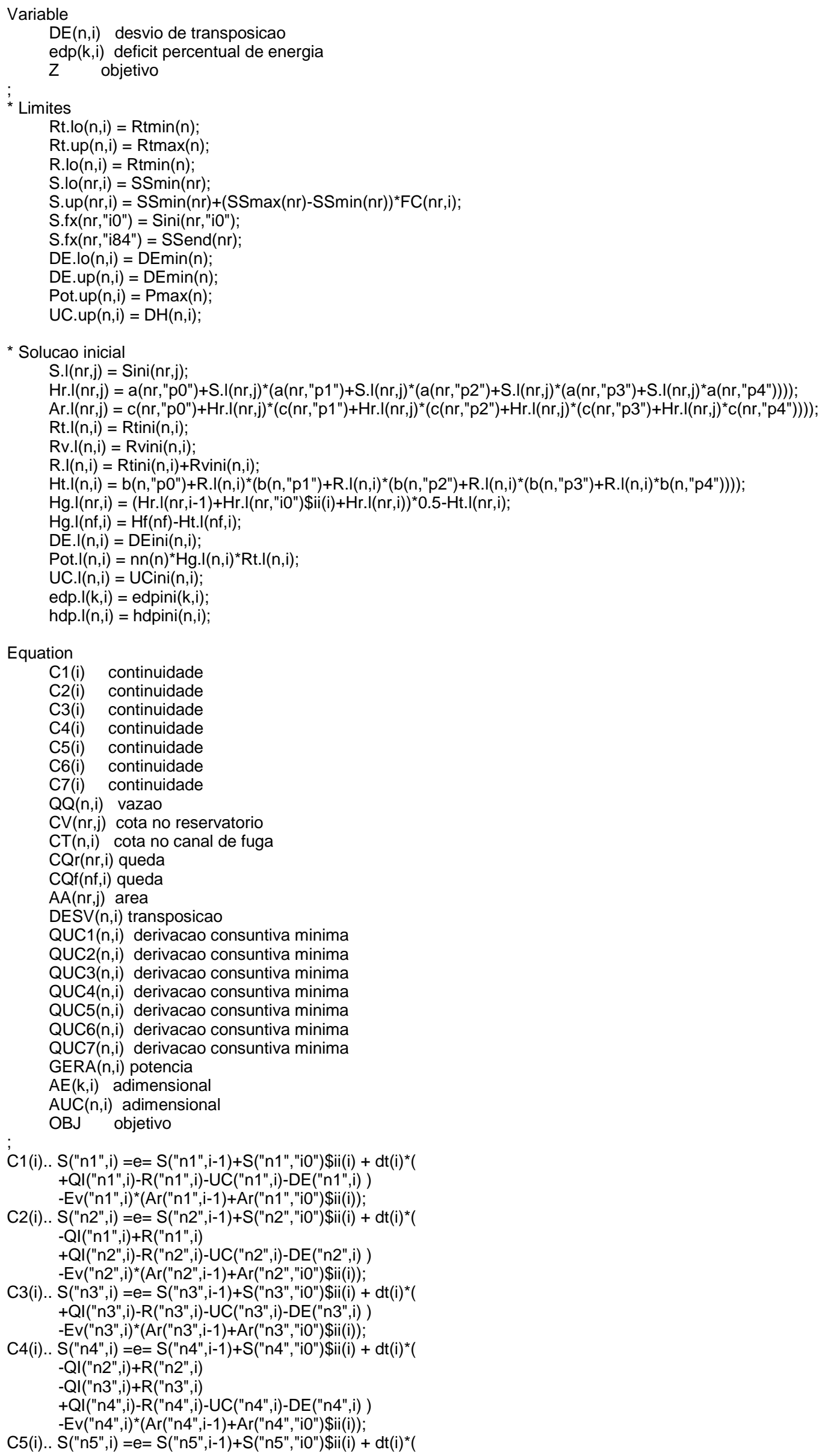

C5(i).. S("n5",i) =e = S("n5",i-1)+S("n5","i0")\$ii(i) + dt(i)*( 
-QI("n4",i)+R("n4",i)

+QI("n5",i)-R("n5",i)-UC("n5",i)-DE("n5",ii) )

C6(i).. $0=e=d t(i)^{*}($

(Ar("n5",i-1)+Ar("n5","i0")\$ii(i));

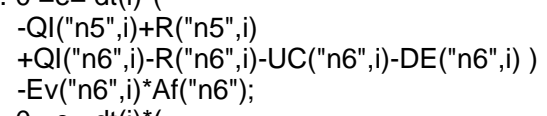

$\mathrm{C} 7(\mathrm{i}) . .0=\mathrm{e}=\mathrm{dt}(\mathrm{i})^{*}($

-QI("n6",i)+R("n6",i)

$+Q((" n 7 ", i)-R(" n 7 ", i)-U C(" n 7 ", i)-D E(" n 7 ", i))$

-Ev("n7",i)*Af("n7")

$Q Q(n, i) . . R(n, i)=e=R t(n, i)+R v(n, i)$;

$\operatorname{DESV}(n, i) . . D E(n, i)=e=\operatorname{DEmin}(n)$;

$C V(n r, j) . . H r(n r, j)=e=a(n r, " p 0 ")+S(n r, j)^{\star}\left(a(n r, " p 1 ")+S(n r, j)^{\star}\left(a(n r, " p 2 ")+S(n r, j)^{*}\left(a(n r, " p 3 ")+S(n r, j)^{*} a(n r, " p 4 ")\right)\right)\right)$;

$C T(n, i) . . H t(n, i)=e=b(n, " p 0 ")+R(n, i)^{*}\left(b(n, " p 1 ")+R(n, i)^{*}\left(b(n, " p 2 ")+R(n, i)^{*}\left(b(n, " p 3 ")+R(n, i)^{*} b(n, " p 4 ")\right)\right)\right)$;

$\mathrm{CQr}(\mathrm{nr}, \mathrm{i}) . . \mathrm{Hg}(\mathrm{nr}, \mathrm{i})=\mathrm{e}=(\mathrm{Hr}(\mathrm{nr}, \mathrm{i}-1)+\mathrm{Hr}(\mathrm{nr}, " \mathrm{iO} 0) \$ \mathrm{ii}(\mathrm{i})+\mathrm{Hr}(\mathrm{nr}, \mathrm{i}))^{*} 0.5-\mathrm{Ht}(\mathrm{nr}, \mathrm{i})$;

$\operatorname{CQf}(n f, i) . . H g(n f, i)=e=H f(n f)-H t(n f, i)$;

$A A(n r, j) . . A r(n r, j)=e=c(n r, " p 0 ")+S(n r, j)^{\star}\left(c(n r, " p 1 ")+S(n r, j)^{*} c(n r, " p 2 ")\right)$;

*QUC usos prioritários segundo ONS

QUC1 $(n, i) . . U C(" n 1 ", i)=g=0.59^{*} \mathrm{DH}(" n 1 ", i)$

QUC2(n,i).. UC("n2",i) $=g=0.43^{*} \mathrm{DH}(" \mathrm{n} 2 ", \mathrm{i})$;

QUC3 $(n, i) . . \cup C(" n 3 ", i)=g=0.09^{*} D H(" n 3 ", i)$;

QUC4(n,i).. UC("n4",i) =g=0.12* DH("n4",i);

QUC5(n,i).. UC("n5",i) =g=0.03*DH("n5",i);

QUC6 (n,i).. UC("n6",i) =g=0.03*DH("n6",i);

QUC7(n,i).. UC("n7",i) =g= 0.46* DH("n7",i);

$\operatorname{GERA}(n, i) . . \operatorname{Pot}(n, i)=e=n n(n)^{*} H g(n, i)^{*} \operatorname{Rt}(n, i)$;

$A E(k, i) . . \operatorname{edp}(k, i)=e=(D D(k, i)-\operatorname{sum}(n, \operatorname{Pot}(n, i))) / D D(k, i)$;

$\operatorname{AUC}(n, i) . . h d p(n, i)=e=(\operatorname{DH}(n, i)-U C(n, i)) / D H(n, i)$;

OBJ.. Z =e $=\operatorname{sum}\left(\mathrm{i},\left(0.5^{*} \operatorname{sqr}(\operatorname{sum}(\mathrm{k}, \operatorname{edp}(\mathrm{k}, \mathrm{i})))+0.5^{*} \operatorname{sqr}(\operatorname{sum}(\mathrm{n}, \mathrm{hdp}(\mathrm{n}, \mathrm{i})))\right)\right)$;

Model

HIDRO

C1,C2,C3,C4,C5,C6,C7,QQ,CV,CT,CQr,CQf,AA,DESV,QUC1,QUC2,QUC3,QUC4,QUC5,QUC6,QUC7,GERA,AE,AUC,OBJ /;

Option NLP = MINOS;

HIDRO.nodlim = 10000;

HIDRO. workspace $=200$;

HIDRO.optfile = 1;

file opt /C:IUsers|Ludmilson|Documentslgamsdirlprojdirlminos.opt/

put opt;

put 'superbasics limit 7050' /;

put 'scale nonlinear variables' /;

put 'optimality tolerance 0.000001 ' /;

putclose;

Option reslim $=36000$;

Option iterlim $=200000$;

Solve HIDRO using NLP minimizing Z; 
Anexo A - Histórico do PLD (30/jun/2001 a 01/jun/2012) segundo CCEE Preço médio $(\mathrm{R} \$ / \mathrm{MWh})$ por submercado

\begin{tabular}{|c|c|c|c|c|c|c|c|c|c|c|c|c|c|c|c|}
\hline Ano & Mês & Data Início & Data Fim & \begin{tabular}{|} 
Pesado \\
SE
\end{tabular} & $\begin{array}{c}\text { Médio } \\
\text { SE }\end{array}$ & Leve SE & $\begin{array}{c}\text { Pesado } \\
\text { S }\end{array}$ & Médio S & Leve S & $\begin{array}{c}\text { Pesado } \\
\text { NE }\end{array}$ & $\begin{array}{c}\text { Médio } \\
\text { NE }\end{array}$ & $\begin{array}{c}\text { Leve } \\
\text { NE }\end{array}$ & $\begin{array}{c}\text { Pesado } \\
\text { N }\end{array}$ & Médio N & Leve $\mathbf{N}$ \\
\hline 2001 & 7 & $30 / 06 / 2001$ & $6 / 07 / 2001$ & 684.00 & 684.00 & 684.00 & 141.61 & 141.61 & 141.61 & 684.00 & 684.00 & 684.00 & 684.00 & 684.00 & 684.00 \\
\hline 2001 & 7 & 07/07/2001 & 3/07/2001 & 684.00 & 684.00 & 684.00 & 4.00 & 4.00 & 4.00 & 684.00 & 684.00 & 684.00 & 684.00 & 84.00 & 684.00 \\
\hline 2001 & 7 & $14 / 07 / 2001$ & $\mathrm{~J} / 07 / 2001$ & 684.00 & 684.00 & 684.00 & 4.00 & 4.00 & 4.00 & 684.00 & 684.00 & 684.00 & 684.00 & 684.00 & 684.00 \\
\hline 2001 & 7 & $21 / 07 / 2001$ & $7 / 07 / 2001$ & 684.00 & 684.00 & 684.00 & 86.94 & 86.94 & 86.94 & 684.00 & 684.00 & 684.00 & 684.00 & 684.00 & 684.00 \\
\hline 2001 & 8 & $28 / 07 / 2001$ & 3/08/2001 & 684.00 & 684.00 & 684.00 & 37.12 & 37.12 & 37.12 & 684.00 & 684.00 & 684.00 & 684.00 & 684.00 & 684.00 \\
\hline 2001 & 8 & $04 / 08 / 2001$ & 0/08/2001 & 684.00 & 684.00 & 684.00 & 4.00 & 4.00 & 4.00 & 684.00 & 684.00 & 684.00 & 684.00 & 684.00 & 684.00 \\
\hline 2001 & 8 & $11 / 08 / 2001$ & $7 / 08 / 2001$ & 684.00 & 684.00 & 684.00 & 37.12 & 37.12 & 37.12 & 684.00 & 684.00 & 684.00 & 684.00 & 684.00 & 684.00 \\
\hline 2001 & 8 & $18 / 08 / 2001$ & $4 / 08 / 2001$ & 684.00 & 684.00 & 684.00 & 60.62 & 60.62 & 60.62 & 684.00 & 684.00 & 684.00 & 684.00 & 684.00 & 684.00 \\
\hline 2001 & 8 & $24 / 08 / 2001$ & $1 / 08 / 2001$ & 684.00 & 684.00 & 684.00 & 86.94 & & 86.94 & 684.00 & 684.00 & 684.00 & 84.00 & & 684.00 \\
\hline 2001 & 9 & $01 / 09 / 2001$ & $7 / 09 / 2001$ & 684.00 & 684.00 & 684.00 & 93.24 & 3.24 & 93.24 & 684.00 & 684.00 & 684.00 & 684.00 & & 684.00 \\
\hline 2001 & 9 & 08/09/2001 & 4/09/2001 & 684.00 & 684.00 & 684.00 & 63.55 & & & 684.00 & 684.00 & 684.00 & & & 684.00 \\
\hline 2001 & 9 & $15 / 09 / 2001$ & $21 / 09 / 2001$ & 684.00 & 684.00 & 684.00 & 79.72 & & 79.72 & 684.00 & 684.00 & 684.00 & & & 684.00 \\
\hline 2001 & 9 & $22 / 09 / 2001$ & $8 / 09 / 2001$ & 336.00 & 336.00 & & 63.55 & & & 562.15 & 562.15 & 562.15 & & & 336.00 \\
\hline 2001 & 10 & $29 / 09 / 2001$ & & 336.00 & 336.00 & & & & & & & 562.15 & & & \\
\hline 2001 & 10 & 001 & 001 & 336.00 & & & & & 4.00 & & & 562.15 & & & \\
\hline 2001 & 10 & & & 336.00 & & & 4.00 & & & & & 562.15 & & & \\
\hline 2001 & 10 & & & 336.00 & & & 4.00 & & & & & 562.15 & & & \\
\hline 2001 & 11 & & 01 & 336.00 & & & 4.00 & & & & & 562.15 & & & \\
\hline 2001 & 11 & & & 336.00 & 336.00 & & & & & & & 562.15 & & & \\
\hline 2001 & 11 & & & 336.00 & & & & & & & & 562.15 & & & \\
\hline 2001 & 11 & & & 336 & & & & & & & & 562.15 & & & \\
\hline 2001 & 11 & & & 336 & & & & & & & & 562.15 & & & \\
\hline 2001 & 12 & & & 336.00 & & & & & & & & 562.15 & & & \\
\hline 2001 & 12 & & & 336.00 & & & & & & & & 562.15 & & & \\
\hline 2001 & 12 & & & 336.00 & & & & & & & & 562.15 & & & \\
\hline 2001 & 12 & & & 336.00 & & & & & & & & 562.15 & & & \\
\hline 2002 & 1 & & & 336.00 & & & & & & & & 562.15 & & & \\
\hline 2002 & 1 & & & 336 & & & & & & & & 562.15 & 00 & & \\
\hline 002 & 1 & & & 336 & & & & & & & & 562.15 & 0 & & \\
\hline 2002 & 1 & & & 336 & & & & & & & & 562.15 & 00 & & \\
\hline 002 & 1 & & & 336.00 & & & 64 & & & & & 562.15 & 0 & & \\
\hline 002 & 2 & & 002 & 134.76 & & & & & & & & 319.41 & 19 & & \\
\hline 2002 & 2 & 02 & 002 & 134.76 & 134.76 & 134.76 & & & & 31 & & & 17 & & \\
\hline 002 & 2 & & & 9.25 & & & & & & & & & 19 & & \\
\hline 2 & 2 & & 02 & & 5.4 & & & & & & & 319.41 & bo & & \\
\hline 002 & 3 & & & & 8.14 & & & & & 319.41 & 319.41 & 319.41 & .49 & 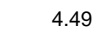 & \\
\hline 002 & 3 & & & 14 & 8. & 8.14 & & & 97 & & 49 & 4.49 & 49 & 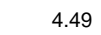 & 49 \\
\hline 2002 & 3 & & & 66 & 4. & 4.66 & 4. & & 12 & 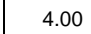 & 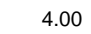 & 4.00 & 00 & & 00 \\
\hline 002 & 3 & & & 70 & 8.70 & 70 & 8. & & 38 & 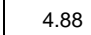 & 88 & 4.88 & 88 & 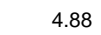 & 88 \\
\hline 002 & 3 & & & 10 & 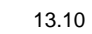 & 10 & 12.3 & & & & 32 & 7.32 & 32 & & 32 \\
\hline 002 & 3 & & & 30 & & 5 & 1 & & & 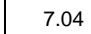 & 4 & 7.04 & .04 & & 7.04 \\
\hline 002 & 4 & & & 64 & & .64 & & & & & 7 & 6.17 & 17 & 17 & 17 \\
\hline 002 & 4 & & & & & .87 & & & & & L & .72 & 72 & & 72 \\
\hline 002 & 4 & & & 34 & & & & & & 8.71 & 1 & .71 & 71 & 1 & 71 \\
\hline 2002 & 4 & & & & & 96 & 16 & & & & 75 & .75 & .75 & 75 & 75 \\
\hline 2002 & 5 & & & 57 & & 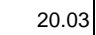 & 20 & & & 0 & 00 & 4.00 & .57 & 09 & 03 \\
\hline 2002 & 5 & & & 27.19 & 4 & 37 & 27 & & 29 & 38 & 38 & 4.38 & 27.19 & 24 & 24.87 \\
\hline 2002 & 5 & & 02 & 58 & 6 & 61 & 20 & & 99 & 4.00 & .00 & 4.00 & 4.00 & .00 & .00 \\
\hline 2002 & 5 & & & 17 & 6 & 36 & ק & & 31 & 3 & 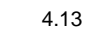 & 4.13 & 13 & 3 & 13 \\
\hline 2002 & 5 & & & 14.51 & 3 & .11 & 11 & & 11 & 0 & .00 & 4.00 & .00 & 00 & 4.00 \\
\hline 2002 & 6 & & & 9.40 & & 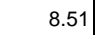 & 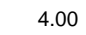 & & 4.00 & 5.57 & 57 & 5.57 & .57 & 57 & 5.57 \\
\hline 2002 & 6 & & & 14.52 & 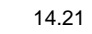 & 13 & 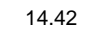 & & 13.96 & 7.69 & 69 & 7.69 & 69 & 69 & 4.70 \\
\hline 2002 & 6 & 002 & 02 & .80 & 37 & 37 & . & 2 & 31 & 7.73 & .73 & 7.73 & .73 & .73 & 6.17 \\
\hline 002 & 6 & & & 75 & & 6 & 15.06 & & & 7.61 & 61 & 7.61 & 61 & 1 & .00 \\
\hline 2002 & 7 & 002 & 002 & 33 & & 83 & 15 & & .83 & 15.89 & 5.89 & 15.89 & 89 & 89 & 15.01 \\
\hline 2002 & 7 & 2002 & 002 & 7.93 & 91 & .56 & .93 & 91 & 17.56 & 17.52 & .52 & 17.52 & 7.52 & 7.52 & 8.15 \\
\hline 002 & 7 & & & 8.04 & & .75 & 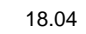 & & 7.75 & 17.35 & & 17.35 & 35 & & 11.12 \\
\hline 2002 & 7 & 002 & 002 & 31 & 30 & .08 & 31 & & 08 & 59 & 59 & 15.59 & 59 & .59 & 6.69 \\
\hline 2002 & 8 & 2002 & 002 & 4.83 & .71 & 61 & 17.12 & & 61 & 15.44 & .44 & 15.44 & .83 & .71 & 14.61 \\
\hline 2002 & 8 & 03/08/2002 & 002 & 13.92 & 13.56 & 13.56 & 16.44 & 16.44 & 13.56 & 13.52 & .52 & 13.52 & 13.52 & 13.52 & 12.92 \\
\hline 2002 & 8 & 08/2002 & 2002 & & & & & & 9.23 & & 72 & 11.72 & 51 & 44 & 9.39 \\
\hline 2002 & 8 & /2002 & 2002 & 10.21 & 10.11 & 9.99 & 10.11 & & 9.85 & 12.41 & 2.41 & 12.41 & 21 & .11 & 9.99 \\
\hline 2002 & 8 & $24 / 08 / 2002$ & 0/08/2002 & 2.11 & 11.80 & 11.79 & 12.11 & 0 & 11.79 & 14.07 & 14.07 & 14.07 & 12.11 & 30 & 11.79 \\
\hline 2002 & 9 & 2002 & 2002 & 7.00 & & & 7.00 & & 6.85 & 5.93 & 93 & 5.86 & 93 & 3 & 5.86 \\
\hline 2002 & 9 & $07 / 09 / 2002$ & 3/09/2002 & 74 & & 6.50 & 7.55 & & 6.50 & 5.87 & 81 & 5.65 & .87 & 81 & 5.65 \\
\hline 2002 & 9 & $14 / 09 / 2002$ & 0/09/2002 & 6.11 & 5.88 & 5.86 & 6.20 & 6 & 5.86 & 5.54 & .54 & 5.54 & .54 & .54 & .54 \\
\hline 2002 & 9 & $21 / 09 / 2002$ & $7 / 09 / 2002$ & 4.99 & 4.87 & 4.83 & 4.83 & & 4.59 & 4.93 & 4.87 & 4.83 & 4.93 & 4.87 & 4.83 \\
\hline 2002 & 10 & $28 / 09 / 2002$ & $4 / 10 / 2002$ & 4.00 & 4.00 & 4.00 & 4.00 & 4.00 & 4.00 & 4.00 & 4.00 & 4.00 & 4.00 & 4.00 & 4.00 \\
\hline 2002 & 10 & 05/10/2002 & $1 / 10 / 2002$ & 4.00 & 4.00 & 4.00 & 4.00 & & 4.00 & 4.00 & 4.00 & 4.00 & 4.00 & .00 & 4.00 \\
\hline 2002 & 10 & $12 / 10 / 2002$ & $8 / 10 / 2002$ & 4.35 & 4.13 & 4.00 & 4.00 & 4.00 & 4.00 & 4.06 & 4.00 & 4.00 & 4.06 & 4.00 & 4.00 \\
\hline 2002 & 10 & 19/10/2002 & $5 / 10 / 2002$ & 5.03 & 4.89 & 4.80 & 4.00 & 4.00 & 4.00 & 4.67 & 4.66 & 4.55 & 4.67 & 4.66 & 4.55 \\
\hline 2002 & 11 & $26 / 10 / 2002$ & $1 / 11 / 2002$ & 7.29 & 7.27 & 7.18 & 7.29 & 7.27 & 7.18 & 6.77 & 6.59 & 6.59 & 6.77 & 6.59 & 6.59 \\
\hline 2002 & 11 & $02 / 11 / 2002$ & $8 / 11 / 2002$ & 7.50 & 7.27 & 7.09 & 4.00 & 4.00 & 4.00 & 6.87 & 6.71 & 6.71 & 6.87 & 6.71 & 6.71 \\
\hline 2002 & 11 & $09 / 11 / 2002$ & 2002 & & 6.00 & 5.78 & & & 4.00 & 5.88 & 5.64 & 5.64 & 6.00 & 5.85 & 5.64 \\
\hline 2002 & 11 & $16 / 11 / 2002$ & $2 / 11 / 2002$ & 6.36 & 6.29 & 6.26 & 4.00 & 4.00 & 4.00 & 6.04 & 5.88 & 5.88 & 6.05 & 5.88 & 5.88 \\
\hline 2002 & 11 & $23 / 11 / 2002$ & $9 / 11 / 2002$ & 6.58 & 6.46 & 6.18 & 5.83 & 5.83 & 5.39 & 5.69 & 5.67 & 5.67 & 7.44 & 7.44 & 6.18 \\
\hline 2002 & 12 & $30 / 11 / 2002$ & & & 5. & 5.51 & & 5.21 & & 5.66 & 5.66 & 5.66 & 5.84 & 5.84 & 5.84 \\
\hline 2002 & 12 & $07 / 12 / 2002$ & 13/12/2002 & 5.74 & 5.70 & 5.54 & 4.00 & 4.00 & 4.00 & 5.74 & 5.74 & 5.74 & 7.27 & 7.27 & 6.97 \\
\hline
\end{tabular}


Anexo A (continuação)

\begin{tabular}{|c|c|c|c|c|c|c|c|c|c|c|c|c|c|c|c|}
\hline Ano & Mês & Data Início & Data Fim & \begin{tabular}{|} 
Pesado \\
SE
\end{tabular} & $\begin{array}{c}\text { Médio } \\
\text { SE }\end{array}$ & Leve SE & $\begin{array}{c}\text { Pesado } \\
\text { S }\end{array}$ & Médio S & Leve S & $\begin{array}{c}\text { Pesado } \\
\mathrm{NE}\end{array}$ & $\begin{array}{c}\text { Médio } \\
\text { NE }\end{array}$ & $\begin{array}{c}\text { Leve } \\
\text { NE }\end{array}$ & \begin{tabular}{|} 
Pesado \\
N
\end{tabular} & lédio N & eve $\mathbf{N}$ \\
\hline 2002 & 12 & $4 / 12 / 2002$ & $0 / 12 / 2002$ & 5.73 & 5.67 & 5.57 & 4.00 & 4.00 & 4.00 & 6.13 & 6.13 & 6.13 & 9.61 & 9.61 & 9.21 \\
\hline 2002 & 12 & /12/2002 & 2002 & 00 & 4.00 & .00 & .00 & & .00 & .01 & .01 & 4.01 & .01 & & 4.01 \\
\hline 2003 & 1 & 3/12/2002 & /01/2003 & 4.00 & 4.00 & .00 & .00 & 00 & 4.00 & 4.00 & 4.00 & 4.00 & .00 & & 4.00 \\
\hline 2003 & 1 & /01/2003 & //01/2003 & 18 & 4.17 & .17 & .16 & 16 & 4.00 & 5.29 & 5.25 & 5.19 & 5.29 & & 5.19 \\
\hline 2003 & 1 & $/ 01 / 2003$ & 7/01/2003 & 4.00 & 4.00 & 4.00 & 4.00 & .00 & 4.00 & 4.00 & 4.00 & 4.00 & 4.00 & & 4.00 \\
\hline 2003 & 1 & $18 / 01 / 2003$ & $4 / 01 / 2003$ & 4.12 & 4.09 & 4.01 & 4.00 & 4.00 & 4.00 & 4.25 & 4.25 & 4.25 & 4.12 & .09 & 4.01 \\
\hline 2003 & 1 & $25 / 01 / 2003$ & 2003 & 4.00 & 4.00 & 4.00 & 4.00 & 4.00 & 4.00 & 4.00 & 4.00 & 4.00 & 4.00 & 00 & 4.00 \\
\hline 2003 & 2 & $01 / 02$ & 003 & 4.00 & 4.00 & 4.00 & 4.00 & 4.00 & 4.00 & 4.00 & 4.00 & 4.00 & 4.00 & & 4.00 \\
\hline 2003 & 2 & & 003 & 4.00 & 4.00 & 4.00 & 4.00 & 4.00 & 4.00 & 4.00 & 4.00 & 4.00 & 4.00 & & .00 \\
\hline 2003 & 2 & $15 / 02$ & & 4.00 & 4.00 & 4.00 & 4.00 & .00 & 4.00 & 4.00 & & 4.00 & .00 & & .00 \\
\hline 2003 & 2 & $22 / 0$ & & 4.00 & 4.00 & 4.00 & 4.00 & 4.00 & 4.00 & & 4.00 & 4.00 & .00 & & .00 \\
\hline 2003 & 3 & /2003 & & 4.00 & 4.00 & 4.00 & 4.00 & & 4.00 & 4.00 & 4.00 & 4.00 & 4.00 & & .00 \\
\hline 2003 & 3 & $08 / 0$ & & 4.00 & 4.00 & 4.00 & 4.00 & & 4.00 & 4.00 & 4.00 & 4.00 & 4.00 & & .00 \\
\hline 2003 & 3 & $15 / 0$ & & 4.00 & 4.00 & 4.00 & 4.00 & & 4.00 & 4.00 & & 4.00 & .00 & & .00 \\
\hline 2003 & 3 & $22 / 0$ & & 4.00 & 4.00 & 4.00 & 4.00 & & 4.00 & & & 4.00 & 4.00 & & 4.00 \\
\hline 2003 & 4 & $29 / 0$ & & 4.00 & 4. & 4.00 & 4.00 & & 4.00 & & & 4.00 & 00 & & .00 \\
\hline 2003 & 4 & $01 / 04 / 2003$ & 003 & 5.48 & 5.48 & 5.48 & 5.48 & & 5.48 & & 48 & 5.48 & .48 & & 48 \\
\hline 2003 & 4 & $05 / 04 / 2003$ & & 5.48 & 5.48 & 5.48 & 5.48 & & 48 & & 48 & 5.48 & .48 & & 48 \\
\hline 2003 & 4 & 03 & & 48 & 5. & 5.48 & 5.48 & & 48 & & & 5.48 & 48 & & 48 \\
\hline 2003 & 4 & $19 / 04 / 2003$ & 003 & 5.48 & 5.48 & 5.48 & 5.48 & & 48 & & 48 & 5.48 & .48 & & 48 \\
\hline 2003 & 4 & & & 5.48 & 5.48 & 5.48 & 5.48 & & 48 & & & 5.48 & 48 & & 48 \\
\hline 2003 & 5 & 003 & & 6.84 & 6.71 & 6.51 & 6.84 & & 6.51 & & & 5.57 & 57 & & 48 \\
\hline 2003 & 5 & 2003 & & 6.73 & 6.65 & 6.60 & 6.73 & & 6.60 & & & 5.96 & 96 & & 48 \\
\hline 2003 & 5 & 2003 & 003 & 7.37 & 7.28 & 7.18 & 7.37 & & 7.18 & 6.25 & 6.25 & 6.25 & 5.25 & & .25 \\
\hline 2003 & 5 & 2003 & & 8.66 & 8.54 & 8.44 & 8.66 & & 8.44 & 7.10 & 7.10 & 7.09 & 7.10 & & 7.09 \\
\hline 2003 & 6 & 2003 & 03 & 12.27 & 12.11 & 11.83 & 12.27 & 11 & 11.83 & 11.49 & 11.49 & 11.49 & 1.49 & & 48 \\
\hline 2003 & 6 & 2003 & & 12.40 & 12.22 & 11.87 & 12.40 & 12.22 & 11.87 & 11.36 & 11.36 & 11.23 & 36 & & 11.23 \\
\hline 2003 & 6 & 2003 & 03 & 9.42 & 9.21 & 9.05 & 9.42 & & 9.05 & 9.42 & 9.21 & 9.05 & .42 & 21 & .05 \\
\hline 2003 & 6 & 2003 & 003 & 10.88 & 1073 & 10.66 & 10.88 & & 10.66 & 10.55 & 10.55 & 10.55 & & & \\
\hline 2003 & 7 & 2003 & 003 & 13.98 & 13.59 & 13.27 & 3.98 & & 13.27 & 9.98 & 9.98 & 9.98 & & & 13.27 \\
\hline 2003 & 7 & 2003 & 003 & 14.95 & 14.34 & 14.29 & 14.95 & & 14.29 & 10.33 & 10.33 & 10.33 & & & 14.29 \\
\hline 2003 & 7 & $12 / 07 / 2003$ & 003 & 14.52 & 13.92 & 13.56 & 17.18 & 01 & 16.83 & 10.84 & 10.84 & 10.84 & 92 & & 13.56 \\
\hline 2003 & 7 & $19 / 07 / 2003$ & 003 & 12.28 & 12.00 & 11.55 & 12.28 & 00 & 11.62 & 904 & 904 & 9.04 & & & 11.55 \\
\hline 2003 & 7 & $26 / 07 / 2003$ & 03 & 12.46 & 8 & 11.74 & 12.46 & & 11.96 & 9.08 & 9.08 & 9.08 & & & 11.74 \\
\hline 2003 & 8 & $02 / 08 / 2003$ & 003 & 16.41 & 15.66 & 15.28 & 17.32 & 17 & 17.11 & 1361 & 13.06 & 13.06 & 66 & & 15.28 \\
\hline 2003 & 8 & 09/08/2003 & 003 & 19.74 & 18.81 & 18.14 & 19.74 & 10 & 18.14 & 140 & 14.28 & 14.28 & & & 18.14 \\
\hline 2003 & 8 & $16 / 08 / 2003$ & 003 & 18.43 & 7 & 17.04 & 20.34 & 3 & 17.87 & 3.84 & 62 & 13.62 & 64 & & 17.04 \\
\hline 2003 & 8 & $23 / 08 / 2003$ & 003 & 17.73 & 16.90 & 16.40 & 22.71 & 22.39 & 16.64 & 1293 & 12.93 & 12.93 & & & 16.40 \\
\hline 2003 & 9 & $30 / 08 / 2003$ & 003 & 17.16 & 17.11 & 16.47 & 19.75 & 0 & 17.11 & 4.29 & 71 & 13.71 & & & 16.47 \\
\hline 2003 & 9 & 06/09/2003 & 2003 & 18.07 & 17.85 & 17.43 & 22.07 & 9 & 17.92 & 14.84 & 24 & 14.24 & 07 & & 17.43 \\
\hline 2003 & 9 & $13 / 09 / 2003$ & 003 & 17.64 & 1707 & 16.80 & 20.93 & 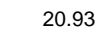 & 17.07 & cos & & 13.62 & & & 16.80 \\
\hline 2003 & 9 & $20 / 09 / 2003$ & 003 & 18.67 & 4 & 17.70 & 22.26 & 4 & 17.91 & 5 & 95 & 16.95 & & & 17.70 \\
\hline 2003 & 10 & $27 / 09 / 2003$ & 003 & 24.45 & 24.20 & 23.32 & 24.66 & 2442 & 24.20 & 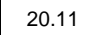 & & 19.86 & & & 23.32 \\
\hline 2003 & 10 & 003 & & 27.47 & 26.74 & 26.28 & 27.51 & & 26.93 & & & & & & 26.28 \\
\hline 2003 & 10 & 003 & 03 & 27.52 & 27. & 26.36 & 28.09 & & 27.06 & & & 20.05 & & & 26.35 \\
\hline 2003 & 10 & $18 / 10 / 2003$ & & & 22.90 & 22.31 & 23.33 & & & & & 17.32 & & & 22.31 \\
\hline 2003 & 10 & $25 / 10$ & & & & & 28.37 & & & & & & & & 26.40 \\
\hline 2003 & 11 & & 03 & & & & & & & & & & & & 23.18 \\
\hline 2003 & 11 & & & & & & & & & & & 23.20 & & & 27.07 \\
\hline 2003 & 11 & & & & & & 35.87 & & 34.15 & & & 26.07 & & & 30.90 \\
\hline 2003 & 11 & & & & & 28.42 & & & 28.71 & no & & 28.42 & & & 28.42 \\
\hline 2003 & 12 & & & 5.07 & 24. & 24.33 & 25.07 & & 24.33 & 22.16 & 22.16 & 21.77 & & & 22.47 \\
\hline 2003 & 12 & & & 5.07 & & & & & & & 82.72 & 82.72 & & & 22.47 \\
\hline 2003 & 12 & & & 3.70 & 23.70 & 23.07 & 23.70 & & 23.07 & 32.72 & 82.72 & 82.72 & & & 21.47 \\
\hline 2003 & 12 & & & & & & & & & & 16.95 & 16.95 & & & 16.95 \\
\hline 2003 & 12 & & & & & 18.45 & 19.08 & & & 18.45 & 18.45 & 18.45 & & & 18.45 \\
\hline 2004 & 1 & $27 / 12 / 2003$ & 004 & 7.39 & & 17.39 & 17.39 & & 17.39 & 58.24 & 58.24 & 58.24 & 39 & 39 & 16.95 \\
\hline 2004 & 1 & 04 & & 5 & & .05 & .05 & & 7.05 & 12.83 & 2.83 & 2.83 & .00 & & 26.91 \\
\hline 2004 & 1 & $10 / 01 / 2004$ & $6 / 01 / 2004$ & 5.47 & 25. & 25.12 & 25.47 & & 25.12 & 315.21 & 315.21 & 272.57 & 14 & 05 & 25.05 \\
\hline 2004 & 1 & $17 / 01 / 2004$ & 004 & 7.58 & 1 & 7.58 & 7.58 & 7.58 & 17.58 & 15.21 & 315.21 & 315.21 & 6.95 & 95 & 16.95 \\
\hline 2004 & 1 & 04 & 04 & 28 & 2 & .28 & 7.28 & & 27.28 & 55.33 & 255.33 & 255.33 & & & 8.59 \\
\hline 2004 & 2 & 2004 & 04 & 8.59 & 8.59 & 3.59 & 8.59 & & 18.59 & 8.59 & 59 & 18.59 & & & 18.59 \\
\hline 2004 & 2 & 2004 & 04 & 9 & 1 & & 9 & & 59 & 9 & 59 & 18.59 & & & 18.59 \\
\hline 2004 & 2 & 004 & 04 & $\begin{array}{lll}9 & \end{array}$ & & & & & & & & & & & 18.59 \\
\hline 004 & 2 & & & & & & & & & & & & & & 18.59 \\
\hline 04 & 3 & & & 9 & & & & & & & & & & & 59 \\
\hline 004 & 3 & & & & & & & & & & & & & & 18.59 \\
\hline 04 & 3 & & & & & & & & & & & 59 & & & 59 \\
\hline 4 & 3 & & & & & & & & & & & & & & 8.59 \\
\hline & 4 & & & & & & & & & & & 59 & & & 18.59 \\
\hline 2004 & 4 & & & 9 & & & 9 & & 18.59 & & & 18.59 & & & 18.59 \\
\hline 2004 & 4 & 004 & & & & & & & & & & & & & 18.59 \\
\hline 2004 & 4 & & & & & & & & & & & & & & 18.59 \\
\hline 2004 & 4 & & & & & & & & & & & & & & 18.59 \\
\hline 2004 & 5 & 004 & & 8.59 & & & 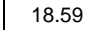 & & 18.59 & & & 18.59 & & & 18.59 \\
\hline 2004 & 5 & & & & & & & & & & & & & & \\
\hline 2004 & 5 & 2004 & 004 & 8.59 & & & 18.59 & & 18.59 & & & 18.59 & & & 18.59 \\
\hline 2004 & 5 & 004 & 004 & 10.3 & & & & & & & & 59 & & & 8.59 \\
\hline 2004 & 6 & $29 / 05 / 2004$ & 4/06/2004 & 18.59 & 10.05 & 18.59 & 10.05 & & 18.59 & 18.59 & 10.05 & 18.59 & & & 18.59 \\
\hline 2004 & 6 & 05/06/2004 & 2004 & 18.59 & 18.59 & 18.59 & 18.59 & 10.05 & 18.59 & 18.59 & 18.59 & 18.59 & 18.59 & 8.59 & 18.59 \\
\hline 2004 & 6 & $12 / 06 / 2004$ & $8 / 06 / 2004$ & 18.59 & 18.59 & 18.59 & 18.59 & 18.59 & 18.59 & 18.59 & 18.59 & 18.59 & 18.59 & 18.59 & 18.59 \\
\hline
\end{tabular}


Anexo A (continuação)

\begin{tabular}{|c|c|c|c|c|c|c|c|c|c|c|c|c|c|c|c|}
\hline no & Mês & Data Início & Data Fim & \begin{tabular}{|c} 
Pesado \\
SE
\end{tabular} & $\begin{array}{c}\text { Médio } \\
\text { SE }\end{array}$ & eve SE & $\begin{array}{c}\text { Pesado } \\
\text { S }\end{array}$ & dio $S$ & Leve S & $\begin{array}{c}\begin{array}{c}\text { Pesado } \\
\mathrm{NE}\end{array} \\
\end{array}$ & $\begin{array}{c}\text { Médio } \\
\text { NE }\end{array}$ & $\begin{array}{c}\text { Leve } \\
\text { NE }\end{array}$ & $\begin{array}{c}\text { Pesado } \\
\text { N }\end{array}$ & Médio N & Leve $\mathrm{N}$ \\
\hline 2004 & 6 & $19 / 06 / 2004$ & $5 / 06 / 2004$ & 18.59 & 18.59 & 18.59 & 18.59 & 18.59 & 18.59 & 18.59 & 18.59 & 18.59 & 18.59 & 18.59 & 18.59 \\
\hline 2004 & 7 & $26 / 06 / 2004$ & $2 / 07 / 2004$ & 3.59 & 18.59 & .59 & 3.59 & & .59 & 18.59 & 18.59 & 18.59 & 8.59 & & 8.59 \\
\hline 2004 & 7 & 03/07/2004 & $9 / 07 / 2004$ & 8.59 & 18.59 & .59 & 18.59 & & 3.59 & 18.59 & 18.59 & 18.59 & 8.59 & & 8.59 \\
\hline 2004 & 7 & 10/07/2004 & 004 & 18.59 & 18.59 & & 18.59 & & & & & 18.59 & .59 & & \\
\hline 2004 & 7 & 04 & 04 & & & & 18.59 & & & & & 18.59 & 3.59 & & .59 \\
\hline 2004 & 7 & $24 / 0$ & 04 & 18.59 & $1 \varepsilon$ & & 18.59 & & .59 & 18.59 & 59 & 18.59 & 3.59 & 59 & .59 \\
\hline 2004 & 8 & $31 / 07 / 2004$ & 004 & 18.59 & 18.59 & & 18.59 & & & 18.59 & 59 & 18.59 & 8.59 & & .59 \\
\hline 2004 & 8 & & & & & & 18.59 & & & & & 18.59 & .59 & & .59 \\
\hline 2004 & 8 & 2004 & 004 & 18.59 & & & 18.59 & & & & & 18.59 & 3.59 & & 59 \\
\hline 2004 & 8 & & & & & & & & & & & 18.59 & .59 & & 59 \\
\hline 2004 & 9 & 28/08/2004 & 004 & .59 & 18.59 & & 18.59 & & & 18.59 & & 18.59 & 3.59 & & .59 \\
\hline 2004 & 9 & 04/09/2004 & 2004 & 18.59 & 18.59 & & 18.59 & & & 18.59 & & 18.59 & 3.59 & & .59 \\
\hline 004 & 9 & & & 18.59 & & & 18.59 & & & & & 18.59 & 3.59 & & .59 \\
\hline 2004 & 9 & & 004 & 18.59 & & & 18.59 & & & & & 18.59 & .59 & & .59 \\
\hline 2004 & 10 & 2004 & & & & & 18.59 & & & & & 18.59 & .59 & & .59 \\
\hline 2004 & 10 & 04 & & & & & 18.59 & & & & & 18.59 & 59 & & .59 \\
\hline 2004 & 10 & 004 & & 19.49 & 19 & & 19.49 & & & & & 18.59 & 49 & & .30 \\
\hline 004 & 10 & & & 18.59 & 18 & & 18.59 & & & & & & 59 & & .59 \\
\hline 2004 & 10 & & & 18.59 & & & 18.59 & & & & & & 59 & & \\
\hline 2004 & 11 & 004 & & 18.59 & 18 & & 18.59 & & & & & & 59 & & .59 \\
\hline 004 & 11 & 004 & & 18.59 & 18 & & 18.59 & & & & & & 59 & & 18.59 \\
\hline 2004 & 11 & 004 & 004 & 18.59 & 18 & & 18.59 & & & & & 18.59 & 59 & & \\
\hline 2004 & 11 & 2004 & 2004 & 18.59 & 18.59 & 18.59 & 18.59 & & 18.59 & 18.59 & & 18.59 & 8.59 & & 18.59 \\
\hline 2004 & 12 & 2004 & 2004 & 18.59 & 18.59 & 18.59 & 18.59 & & 18.59 & 18.59 & & 18.59 & 8.59 & & 18.59 \\
\hline 004 & 12 & 004 & 004 & 18.59 & 18.59 & 18.59 & 18.59 & & 18.59 & 18.59 & & 18.59 & 8.59 & & 18.59 \\
\hline 2004 & 12 & 004 & 004 & 18.59 & 18.59 & 18.59 & 18.59 & & 18.59 & 18.59 & & 18.59 & 8.59 & & 18.59 \\
\hline 2004 & 12 & 004 & & 18.59 & 18.59 & 18.59 & 18.59 & & 18.59 & 18.59 & & 18.59 & 8.59 & & 18.59 \\
\hline 2004 & 12 & 004 & & 18.59 & 18.59 & 18.59 & 18.59 & & 18.59 & 18.59 & & 18.59 & 59 & & 18.59 \\
\hline 2005 & 1 & 005 & & 18.33 & 18.33 & 3.33 & 18.33 & & 18.33 & 18.33 & & 18.33 & 33 & & 3.33 \\
\hline 2005 & 1 & $08 / 0$ & 05 & 18.33 & 18. & 3.33 & 18.33 & & 18.33 & 18.33 & & 18.33 & 33 & & 33 \\
\hline 2005 & 1 & $15 / 01$ & 005 & 18.33 & 18.33 & 18.33 & 18.33 & & & 18.33 & & 18.33 & 33 & & \\
\hline 2005 & 1 & $22 / 01 / 2005$ & 005 & 18.33 & 18. & & 18.33 & & & 1833 & & & & & \\
\hline 2005 & 2 & $29 / 0$ & 005 & 18.33 & 18 & & 18 & & & 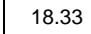 & & & & & \\
\hline 2005 & 2 & 05 & 05 & 18.33 & 18 & 33 & 18.33 & & 33 & 18 & & & & & 33 \\
\hline 2005 & 2 & $12 / 0$ & & 1833 & 18 & & 18.33 & & & & & & & & \\
\hline 2005 & 2 & & & 18.33 & 18 & & 18 & & & & & & & & \\
\hline 2005 & 3 & 5 & 5 & 18.33 & 18 & 3 & 25 & & 0 & & & & & & \\
\hline 2005 & 3 & 05 & & $18 \quad$ & 18 & 3 & 27 & & 66 & 18. & & & & & \\
\hline 2005 & 3 & 5 & 05 & 33 & 18 & 33 & 25.82 & & 21 & 18. & & & & & 33 \\
\hline 2005 & 3 & & & 18 & 18 & 33 & 25.96 & & 31 & 10 & & & & & \\
\hline 2005 & 4 & 5 & & 10 & & 33 & 33.50 & & 01 & & & & & & \\
\hline 2005 & 4 & 02 & & 18.33 & & 33 & 137.05 & & 02 & & & & & & \\
\hline 2005 & 4 & & & OR & & & 49.16 & & & & & & & & \\
\hline 2005 & 4 & & & & & & 75.82 & & & & & & & & \\
\hline 2005 & 4 & & & & 33 & & 101.73 & & & & & & & & \\
\hline 2005 & 5 & & & 48.82 & 47 & & & & & & & & & & .33 \\
\hline 2005 & 5 & & & & & & 132.35 & & & & & & & & \\
\hline 2005 & 5 & & & & & 49.38 & 180.73 & & & & & 18.33 & & & .33 \\
\hline 2005 & 5 & & & & & & & & & & & & & & 18.33 \\
\hline 2005 & 6 & & & 8.91 & & & 28.76 & & & & & 18.33 & & & \\
\hline 2005 & 6 & & & 18.33 & & & 18.33 & & & & & 18.33 & 33 & & 18.33 \\
\hline 2005 & 6 & & & & & & 31.80 & & & & & 18.33 & 80 & & \\
\hline 2005 & 6 & & & & & & & & & & & & & & 29.72 \\
\hline 2005 & 7 & & & & & & & & & & & 18.33 & 99 & & 24.37 \\
\hline 2005 & 7 & & & & & & & & & & & 18.33 & & & 26.15 \\
\hline 2005 & 7 & & & & & & 33.28 & & & & & 18.33 & 28 & & 32.72 \\
\hline 2005 & 7 & & & 6.24 & & 5.26 & 36.24 & & & & & 18.33 & 24 & & 26 \\
\hline 2005 & 7 & & & & & & & & & & & & & & \\
\hline 2005 & 8 & $30 / 07$ & 005 & 0.06 & & & 29 & & & & & 18.33 & 62 & & 46 \\
\hline 2005 & 8 & 0 & $2 /$ & 1.93 & & & & & & & & 18.33 & & & \\
\hline 5 & 8 & & & & & & & & & & & & & & \\
\hline 2005 & 8 & 005 & 15 & & & & & & & & & 1 & & & \\
\hline 2005 & 9 & & & & & & & & & & & & & & 7.10 \\
\hline 2005 & 9 & & & & & & & & & & & & & & 93 \\
\hline 005 & 9 & & & & & & & & & & & & & & 76 \\
\hline 005 & 9 & & & & & & & & & & & & & & 42 \\
\hline 2005 & 9 & & & & & & & & & & & & & & 09 \\
\hline 5 & 0 & & & & & & & & & & & & & & 56 \\
\hline & 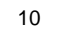 & & & & & & & & & & & & & & .44 \\
\hline & 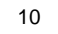 & & & & & & & & & & & & & & 24 \\
\hline 2005 & 10 & & & & & & & & & & & & & & 47.98 \\
\hline 2005 & 11 & & & 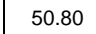 & & & 18 & & & & & 21.01 & & & 47.48 \\
\hline & 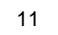 & & & & & & & & & & & & & & 31.00 \\
\hline 2005 & 11 & & & & & & 18 & & & & & 18.54 & & & 32.06 \\
\hline 2005 & 11 & 2005 & & 8.11 & & & & & & & & 21.36 & & & 35.50 \\
\hline 2005 & 12 & & & & & & & & & & & & & & 31.80 \\
\hline 2005 & 12 & 03/12/2005 & 09/12/2005 & 8.33 & & & 18. & & & & & 18.33 & & & 18.33 \\
\hline 2005 & 12 & 005 & 005 & 0.00 & & & & & & & & & & & \\
\hline 2005 & 12 & $17 / 12 / 2005$ & 2005 & 18.33 & & & 18.33 & & 18.33 & & & 18.33 & & & 18.33 \\
\hline 2005 & 12 & $24 / 12 / 2005$ & 005 & 18.33 & & & 18.3 & & & & & 18.33 & & & 18.33 \\
\hline 2006 & 1 & $31 / 12 / 2005$ & $06 / 01 / 2006$ & 16.92 & 16.92 & 16.92 & 16.92 & 16.92 & 16.92 & 16.92 & 16.92 & 16.92 & 16.92 & 16.92 & 16.92 \\
\hline
\end{tabular}


Anexo A (continuação)

\begin{tabular}{|c|c|c|c|c|c|c|c|c|c|c|c|c|c|c|c|}
\hline 0 & Mês & ício & Fim & $\begin{array}{l}\text { Pesado } \\
\text { SE }\end{array}$ & $\begin{array}{l}\text { Médio } \\
\text { SE }\end{array}$ & eve SE & $\begin{array}{c}\text { Pesado } \\
\text { S }\end{array}$ & s & ve $\mathrm{S}$ & $\begin{array}{c}\text { Pesado } \\
\text { NE }\end{array}$ & $\begin{array}{c}\text { Médio } \\
\mathrm{NE}\end{array}$ & $\begin{array}{c}\text { Leve } \\
\mathrm{NE}\end{array}$ & \begin{tabular}{|c} 
Pesado \\
N
\end{tabular} & & \\
\hline$\overline{006}$ & 1 & /01/2006 & $3 / 01 / 2006$ & 16.92 & 16.92 & 16.92 & 16.92 & 692 & 16.92 & 16.92 & 16.92 & 16.92 & 16.92 & 16.92 & $\overline{6.92}$ \\
\hline 06 & 1 & & & & & & & & & & & 6.92 & & & \\
\hline 2006 & 1 & 000 & & & & & & & & & 6.92 & 16.92 & .92 & & \\
\hline 2006 & 2 & 006 & & 68.78 & 68.78 & 66.75 & & & & & & 34.10 & & & \\
\hline 2006 & 2 & 2006 & 2006 & & 62.72 & & & & & & 7.62 & .37 & 6.92 & & \\
\hline 2006 & 2 & /02/2006 & 2006 & & & 82.97 & 86.64 & & & & 15.04 & 44.74 & & & \\
\hline 2006 & 2 & $18 / 02 / 2006$ & & & 36.54 & 33.04 & & & & & 30.73 & 0.53 & 30.73 & .73 & \\
\hline 2006 & 3 & $25 / 02 / 2006$ & 006 & & 38.93 & 36.78 & & & & & 10.00 & 39.74 & 6.92 & .92 & 6.92 \\
\hline 2006 & 3 & & & 40.60 & 40.02 & 37.85 & & & & & 40.02 & & & & \\
\hline 2006 & 3 & 2006 & & 16.92 & 16.92 & 16.92 & 45.36 & & & & 39.27 & 39.01 & & 92 & .92 \\
\hline 2006 & 3 & $18 / 03 / 2006$ & 2006 & $160 ?$ & 16.92 & 16.92 & 42.09 & & & & 2.67 & 32.67 & & & 16.92 \\
\hline 2006 & 3 & $25 / 03 / 2006$ & 2006 & 39.35 & 38.12 & 34.37 & 39.69 & & & & 30.95 & 30.95 & & & 16.92 \\
\hline 2006 & 4 & & & 010 & 23.91 & 22.46 & 24.21 & & & & 6.92 & 16.92 & & & 16.92 \\
\hline 2006 & 4 & 006 & 006 & 22.14 & 21.81 & 20.78 & 22.21 & & & & 6.92 & 16.92 & & & 16.92 \\
\hline 2006 & 4 & & & 100 & 17.55 & 17.06 & 18.02 & & & & 6.92 & 16.92 & & & 16.92 \\
\hline 2006 & 4 & 006 & 006 & 16.92 & 16.92 & 16.92 & 16.92 & & & & 6.92 & 16.92 & & & \\
\hline 2006 & 5 & $29 / 0$ & 2006 & 37.52 & 36.64 & 35.76 & 37.52 & & & & 16.92 & 16.92 & & & 16.92 \\
\hline 2006 & 5 & & & 500 & & 48.90 & 50.04 & & & & 8.94 & & & & .92 \\
\hline 2006 & 5 & 006 & 006 & & 56.47 & 55.75 & 57.27 & & & & 86 & 20.72 & & & .92 \\
\hline 2006 & 5 & 2006 & 006 & 50 & 55.71 & 55.29 & 57.47 & & & & 20.30 & 20.16 & & & 6.92 \\
\hline 2006 & 6 & & & & 60.21 & 59.60 & & & & & & & & & .92 \\
\hline 2006 & 6 & & 006 & & & 61.31 & & & & & 2.38 & & & & .92 \\
\hline 2006 & 6 & & & & & 64.50 & & & & & & & & & \\
\hline 2006 & 6 & & & & & & & & & & & & & & \\
\hline 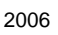 & 6 & & & & & & & & & & & & & & \\
\hline & 7 & & & & & & & & & & & & & & \\
\hline 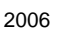 & 7 & & & & & & & & & & & & & & \\
\hline & 7 & & & & & & & & & & & & & & \\
\hline ( & 7 & & & & & & & & & & & & & & \\
\hline o & 8 & & & & & & 108 & & & & & & & & \\
\hline 6 & 8 & & & 101 & 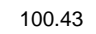 & & 3 & & & & & & & & \\
\hline 6 & 8 & & & 1 & 1 & 45 & 10 & & & & & & & & \\
\hline 2006 & 8 & & & 102. & a & 53 & 1 & & & & & & & & \\
\hline 2006 & 9 & & & 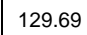 & 12 & 24 & 1 & & & & & & & & \\
\hline 2006 & 9 & 06 & & 1 & 7 & 42 & 12 & & & & & & & & \\
\hline 2006 & 9 & & & 120. & 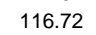 & & 120 & & & & & & & & \\
\hline 2006 & 9 & 06 & & 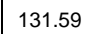 & 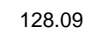 & 32 & 59 & & & & 38 & & & & \\
\hline 2006 & 9 & & & 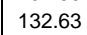 & 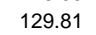 & 39 & 1 & & & & & & & & \\
\hline 2006 & 10 & 06 & & 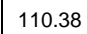 & 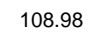 & 57 & 38 & & & & 23 & & & & \\
\hline 2006 & 10 & & & 4 & 0 & 73 & 115 & & & & 2 & & & & \\
\hline 2006 & 10 & & & & & & & & & & & & & & \\
\hline 2006 & 10 & & & & & 71 & & & & & & & & & \\
\hline 2006 & 11 & & & & & 69.65 & & & & & & & & & \\
\hline 2006 & 11 & & & & & & & & & & & & & & \\
\hline 2006 & 11 & & & & & & & & & & & & & & \\
\hline 2006 & 11 & & & & & & & & & & & & & & 27 \\
\hline 2006 & 11 & & & & & & & & & & & & & & \\
\hline 2006 & 12 & & & & & & & & & & & & & & \\
\hline 6 & 12 & & & & & & & & & & & & & & \\
\hline 2006 & 12 & & & & & & & & & & & & & & \\
\hline 2006 & 12 & & & & & & & & & & & & & & \\
\hline $2 c$ & 1 & & & & & & & & & & & & & & \\
\hline 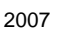 & 1 & & & & & & & & & & & & & & \\
\hline 2 & 1 & & & & & & & & & & & & & & \\
\hline 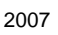 & 1 & & & & & & & & & & & & & & \\
\hline 20 & 2 & & & & & & & & & & & & & & \\
\hline 200 & 2 & & & & & & & & & & & & & & \\
\hline $2 C$ & 2 & & & & & & & & & & & & & & \\
\hline 200 & 2 & & & & & & & & & & & & & & \\
\hline 200 & 2 & & & & & & & & & & & & & & \\
\hline & 3 & & & & & & & & & & & & & & \\
\hline 200 & 3 & & & & & & & & & & & & & & \\
\hline 200 & 3 & & & & & & & & & & & & & & \\
\hline 200 & 3 & & & & & & & & & & & & & & \\
\hline & 4 & & & & & & & & & & & & & & \\
\hline 200 & 4 & & & & & 58 & & & & & & & & & \\
\hline & 4 & & & & & & & & & & & & & & \\
\hline & 4 & & & & & & & & & & & & & & \\
\hline & 5 & & & & & & & & & & & & & & \\
\hline 200 & 5 & & & & & & & & & & & & & & \\
\hline & 5 & & & & & & & & & & & & & & \\
\hline & 5 & & & & & & & & & & & & & & \\
\hline & 6 & & & & & & & & & & & & & & \\
\hline & 6 & & & & & & & & & & & & & & \\
\hline 200 & 6 & & & & & & & & & & & & & & \\
\hline 200 & 6 & & & & & & & & & & & & & & \\
\hline 200 & 6 & & & & & & & & & & & & & & \\
\hline 200 & 7 & & & & & & & & & & & & & & \\
\hline 200 & 7 & & & & & & & & & & & & & & \\
\hline 2007 & 7 & & & & & & & & & & & & & & \\
\hline 2007 & 7 & $21 / 07 / 2007$ & $27 / 07 / 2007$ & 120.18 & 116.88 & 116.30 & 116.79 & 116.79 & 115.90 & 120.18 & 116.88 & 116.30 & 120.18 & 116.88 & 3116.30 \\
\hline
\end{tabular}


Anexo A (continuação)

\begin{tabular}{|c|c|c|c|c|c|c|c|c|c|c|c|c|c|c|c|}
\hline Ano & Mês & Data Início & Data Fim & \begin{tabular}{|} 
Pesado \\
SE
\end{tabular} & $\begin{array}{l}\text { Médio } \\
\text { SE }\end{array}$ & Leve SE & $\begin{array}{c}\text { Pesado } \\
\text { S }\end{array}$ & Médio S & Leve S & \begin{tabular}{|} 
Pesado \\
NE
\end{tabular} & $\begin{array}{c}\text { Médio } \\
\mathrm{NE}\end{array}$ & $\begin{array}{c}\text { Leve } \\
\text { NE }\end{array}$ & \begin{tabular}{|c|} 
Pesado \\
N
\end{tabular} & Médio N & Leve \\
\hline 2007 & 8 & $3 / 07 / 2007$ & $3 / 08 / 2007$ & 61.74 & 60.44 & 57.95 & 57.95 & 57.95 & 57.95 & 61.74 & 61.66 & 61.66 & 61.74 & 1.66 & 51.66 \\
\hline 2007 & 8 & 4/08/2007 & $\mathrm{J} / 08 / 2007$ & 29.98 & 29.52 & 28.31 & 17.59 & .59 & 7.59 & 5.27 & 35.27 & 35.27 & 29.98 & 9.52 & 9.52 \\
\hline 2007 & 8 & //08/2007 & $7 / 08 / 2007$ & 29.25 & 28.23 & 27.21 & 27.21 & 27.21 & 6.94 & 37.68 & 37.68 & 37.68 & 37.68 & 37.68 & 37.68 \\
\hline 2007 & 8 & 8/08/2007 & $4 / 08 / 2007$ & 35.19 & 34.01 & 33.88 & 33.88 & 33.88 & 33.88 & 1.74 & 41.67 & 41.67 & 1.67 & 1.67 & 39.71 \\
\hline 2007 & 8 & $25 / 08 / 2007$ & $1 / 08 / 2007$ & 59.40 & 56.92 & 56.58 & 56.58 & 56.58 & 56.58 & 61.98 & 61.98 & 61.58 & 61.98 & 61.98 & 61.58 \\
\hline 2007 & 9 & 01/09/2007 & 07/09/2007 & 129.18 & 128.10 & 128.10 & 129.18 & 128.10 & 128.10 & 126.97 & 126.51 & 126.51 & 129.18 & 128.10 & 128.10 \\
\hline 2007 & 9 & 8/09/2007 & $14 / 09 / 2007$ & 132.65 & 130.81 & 130.81 & 132.65 & 130.81 & 130.81 & 132.65 & 130.81 & 130.81 & 32.65 & 130.81 & 130.81 \\
\hline 2007 & 9 & $5 / 09 / 2007$ & $21 / 09 / 2007$ & 150.11 & 147.26 & 147.26 & 150.11 & 149.41 & 147.26 & 150.11 & 147.26 & 146.73 & 150.11 & 147.26 & 147.26 \\
\hline 2007 & 9 & 2/09/2007 & 28/09/2007 & 189.13 & 186.16 & 186.16 & 189.13 & 186.16 & 186.16 & 189.13 & 186.16 & 186.16 & 189.13 & 186.16 & 186.16 \\
\hline 2007 & 10 & 29/09/2007 & $05 / 10 / 2007$ & 168.46 & 168.46 & 165.13 & 168.46 & 168.46 & 165.13 & 168.46 & 168.46 & 165.13 & 168.46 & 168.46 & 165.13 \\
\hline 2007 & 10 & 06/10/2007 & $12 / 10 / 2007$ & 173.85 & 172.08 & 172.08 & 173.85 & 172.08 & 172.08 & 173.85 & 169.29 & 168.68 & 173.85 & 172.08 & 172.08 \\
\hline 2007 & 10 & 3/10/2007 & 19/10/2007 & 207.66 & 205.54 & 205.54 & 207.66 & 205.54 & 205.54 & 207.66 & 205.54 & 205.54 & 207.66 & 205.54 & 205.54 \\
\hline 2007 & 10 & 2007 & $26 / 1$ & 211.84 & 209.96 & 209.70 & 211.84 & 96 & 209.70 & 211.84 & 209.96 & 209.21 & 1.84 & & 9.70 \\
\hline 2007 & 11 & 27/10/2007 & $02 / 11 / 2007$ & 237.66 & 237.66 & 237.66 & 237.66 & 66 & 237.66 & 237.66 & 237.66 & 237.66 & 237.66 & & .66 \\
\hline 2007 & 11 & 3/11/2007 & $09 / 1$ & 224.10 & 223.89 & 223.89 & 224.10 & 89 & 223.89 & 224.10 & 223.89 & 223.89 & 224.10 & 89 & 223.89 \\
\hline 2007 & 11 & 10/11/2007 & $16 / 1$ & 182.68 & 181.30 & 181.30 & 182.68 & 30 & 181.30 & 182.68 & 181.30 & 181.30 & 182.68 & & 181.30 \\
\hline 2007 & 11 & 2007 & 2007 & 150.54 & 150.54 & 150.54 & 150.54 & 54 & 150.54 & 150.54 & 150.54 & 150.54 & 0.54 & 54 & 150.54 \\
\hline 2007 & 11 & 2007 & 007 & 170.27 & 169.65 & 169.19 & 170.27 & 65 & 169.19 & 170.27 & 169.65 & 169.19 & 0.27 & 65 & 169.19 \\
\hline 2007 & 12 & /2007 & 007 & 189.25 & 189.25 & 189.25 & 189.25 & & 189.25 & 189.25 & 189.25 & 189.25 & 9.25 & 25 & 189.25 \\
\hline 2007 & 12 & 07 & 007 & 212.20 & 212.20 & 212.20 & 212.20 & & 212.20 & 212.20 & .20 & 212.20 & 2.20 & 20 & .20 \\
\hline 2007 & 12 & 07 & 007 & 200 & 200.48 & 200.48 & 200.48 & & 200.48 & .48 & .48 & 200.48 & 48 & & 2 \\
\hline 2007 & 12 & 07 & 007 & 199.76 & 199.76 & 199.76 & 199.76 & & 199.76 & .76 & .76 & 199.76 & 76 & 76 & 1 \\
\hline 2008 & 1 & 07 & 008 & 247.01 & 247. & 247.01 & 247.01 & & 247.01 & 247.01 & .01 & 247.01 & 01 & 01 & 2 \\
\hline 2008 & 1 & 88 & 08 & 475.53 & 47 & 472.21 & 475.53 & & 472.21 & 475.53 & 3.30 & 472.21 & 53 & & 21 \\
\hline 2008 & 1 & & 008 & 569 & 569. & .59 & 569.59 & & 569.59 & 59 & 59 & 569.59 & & & \\
\hline 2008 & 1 & & 008 & 569.59 & 569.59 & 569.59 & 569.59 & & 569.59 & 548.14 & 14 & 548.14 & & & \\
\hline 2008 & 2 & 08 & 008 & 550.28 & 550.28 & 550.28 & 550.28 & 28 & 550.28 & 550.28 & .28 & 550.28 & 28 & & .28 \\
\hline 2008 & 2 & 08 & 008 & 256.05 & 255.93 & 253.32 & 256.05 & 93 & 253.32 & 256.05 & .05 & 256.05 & 05 & 05 & 2 \\
\hline 2008 & 2 & 08 & 008 & 124.75 & 122.93 & 122.33 & 124.75 & & 122.33 & .30 & .30 & 126.30 & 75 & 93 & 1 \\
\hline 2008 & 2 & 08 & 008 & 163. & 163 & 155.84 & 163.45 & & 155.84 & 180.33 & 33 & 180.33 & 45 & 45 & 1 \\
\hline 2008 & 2 & & 08 & 217.48 & 216 & 207.36 & 217.48 & 2 & 207.36 & 247.02 & .02 & 247.02 & 48 & 94 & 2 \\
\hline 2008 & 3 & & 08 & 140 & $14 C$ & 137.23 & 140.14 & & 137.23 & 69 & 19 & 135.19 & 69 & & 1 \\
\hline 2008 & 3 & & 08 & 135 & 13 & 129.66 & 135.26 & & 129.66 & 12 & 78 & 124.86 & & & 1 \\
\hline 2008 & 3 & & 08 & 179.91 & 174 & 173.39 & 179.91 & & 173.39 & 168 & 16 & 167.60 & 71 & & 1 \\
\hline 2008 & 3 & 22 & $28 /$ & 80.48 & 7 & 63.99 & 85.52 & 2 & 63.99 & 80.48 & 48 & 80.48 & 48 & & 99 \\
\hline 2008 & 4 & & 08 & 88.21 & 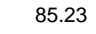 & 27 & 93.36 & & 82.27 & 85.80 & 23 & 85.23 & 80 & & 47 \\
\hline 2008 & 4 & & 08 & 121.95 & 117. & 115.62 & 124.13 & 12 & 115.62 & 113.25 & 11 & 113.25 & 25 & & 47 \\
\hline 2008 & 4 & & 008 & 1 & 6 & 68.18 & 74.01 & & 68.18 & 70.01 & 18 & 68.18 & 01 & & 47 \\
\hline 2008 & 4 & & $25 /$ & 4 & 43 & 15.47 & 51.60 & & 15.47 & 74 & 24 & 48.24 & 74 & & 47 \\
\hline 2008 & 5 & $26 /$ & $02 /$ & 42 & 41 & 39.19 & 42.11 & & 39.19 & 42.11 & .33 & 41.33 & 11 & & 47 \\
\hline 2008 & 5 & & 09 & 6 & 2 & 28.48 & 29.66 & & 28.48 & 29.66 & 29.32 & 29.32 & 66 & & 47 \\
\hline 2008 & 5 & & 16 & 7 & & 17 & 15.47 & & 15.47 & 15.47 & 47 & 15.47 & 47 & & 47 \\
\hline 2008 & 5 & 17 & 008 & 7 & 9 & 45 & 34.77 & & 3.45 & 34.77 & 29 & 34.29 & 77 & & \\
\hline 2008 & 5 & & 008 & 2 & & 34 & 51.62 & & 9.34 & 51.62 & & 11 & & & \\
\hline 2008 & 6 & & 008 & 39 & 12 & 76.12 & 76.89 & & 76.12 & 72.61 & 85 & 71.85 & 61 & & \\
\hline 2008 & 6 & & 008 & 77.02 & 76.16 & .03 & 77.02 & & 6.03 & 77.02 & 16 & 76.03 & 02 & & 03 \\
\hline 2008 & 6 & & 008 & 71.74 & 70.50 & 88 & 71.74 & & 9.88 & 74 & 51 & 88 & & & 38 \\
\hline 2008 & 6 & & 008 & 77.73 & 76.72 & 0.72 & 77.73 & & 6.72 & 7.73 & .72 & 76.72 & 73 & 72 & 72 \\
\hline 2008 & 7 & & & & & 11 & .07 & & 3.11 & 07 & 11 & 88.11 & & & 11 \\
\hline 2008 & 7 & & 08 & 9 & & 32 & 79 & & 1.32 & 79 & 32 & 91.32 & & 32 & \\
\hline 2008 & 7 & & 008 & 103.31 & 102.58 & 102.53 & 103.31 & & 102.53 & 03.31 & 102.58 & 102.53 & 31 & 58 & 10 \\
\hline 2008 & 7 & & 2008 & 111.69 & & .12 & 1.69 & & 110.12 & 11.69 & .23 & 110.12 & & 23 & \\
\hline 2008 & 8 & & 2008 & 147.75 & 146.66 & .35 & 7.75 & & 145.35 & 47.75 & 66 & 145.35 & & 66 & \\
\hline 2008 & 8 & 02/08/2008 & 08/08/2008 & 140.43 & 138.64 & 138.25 & 140.43 & & 138.25 & 140.43 & 138.64 & 138.25 & & 64 & 138.25 \\
\hline 2008 & 8 & & 008 & 121.54 & 117.87 & 117.49 & 121.54 & & 117.49 & 121.54 & 117.87 & 117.49 & & 87 & 117.49 \\
\hline 2008 & 8 & 16/08/2008 & $22 / 08 / 2008$ & 81.49 & 13 & .05 & 77.05 & 05 & 77.05 & .49 & 13 & 77.05 & 49 & 13 & 05 \\
\hline 2008 & 8 & 23/08/2008 & 2008 & 74.29 & 72.65 & 69.38 & 66.79 & 79 & 66.79 & 74.06 & 72.65 & 69.38 & 29 & 65 & 38 \\
\hline 2008 & 9 & $30 / 08 / 2008$ & 05/09/2008 & 96.02 & 25 & .25 & 93.25 & 25 & 93.25 & 96.02 & 25 & 93.25 & 02 & 25 & 25 \\
\hline 2008 & 9 & 06/09/2008 & $12 / 09 / 2008$ & 109.04 & 105.83 & 105.62 & 106.66 & & 105.62 & 108.86 & 105.83 & 105.62 & 109.04 & 105.83 & 105.62 \\
\hline 2008 & 9 & 13/09/2008 & 19/09/2008 & 122.97 & 119.06 & 118.04 & 118.04 & & 118.04 & 122.48 & 119.06 & 118.04 & 97 & 06 & 118.04 \\
\hline 2008 & 9 & 20/09/2008 & $26 / 09 / 2008$ & 126.19 & & 120.97 & 120.97 & & 120.97 & 126.19 & 19 & 120.97 & 19 & 19 & 12 \\
\hline 2008 & 10 & 27/09/2008 & 03/10/2008 & 101.80 & 100.39 & 100.23 & \begin{tabular}{|l|}
101.80 \\
\end{tabular} & 100.39 & 100.23 & 101.80 & 100.39 & 100.23 & 101.80 & 100.39 & 100.23 \\
\hline 2008 & 10 & $04 / 10 / 2008$ & $10 / 10 / 2008$ & 98.98 & 98.10 & 97.53 & 98.98 & 98.10 & 97.53 & 98.98 & 98.10 & 97.53 & 98.98 & 98.10 & 97.53 \\
\hline 2008 & 10 & $11 / 10 / 2008$ & $17 / 10 / 2008$ & 76.91 & 75.98 & 74.28 & 74.51 & 74.34 & 74.28 & 76.91 & 75.98 & 74.28 & 76.91 & 75.98 & 74.28 \\
\hline 2008 & 10 & 18/10/2008 & $24 / 10 / 2008$ & 94.07 & 93.23 & 93.20 & 94.07 & 93.23 & 93.20 & 94.07 & 93.23 & 93.20 & 94.07 & 93.23 & 93.20 \\
\hline 2008 & 10 & $25 / 10 / 2008$ & $31 / 10 / 2008$ & 100.76 & 99.75 & 98.71 & $\mid$\begin{tabular}{|l|}
100.76 \\
\end{tabular} & 99.75 & 98.71 & 100.76 & 99.75 & 98.71 & 100.76 & 99.75 & 98.71 \\
\hline 2008 & 11 & 01/11/2008 & $07 / 11 / 2008$ & 105.42 & 105.39 & 103.73 & 103.73 & 103.73 & 36.41 & 105.42 & 105.39 & 103.73 & 105.42 & 105.39 & 103.73 \\
\hline 2008 & 11 & 08/11/2008 & $14 / 11 / 2008$ & 120.15 & 120.12 & 115.28 & 104.08 & 104.08 & 104.08 & 120.15 & 120.12 & 115.28 & 120.15 & 120.12 & 115.28 \\
\hline 2008 & 11 & 15/11/2008 & $21 / 11 / 2008$ & 113.85 & 113.75 & 109.17 & 100.21 & 100.21 & 100.21 & 113.85 & 113.75 & 109.17 & 113.85 & 113.75 & 109.17 \\
\hline 2008 & 11 & 22/11/2008 & $28 / 11 / 2008$ & 93.74 & 93.60 & 91.04 & 91.04 & 91.04 & 91.04 & 93.74 & 93.60 & 91.04 & 93.74 & 93.60 & 91.04 \\
\hline 2008 & 12 & 29/11/2008 & 05/12/2008 & 97.08 & 95.35 & 95.35 & 95.35 & 95.35 & 95.35 & 97.08 & 95.35 & 95.35 & 97.08 & 95.35 & 95.35 \\
\hline 2008 & 12 & $06 / 12 / 2008$ & $12 / 12 / 2008$ & 103.56 & 103.56 & 103.42 & \begin{tabular}{|l|}
103.56 \\
\end{tabular} & 103.56 & 103.42 & 103.56 & 103.56 & 103.42 & 103.56 & 103.56 & 103.42 \\
\hline 2008 & 12 & $13 / 12 / 2008$ & $19 / 12 / 2008$ & 113.15 & 113.15 & 113.15 & 113.15 & 113.15 & 113.15 & 113.15 & 113.15 & 113.15 & 113.15 & 113.15 & 113.15 \\
\hline 2008 & 12 & 20/12/2008 & $26 / 12 / 2008$ & 91.74 & 91.74 & 91.34 & 91.74 & 91.74 & 91.34 & 91.74 & 91.74 & 91.34 & 91.74 & 91.74 & 91.34 \\
\hline 2009 & 1 & $27 / 12 / 2008$ & 02/01/2009 & 74.16 & 74.10 & 74.10 & 74.16 & 74.10 & 74.10 & 74.16 & 74.10 & 74.10 & 74.16 & 74.10 & 74.10 \\
\hline 2009 & 1 & 03/01/2009 & 09/01/2009 & 28.13 & 28.13 & 28.13 & 28.13 & 28.13 & 28.13 & 26.95 & 26.95 & 25.86 & 26.95 & 26.95 & 25.86 \\
\hline 2009 & 1 & 10/01/2009 & $16 / 01 / 2009$ & 62.66 & 62.66 & 62.27 & 62.66 & 62.66 & 62.27 & 62.08 & 61.21 & 61.21 & 62.08 & 61.21 & 61.21 \\
\hline 2009 & 1 & $17 / 01 / 2009$ & $23 / 01 / 2009$ & 140.66 & 140.59 & 137.52 & \begin{tabular}{|l|}
140.66 \\
\end{tabular} & 140.59 & 137.52 & 125.44 & 125.44 & 125.44 & 127.66 & 125.44 & 125.44 \\
\hline 2009 & 1 & $24 / 01 / 2009$ & $30 / 01 / 2009$ & 110.71 & 110.54 & 108.40 & 110.71 & 110.71 & 108.40 & 107.59 & 107.59 & 107.59 & 107.59 & 107.59 & 107.59 \\
\hline 2009 & 2 & $31 / 01 / 2009$ & 06/02/2009 & 65.40 & 65.40 & 65.15 & 65.40 & 65.40 & 65.15 & 16.31 & 16.31 & 16.31 & 16.31 & 16.31 & 16.31 \\
\hline 2009 & 2 & $07 / 02 / 2009$ & $13 / 02 / 2009$ & 75.61 & 75.61 & 61.44 & 75.61 & 75.61 & 61.44 & 27.06 & 27.06 & 27.06 & 27.06 & 27.06 & 27.06 \\
\hline
\end{tabular}


Anexo A (continuação)

\begin{tabular}{|c|c|c|c|c|c|c|c|c|c|c|c|c|c|c|c|}
\hline no & Mês & Data Início & Data Fim & \begin{tabular}{|} 
Pesado \\
SE
\end{tabular} & $\begin{array}{l}\text { Médio } \\
\text { SE }\end{array}$ & eve SE & $\begin{array}{c}\text { Pesado } \\
\text { S }\end{array}$ & dio $S$ & eve $S$ & $\begin{array}{c}\text { Pesado } \\
\mathrm{NE}\end{array}$ & $\begin{array}{l}\text { Médio } \\
\text { NE }\end{array}$ & $\begin{array}{c}\text { Leve } \\
\text { NE }\end{array}$ & $\begin{array}{l}\text { esado } \\
\text { N }\end{array}$ & Médio N & 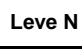 \\
\hline 2009 & 2 & $14 / 02 / 2009$ & $0 / 02 / 2009$ & 66.27 & 63.49 & 43.08 & 84.64 & 4.64 & 84.55 & 43.68 & 43.68 & 43.08 & 43.68 & 3.68 & 43.08 \\
\hline 009 & 2 & 2/2009 & & 31 & 31 & 31 & .87 & & 31 & 31 & .31 & 6.31 & & & \\
\hline 2009 & 3 & $/ 02 / 2009$ & /03/2009 & 58 & 33 & .91 & .58 & & .91 & 42 & & 9.91 & & & \\
\hline 2009 & 3 & /03/2009 & 2009 & 39 & & .70 & .39 & & .70 & & & 76.91 & & & 6.31 \\
\hline 2009 & 3 & 4/03/2009 & 009 & 109.29 & 8.20 & 106.95 & 109.29 & 3.20 & .95 & 86 & & 95.73 & & & 6.31 \\
\hline 2009 & 3 & /03/2009 & 7/03/2009 & 101.79 & 98.20 & 94.06 & 101.79 & & .06 & 21 & & 91.75 & & & 6.31 \\
\hline 2009 & 4 & 3/03/2009 & 009 & 108.31 & 106.33 & 105.13 & 108.31 & 33 & 105.13 & .98 & & 97.34 & 31 & & 6.31 \\
\hline 2009 & 4 & & & 49.38 & & 16.31 & 49.38 & & 6.31 & .22 & & 29.95 & & & \\
\hline 2009 & 4 & & & 51.64 & & 49.12 & 1.64 & & 9.12 & 3.31 & .31 & 16.31 & & & \\
\hline 2009 & 4 & & & 40.24 & & 37.93 & 0.24 & & 37.93 & & & 16.31 & & & \\
\hline 2009 & 4 & & & & & & 46.66 & & 45.12 & 6.31 & 31 & 16.31 & & & \\
\hline 2009 & 5 & & & & & & 6.98 & & 5.76 & & & 36.21 & & & \\
\hline 2009 & 5 & & & & & & & & & & & 28.68 & & & \\
\hline 2009 & 5 & & & & & & & & & & & 28.68 & & & \\
\hline 2009 & 5 & & & & & & & & & & & 29.47 & & & \\
\hline 2009 & 6 & & & & & & & & & & & 26.94 & & & \\
\hline 2009 & 6 & $06 / 0$ & & & & & & & & & & 25.39 & & & \\
\hline 2009 & 6 & & & & & & & & & & & & & & \\
\hline 2009 & 6 & & & & & & & & & & & & & & \\
\hline 2009 & 7 & & & & & & & & & & & & & & \\
\hline 009 & 7 & & & & & & & & & & & & & & \\
\hline 009 & 7 & & & & & & & & & & & & & & \\
\hline 2009 & 7 & & & & & & & & & & & 17.31 & & & \\
\hline 009 & 7 & & & 21.67 & & & & & & & & & & & \\
\hline 009 & 8 & & & & & & & & & & & 16.31 & & & \\
\hline 009 & 8 & & & & & & & & & & & 16.31 & & & \\
\hline 009 & 8 & & & & & & & & & & & & & & \\
\hline 2009 & 8 & & & & & & & & & & & & & & \\
\hline 009 & 9 & & & & & & & & & & & & & & \\
\hline 2009 & 9 & & & 16.31 & & & & & & & & & & & \\
\hline 2009 & 9 & 009 & & 16.31 & & & & & & & & & & & \\
\hline 2009 & 9 & 2009 & & 16.31 & & 31 & 31 & & & & & & & & 16.31 \\
\hline 009 & 10 & i/09/2009 & & 16.31 & & 31 & 31 & & 16.31 & & & 16.31 & & & 16.31 \\
\hline 2009 & 10 & 009 & & 16.31 & & 31 & 31 & & 16.31 & & & & & & 16.31 \\
\hline 2009 & 10 & 2009 & 09 & 16.31 & 1 & 6.31 & 16.31 & & 16.31 & 31 & & 16.31 & & & 16.31 \\
\hline 2009 & 10 & 2009 & 09 & 16.31 & & 6.31 & 16.31 & & 16.31 & 16.31 & & 16.31 & & & 16.31 \\
\hline 2009 & 10 & 009 & 09 & 31 & & .31 & 16.31 & & 16.31 & 31 & & 16.31 & & & 16.31 \\
\hline 2009 & 11 & 2009 & 09 & 16.31 & 40 & 6.31 & 16.31 & & 16.31 & 16.31 & & 16.31 & & & 16.31 \\
\hline 2009 & 11 & 009 & 09 & 16.31 & & 6.31 & 16.31 & & 16.31 & 31 & & 16.31 & & & 16.31 \\
\hline 2009 & 11 & 2009 & 009 & 16.31 & & 6.31 & 16.31 & & 16.31 & 16.31 & & 16.31 & & & 16.31 \\
\hline 2009 & 11 & 009 & & 1621 & & 6.31 & 16.31 & & & 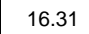 & & & & & \\
\hline 2009 & 12 & 09 & 09 & 31 & & 31 & 31 & & 31 & 1 & & 16.31 & & & 16.31 \\
\hline 2009 & 12 & & & 1801 & & & & & & & & & & & \\
\hline 2009 & 12 & & & & & & & & & & & & & & \\
\hline 2009 & 12 & 99 & & & & & & & & & & & & & \\
\hline 2009 & 12 & & & & & & & & & & & & & & \\
\hline 2010 & 1 & & & & & & & & & & & & & & \\
\hline 2010 & 1 & & & & & & & & & & & & & & \\
\hline 2010 & 1 & & & & & & & & & & & & & & \\
\hline 2010 & 1 & & & & & & & & & & & & & & \\
\hline 2010 & 2 & & & & & & & & & & & & & & \\
\hline 2010 & 2 & & & & & & & & & & & & & & \\
\hline 2010 & 2 & & & & & & & & & & & & & & \\
\hline 2010 & 2 & & & & & & & & & & & & & & \\
\hline 2010 & 3 & & & & & & & & & & & & & & \\
\hline 2010 & 3 & & & & & & & & & & & & & & \\
\hline 2010 & 3 & & & & & & & & & & & & & & \\
\hline 2010 & 3 & & & & & & & & & & & & & & \\
\hline 2010 & 4 & & & & & & & & & & & 38.19 & & & \\
\hline 2010 & 4 & 010 & & 6.7 & & 30 & & & & & 58 & 26.58 & & & \\
\hline & 4 & & & & & & & & & & & 63 & & & \\
\hline 2010 & 4 & & & t. & & & & & & & & 23.48 & & & \\
\hline 2010 & 4 & & & & & & & & & & & 71 & & & \\
\hline 0 & 5 & & & & & & & & & & & 01 & & & \\
\hline & 5 & & & & & & & & & & & 50 & & & \\
\hline & 5 & & & & & & & & & & & 48 & & & \\
\hline & 5 & & & & & & & & & & & & & & \\
\hline & 6 & & & & & & & & & & & 7 & & & 07 \\
\hline & 6 & & & & & & & & & & & & & & \\
\hline & 6 & & & & & & & & & & & & & & \\
\hline & 6 & & & & & & & & & & & 43 & & & 43 \\
\hline & 7 & & & & & & & & & & & & & & \\
\hline & 7 & & & & & & & & & & & & & & \\
\hline & 7 & & & 100.03 & & & & & & & & & & & \\
\hline 2010 & 7 & & & & & & & & & & & & & & 94.51 \\
\hline & 7 & & & & & & & & & & & & & & \\
\hline 2010 & 8 & & & 107.23 & & & & & & & & & & & \\
\hline 201 & 8 & & & & & & & & & & & & & & \\
\hline 2010 & 8 & 2010 & 010 & 120.23 & & & 120.23 & & & & & 118.18 & & & 118.18 \\
\hline 2010 & 8 & 010 & 010 & 125.73 & & 122.27 & 125.73 & & 122.27 & 12 & & 123.77 & & 123.77 & 123.57 \\
\hline 2010 & 9 & 28/08/2010 & $3 / 09 / 2010$ & 111.40 & 05.87 & 04.53 & 111.40 & 05.87 & 104.52 & 154.88 & 54.88 & 154.8 & 154.88 & 154.88 & 154.88 \\
\hline
\end{tabular}


Anexo A (continuação)

\begin{tabular}{|c|c|c|c|c|c|c|c|c|c|c|c|c|c|c|c|}
\hline no & Mês & Data Início & ata Fim & $\begin{array}{c}\text { Pesado } \\
\text { SE }\end{array}$ & $\begin{array}{c}\text { Médio } \\
\text { SE }\end{array}$ & Leve SE & \begin{tabular}{|} 
Pesado \\
S
\end{tabular} & Médi & eve S & $\begin{array}{c}\begin{array}{c}\text { Pesado } \\
\mathrm{NE}\end{array} \\
\text { 作 }\end{array}$ & $\begin{array}{c}\text { Médio } \\
\text { NE }\end{array}$ & $\begin{array}{c}\text { Leve } \\
\text { NE }\end{array}$ & $\underset{\text { N }}{\text { Pesado }}$ & Médio N & ( \\
\hline$\overline{010}$ & 9 & $/ 09 / 2010$ & $0 / 09 / 2010$ & 137.60 & 125.78 & 124.43 & 128.26 & 125.78 & 24.43 & 174.53 & 174.53 & 174.53 & 174.53 & 74.53 & 174.53 \\
\hline 10 & 9 & & & & 17.30 & & 2.46 & & & 2.78 & 1.65 & 171.65 & & & \\
\hline 10 & 9 & $09 / 2010$ & 10 & 139.53 & 32.52 & & 4.59 & & & 7.76 & 187.76 & 187.76 & 7.76 & & \\
\hline 10 & 0 & 010 & & 170.74 & 168.95 & & 170.74 & & & 6.32 & 6.32 & 246.32 & 6.32 & & 20 \\
\hline 10 & 10 & 010 & 10 & 149.09 & 142.04 & & 149.09 & & & .61 & .61 & 221.61 & 1.61 & & \\
\hline 10 & 10 & & & 124.99 & 117.78 & 112 & 124.99 & & .70 & 181.54 & 180.34 & 180.34 & 1.54 & .34 & 0.34 \\
\hline 10 & 10 & & & 146.88 & 144.62 & 140.34 & 146.88 & & 0.34 & 257.54 & 257.54 & 257.54 & 7.54 & & 7.54 \\
\hline 2010 & 10 & & & & 145.38 & 140.62 & 145.43 & & 0.62 & 294.33 & 292.40 & 292.40 & 4.33 & & 92.40 \\
\hline 2010 & 1 & & & & & 14 & 149.48 & & .15 & 149.48 & .03 & 147.15 & 9.48 & & \\
\hline 2010 & 1 & & & & & & 121.71 & & & 121.71 & & 117.68 & 1.71 & & \\
\hline 2010 & 1 & & & 128 & & 125.45 & 128.58 & & 125.45 & 128.58 & 125.45 & 125.45 & 28.58 & & \\
\hline 2010 & 11 & & & 103.41 & & & 103.41 & & 98.34 & 103.41 & & 98.15 & 3.41 & & \\
\hline 2010 & 12 & & & & & & & & & & & 77.56 & .79 & & .56 \\
\hline 2010 & 12 & & & 92.88 & & & 92.88 & & & & & 82.34 & 2.88 & & \\
\hline 2010 & 12 & & & 78.04 & & & 78.04 & & & & & 72.00 & 3.04 & & .00 \\
\hline 2010 & 12 & & & & & & 66.99 & & & & & 1.98 & .99 & & \\
\hline 2010 & 12 & & & 55.09 & & & 55.09 & & & & & 2.44 & .09 & & \\
\hline 2011 & 1 & & & & & & & & & & & 4.56 & .15 & & \\
\hline 2011 & 1 & & & & & & 18.59 & & & & & 17.91 & 59 & & \\
\hline 2011 & 1 & & & 26.06 & & & 26.06 & & & & & 24.88 & .93 & & \\
\hline 2011 & 1 & & & 22.64 & & & & & & & & 22.39 & 64 & & \\
\hline 2011 & 2 & & 011 & & & & & & & & & 22.40 & .08 & & \\
\hline 2011 & 2 & & & & & & & & & & & 8.24 & .87 & & \\
\hline 011 & 2 & & & & & & & & & & & 50.18 & .21 & & \\
\hline 011 & 2 & & & & & & & & & & & 57.83 & & & \\
\hline 011 & 3 & & & 84.34 & & & & & & & & 84.22 & 34 & & \\
\hline 011 & 3 & & & & & & & & & & & 12.08 & 08 & & \\
\hline 011 & 3 & & & 8.27 & & & & & & & & 38.27 & 27 & & \\
\hline 011 & 3 & & & & & & & & & & & 13.47 & & & \\
\hline 2011 & 4 & & & & & & & & & & & 12.08 & .08 & & \\
\hline 2011 & 4 & & & & & & 12.08 & & & & & 12.08 & .08 & & \\
\hline 2011 & 4 & & & 08 & & & 12.08 & & & & & 12.08 & .08 & & \\
\hline 2011 & 4 & & & 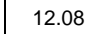 & & & 12.08 & & & & & 12.08 & & & \\
\hline 2011 & 4 & & & 12.08 & & & 8 & & & & & 12.08 & & & \\
\hline 2011 & 5 & & 11 & 94 & & & 15.94 & & & & & 15.38 & 94 & & \\
\hline 2011 & 5 & & 011 & 32 & & & 1432 & & & & & 13.54 & & & \\
\hline 2011 & 5 & & 11 & 11 & & & 1 & & & & & 15.11 & & & \\
\hline 2011 & 5 & & 2011 & 746 & 9 & & 17.46 & & & 46 & & 16.90 & 46 & & \\
\hline 2011 & 6 & 011 & 011 & 46 & 6 & & 46 & & 96 & 46 & & 28.60 & 46 & & \\
\hline 2011 & 6 & 2011 & 2011 & 2025 & 3274 & & 25 & & 73 & 25 & & 32.73 & 25 & & \\
\hline 2011 & 6 & & & 5 & (2) & & 5.72 & & & & & 34.63 & 72 & & \\
\hline 2011 & 6 & & 011 & 30.59 & 8 & & 59 & & 23 & 59 & & 29.23 & 59 & & \\
\hline 2011 & 6 & & & 10 & 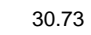 & & & & & & & 29.70 & 22 & & \\
\hline 2011 & 7 & & & & & & & & & & & .48 & & & \\
\hline 2011 & 7 & & & & & & & & & & & 22.97 & & & \\
\hline 2011 & 7 & & & & & & & & & & & & & & \\
\hline & 7 & & & & & & & & & & & & & & \\
\hline 2011 & 8 & & & & & & & & & & & .98 & & & \\
\hline 2011 & 8 & & & & & & & & & & & & & & \\
\hline 2011 & 8 & & & & & & & & & & & & & & \\
\hline 2011 & 8 & & & & & & & & & & & 41 & & & \\
\hline 2011 & 9 & & & & & & & & & & & 16.09 & & & \\
\hline 2011 & 9 & & & & & & & & & & & & & & \\
\hline 2011 & 9 & & & & & & & & & & & 20.25 & & & \\
\hline 2011 & 9 & & & & & & & & & & & 22.83 & & & \\
\hline 2011 & 9 & & & & & & & & & & & 23.61 & & & \\
\hline 2011 & & & & & & & & & & & & 41.99 & .03 & & \\
\hline 2011 & & & & & & & & & & & & 42.75 & & & \\
\hline 2011 & 10 & & & & & & & & & & & 37.54 & 14 & & \\
\hline 2011 & 10 & & & & & & & & & & 92 & 22.95 & 10 & 92 & \\
\hline 2011 & 1 & & & & & & & & & & & 37.73 & & & \\
\hline 2011 & 1 & & & & & & & & & & & 42.94 & 03 & & \\
\hline 2011 & 1 & & & & & & & & & & & 9.01 & & & \\
\hline 2011 & 1 & & & & & & & & & & & .94 & & & \\
\hline 2011 & 2 & & & & & & & & & & & & & & \\
\hline 20 & 2 & & & & & & & & & & & 9.68 & & & \\
\hline & 2 & & & & & & & & & & & & & & \\
\hline 2 & 12 & & & & & & & & & & & 4.51 & & & \\
\hline & 12 & & & & & & & & & & & .32 & & & \\
\hline & 1 & & & & & & & & & & & 12.20 & & & 12.20 \\
\hline & 1 & & & & & & & & & & & 12.20 & & & 20 \\
\hline & 1 & & & & & & & & & & & 12.20 & & & 2.20 \\
\hline & 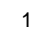 & & & & & & & & & & & & & & \\
\hline & 2 & & & & & & & & & & & 12.20 & & & \\
\hline & 2 & & & & & & & & & & & 12.20 & & & 12.20 \\
\hline & 2 & & & & & & & & & & & & & & \\
\hline 2012 & 2 & & & & & & & & & & & 12.20 & & & 12.20 \\
\hline & 2 & & & & & & & & & & & & & & \\
\hline 2012 & 3 & & & & & & & & & & & 86.52 & 6.52 & 6.52 & 86.52 \\
\hline 2012 & 3 & 012 & 012 & 9.24 & -7 & 2 & 139.24 & & & & & 116.31 & 117.08 & 117.08 & 116.31 \\
\hline 2012 & 3 & 17/03/2012 & $3 / 03 / 2012$ & 2.26 & 11.05 & 39.53 & 142.26 & 1.05 & 39.53 & 19.74 & 19.42 & 8.6 & 19.74 & & \\
\hline
\end{tabular}


Anexo A (conclusão)

\begin{tabular}{|c|c|c|c|c|c|c|c|c|c|c|c|c|c|c|c|}
\hline Ano & Mês & Data Início & Data Fim & \begin{tabular}{|c}
$\begin{array}{c}\text { Pesado } \\
\text { SE }\end{array}$ \\
\end{tabular} & $\begin{array}{c}\text { Médio } \\
\text { SE }\end{array}$ & Leve SE & $\begin{array}{c}\text { Pesado } \\
\text { S }\end{array}$ & Médio S & Leve S & $\begin{array}{c}\text { Pesado } \\
\mathrm{NE}\end{array}$ & $\begin{array}{c}\text { Médio } \\
\text { NE }\end{array}$ & $\begin{array}{c}\text { Leve } \\
\mathrm{NE}\end{array}$ & $\begin{array}{c}\text { Pesado } \\
\mathbf{N}\end{array}$ & Médio & Leve \\
\hline 2012 & 3 & $24 / 03 / 2012$ & $30 / 03 / 2012$ & 134.91 & 133.48 & 130.51 & 134.91 & 133.48 & 130.51 & 134.91 & 133.48 & 130.51 & 134.91 & 133.48 & 130.51 \\
\hline 2012 & 4 & $31 / 03 / 2012$ & $06 / 04 / 2012$ & 187.82 & 185.44 & 185.44 & 187.82 & 185.44 & 185.44 & 174.02 & 168.63 & 166.95 & 74.02 & 8.63 & 166.95 \\
\hline 2012 & 4 & 07/04/2012 & $13 / 04 / 2012$ & 201.95 & 194.07 & 186.15 & 201.95 & 201.95 & 186.15 & 189.58 & 187.38 & 186.15 & 89.58 & 37.38 & 186.15 \\
\hline 2012 & 4 & $14 / 04 / 2012$ & 20/04/2012 & 210.35 & 204.01 & 196.83 & 219.00 & .00 & 196.83 & 184.26 & 181.42 & 179.13 & 184.26 & 1.42 & 179.13 \\
\hline 2012 & 4 & $21 / 04 / 2012$ & $27 / 04 / 2012$ & 197.19 & 192.76 & 189.19 & 197.19 & 192.76 & 189.19 & 197.19 & 192.76 & 189.19 & 197.19 & 192.76 & 189.19 \\
\hline 2012 & 5 & 28/04/2012 & 04/05/2012 & 190.83 & 188.96 & 188.82 & 190.83 & 188.96 & 188.82 & 187.83 & 187.83 & 180.20 & 187.83 & 187.83 & 180.20 \\
\hline 2012 & 5 & 05/05/2012 & $11 / 05 / 2012$ & 181.05 & 180.20 & 179.28 & 181.05 & 180.20 & 179.28 & 181.05 & 180.20 & 179.28 & 181.05 & 180.20 & 179.28 \\
\hline 2012 & 5 & $12 / 05 / 2012$ & 18/05/2012 & 171.67 & 171.66 & 168.50 & 171.67 & 171.66 & 168.50 & 171.67 & 171.66 & 168.50 & 171.67 & 171.66 & 168.50 \\
\hline 2012 & 5 & $19 / 0$ & $25 / 0$ & 191.92 & .89 & 188.99 & 191.92 & 89 & 188.99 & 191.92 & 191.89 & 188.99 & 191.92 & 1.89 & 188.99 \\
\hline 2012 & 5 & $20 / 05 / 2012$ & 01/06/2012 & 179.19 & 177.49 & 176.42 & 179.19 & 177.49 & 176.42 & 179.19 & 177.49 & 176.42 & 179.19 & 177.49 & 176.42 \\
\hline
\end{tabular}


Anexo B - Série histórica de ENA (MWmed) na bacia do rio S. Francisco

\begin{tabular}{|c|c|c|c|c|c|c|c|c|c|c|c|c|c|}
\hline Ano & jan & fev & mar & $a b r$ & mai & jun & jul & ago & set & out & nov & dez & Média \\
\hline 1931 & 14217 & 13666 & 19396 & 21068 & 14387 & 7267 & 5592 & 4826 & 4293 & 4047 & 5617 & 6269 & 10054 \\
\hline 1932 & 11290 & 13701 & 9757 & 6113 & 4272 & 3853 & 3480 & 2952 & 2672 & 2849 & 5382 & 10522 & 6404 \\
\hline 1933 & 14814 & 16852 & 10252 & 8167 & 5828 & 4047 & 3717 & 3212 & 2736 & 3221 & 5263 & 9327 & 7286 \\
\hline 1934 & 17319 & 13767 & 7978 & 4935 & 5229 & 3514 & 2944 & 2656 & 2935 & 2908 & 2741 & 4715 & 5970 \\
\hline 1935 & 12524 & 16832 & 17248 & 13596 & 12402 & 6131 & 4684 & 3763 & 3181 & 3172 & 3585 & 6867 & 8665 \\
\hline 1936 & 8214 & 7588 & 12071 & 8744 & 6371 & 3927 & 3256 & 2795 & 2582 & 2885 & 4402 & 7720 & 5880 \\
\hline 1937 & 13451 & 16549 & 13580 & 9622 & 7125 & 4407 & 3682 & 3083 & 2692 & 2719 & 6565 & 13748 & 8102 \\
\hline 1938 & 18186 & 13692 & 11770 & 7307 & 5131 & 4254 & 3481 & 3075 & 2870 & 2740 & 4182 & 9149 & 7153 \\
\hline 1939 & 15568 & 17543 & 15884 & 6684 & 4936 & 3889 & 3344 & 3100 & 2820 & 3740 & 3139 & 5076 & 7144 \\
\hline 1940 & 9492 & 14243 & 18873 & 14317 & 6169 & 4365 & 3558 & 3175 & 2611 & 2790 & 5556 & 12406 & 8130 \\
\hline 1941 & 14674 & 14132 & 13934 & 14280 & 9172 & 5030 & 4229 & 3797 & 3055 & 3279 & 4801 & 7144 & 8127 \\
\hline 1942 & 13375 & 13982 & 15336 & 10938 & 7038 & 4656 & 3890 & 3333 & 3041 & 3860 & 6201 & 15348 & 8417 \\
\hline 1943 & 19490 & 26927 & 25374 & 16170 & 8960 & 6400 & 5368 & 4571 & 3928 & 4032 & 6285 & 15148 & 11888 \\
\hline 1944 & 18387 & 15205 & 15197 & 11653 & 7754 & 5208 & 4389 & 3801 & 3292 & 2876 & 4875 & 10876 & 8626 \\
\hline 1945 & 16779 & 20733 & 23882 & 22124 & 25724 & 12966 & 7798 & 6212 & 5104 & 5490 & 9204 & 16408 & 14369 \\
\hline 1946 & 21080 & 30690 & 14158 & 16283 & 11098 & 7397 & 5968 & 5122 & 4407 & 15 & 992 & 11228 & 11495 \\
\hline 1947 & 11291 & 15117 & 18468 & 22961 & 14058 & 7090 & 5765 & 4893 & 4732 & 4303 & 8975 & 12618 & 10856 \\
\hline 1948 & 18234 & 13837 & 16485 & 12491 & 6674 & 5453 & 4674 & 4026 & 3519 & 3672 & 4446 & 14457 & 8997 \\
\hline 1949 & 22264 & 27887 & 37478 & 23211 & 10760 & 7845 & 6446 & 33 & 4612 & 34 & 8325 & 8814 & 13942 \\
\hline 1950 & 13609 & 13822 & 10895 & 11568 & 8091 & 5223 & 4500 & 3895 & 3222 & 3714 & 5841 & 12206 & 8049 \\
\hline 1951 & 12995 & 12541 & 14132 & 14649 & 8160 & 5580 & 4480 & 3821 & 3311 & 3044 & 2885 & 4371 & 7497 \\
\hline 1952 & 9722 & 13939 & 17853 & 20722 & 10621 & 5940 & 4841 & 3949 & 3497 & 3469 & 4768 & 10008 & 9111 \\
\hline 1953 & 11426 & 5354 & 7876 & 11359 & 6171 & 3959 & 3303 & 2900 & 2568 & 3174 & 4457 & 9000 & 5962 \\
\hline 1954 & 13778 & 8164 & 9054 & 7383 & 4368 & 3683 & 2924 & 2554 & 2144 & 1916 & 2557 & 9741 & 5689 \\
\hline 1955 & 7911 & 12001 & 6759 & 7758 & 4661 & 3204 & 2695 & 2352 & 2032 & 55 & 5452 & 9618 & 5533 \\
\hline 1956 & 15655 & 7760 & 13042 & 8613 & 5153 & 4904 & 4091 & 3186 & 2730 & 2494 & 3825 & 10883 & 6861 \\
\hline 1957 & 17529 & 21069 & 21811 & 24039 & 18618 & 8689 & 6077 & 4962 & 4103 & 4462 & 4216 & 12482 & 12338 \\
\hline 1958 & 11541 & 14926 & 10958 & 9297 & 7392 & 5078 & 4184 & 4219 & 3289 & 58 & 5550 & 4862 & 7130 \\
\hline 1959 & 10608 & 11303 & 10111 & 8737 & 4181 & 3376 & 3013 & 2674 & 2411 & 2452 & 4621 & 7711 & 5933 \\
\hline 1960 & 9739 & 16672 & 25450 & 20713 & 7726 & 5347 & 4118 & 3 & 2929 & $\hat{~} 2$ & 34 & 82 & 9441 \\
\hline 1961 & 16799 & 22937 & 19562 & 11140 & 7037 & 5282 & 4161 & 31 & 2973 & 77 & 26 & 601 & 8644 \\
\hline 1962 & 10306 & 15952 & 13432 & 10170 & 6008 & 4454 & 3728 & 3074 & 2493 & 0 & 5558 & 8886 & 7278 \\
\hline 1963 & 16531 & 19505 & 11259 & 5145 & 4243 & 3342 & 2938 & 2 & 2370 & & 2568 & 409 & 6344 \\
\hline 1964 & 9972 & 23243 & 17095 & 8501 & 4922 & 3522 & 3036 & 2765 & 2207 & 36 & 7656 & 12216 & 8139 \\
\hline 1965 & 15564 & 15496 & 16668 & 18000 & 9120 & 5605 & 4502 & 3805 & 3166 & 4 & 7582 & 12206 & 9644 \\
\hline 1966 & 13171 & 18259 & 19760 & 14299 & 8075 & 5821 & 4643 & 4094 & 3514 & 31 & 5498 & 7536 & 9017 \\
\hline 1967 & 15121 & 14181 & 13080 & 13036 & 8212 & 4694 & 3924 & 3400 & 2918 & 2684 & 4697 & 11320 & 8106 \\
\hline 1968 & 16053 & 14192 & 19453 & 15959 & 7274 & 4919 & 4261 & 3865 & 3680 & 3628 & 4982 & 12633 & 9242 \\
\hline 1969 & 9271 & 12023 & 12618 & 7801 & 4919 & 3724 & 3283 & 2910 & 2494 & 2614 & 6946 & 14362 & 6914 \\
\hline 1970 & 17996 & 18596 & 14921 & 7853 & 5912 & 4254 & 3752 & 3277 & 3160 & 4431 & 8060 & 8263 & 8373 \\
\hline 1971 & 4988 & 4265 & 5121 & 4889 & 3584 & 2618 & 2399 & 2163 & 2169 & 3181 & 6554 & 18168 & 5008 \\
\hline 1972 & 15738 & 8603 & 10093 & 8878 & 5896 & 3790 & 3342 & & 2580 & 3891 & 5802 & 11522 & 6939 \\
\hline 1973 & 13749 & 11422 & 11025 & 13684 & 6643 & 4398 & 3744 & 3058 & 2513 & 3672 & 9415 & 13034 & 8030 \\
\hline 1974 & 13785 & 10673 & 12516 & 17900 & 9862 & 5255 & 4181 & 3689 & 3232 & 3164 & 5297 & 7222 & 8065 \\
\hline 1975 & 12736 & 12157 & 8291 & 7165 & 6313 & 3768 & 3765 & 2898 & 2417 & 2712 & 6657 & 8283 & 6430 \\
\hline 1976 & 6152 & 5770 & 6348 & 5347 & 3134 & 3025 & 2405 & 2246 & 2659 & 4305 & 6167 & 13841 & 5117 \\
\hline 1977 & 14865 & 17850 & 6988 & 6763 & 5890 & 4025 & 3412 & 2815 & 2679 & 3323 & 4103 & 8191 & 6742 \\
\hline 1978 & 16398 & 15517 & 19570 & 12141 & 8072 & 6634 & 4570 & 4339 & 3543 & 4266 & 6118 & 11155 & 9360 \\
\hline 1979 & 17881 & 28203 & 45978 & 23178 & 11294 & 8249 & 6707 & 5838 & 5845 & 5901 & 9441 & 9920 & 14870 \\
\hline 1980 & 18621 & 28947 & 32211 & 14114 & 10869 & 7106 & 6561 & 5577 & 4939 & 5209 & 6646 & 13495 & 12858 \\
\hline 1981 & 17428 & 15418 & 13612 & 17845 & 8595 & 6053 & 4913 & 4421 & 4088 & 5394 & 12491 & 18497 & 10730 \\
\hline 1982 & 20706 & 23499 & 22689 & 20968 & 12434 & 8093 & 6355 & 5325 & 4871 & 5064 & 5097 & 5813 & 11743 \\
\hline 1983 & 15127 & 23459 & 28459 & 21669 & 14277 & 8394 & 6448 & 5786 & 4599 & 6058 & 11557 & 17700 & 13628 \\
\hline 1984 & 19515 & 9733 & 8326 & 12126 & 6151 & 4320 & 3790 & 3411 & 4087 & 4355 & 5364 & 11251 & 7702 \\
\hline 1985 & 17606 & 24677 & 22297 & 21551 & 9774 & 6050 & 4849 & 4301 & 4177 & 5243 & 6759 & 10250 & 11461 \\
\hline
\end{tabular}


Anexo B (conclusão)

\begin{tabular}{|c|c|c|c|c|c|c|c|c|c|c|c|c|c|}
\hline Ano & jan & fev & mar & $a b r$ & mai & jun & jul & ago & set & out & nov & dez & Média \\
\hline 1986 & 18146 & 22846 & 15433 & 7505 & 5547 & 4140 & 3854 & 3826 & 3556 & 3056 & 3443 & 5656 & 8084 \\
\hline 1987 & 9787 & 8150 & 7954 & 9022 & 5436 & 3681 & 3351 & 2665 & 2615 & 2941 & 4206 & 10491 & 5858 \\
\hline 1988 & 16025 & 11356 & 13521 & 10243 & 6412 & 3847 & 3244 & 3261 & 3124 & 3239 & 5008 & 7514 & 7233 \\
\hline 1989 & 11259 & 7968 & 9372 & 5721 & 4024 & 3162 & 3088 & 2915 & 2729 & 2896 & 5192 & 17434 & 6313 \\
\hline 1990 & 27552 & 12316 & 9535 & 6511 & 4165 & 3262 & 3342 & 3086 & 3103 & 3391 & 4118 & 4722 & 7092 \\
\hline 1991 & 10372 & 16052 & 14595 & 15961 & 7840 & 4714 & 3780 & 3431 & 3215 & 4158 & 5785 & 9598 & 8292 \\
\hline 1992 & 14583 & 27798 & 39325 & 13379 & 8787 & 5736 & 4587 & 4215 & 4292 & 5673 & 12272 & 14951 & 12967 \\
\hline 1993 & 17689 & 14159 & 12781 & 8122 & 5736 & 4403 & 3808 & 3645 & 3261 & 3811 & 3966 & 5753 & 7261 \\
\hline 1994 & 15743 & 14657 & 14665 & 15188 & 6921 & 4955 & 4206 & 3425 & 3410 & 2709 & 2997 & 9162 & 8170 \\
\hline 1995 & 8980 & 9237 & 9462 & 8235 & 5525 & 4247 & 3302 & 2897 & 2316 & 2816 & 5072 & 9511 & 5967 \\
\hline 1996 & 13993 & 7180 & 6597 & 5700 & 4012 & 3135 & 2624 & 2060 & 2062 & 2428 & 5012 & 10355 & 5430 \\
\hline 1997 & 18745 & 15085 & 12932 & 13279 & 7824 & 5374 & 4120 & 3713 & 3246 & 3369 & 3951 & 9499 & 8428 \\
\hline 1998 & 10594 & 10074 & 9702 & 4963 & 3724 & 2970 & 2531 & 2343 & 2075 & 2132 & 5618 & 9428 & 5513 \\
\hline 1999 & 9411 & 5773 & 11912 & 7741 & 3918 & 2734 & 2357 & 2023 & 2250 & 1808 & 4520 & 9395 & 5320 \\
\hline 2000 & 12776 & 15464 & 13478 & 10852 & 5416 & 3664 & 2852 & 2939 & 2773 & 2414 & 5035 & 10726 & 7366 \\
\hline 2001 & 10247 & 5277 & 5248 & 3919 & 2521 & 2468 & 1989 & 1843 & 1942 & 2188 & 3483 & 6494 & 3968 \\
\hline 2002 & 15221 & 14308 & 10773 & 6850 & 3295 & 2652 & 2496 & 1931 & 1508 & 1939 & 2756 & 5512 & 5770 \\
\hline 2003 & 12384 & 13394 & 8143 & 7895 & 4146 & 2955 & 2648 & 2227 & 2027 & 1495 & 2455 & 4829 & 5383 \\
\hline 2004 & 9273 & 14869 & 19987 & 15829 & 8536 & 4548 & 3916 & 3066 & 2684 & 2623 & 3088 & 5464 & 7824 \\
\hline 2005 & 12273 & 14671 & 14724 & 12342 & 6703 & 4408 & 3568 & 2940 & 2920 & 2754 & 4114 & 12908 & 7860 \\
\hline 2006 & 13164 & 7192 & 10647 & 12634 & 6822 & 3922 & 3221 & 3015 & 2903 & 3938 & 7884 & 12169 & 7293 \\
\hline 2007 & 17907 & 21551 & 20328 & 7769 & 4617 & 3857 & 3001 & 2950 & 2193 & 1761 & 1881 & 4671 & 7707 \\
\hline 2008 & 6055 & 12098 & 13678 & 14247 & 5937 & 3432 & 2794 & 2520 & 2036 & 2199 & 2664 & 7150 & 6234 \\
\hline 2009 & 16207 & 15216 & 10958 & 13193 & 7713 & 4589 & 3732 & 2950 & 3060 & 4054 & 7399 & 8056 & 8094 \\
\hline Média & 14172 & 15086 & 15091 & 12060 & 7371 & 4847 & 3982 & 3469 & 3114 & 3391 & 5429 & 9941 & 8163 \\
\hline
\end{tabular}




\section{Anexo C - Resultados do Cenário I para o período abr/1998-mar/2005}

Vazão média fornecida a uso consuntivo (UC), vazão turbinada média (R'), energia gerada $(E)$, armazenamento médio dos reservatórios (Smédio), vazão vertida média (R") e vazão transposta média (DE)

\begin{tabular}{|c|c|c|c|c|c|c|c|}
\hline & \multirow{2}{*}{ Reservatório } & \multicolumn{3}{|c|}{ Transposição ativa } & \multicolumn{3}{|c|}{ Transposição inativa } \\
\hline & & TMA300 & TMA400 & TMA500 & TMA300 & TMA400 & TMA500 \\
\hline \multirow{7}{*}{$\mathrm{UC}\left(\mathrm{m}^{3} / \mathrm{s}\right)$} & RBA & 1,8 & 1,8 & 1,8 & 1,8 & 1,8 & 1,8 \\
\hline & TMA & 6,4 & 6,4 & 6,4 & 6,4 & 6,4 & 6,4 \\
\hline & QUE & 0,9 & 0,9 & 0,9 & 0,9 & 0,9 & 0,9 \\
\hline & SOB & 58,4 & 58,4 & 58,4 & 58,4 & 58,4 & 58,4 \\
\hline & ITP & 50,8 & 50,8 & 50,8 & 50,8 & 50,8 & 50,8 \\
\hline & PAM & 2,1 & 2,1 & 2,1 & 2,1 & 2,1 & 2,1 \\
\hline & $\mathrm{XIN}$ & 0,3 & 0,3 & 0,3 & 0,3 & 0,3 & 0,3 \\
\hline \multirow{7}{*}{$R^{\prime}\left(m^{3} / s\right)$} & RBA & 85,7 & 85,7 & 85,9 & 85,7 & 85,9 & 85,8 \\
\hline & TMA & 521,9 & 531,3 & 539,1 & 521,6 & 533,3 & 538,7 \\
\hline & QUE & 34,3 & 34,2 & 34,2 & 34,3 & 34,2 & 34,2 \\
\hline & SOB & 1775,6 & 1774,0 & 1770,4 & 1775,1 & 1773,1 & 1769,6 \\
\hline & ITP & 1713,4 & 1711,8 & 1708,0 & 1739,3 & 1737,2 & 1733,6 \\
\hline & PAM & 1706,6 & 1705,0 & 1701,2 & 1732,4 & 1730,4 & 1726,8 \\
\hline & XIN & 1703,5 & 1701,9 & 1697,4 & 1729,4 & 1727,3 & 1722,7 \\
\hline \multirow{7}{*}{ E (MWmed) } & RBA & 27,8 & 27,7 & 27,7 & 27,7 & 27,7 & 27,7 \\
\hline & TMA & 226,6 & 229,1 & 226,8 & 226,6 & 229,7 & 226,8 \\
\hline & QUE & 56,5 & 56,5 & 56,4 & 56,5 & 56,5 & 56,4 \\
\hline & SOB & 373,1 & 374,3 & 378,2 & 373,4 & 375,2 & 378,6 \\
\hline & ITP & 786,3 & 785,9 & 784,8 & 798,4 & 797,7 & 796,9 \\
\hline & PAM & 1750,1 & 1748,4 & 1744,5 & 1776,6 & 1774,4 & 1770,8 \\
\hline & XIN & 1891,2 & 1889,4 & 1884,5 & 1919,2 & 1916,9 & 1911,9 \\
\hline \multirow{5}{*}{$\begin{array}{c}\text { Smédio } \\
\left(\mathrm{hm}^{3}\right)\end{array}$} & RBA & 224,31 & 223,14 & 222,71 & 219,93 & 222,20 & 221,32 \\
\hline & TMA & 14531,15 & 14250,12 & 13185,94 & 14549,85 & 14218,27 & 13223,52 \\
\hline & QUE & 385,91 & 388,36 & 391,74 & 383,61 & 390,75 & 392,34 \\
\hline & SOB & 14292,58 & 14539,49 & 15157,35 & 14361,53 & 14681,65 & 15230,35 \\
\hline & ITP & 9937,24 & 9950,92 & 9977,83 & 9948,40 & 9961,36 & 9994,56 \\
\hline \multirow{7}{*}{$R^{\prime \prime}\left(m^{3} / s\right)$} & RBA & 42,24 & 42,25 & 42,01 & 42,26 & 42,04 & 42,12 \\
\hline & TMA & 38,36 & 29,18 & 22,03 & 38,67 & 27,21 & 22,43 \\
\hline & QUE & 6,00 & 6,02 & 6,07 & 6,00 & 6,00 & 6,04 \\
\hline & SOB & 0,00 & 0,00 & 0,00 & 0,00 & 0,00 & 0,00 \\
\hline & ITP & 0,00 & 0,00 & 0,00 & 0,00 & 0,00 & 0,00 \\
\hline & PAM & 0,00 & 0,00 & 0,00 & 0,00 & 0,00 & 0,00 \\
\hline & XIN & 0,00 & 0,00 & 0,73 & 0,00 & 0,00 & 1,04 \\
\hline $\mathrm{DE}\left(\mathrm{m}^{3} / \mathrm{s}\right)$ & & 26,4 & 26,4 & 26,4 & 0,0 & 0,0 & 0,0 \\
\hline
\end{tabular}




\section{Anexo D - Resultados do Cenário II para o período abr/1998-mar/2005}

Vazão média fornecida a uso consuntivo (UC), vazão turbinada média ( $\left.R^{\prime}\right)$, energia gerada (E), armazenamento médio dos reservatórios (Smédio), vazão vertida média (R") e vazão transposta média (DE)

\begin{tabular}{|c|c|c|c|c|c|c|c|}
\hline & \multirow{2}{*}{ Reservatório } & \multicolumn{3}{|c|}{ Transposição ativa } & \multicolumn{3}{|c|}{ Transposição inativa } \\
\hline & & TMA300 & TMA400 & TMA500 & TMA300 & TMA400 & TMA500 \\
\hline \multirow{7}{*}{$\mathrm{UC}\left(\mathrm{m}^{3} / \mathrm{s}\right)$} & RBA & 2,7 & 2,7 & 2,7 & 2,7 & 2,7 & 2,7 \\
\hline & TMA & 9,6 & 9,6 & 9,6 & 9,6 & 9,6 & 9,6 \\
\hline & QUE & 1,4 & 1,4 & 1,4 & 1,4 & 1,4 & 1,4 \\
\hline & SOB & 87,2 & 87,2 & 87,2 & 87,3 & 87,3 & 87,3 \\
\hline & ITP & 76,1 & 76,1 & 76,1 & 76,1 & 76,1 & 76,1 \\
\hline & PAM & 3,0 & 3,0 & 3,0 & 3,0 & 3,0 & 3,0 \\
\hline & XIN & 0,4 & 0,4 & 0,4 & 0,4 & 0,4 & 0,4 \\
\hline \multirow{7}{*}{$R^{\prime}\left(m^{3} / s\right)$} & RBA & 84,9 & 85,1 & 85,1 & 85,1 & 85,2 & 85,0 \\
\hline & TMA & 520,8 & 531,5 & 536,0 & 519,6 & 530,9 & 536,0 \\
\hline & QUE & 34,1 & 34,1 & 34,0 & 34,1 & 34,1 & 34,0 \\
\hline & SOB & 1743,1 & 1741,5 & 1738,3 & 1742,9 & 1740,9 & 1737,7 \\
\hline & ITP & 1655,8 & 1654,1 & 1650,8 & 1681,7 & 1679,9 & 1676,5 \\
\hline & PAM & 1647,9 & 1646,3 & 1643,0 & 1673,9 & 1672,1 & 1668,7 \\
\hline & XIN & 1644,7 & 1643,1 & 1639,8 & 1670,7 & 1668,8 & 1665,2 \\
\hline \multirow{7}{*}{$\begin{array}{c}E \\
\text { (MWmed) }\end{array}$} & RBA & 27,6 & 27,5 & 27,6 & 27,5 & 27,5 & 27,5 \\
\hline & TMA & 225,8 & 228,7 & 225,4 & 225,5 & 228,7 & 225,4 \\
\hline & QUE & 56,2 & 56,2 & 56,1 & 56,2 & 56,2 & 56,1 \\
\hline & SOB & 366,0 & 367,2 & 370,4 & 366,0 & 367,6 & 370,9 \\
\hline & ITP & 759,4 & 758,8 & 757,9 & 771,9 & 770,8 & 770,0 \\
\hline & PAM & 1689,9 & 1688,2 & 1684,8 & 1716,6 & 1714,6 & 1711,2 \\
\hline & XIN & 1827,4 & 1825,6 & 1822,0 & 1855,6 & 1853,5 & 1849,5 \\
\hline \multirow{5}{*}{$\begin{array}{c}\text { Smédio } \\
\left(\mathrm{hm}^{3}\right)\end{array}$} & RBA & 226,09 & 223,72 & 224,52 & 221,33 & 221,06 & 221,18 \\
\hline & TMA & 14474,95 & 14177,47 & 13154,74 & 14492,23 & 14213,42 & 13161,10 \\
\hline & QUE & 384,13 & 379,34 & 389,40 & 381,04 & 389,50 & 393,56 \\
\hline & SOB & 14161,05 & 14417,15 & 14939,69 & 14182,98 & 14483,55 & 15024,06 \\
\hline & ITP & 9913,60 & 9923,35 & 9947,30 & 9942,36 & 9932,32 & 9963,07 \\
\hline \multirow{7}{*}{$R^{\prime \prime}\left(m^{3} / s\right)$} & RBA & 42,08 & 41,88 & 41,92 & 41,98 & 41,81 & 42,04 \\
\hline & TMA & 35,40 & 24,85 & 20,99 & 36,63 & 25,42 & 21,01 \\
\hline & QUE & 5,72 & 5,72 & 5,81 & 5,74 & 5,74 & 5,78 \\
\hline & SOB & 0,00 & 0,00 & 0,00 & 0,00 & 0,00 & 0,00 \\
\hline & ITP & 0,00 & 0,00 & 0,00 & 0,00 & 0,00 & 0,00 \\
\hline & PAM & 0,00 & 0,00 & 0,00 & 0,00 & 0,00 & 0,00 \\
\hline & XIN & 0,00 & 0,00 & 0,00 & 0,00 & 0,00 & 0,30 \\
\hline $\mathrm{DE}\left(\mathrm{m}^{3} / \mathrm{s}\right)$ & & 26,4 & 26,4 & 26,4 & 0,0 & 0,0 & 0,0 \\
\hline
\end{tabular}


Anexo E - Resultados do Cenário III para o período abr/1998-mar/2005

Vazão média fornecida a uso consuntivo (UC), vazão turbinada média ( $\left.R^{\prime}\right)$, energia gerada $(E)$, armazenamento médio dos reservatórios (Smédio), vazão vertida média (R") e vazão transposta média (DE)

\begin{tabular}{|c|c|c|c|c|c|c|c|}
\hline & \multirow{2}{*}{ Reservatório } & \multicolumn{3}{|c|}{ Transposição ativa } & \multicolumn{3}{|c|}{ Transposição inativa } \\
\hline & & TMA300 & TMA400 & TMA500 & TMA300 & TMA400 & TMA500 \\
\hline \multirow{7}{*}{$\mathrm{UC}\left(\mathrm{m}^{3} / \mathrm{s}\right)$} & RBA & 3,6 & 3,6 & 3,6 & 3,6 & 3,6 & 3,6 \\
\hline & TMA & 12,9 & 12,9 & 12,9 & 12,9 & 12,9 & 12,9 \\
\hline & QUE & 1,8 & 1,8 & 1,8 & 1,8 & 1,8 & 1,8 \\
\hline & SOB & 115,8 & 115,8 & 115,8 & 115,9 & 115,9 & 115,9 \\
\hline & ITP & 101,3 & 101,3 & 101,3 & 101,3 & 101,3 & 101,3 \\
\hline & PAM & 4,1 & 4,1 & 4,1 & 4,1 & 4,1 & 4,1 \\
\hline & XIN & 0,6 & 0,6 & 0,6 & 0,6 & 0,6 & 0,6 \\
\hline \multirow{7}{*}{$R^{\prime}\left(m^{3} / s\right)$} & RBA & 84,2 & 84,2 & 84,4 & 84,4 & 84,4 & 84,3 \\
\hline & TMA & 520,7 & 531,0 & 533,8 & 519,9 & 531,0 & 533,6 \\
\hline & QUE & 33,9 & 33,9 & 33,8 & 33,9 & 33,9 & 33,8 \\
\hline & SOB & 1711,4 & 1709,7 & 1705,8 & 1711,0 & 1708,7 & 1705,5 \\
\hline & ITP & 1598,8 & 1597,2 & 1593,2 & 1624,8 & 1622,6 & 1619,2 \\
\hline & PAM & 1590,0 & 1588,3 & 1584,4 & 1615,9 & 1613,7 & 1610,4 \\
\hline & XIN & 1586,6 & 1585,0 & 1581,0 & 1612,6 & 1610,4 & 1607,0 \\
\hline \multirow{7}{*}{ E (MWmed) } & RBA & 27,4 & 27,3 & 27,4 & 27,3 & 27,3 & 27,3 \\
\hline & TMA & 224,9 & 227,7 & 223,9 & 224,8 & 228,2 & 224,0 \\
\hline & QUE & 55,9 & 55,9 & 55,8 & 55,9 & 55,9 & 55,8 \\
\hline & SOB & 358,6 & 360,1 & 363,6 & 358,8 & 360,5 & 363,7 \\
\hline & ITP & 733,2 & 732,4 & 731,1 & 745,1 & 743,9 & 743,2 \\
\hline & PAM & 1630,5 & 1628,8 & 1624,7 & 1657,1 & 1654,9 & 1651,4 \\
\hline & XIN & 1764,3 & 1762,5 & 1758,2 & 1792,5 & 1790,1 & 1786,5 \\
\hline \multirow{5}{*}{$\begin{array}{c}\text { Smédio } \\
\left(\mathrm{hm}^{3}\right)\end{array}$} & RBA & 226,95 & 225,42 & 225,28 & 223,08 & 223,72 & 223,37 \\
\hline & TMA & 14341,50 & 14061,13 & 13055,69 & 14381,73 & 14133,98 & 13070,56 \\
\hline & QUE & 382,31 & 379,55 & 390,59 & 383,39 & 382,64 & 383,04 \\
\hline & SOB & 13960,88 & 14231,95 & 14867,30 & 14000,25 & 14347,56 & 14905,65 \\
\hline & ITP & 9907,29 & 9905,81 & 9929,29 & 9909,43 & 9899,60 & 9935,41 \\
\hline \multirow{7}{*}{$R^{\prime \prime}\left(m^{3} / s\right)$} & RBA & 41,93 & 41,88 & 41,72 & 41,70 & 41,76 & 41,81 \\
\hline & TMA & 31,44 & 21,31 & 19,20 & 32,18 & 21,26 & 19,39 \\
\hline & QUE & 5,45 & 5,47 & 5,54 & 5,45 & 5,44 & 5,51 \\
\hline & SOB & 0,00 & 0,00 & 0,00 & 0,00 & 0,00 & 0,00 \\
\hline & ITP & 0,00 & 0,00 & 0,00 & 0,00 & 0,00 & 0,00 \\
\hline & PAM & 0,00 & 0,00 & 0,00 & 0,00 & 0,00 & 0,00 \\
\hline & XIN & 0,00 & 0,00 & 0,00 & 0,00 & 0,00 & 0,00 \\
\hline $\mathrm{DE}\left(\mathrm{m}^{3} / \mathrm{s}\right)$ & & 26,4 & 26,4 & 26,4 & 0,0 & 0,0 & 0,0 \\
\hline
\end{tabular}


Anexo F - Resultados do Cenário IV para o período abr/1998-mar/2005

Vazão média fornecida a uso consuntivo (UC), vazão turbinada média ( $\left.R^{\prime}\right)$, energia gerada ( $\left.E\right)$, armazenamento médio dos reservatórios (Smédio), vazão vertida média (R") e vazão transposta média (DE)

\begin{tabular}{|c|c|c|c|c|c|c|c|}
\hline & \multirow{2}{*}{ Reservatório } & \multicolumn{3}{|c|}{ Transposição ativa } & \multicolumn{3}{|c|}{ Transposição inativa } \\
\hline & & TMA300 & TMA400 & TMA500 & TMA300 & TMA400 & TMA500 \\
\hline \multirow{7}{*}{$\mathrm{UC}\left(\mathrm{m}^{3} / \mathrm{s}\right)$} & RBA & 4,5 & 4,5 & 4,5 & 4,5 & 4,5 & 4,5 \\
\hline & TMA & 16,1 & 16,1 & 16,1 & 16,1 & 16,1 & 16,1 \\
\hline & QUE & 2,3 & 2,3 & 2,3 & 2,3 & 2,3 & 2,3 \\
\hline & SOB & 144,1 & 144,1 & 144,1 & 144,2 & 144,2 & 144,2 \\
\hline & ITP & 126,4 & 126,4 & 126,4 & 126,5 & 126,5 & 126,4 \\
\hline & PAM & 5,1 & 5,1 & 5,1 & 5,1 & 5,1 & 5,1 \\
\hline & XIN & 0,7 & 0,7 & 0,7 & 0,7 & 0,7 & 0,7 \\
\hline \multirow{7}{*}{$R^{\prime}\left(m^{3} / s\right)$} & RBA & 83,7 & 83,7 & 83,7 & 83,8 & 83,8 & 83,7 \\
\hline & TMA & 522,2 & 528,9 & 531,7 & 522,5 & 530,6 & 531,0 \\
\hline & QUE & 33,8 & 33,7 & 33,6 & 33,8 & 33,8 & 33,7 \\
\hline & SOB & 1679,3 & 1677,7 & 1673,9 & 1678,5 & 1677,0 & 1673,4 \\
\hline & ITP & 1541,8 & 1540,2 & 1536,3 & 1567,3 & 1565,8 & 1562,0 \\
\hline & PAM & 1531,9 & 1530,3 & 1526,4 & 1557,5 & 1555,9 & 1552,2 \\
\hline & XIN & 1528,4 & 1526,8 & 1522,9 & 1554,0 & 1552,4 & 1548,7 \\
\hline \multirow{7}{*}{$E(M W m e d)$} & RBA & 27,2 & 27,1 & 27,2 & 27,1 & 27,1 & 27,1 \\
\hline & TMA & 225,0 & 226,8 & 222,8 & 225,3 & 227,5 & 222,7 \\
\hline & QUE & 55,5 & 55,5 & 55,4 & 55,6 & 55,5 & 55,5 \\
\hline & SOB & 351,7 & 353,0 & 356,5 & 352,1 & 353,4 & 356,7 \\
\hline & ITP & 706,4 & 705,9 & 704,8 & 718,2 & 717,7 & 716,6 \\
\hline & PAM & 1571,0 & 1569,3 & 1565,3 & 1597,1 & 1595,5 & 1591,7 \\
\hline & XIN & 1701,1 & 1699,3 & 1695,1 & 1728,8 & 1727,1 & 1723,1 \\
\hline \multirow{5}{*}{$\begin{array}{c}\text { Smédio } \\
\left(\mathrm{hm}^{3}\right)\end{array}$} & RBA & 226,10 & 224,79 & 225,35 & 222,00 & 223,38 & 223,26 \\
\hline & TMA & 14236,13 & 14059,60 & 12971,25 & 14260,55 & 14043,88 & 13012,52 \\
\hline & QUE & 365,90 & 379,95 & 391,05 & 374,24 & 372,40 & 386,06 \\
\hline & SOB & 13841,23 & 14105,25 & 14743,57 & 13942,19 & 14190,15 & 14803,13 \\
\hline & ITP & 9874,47 & 9882,28 & 9917,75 & 9880,33 & 9885,84 & 9917,59 \\
\hline \multirow{7}{*}{$R^{\prime \prime}\left(m^{3} / s\right)$} & RBA & 41,54 & 41,51 & 41,49 & 41,43 & 41,43 & 41,49 \\
\hline & TMA & 25,83 & 19,27 & 17,15 & 25,51 & 17,60 & 17,88 \\
\hline & QUE & 5,13 & 5,20 & 5,28 & 5,15 & 5,15 & 5,22 \\
\hline & SOB & 0,00 & 0,00 & 0,00 & 0,00 & 0,00 & 0,00 \\
\hline & ITP & 0,00 & 0,00 & 0,00 & 0,00 & 0,00 & 0,00 \\
\hline & PAM & 0,00 & 0,00 & 0,00 & 0,00 & 0,00 & 0,00 \\
\hline & XIN & 0,00 & 0,00 & 0,00 & 0,00 & 0,00 & 0,00 \\
\hline$D E\left(\mathrm{~m}^{3} / \mathrm{s}\right)$ & & 26,4 & 26,4 & 26,4 & 0,0 & 0,0 & 0,0 \\
\hline
\end{tabular}


Anexo G - Resultados do Cenário V para o período abr/1998-mar/2005

Vazão média fornecida a uso consuntivo (UC), vazão turbinada média ( $\left.R^{\prime}\right)$, energia gerada (E), armazenamento médio dos reservatórios (Smédio), vazão vertida média (R") e vazão transposta média (DE)

\begin{tabular}{|c|c|c|c|c|c|c|c|}
\hline & \multirow{2}{*}{ Reservatório } & \multicolumn{3}{|c|}{ Transposição ativa } & \multicolumn{3}{|c|}{ Transposição inativa } \\
\hline & & TMA300 & TMA400 & TMA500 & TMA300 & TMA400 & TMA500 \\
\hline \multirow{7}{*}{$\mathrm{UC}\left(\mathrm{m}^{3} / \mathrm{s}\right)$} & RBA & 5,4 & 5,4 & 5,4 & 5,4 & 5,4 & 5,4 \\
\hline & TMA & 19,3 & 19,3 & 19,3 & 19,3 & 19,3 & 19,3 \\
\hline & QUE & 2,7 & 2,7 & 2,7 & 2,7 & 2,7 & 2,7 \\
\hline & SOB & 171,9 & 171,9 & 171,9 & 172,1 & 172,1 & 172,1 \\
\hline & ITP & 151,4 & 151,4 & 151,4 & 151,5 & 151,5 & 151,5 \\
\hline & PAM & 6,1 & 6,1 & 6,1 & 6,1 & 6,1 & 6,1 \\
\hline & XIN & 0,8 & 0,8 & 0,8 & 0,8 & 0,8 & 0,8 \\
\hline \multirow{7}{*}{$R^{\prime}\left(m^{3} / s\right)$} & RBA & 82,9 & 83,0 & 83,1 & 82,9 & 82,8 & 83,0 \\
\hline & TMA & 521,4 & 527,4 & 529,3 & 519,8 & 527,4 & 529,3 \\
\hline & QUE & 33,6 & 33,6 & 33,5 & 33,6 & 33,6 & 33,5 \\
\hline & SOB & 1647,6 & 1646,2 & 1642,9 & 1647,4 & 1646,0 & 1642,1 \\
\hline & ITP & 1485,2 & 1483,8 & 1480,4 & 1511,3 & 1510,0 & 1505,9 \\
\hline & PAM & 1474,3 & 1472,9 & 1469,5 & 1500,4 & 1499,1 & 1495,0 \\
\hline & XIN & 1470,7 & 1469,3 & 1465,9 & 1496,8 & 1495,5 & 1491,4 \\
\hline \multirow{7}{*}{ E (MWmed) } & RBA & 27,0 & 26,9 & 26,9 & 26,9 & 26,9 & 26,9 \\
\hline & TMA & 224,5 & 226,1 & 220,8 & 224,1 & 226,0 & 220,9 \\
\hline & QUE & 55,1 & 55,2 & 55,2 & 55,1 & 55,2 & 55,2 \\
\hline & SOB & 344,9 & 346,1 & 349,2 & 345,0 & 346,1 & 349,8 \\
\hline & ITP & 680,0 & 679,5 & 678,7 & 692,1 & 691,5 & 690,6 \\
\hline & PAM & 1511,8 & 1510,4 & 1506,9 & 1538,6 & 1537,2 & 1533,1 \\
\hline & XIN & 1638,3 & 1636,8 & 1633,1 & 1666,7 & 1665,3 & 1660,8 \\
\hline \multirow{5}{*}{$\begin{array}{c}\text { Smédio } \\
\left(\mathrm{hm}^{3}\right)\end{array}$} & RBA & 226,37 & 225,10 & 224,76 & 223,33 & 223,82 & 223,83 \\
\hline & TMA & 14200,73 & 14031,15 & 12824,97 & 14253,77 & 14017,49 & 12843,46 \\
\hline & QUE & 360,49 & 358,53 & 386,51 & 357,17 & 364,57 & 376,21 \\
\hline & SOB & 13761,05 & 13993,52 & 14551,67 & 13766,40 & 13994,25 & 14657,75 \\
\hline & ITP & 9847,91 & 9852,43 & 9889,89 & 9850,79 & 9853,97 & 9900,74 \\
\hline \multirow{7}{*}{$R^{\prime \prime}\left(m^{3} / s\right)$} & RBA & 41,38 & 41,29 & 41,25 & 41,39 & 41,49 & 41,29 \\
\hline & TMA & 22,54 & 16,65 & 15,51 & 24,16 & 16,64 & 15,60 \\
\hline & QUE & 4,92 & 4,92 & 5,00 & 4,89 & 4,89 & 4,95 \\
\hline & SOB & 0,00 & 0,00 & 0,00 & 0,00 & 0,00 & 0,00 \\
\hline & ITP & 0,00 & 0,00 & 0,00 & 0,00 & 0,00 & 0,00 \\
\hline & PAM & 0,00 & 0,00 & 0,00 & 0,00 & 0,00 & 0,00 \\
\hline & XIN & 0,00 & 0,00 & 0,00 & 0,00 & 0,00 & 0,00 \\
\hline $\mathrm{DE}\left(\mathrm{m}^{3} / \mathrm{s}\right)$ & & 26,4 & 26,4 & 26,4 & 0,0 & 0,0 & 0,0 \\
\hline
\end{tabular}


Anexo H - Resultados do Cenário VI para o período abr/1998-mar/2005

Vazão média fornecida a uso consuntivo (UC), vazão turbinada média ( $\left.R^{\prime}\right)$, energia gerada $(E)$, armazenamento médio dos reservatórios (Smédio), vazão vertida média (R") e vazão transposta média (DE)

\begin{tabular}{|c|c|c|c|c|c|c|c|}
\hline & \multirow{2}{*}{ Reservatório } & \multicolumn{3}{|c|}{ Transposição ativa } & \multicolumn{3}{|c|}{ Transposição inativa } \\
\hline & & TMA300 & TMA400 & TMA500 & TMA300 & TMA400 & TMA500 \\
\hline \multirow{7}{*}{$\mathrm{UC}\left(\mathrm{m}^{3} / \mathrm{s}\right)$} & RBA & 13,1 & 13,1 & 13,1 & 13,1 & 13,1 & 13,1 \\
\hline & TMA & 38,3 & 38,3 & 38,3 & 38,3 & 38,3 & 38,3 \\
\hline & QUE & 1,4 & 1,4 & 1,4 & 1,4 & 1,4 & 1,4 \\
\hline & SOB & 330,4 & 325,1 & 309,3 & 355,3 & 349,8 & 332,8 \\
\hline & ITP & 131,9 & 131,9 & 131,9 & 131,9 & 131,9 & 131,9 \\
\hline & PAM & 5,1 & 5,1 & 5,1 & 5,1 & 5,1 & 5,1 \\
\hline & XIN & 0,3 & 0,3 & 0,3 & 0,3 & 0,3 & 0,3 \\
\hline \multirow{7}{*}{$R^{\prime}\left(m^{3} / s\right)$} & RBA & 78,2 & 78,3 & 78,1 & 78,2 & 78,2 & 78,3 \\
\hline & TMA & 409,1 & 454,7 & 503,7 & 419,5 & 459,3 & 503,7 \\
\hline & QUE & 34,1 & 34,1 & 32,4 & 34,1 & 34,1 & 33,1 \\
\hline & SOB & 1461,8 & 1461,8 & 1464,7 & 1435,2 & 1435,2 & 1438,4 \\
\hline & ITP & 1319,2 & 1319,2 & 1321,5 & 1319,2 & 1319,2 & 1321,8 \\
\hline & PAM & 1309,3 & 1309,3 & 1311,6 & 1309,3 & 1309,3 & 1311,9 \\
\hline & XIN & 1306,2 & 1306,2 & 1308,5 & 1306,2 & 1306,2 & 1308,8 \\
\hline \multirow{7}{*}{ E (MWmed) } & RBA & 25,4 & 25,4 & 25,4 & 25,4 & 25,4 & 25,4 \\
\hline & TMA & 181,9 & 199,4 & 208,4 & 186,9 & 201,8 & 208,4 \\
\hline & QUE & 56,1 & 56,1 & 53,9 & 56,1 & 56,1 & 54,9 \\
\hline & SOB & 309,0 & 313,7 & 327,4 & 304,9 & 309,7 & 324,1 \\
\hline & ITP & 603,2 & 603,1 & 606,5 & 602,5 & 602,4 & 605,9 \\
\hline & PAM & 1342,7 & 1342,7 & 1345,0 & 1342,7 & 1342,7 & 1345,3 \\
\hline & XIN & 1459,3 & 1459,3 & 1461,8 & 1459,3 & 1459,3 & 1462,2 \\
\hline \multirow{5}{*}{$\begin{array}{c}\text { Smédio } \\
\left(\mathrm{hm}^{3}\right)\end{array}$} & RBA & 223,43 & 224,84 & 224,15 & 224,51 & 224,32 & 223,12 \\
\hline & TMA & 15692,70 & 14885,04 & 12369,69 & 15722,39 & 14932,11 & 12370,48 \\
\hline & QUE & 366,16 & 367,74 & 436,57 & 370,78 & 377,22 & 428,43 \\
\hline & SOB & 14080,67 & 14787,10 & 16714,11 & 14263,35 & 15010,58 & 17092,60 \\
\hline & ITP & 9790,83 & 9782,57 & 9927,85 & 9742,42 & 9736,30 & 9879,21 \\
\hline \multirow{7}{*}{$R^{\prime \prime}\left(m^{3} / s\right)$} & RBA & 39,93 & 39,69 & 39,66 & 40,30 & 40,04 & 40,28 \\
\hline & TMA & 91,73 & 91,76 & 91,78 & 94,38 & 92,45 & 95,29 \\
\hline & QUE & 19,68 & 19,68 & 19,67 & 19,91 & 20,21 & 20,31 \\
\hline & SOB & 54,76 & 61,08 & 62,79 & 85,15 & 102,51 & 91,01 \\
\hline & ITP & 111,79 & 116,71 & 114,61 & 128,02 & 128,17 & 135,30 \\
\hline & PAM & 94,34 & 101,59 & 102,50 & 112,75 & 117,00 & 119,05 \\
\hline & XIN & 180,93 & 189,40 & 191,05 & 201,33 & 206,79 & 213,47 \\
\hline $\mathrm{DE}\left(\mathrm{m}^{3} / \mathrm{s}\right)$ & & 26,4 & 0,0 & 26,4 & 0,0 & 0,0 & 0,0 \\
\hline
\end{tabular}




\section{Anexo I - Resultados do Cenário I para o período abr/1950-mar/1957}

Vazão média fornecida a uso consuntivo (UC), vazão turbinada média (R'), energia gerada (E), armazenamento médio dos reservatórios (Smédio), vazão vertida média (R") e vazão transposta média (DE)

\begin{tabular}{|c|c|c|c|c|c|c|c|}
\hline & \multirow{2}{*}{ Reservatório } & \multicolumn{3}{|c|}{ Transposição ativa } & \multicolumn{3}{|c|}{ Transposição inativa } \\
\hline & & TMA300 & TMA400 & TMA437 & TMA300 & TMA400 & TMA437 \\
\hline \multirow{7}{*}{$\mathrm{UC}\left(\mathrm{m}^{3} / \mathrm{s}\right)$} & RBA & 1,8 & 1,8 & 1,8 & 1,8 & 1,8 & 1,8 \\
\hline & TMA & 6,4 & 6,4 & 6,4 & 6,4 & 6,4 & 6,4 \\
\hline & QUE & 0,9 & 0,9 & 0,9 & 0,9 & 0,9 & 0,9 \\
\hline & SOB & 58,6 & 58,5 & 58,5 & 58,6 & 58,6 & 58,6 \\
\hline & ITP & 50,9 & 50,9 & 50,9 & 50,9 & 50,9 & 50,9 \\
\hline & PAM & 2,1 & 2,1 & 2,1 & 2,1 & 2,1 & 2,1 \\
\hline & XIN & 0,3 & 0,3 & 0,3 & 0,3 & 0,3 & 0,3 \\
\hline \multirow{7}{*}{$R^{\prime}\left(m^{3} / s\right)$} & RBA & 89,3 & 89,5 & 89,5 & 88,9 & 89,2 & 88,9 \\
\hline & TMA & 464,9 & 465,1 & 465,2 & 462,4 & 464,4 & 461,7 \\
\hline & QUE & 34,9 & 34,9 & 34,9 & 34,7 & 34,3 & 34,2 \\
\hline & SOB & 2112,7 & 2103,5 & 2098,4 & 2083,3 & 2062,8 & 2071,6 \\
\hline & ITP & 1999,8 & 1995,2 & 1993,0 & 2018,6 & 2015,6 & 2005,3 \\
\hline & PAM & 2005,8 & 1998,9 & 1993,6 & 2022,5 & 2015,3 & 2010,1 \\
\hline & XIN & 1916,1 & 1907,9 & 1902,0 & 1930,8 & 1922,4 & 1912,6 \\
\hline \multirow{7}{*}{ E (MWmed) } & RBA & 29,1 & 29,2 & 29,1 & 28,9 & 28,9 & 28,9 \\
\hline & TMA & 209,2 & 209,6 & 209,6 & 207,3 & 208,9 & 207,8 \\
\hline & QUE & 57,6 & 57,6 & 57,6 & 57,3 & 56,9 & 56,7 \\
\hline & SOB & 460,9 & 461,9 & 465,1 & 453,3 & 452,5 & 457,4 \\
\hline & ITP & 910,1 & 907,7 & 905,5 & 916,9 & 914,3 & 912,2 \\
\hline & PAM & 2056,9 & 2049,8 & 2044,4 & 2074,0 & 2066,7 & 2061,3 \\
\hline & XIN & 2118,0 & 2109,0 & 2102,5 & 2133,5 & 2124,4 & 2113,6 \\
\hline \multirow{5}{*}{$\begin{array}{c}\text { Smédio } \\
\left(\mathrm{hm}^{3}\right)\end{array}$} & RBA & 228,72 & 227,21 & 226,27 & 225,07 & 221,78 & 223,84 \\
\hline & TMA & 15751,11 & 15609,71 & 15462,09 & 15623,74 & 15540,34 & 15410,45 \\
\hline & QUE & 410,25 & 410,25 & 405,43 & 414,07 & 421,55 & 424,15 \\
\hline & SOB & 17811,02 & 18240,20 & 18752,78 & 17707,04 & 18131,59 & 18563,53 \\
\hline & ITP & 9657,35 & 9644,61 & 9608,36 & 9590,12 & 9551,27 & 9650,51 \\
\hline \multirow{7}{*}{$R^{\prime \prime}\left(m^{3} / s\right)$} & RBA & 39,93 & 39,69 & 39,66 & 40,30 & 40,04 & 40,28 \\
\hline & TMA & 91,73 & 91,76 & 91,78 & 94,38 & 92,45 & 95,29 \\
\hline & QUE & 19,68 & 19,68 & 19,67 & 19,91 & 20,21 & 20,31 \\
\hline & SOB & 54,76 & 61,08 & 62,79 & 85,15 & 102,51 & 91,01 \\
\hline & ITP & 111,79 & 116,71 & 114,61 & 128,02 & 128,17 & 135,30 \\
\hline & PAM & 94,34 & 101,59 & 102,50 & 112,75 & 117,00 & 119,05 \\
\hline & XIN & 180,93 & 189,40 & 191,05 & 201,33 & 206,79 & 213,47 \\
\hline $\mathrm{DE}\left(\mathrm{m}^{3} / \mathrm{s}\right)$ & & 33,8 & 30,7 & 31,7 & 0,0 & 0,0 & 0,0 \\
\hline
\end{tabular}


Anexo J - Resultados do Cenário II para o período abr/1950-mar/1957

Vazão média fornecida a uso consuntivo (UC), vazão turbinada média ( $\left.R^{\prime}\right)$, energia gerada $(E)$, armazenamento médio dos reservatórios (Smédio), vazão vertida média (R") e vazão transposta média (DE)

\begin{tabular}{|c|c|c|c|c|c|c|c|}
\hline & \multirow{2}{*}{ Reservatório } & \multicolumn{3}{|c|}{ Transposição ativa } & \multicolumn{3}{|c|}{ Transposição inativa } \\
\hline & & TMA300 & TMA400 & TMA437 & TMA300 & TMA400 & TMA437 \\
\hline \multirow{7}{*}{$\mathrm{UC}\left(\mathrm{m}^{3} / \mathrm{s}\right)$} & RBA & 2,7 & 2,7 & 2,7 & 2,7 & 2,7 & 2,7 \\
\hline & TMA & 9,6 & 9,6 & 9,1 & 9,6 & 9,6 & 9,1 \\
\hline & QUE & 1,4 & 1,4 & 1,4 & 1,4 & 1,4 & 1,4 \\
\hline & SOB & 87,7 & 87,7 & 87,9 & 87,7 & 87,7 & 87,9 \\
\hline & ITP & 76,3 & 76,3 & 76,4 & 76,3 & 76,3 & 76,4 \\
\hline & PAM & 3,0 & 3,0 & 3,0 & 3,0 & 3,0 & 3,0 \\
\hline & XIN & 0,4 & 0,4 & 0,4 & 0,4 & 0,4 & 0,4 \\
\hline \multirow{7}{*}{$R^{\prime}\left(m^{3} / s\right)$} & RBA & 88,6 & 89,1 & 87,3 & 88,2 & 88,5 & 87,4 \\
\hline & TMA & 462,3 & 463,8 & 463,8 & 456,7 & 459,6 & 460,2 \\
\hline & QUE & 34,9 & 35,0 & 34,8 & 34,7 & 34,2 & 34,3 \\
\hline & SOB & 2085,6 & 2079,0 & 2069,1 & 2054,0 & 2038,9 & 2039,1 \\
\hline & ITP & 1961,8 & 1959,5 & 1951,8 & 1981,9 & 1971,4 & 1976,5 \\
\hline & PAM & 1966,4 & 1959,0 & 1953,6 & 1983,1 & 1975,5 & 1970,2 \\
\hline & XIN & 1882,8 & 1874,2 & 1868,4 & 1897,3 & 1888,6 & 1882,9 \\
\hline \multirow{7}{*}{ E (MWmed) } & RBA & 28,9 & 29,1 & 28,5 & 28,7 & 28,8 & 28,6 \\
\hline & TMA & 208,1 & 208,6 & 208,7 & 205,6 & 206,9 & 207,1 \\
\hline & QUE & 57,6 & 57,6 & 57,6 & 57,3 & 56,6 & 56,8 \\
\hline & SOB & 454,9 & 457,4 & 460,0 & 447,5 & 448,2 & 452,5 \\
\hline & ITP & 892,3 & 889,7 & 887,7 & 898,7 & 897,2 & 893,7 \\
\hline & PAM & 2016,5 & 2008,9 & 2003,3 & 2033,6 & 2025,8 & 2020,4 \\
\hline & XIN & 2082,3 & 2072,9 & 2066,5 & 2097,7 & 2088,3 & 2082,0 \\
\hline \multirow{5}{*}{$\begin{array}{c}\text { Smédio } \\
\left(\mathrm{hm}^{3}\right)\end{array}$} & RBA & 229,04 & 228,35 & 226,79 & 226,49 & 223,14 & 226,30 \\
\hline & TMA & 15774,39 & 15497,16 & 15359,30 & 15789,13 & 15561,58 & 15373,53 \\
\hline & QUE & 398,97 & 396,91 & 415,49 & 409,84 & 423,53 & 425,58 \\
\hline & SOB & 17719,94 & 18207,09 & 18806,95 & 17586,45 & 18046,44 & 18691,66 \\
\hline & ITP & 9636,50 & 9592,69 & 9654,79 & 9551,04 & 9676,77 & 9469,73 \\
\hline \multirow{7}{*}{$R^{\prime \prime}\left(m^{3} / s\right)$} & RBA & 39,66 & 39,16 & 41,00 & 40,07 & 39,75 & 40,89 \\
\hline & TMA & 90,27 & 88,92 & 89,60 & 95,83 & 93,19 & 93,26 \\
\hline & QUE & 19,20 & 19,17 & 19,32 & 19,47 & 19,94 & 19,85 \\
\hline & SOB & 48,96 & 52,05 & 58,36 & 82,04 & 93,66 & 89,24 \\
\hline & ITP & 92,74 & 91,73 & 98,53 & 106,90 & 113,62 & 105,01 \\
\hline & PAM & 75,73 & 79,89 & 84,34 & 93,32 & 97,14 & 98,89 \\
\hline & XIN & 156,04 & 161,38 & 166,23 & 175,83 & 180,72 & 182,91 \\
\hline $\mathrm{DE}\left(\mathrm{m}^{3} / \mathrm{s}\right)$ & & 32,7 & 32,7 & 29,6 & 0,0 & 0,0 & 0,0 \\
\hline
\end{tabular}


Anexo K - Resultados do Cenário III para o período abr/1950-mar/1957

Vazão média fornecida a uso consuntivo (UC), vazão turbinada média (R'), energia gerada ( $E)$, armazenamento médio dos reservatórios (Smédio), vazão vertida média (R") e vazão transposta média (DE)

\begin{tabular}{|c|c|c|c|c|c|c|c|}
\hline & \multirow{2}{*}{ Reservatório } & \multicolumn{3}{|c|}{ Transposição ativa } & \multicolumn{3}{|c|}{ Transposição inativa } \\
\hline & & TMA300 & TMA400 & TMA437 & TMA300 & TMA400 & TMA437 \\
\hline \multirow{7}{*}{$\mathrm{UC}\left(\mathrm{m}^{3} / \mathrm{s}\right)$} & RBA & 3,6 & 3,6 & 3,6 & 3,6 & 3,6 & $\overline{3,6}$ \\
\hline & TMA & 12,9 & 12,9 & 9,9 & 12,9 & 12,9 & 9,9 \\
\hline & QUE & 1,8 & 1,8 & 1,8 & 1,8 & 1,8 & 1,8 \\
\hline & SOB & 116,7 & 116,7 & 117,2 & 116,7 & 116,7 & 117,2 \\
\hline & ITP & 101,6 & 101,6 & 101,8 & 101,6 & 101,6 & 101,8 \\
\hline & PAM & 4,1 & 4,1 & 4,1 & 4,1 & 4,1 & 4,1 \\
\hline & XIN & 0,6 & 0,6 & 0,6 & 0,6 & 0,6 & 0,6 \\
\hline \multirow{7}{*}{$R^{\prime}\left(m^{3} / s\right)$} & RBA & 88,4 & 88,6 & 86,6 & 88,0 & 88,2 & 86,9 \\
\hline & TMA & 460,5 & 460,6 & 463,8 & 455,3 & 454,2 & 459,1 \\
\hline & QUE & 34,9 & 34,7 & 34,7 & 34,3 & 34,2 & 34,3 \\
\hline & SOB & 2064,0 & 2054,6 & 2052,3 & 2034,8 & 2024,3 & 2017,9 \\
\hline & ITP & 1921,5 & 1914,9 & 1911,2 & 1942,7 & 1942,3 & 1931,9 \\
\hline & PAM & 1927,0 & 1919,3 & 1916,3 & 1944,1 & 1936,3 & 1933,3 \\
\hline & XIN & 1845,0 & 1837,3 & 1834,3 & 1861,9 & 1854,2 & 1851,2 \\
\hline \multirow{7}{*}{ E (MWmed) } & RBA & 28,8 & 28,8 & 28,2 & 28,6 & 28,6 & 28,3 \\
\hline & TMA & 207,2 & 207,5 & 208,7 & 205,1 & 204,7 & 206,9 \\
\hline & QUE & 57,4 & 57,4 & 57,4 & 56,7 & 56,7 & 56,8 \\
\hline & SOB & 449,3 & 450,9 & 454,8 & 444,3 & 445,8 & 448,5 \\
\hline & ITP & 874,6 & 871,8 & 870,9 & 882,4 & 879,6 & 877,2 \\
\hline & PAM & 1976,1 & 1968,2 & 1965,1 & 1993,6 & 1985,7 & 1982,5 \\
\hline & XIN & 2041,7 & 2033,3 & 2030,0 & 2059,8 & 2051,4 & 2048,2 \\
\hline \multirow{5}{*}{$\begin{array}{c}\text { Smédio } \\
\left(\mathrm{hm}^{3}\right)\end{array}$} & RBA & 227,22 & 226,18 & 223,16 & 226,26 & 222,39 & 224,98 \\
\hline & TMA & 15725,68 & 15549,15 & 15356,37 & 15809,35 & 15602,35 & 15432,68 \\
\hline & QUE & 395,68 & 411,34 & 415,26 & 410,39 & 421,04 & 417,12 \\
\hline & SOB & 17513,28 & 17965,87 & 18573,91 & 17669,80 & 18204,84 & 18694,11 \\
\hline & ITP & 9672,39 & 9692,65 & 9713,19 & 9612,99 & 9521,73 & 9610,01 \\
\hline \multirow{7}{*}{$R^{\prime \prime}\left(m^{3} / s\right)$} & RBA & 38,92 & 38,81 & 40,75 & 39,35 & 39,13 & 40,52 \\
\hline & TMA & 87,93 & 87,97 & 87,95 & 93,13 & 94,42 & 92,63 \\
\hline & QUE & 18,81 & 18,92 & 18,94 & 19,36 & 19,43 & 19,38 \\
\hline & SOB & 38,38 & 44,70 & 45,39 & 66,87 & 73,14 & 79,44 \\
\hline & ITP & 75,34 & 81,97 & 85,97 & 86,31 & 83,02 & 92,59 \\
\hline & PAM & 56,37 & 64,12 & 67,46 & 71,48 & 75,51 & 77,80 \\
\hline & XIN & 134,99 & 142,67 & 146,00 & 150,30 & 154,26 & 156,42 \\
\hline $\mathrm{DE}\left(\mathrm{m}^{3} / \mathrm{s}\right)$ & & 32,8 & 29,6 & 27,5 & 0,0 & 0,0 & 0,0 \\
\hline
\end{tabular}


Anexo L - Resultados do Cenário IV para o período abr/1950-mar/1957

Vazão média fornecida a uso consuntivo (UC), vazão turbinada média (R'), energia gerada (E), armazenamento médio dos reservatórios (Smédio), vazão vertida média (R") e vazão transposta média (DE)

\begin{tabular}{|c|c|c|c|c|c|c|c|}
\hline & \multirow{2}{*}{ Reservatório } & \multicolumn{3}{|c|}{ Transposição ativa } & \multicolumn{3}{|c|}{ Transposição inativa } \\
\hline & & TMA300 & TMA400 & TMA437 & TMA300 & TMA400 & TMA437 \\
\hline \multirow{7}{*}{$\mathrm{UC}\left(\mathrm{m}^{3} / \mathrm{s}\right)$} & RBA & 4,5 & 4,5 & 4,5 & 4,5 & 4,5 & 4,5 \\
\hline & TMA & 16,1 & 16,1 & 10,6 & 16,1 & 16,1 & 10,6 \\
\hline & QUE & 2,3 & 2,3 & 2,3 & 2,3 & 2,3 & 2,3 \\
\hline & SOB & 145,5 & 145,5 & 146,5 & 145,6 & 145,5 & 146,5 \\
\hline & ITP & 126,9 & 126,9 & 127,2 & 126,9 & 126,9 & 127,2 \\
\hline & PAM & 5,1 & 5,1 & 5,1 & 5,1 & 5,1 & 5,1 \\
\hline & XIN & 0,7 & 0,7 & 0,7 & 0,7 & 0,7 & 0,7 \\
\hline \multirow{7}{*}{$R^{\prime}\left(m^{3} / s\right)$} & RBA & 87,8 & 87,9 & 85,8 & 87,6 & 88,0 & 86,0 \\
\hline & TMA & 458,0 & 458,2 & 463,9 & 453,9 & 452,5 & 459,1 \\
\hline & QUE & 34,9 & 34,8 & 34,8 & 34,7 & 34,5 & 34,5 \\
\hline & SOB & 2031,1 & 2025,3 & 2026,0 & 2012,8 & 2008,2 & 2003,2 \\
\hline & ITP & 1887,4 & 1880,6 & 1878,3 & 1906,1 & 1902,0 & 1900,2 \\
\hline & PAM & 1887,4 & 1879,7 & 1878,8 & 1904,4 & 1896,7 & 1895,8 \\
\hline & XIN & 1805,4 & 1797,8 & 1796,9 & 1822,6 & 1815,0 & 1814,2 \\
\hline \multirow{7}{*}{ E (MWmed) } & RBA & 28,6 & 28,6 & 28,0 & 28,5 & 28,5 & 28,0 \\
\hline & TMA & 206,2 & 206,5 & 208,7 & 204,7 & 204,2 & 206,8 \\
\hline & QUE & 57,5 & 57,5 & 57,5 & 57,3 & 57,3 & 57,3 \\
\hline & SOB & 443,5 & 445,5 & 449,2 & 437,8 & 440,3 & 443,3 \\
\hline & ITP & 856,6 & 854,0 & 853,9 & 863,4 & 860,5 & 860,0 \\
\hline & PAM & 1935,5 & 1927,6 & 1926,7 & 1952,9 & 1945,0 & 1944,1 \\
\hline & XIN & 1999,1 & 1990,8 & 1989,8 & 2017,5 & 2009,2 & 2008,3 \\
\hline \multirow{5}{*}{$\begin{array}{c}\text { Smédio } \\
\left(\mathrm{hm}^{3}\right)\end{array}$} & RBA & 227,81 & 225,71 & 225,87 & 224,23 & 221,19 & 223,97 \\
\hline & TMA & 15743,65 & 15546,99 & 15348,86 & 15845,49 & 15625,12 & 15423,18 \\
\hline & QUE & 390,53 & 413,29 & 414,39 & 394,61 & 426,02 & 426,02 \\
\hline & SOB & 17573,48 & 18021,87 & 18492,74 & 17483,61 & 17968,10 & 18469,95 \\
\hline & ITP & 9580,73 & 9607,59 & 9644,02 & 9526,98 & 9498,76 & 9517,22 \\
\hline \multirow{7}{*}{$R^{\prime \prime}\left(m^{3} / s\right)$} & RBA & 38,65 & 38,53 & 40,68 & 38,82 & 38,48 & 40,45 \\
\hline & TMA & 86,29 & 86,30 & 86,30 & 90,39 & 92,00 & 90,98 \\
\hline & QUE & 18,29 & 18,42 & 18,43 & 18,49 & 18,67 & 18,67 \\
\hline & SOB & 37,63 & 40,31 & 41,08 & 56,43 & 57,48 & 63,84 \\
\hline & ITP & 53,06 & 58,89 & 62,02 & 65,63 & 66,39 & 69,06 \\
\hline & PAM & 38,52 & 45,25 & 47,05 & 52,85 & 57,16 & 59,01 \\
\hline & XIN & 116,98 & 123,60 & 125,38 & 131,11 & 135,34 & 137,06 \\
\hline $\mathrm{DE}\left(\mathrm{m}^{3} / \mathrm{s}\right)$ & & 30,6 & 28,4 & 28,5 & 0,0 & 0,0 & 0,0 \\
\hline
\end{tabular}


Anexo M - Resultados do Cenário V para o período abr/1950-mar/1957

Vazão média fornecida a uso consuntivo (UC), vazão turbinada média (R'), energia gerada (E), armazenamento médio dos reservatórios (Smédio), vazão vertida média (R") e vazão transposta média (DE)

\begin{tabular}{|c|c|c|c|c|c|c|c|}
\hline & \multirow{2}{*}{ Reservatório } & \multicolumn{3}{|c|}{ Transposição ativa } & \multicolumn{3}{|c|}{ Transposição inativa } \\
\hline & & TMA300 & TMA400 & TMA437 & TMA300 & TMA400 & TMA437 \\
\hline \multirow{7}{*}{$\mathrm{UC}\left(\mathrm{m}^{3} / \mathrm{s}\right)$} & RBA & 5,4 & 5,4 & 4,1 & 5,4 & 5,4 & 4,1 \\
\hline & TMA & 19,3 & 19,3 & 12,7 & 19,3 & 19,3 & 12,7 \\
\hline & QUE & 2,7 & 2,7 & 2,7 & 2,7 & 2,7 & 2,7 \\
\hline & SOB & 174,1 & 174,0 & 175,7 & 174,2 & 174,1 & 175,7 \\
\hline & ITP & 152,1 & 152,1 & 152,6 & 152,1 & 152,1 & 152,6 \\
\hline & PAM & 6,1 & 6,1 & 6,1 & 6,1 & 6,1 & 6,1 \\
\hline & XIN & 0,8 & 0,8 & 0,8 & 0,8 & 0,8 & 0,8 \\
\hline \multirow{7}{*}{$R^{\prime}\left(m^{3} / s\right)$} & RBA & 87,2 & 87,2 & 86,5 & 87,0 & 87,1 & 86,0 \\
\hline & TMA & 455,2 & 455,4 & 463,8 & 450,7 & 450,9 & 458,9 \\
\hline & QUE & 34,7 & 34,6 & 34,6 & 34,4 & 34,4 & 34,5 \\
\hline & SOB & 2006,2 & 2000,9 & 2004,5 & 1989,5 & 1982,4 & 1987,4 \\
\hline & ITP & 1848,9 & 1836,4 & 1833,5 & 1865,2 & 1853,3 & 1854,6 \\
\hline & PAM & 1842,8 & 1834,9 & 1836,0 & 1863,4 & 1855,3 & 1856,7 \\
\hline & XIN & 1765,9 & 1758,1 & 1759,2 & 1783,1 & 1775,2 & 1776,5 \\
\hline \multirow{7}{*}{ E (MWmed) } & RBA & 28,4 & 28,4 & 28,2 & 28,2 & 28,3 & 28,1 \\
\hline & TMA & 205,2 & 205,4 & 208,8 & 203,3 & 203,4 & 206,6 \\
\hline & QUE & 57,2 & 57,2 & 57,2 & 56,7 & 57,1 & 57,1 \\
\hline & SOB & 437,6 & 439,9 & 443,4 & 434,2 & 434,2 & 438,0 \\
\hline & ITP & 838,9 & 836,3 & 837,1 & 846,4 & 843,4 & 844,3 \\
\hline & PAM & 1889,8 & 1881,6 & 1882,7 & 1910,9 & 1902,6 & 1903,9 \\
\hline & XIN & 1956,7 & 1948,0 & 1949,2 & 1975,1 & 1966,4 & 1967,7 \\
\hline \multirow{5}{*}{$\begin{array}{c}\text { Smédio } \\
\left(\mathrm{hm}^{3}\right)\end{array}$} & RBA & 227,59 & 227,44 & 226,03 & 224,27 & 224,13 & 226,42 \\
\hline & TMA & 15773,99 & 15557,17 & 15372,23 & 15831,59 & 15577,10 & 15399,14 \\
\hline & QUE & 400,10 & 415,30 & 418,56 & 399,93 & 419,21 & 416,71 \\
\hline & SOB & 17378,53 & 17853,02 & 18258,18 & 17452,70 & 17815,53 & 18232,34 \\
\hline & ITP & 9580,30 & 9703,09 & 9780,41 & 9585,95 & 9686,74 & 9700,13 \\
\hline \multirow{7}{*}{$R^{\prime \prime}\left(m^{3} / s\right)$} & RBA & 38,32 & 38,34 & 40,44 & 38,61 & 38,48 & 40,90 \\
\hline & TMA & 84,93 & 84,93 & 84,68 & 89,48 & 89,46 & 89,61 \\
\hline & QUE & 18,10 & 18,17 & 18,18 & 18,43 & 18,32 & 18,30 \\
\hline & SOB & 30,91 & 33,04 & 33,21 & 47,18 & 51,82 & 50,53 \\
\hline & ITP & 35,90 & 47,89 & 49,53 & 48,56 & 57,63 & 59,47 \\
\hline & PAM & 26,45 & 33,93 & 31,54 & 34,85 & 40,11 & 41,92 \\
\hline & XIN & 99,68 & 107,01 & 104,66 & 111,50 & 116,59 & 118,44 \\
\hline $\mathrm{DE}\left(\mathrm{m}^{3} / \mathrm{s}\right)$ & & 29,5 & 26,4 & 30,5 & 0,0 & 0,0 & 0,0 \\
\hline
\end{tabular}




\section{Anexo N - Resultados do Cenário VI para o período abr/1950-mar/1957}

Vazão média fornecida a uso consuntivo (UC), vazão turbinada média (R'), energia gerada ( $E$ ), armazenamento médio dos reservatórios (Smédio), vazão vertida média (R") e vazão transposta média (DE)

\begin{tabular}{|c|c|c|c|c|c|c|c|}
\hline & \multirow{2}{*}{ Reservatório- } & \multicolumn{3}{|c|}{ Transposição ativa } & \multicolumn{3}{|c|}{ Transposição inativa } \\
\hline & & TMA300 & TMA400 & TMA437 & TMA300 & TMA400 & TMA437 \\
\hline \multirow{7}{*}{$\mathrm{UC}\left(\mathrm{m}^{3} / \mathrm{s}\right)$} & RBA & 12,9 & 12,9 & 9,6 & 12,9 & 12,9 & 9,6 \\
\hline & TMA & 38,3 & 37,1 & 17,7 & 38,3 & 37,1 & 17,7 \\
\hline & QUE & 1,4 & 1,4 & 1,4 & 1,4 & 1,4 & 1,4 \\
\hline & SOB & 412,2 & 421,3 & 424,3 & 412,8 & 422,1 & 424,5 \\
\hline & ITP & 131,9 & 131,9 & 131,9 & 131,9 & 131,9 & 131,9 \\
\hline & PAM & 5,1 & 5,1 & 5,1 & 5,1 & 5,1 & 5,1 \\
\hline & XIN & 0,3 & 0,3 & 0,3 & 0,3 & 0,3 & 0,3 \\
\hline \multirow{7}{*}{$R^{\prime}\left(m^{3} / s\right)$} & RBA & 82,6 & 82,1 & 82,7 & 82,6 & 82,3 & 83,1 \\
\hline & TMA & 441,6 & 443,1 & 463,1 & 436,1 & 440,2 & 463,0 \\
\hline & QUE & 34,8 & 34,6 & 34,5 & 34,7 & 34,5 & 34,5 \\
\hline & SOB & 1757,0 & 1743,3 & 1763,9 & 1757,5 & 1743,5 & 1763,6 \\
\hline & ITP & 1632,2 & 1618,6 & 1637,9 & 1658,4 & 1644,0 & 1662,6 \\
\hline & PAM & 1619,1 & 1605,4 & 1625,6 & 1645,3 & 1631,3 & 1651,0 \\
\hline & XIN & 1604,4 & 1586,2 & 1604,6 & 1625,7 & 1607,2 & 1625,6 \\
\hline \multirow{7}{*}{ E (MWmed) } & RBA & 27,0 & 26,8 & 27,0 & 26,9 & 26,7 & 27,1 \\
\hline & TMA & 198,2 & 199,1 & 208,2 & 196,5 & 198,6 & 208,2 \\
\hline & QUE & 57,3 & 57,3 & 57,3 & 57,3 & 57,3 & 57,3 \\
\hline & SOB & 387,8 & 390,3 & 393,2 & 386,3 & 389,0 & 393,1 \\
\hline & ITP & 749,2 & 742,5 & 751,7 & 761,1 & 754,0 & 763,2 \\
\hline & PAM & 1660,3 & 1646,3 & 1667,0 & 1687,2 & 1672,9 & 1693,0 \\
\hline & XIN & 1782,9 & 1763,0 & 1783,0 & 1805,9 & 1785,7 & 1805,6 \\
\hline \multirow{5}{*}{$\begin{array}{c}\text { Smédio } \\
\left(\mathrm{hm}^{3}\right)\end{array}$} & RBA & 229,45 & 226,25 & 227,96 & 225,75 & 222,10 & 226,82 \\
\hline & TMA & 15480,04 & 15196,42 & 15322,17 & 15661,57 & 15348,72 & 15334,23 \\
\hline & QUE & 399,17 & 423,99 & 436,26 & 413,35 & 436,90 & 432,71 \\
\hline & SOB & 17243,40 & 18072,95 & 17922,20 & 17046,25 & 17904,69 & 17920,31 \\
\hline & ITP & 9946,87 & 9924,58 & 9950,97 & 9939,70 & 9919,92 & 9955,94 \\
\hline \multirow{7}{*}{$R^{\prime \prime}\left(m^{3} / s\right)$} & RBA & 35,43 & 36,00 & 38,63 & 35,44 & 35,83 & 38,26 \\
\hline & TMA & 72,29 & 72,21 & 74,82 & 77,71 & 74,97 & 74,97 \\
\hline & QUE & 19,28 & 19,41 & 19,50 & 19,38 & 19,50 & 19,49 \\
\hline & SOB & 18,25 & 18,24 & 17,87 & 17,85 & 17,85 & 17,88 \\
\hline & ITP & 12,58 & 12,58 & 13,43 & 12,89 & 13,35 & 14,86 \\
\hline & PAM & 11,22 & 11,22 & 11,22 & 11,52 & 11,52 & 11,95 \\
\hline & XIN & 22,76 & 27,26 & 29,04 & 27,95 & 32,46 & 34,21 \\
\hline $\mathrm{DE}\left(\mathrm{m}^{3} / \mathrm{s}\right)$ & & 26,4 & 26,4 & 26,4 & 0,0 & 0,0 & 0,0 \\
\hline
\end{tabular}

